Rodolfo Krul Tessari

\title{
Projeto Ótimo de Poços de Petróleo Baseado em Confiabilidade
}

São Carlos 



\section{Rodolfo Krul Tessari}

\section{Projeto Ótimo de Poços de Petróleo Baseado em Confiabilidade}

Tese de doutorado apresentada ao Programa de Pós-graduação em Engenharia de Estruturas da Escola de Engenharia de São Carlos (EESCUSP) como requisito para obtenção do título de Doutor em Ciências.

\section{VERSÃO CORRIGIDA}

A versão original encontra-se na Escola de Engenharia de São Carlos

Escola de Engenharia de São Carlos - EESC

Universidade de São Paulo - USP

Programa de Pós-Graduação em Engenharia de Estruturas

Orientador: Prof. Dr. André Teófilo Beck

São Carlos

2020 
AUTORIZO A REPRODUÇÃO TOTAL OU PARCIAL DESTE TRABALHO, POR QUALQUER MEIO CONVENCIONAL OU ELETRÔNICO, PARA FINS DE ESTUDO E PESQUISA, DESDE QUE CITADA A FONTE.

Ficha catalográfica elaborada pela Biblioteca Prof. Dr. Sérgio Rodrigues Fontes da EESC/USP com os dados inseridos pelo(a) autor(a).

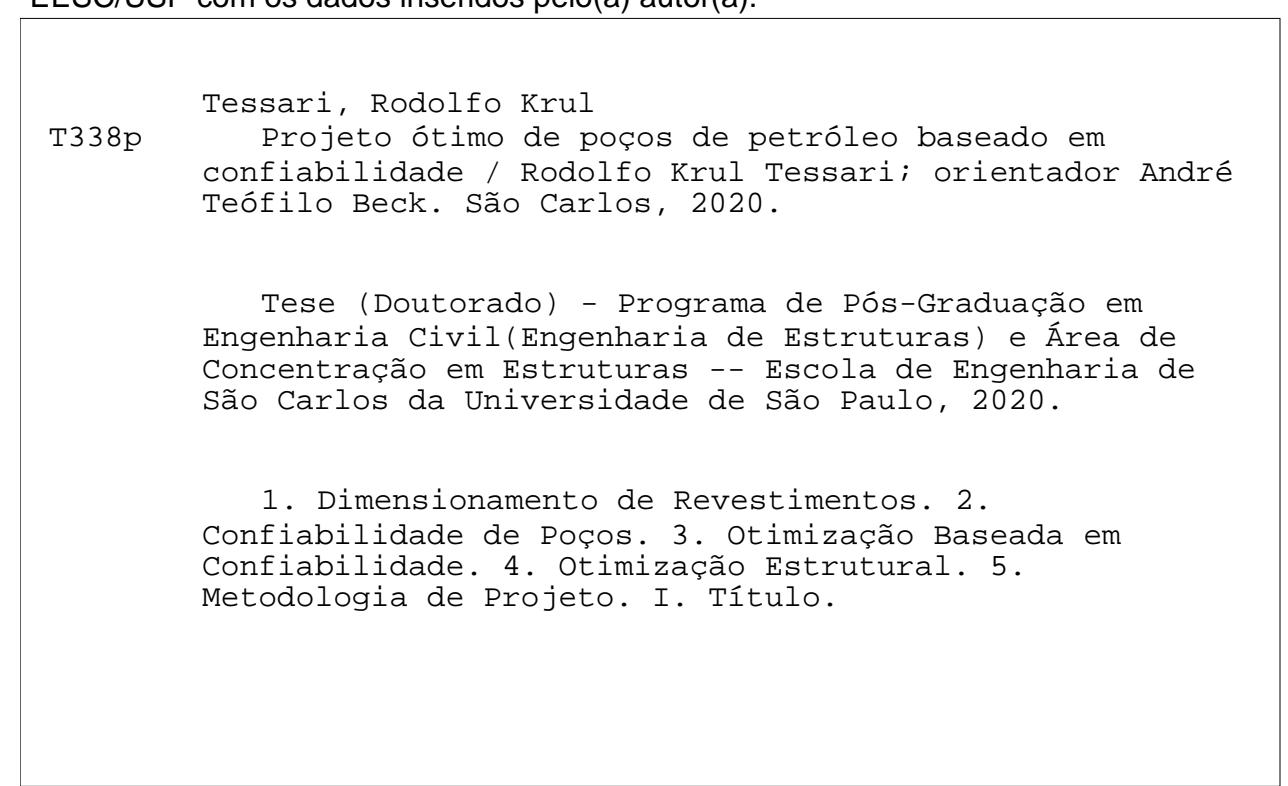

Eduardo Graziosi Silva - CRB - 8/8907 


\section{FOLHA DE JULGAMENTO}

Candidato: Engenheiro RODOLFO KRUL TESSARI.

Título da tese: "Projeto ótimo de poços de petróleo baseado em confiabilidade".

Data da defesa: 08/11/2019.

Comissão Julgadora:

Resultado:

Prof. Associado André Teófilo Beck

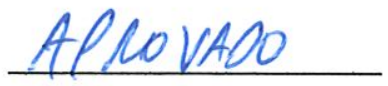

(Orientador)

(Escola de Engenharia de São Carlos/EESC)

Dr. Cristiano Eduardo Agsotini

APRO VADO

(Petróleo Brasileiro S.A./PETROBRAS)

Prof. Dr. Eduardo Toledo de Lima Junior

APRO VADO

(Universidade Federal de Alagoas/UFAL)

Prof. Dr. Diogo Lira Cecílio

APROVADO

(Universidade Federal do Rio Grande do SUI/UFRGS)

Prof. Dr. Luis Volnei Sudati Sagrilo

APROVADO

(Universidade Federal do Rio de Janeiro/UFRJ)

Coordenador do Programa de Pós-Graduação em Engenharia Civil (Engenharia de Estruturas):

Prof. Associado Vladimir Guilherme Haach

Presidente da Comissão de Pós-Graduação:

Prof. Titular Murilo Araujo Romero 



\section{Agradecimentos}

Meus principais agradecimentos são dedicados à minha família. À minha esposa Raquel, que manteve-se minha incondicional companheira durante todo o período em que estive afastado para me dedicar à conclusão deste trabalho. À minha querida mãe, Ligia, que sempre me incentivou aos estudos e construiu minha base disciplinar, sem a qual certamente não haveria chegado tão longe. Também por ter me ensinado a usar uma das mais úteis ferramentas que trago comigo desde pequeno: o português e sua gramática. Ao meu pai e igualmente ídolo, Nivaldo, que me mostrou a matemática, essencial não apenas à minha formação em Engenharia, mas à mudança da minha percepção sobre o mundo em si. À minha irmã, Rachel, que nunca me negou ajuda e sem dúvida me tornou uma pessoa mais altruísta. À minha tia Lourdes, que sempre me confortou com palavras e me fez sentir mais forte nos momentos em que pensei em desistir. $\mathrm{E}$ ao meu nono e nona, que mesmo sem entender direito o que eu fiz durante esses quatro longos anos, sempre perguntaram a respeito e demonstraram orgulho do homem que me tornei.

Agradeço também ao meu orientador, André Beck, por acreditar em meu trabalho e tê-lo orientado da melhor forma possível, mesmo com meu distanciamento em algumas ocasiões para dar prioridade aos meus afazeres enquanto docente.

Aos grandes amigos que fiz durante minha passagem por São Carlos: Sergio, Victor, Morkis, Júlio, Delfino, Edwin, Juan, Silvia, Giovanni, Sónia e Gustavo. Obrigado pelo ótimos anos de convivência, plenos de momentos de felicidade e memórias inesquecíveis.

Gostaria de agradecer também ao professor Edson Leonel, que tanto me ensinou enquanto seu aluno PAE. Com base em todas as nossas conversas e em suas aulas pude aprimorar minha didática e me tornar um melhor profissional.

Não poderia esquecer de agradecer aos colegas da SimWorx que me ajudaram no início desta jornada e aos professores Luis Volnei Sudati Sagrilo e Wellison Gomes, cujas valiosas ponderações durante minha banca de qualificação certamente ajudaram a engrandecer meu trabalho.

Por fim, agradeço à CAPES pelo apoio financeiro no início de minha pesquisa, à UTFPR pela concessão de meu afastamento parcial e a todos os cidadãos que custearam minha formação. Espero um dia retornar à sociedade muito mais do que me foi dado.

Muito obrigado a todos! 



\section{Resumo}

TESSARI, R. K. Projeto ótimo de poços de petróleo baseado em confiabilidade. 2020. 210 p. Tese (Doutorado em Engenharia Civil (Estruturas)) - Escola de Engenharia de São Carlos, Universidade de São Paulo, São Carlos, 2020.

Poços de exploração de óleo e gás são estruturas complexas, de custo extremamente elevado e de alta responsabilidade. Falhas no revestimento destas estruturas têm potencial para causar enormes prejuízos econômicos e ambientais. Em virtude dos grandes acidentes ocorridos recentemente, órgãos regulatórios têm se tornado mais rigorosos e já preveem a adoção de critérios probabilísticos para o projeto de poços. A alta complexidade do projeto em sua maneira atual (determinística) atrelada à dificuldade em quantificar as probabilidades de falha dos revestimentos já representam um grande desafio em si, porém a otimização dos revestimentos configura uma tendência futura que se pretende antecipar e desenvolver no presente trabalho. O objetivo geral consiste no desenvolvimento de uma metodologia para a otimização de revestimentos de poços com base em requisitos expressos em termos de probabilidades de falha. Para isso, estudou-se inicialmente o procedimento de cálculo para o projeto determinístico de revestimentos e identificou-se os principais parâmetros manipulados pelo projetista. Em seguida, equacionou-se os modos de falha causados por tensões triaxiais e pressões diferenciais de ruptura e colapso. O estudo procedeu com a descrição estatística das variáveis de comportamento aleatório que afetam cada modelo de resistência e com a investigação dos níveis de confiabilidade adequados a diferentes campos da engenharia estrutural. Após a análise dos métodos de otimização matemática, um algoritmo de enumeração parcial do tipo branch and bound $(\mathrm{B} \& \mathrm{~B})$ foi escolhido para a solução do problema de poços. A integração de todos esses saberes deu origem à metodologia proposta. Paralelamente, foi desenvolvido um código computacional capaz de realizar o cálculo das pressões hidrostáticas, da força axial e da tensão interna em cada ponto do revestimento ao longo de sua profundidade, tendo passado por um processo de validação. A este código (determinístico) foram integradas rotinas específicas para estimativa da confiabilidade estrutural e rotinas de otimização. Estudos de caso foram conduzidos a fim de ilustrar a aplicabilidade da metodologia e quantificar seu desempenho. Os resultados mostraram que a metodologia é capaz de garantir o atendimento do nível de confiabilidade alvo frente a todos os modos de falha e cenários de carregamento considerados, permitindo a seleção autônoma dos revestimentos que proporcionam o mínimo custo ou o menor peso total da fase. A metodologia contribui para o avanço do setor de exploração de gás e óleo ao aproximar a probabilidade de falha real dos revestimentos da probabilidade definida em projeto, reduzindo assim a margem de segurança existente nos projetos determinísticos. Proporciona economia na etapa de planejamento, sem comprometer a segurança do poço durante o seu ciclo de vida.

Palavras-chaves: Dimensionamento de Revestimentos. Confiabilidade de Poços. Otimização Baseada em Confiabilidade. Otimização Estrutural. Metodologia de Projeto. 



\section{Abstract}

TESSARI, R. K. Reliability-based well casing design optimization. 2020. 210 p. Thesis (PhD. in Civil Engineering (Structures)) - School of Engineering of São Carlos, University of São Paulo, São Carlos, 2020.

Oil and gas exploration wells are complex structures, extremely expensive and of high responsibility. Failures in the casing of such structures can cause enormous economic and environmental damage. Due to recent major accidents, oil exploration regulations have become more strict and move towards the adoption of probabilistic criteria for well design. The high complexity of design in its current (deterministic) way coupled with the difficulty in quantifying the probabilities of casing failure already pose a great challenge, but casing optimization is a future trend that we intend to anticipate and develop in the present work. The main goal is to develop a methodology for well casing design optimization based on requirements expressed in terms of failure probabilities. In order to do this, the calculation procedure for the deterministic design of casings was initially studied and the main parameters manipulated by the designer were identified. Then, failure modes caused by triaxial stresses and differential rupture and collapse pressures were equated. The studied proceeded with the statistical description of the variables with random behavior that affect each of the resistance models and the investigation of the appropriate reliability levels for different fields of structural engineering. After the analysis of mathematical optimization methods, it was decided to use a partial "branch and bound" (B\&B) enumeration algorithm to solve the well problem. The integration of all this knowledge gave rise to the proposed methodology. In parallel, a computational code capable of calculating the hydrostatic pressure, axial force and internal tension at each point of the casing along its depth was developed, which went through a validation process. Specific routines for structural reliability estimation and optimization routines were then integrated into this (deterministic) code. Case studies were conducted to illustrate the applicability of the methodology and quantify its performance. The results showed that the methodology is capable of guaranteeing the fulfillment of the target reliability level for all failure modes and load scenarios considered, allowing the autonomous selection of casings that provide the least cost or the lowest total string weight. The methodology contributes to the advancement of the oil and gas exploration industry by approximating the actual casing failure probability to the predefined design probability, thus reducing the safety margin existing in deterministic designs. It provides savings at the planning stage without compromising well safety during its lifecycle.

Keywords: Casing Desing. Well Reliability. Reliability-Based Design Optimization. Structural Optimization. Design Methodology. 



\section{Lista de figuras}

Figura 1.1 - Formação geológica do pré-sal. . . . . . . . . . . . . . 23

Figura 3.1 - Configuração típica de um poço com $19000 \mathrm{ft}(5790 \mathrm{~m})$ de profundidade. . . . . 40

Figura 3.2 - Definição da profundidade de assentamento das sapatas dos revestimentos de um poço com base na pressão de poros e na pressão de fratura. . . . . . . . . . . . . 41

Figura 3.3 - Diâmetros típicos (em polegadas) de furos e revestimentos para formações rochosas. 43

Figura 4.1 - Cenário de colapso durante a cimentação do revestimento. . . . . . . . . . . 50

Figura 4.2 - Perfis de pressão para cenário de colapso durante operação de cimentação. Adaptado de Souza (2015). . . . . . . . . . . . . . . . . 5 51

Figura 4.3 - Cenário de evacuação parcial durante a perfuração da próxima fase. . . . . . . . 52

Figura 4.4 - Perfis de pressão para cenário de perda de circulação. . . . . . . . . . . . 53

Figura 4.5 - Cenário de colapso durante a fase de produção. . . . . . . . . . . . . . 54

Figura 4.6 - Perfis de pressão no anular para cenários de ruptura. . . . . . . . . . . 55

Figura 4.7 - Perfis de pressão interna e externa para cenário de ruptura durante a cimentação. 56

Figura 4.8 - Pressão de teste para carga de serviço de perfuração da próxima fase. . . . . . . 57

Figura 4.9 - Cenários de ruptura durante a fase de perfuração. . . . . . . . . . . . . . 59

Figura 4.10 - Perfis de pressão interna para coluna de revestimento completamente preenchida por gás. . . . . . . . . . . . . . . . . . . . . . 61

Figura 4.11 - Perfis de pressão interna para coluna de revestimento parcialmente preenchida por fluido de perfuração. . . . . . . . . . . . . . . . . 61

Figura 4.12 - Cenário de ruptura durante a fase de produção. . . . . . . . . . . . . . . 62

Figura 5.1 - Forças de empuxo nos ombros do revestimento. . . . . . . . . . . 66

Figura 5.2 - Condição inicial de forças axiais. . . . . . . . . . . . . 68

Figura 5.3 - Metodologia para cálculo de deslocamentos nos trechos livre e cimentado. . . . 69

Figura 5.4 - Perfis de temperatura usuais e discretização do problema. . . . . . . . . . . 70

Figura 5.5 - Deslocamento devido ao efeito pistão. . . . . . . . . . . . . 72

Figura 5.6 - Deslocamento devido ao efeito pistão. . . . . . . . . . . . . . . . 74

Figura 5.7 - Sistema de coordenadas cilíndrico e componentes de tensão no corpo do tubo. . 75

Figura 5.8 - Discretização do trecho livre para cálculo do deslocamento devido ao efeito ballooning. . . . . . . . . . . . . . . 77

Figura 5.9 - Determinação do diagrama de esforços axiais efetivos. . . . . . . . . . . 78

Figura 5.10 - Tensões axiais de flexão. . . . . . . . . . . . . . . . . . . 79

Figura 6.1 - Modos de falha de revestimentos. . . . . . . . . . . . . . 81

Figura 6.2 - Representação gráfica do critério de Tresca para o caso plano e tridimensional. 94

Figura 6.3 - Representação gráfica do critério de von Mises para o caso plano e tridimensional. 95 
Figura 7.1 - Amostragem simples e por hipercubo latino. . . . . . . . . . . . . . . 109

Figura 7.2 - Cenários de carregamento analisados. . . . . . . . . . . . . . . . 114

Figura 7.3 - Índices de confiabilidade para o modo de falha triaxial (critério de von Mises). . 115

Figura 9.1 - Fluxograma da solução de um problema de otimização baseada em confiabilidade. 133

Figura 9.2 - Algoritmo Branch and Bound (B\&B) . . . . . . . . . . . . . . . . 139

Figura 9.3 - Fluxograma para o projeto ótimo de poços baseado em confiabilidade. . . . . . 141

Figura 10.1 - Configuração do poço de referência. . . . . . . . . . . . . . . . . . . . . 144

Figura 10.2 - Revestimento Condutor: perfis de pressões diferenciais calculados (C) e do Wellcat $(\mathrm{W}) \ldots \ldots \ldots \ldots \ldots \ldots$

Figura 10.3 - Revestimento Condutor: forças axiais calculadas (C) e do Wellcat (W). . . . . . 146

Figura 10.4 - Revestimento de Superfície: cenários de carregamento durante a etapa de cimentação.148

Figura 10.5 - Revest. de Superfície: condições iniciais de forças axiais calculadas (C) e do

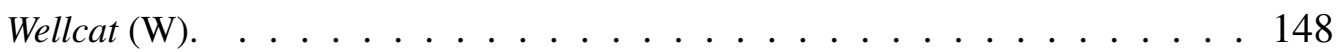

Figura 10.6 - Revestimento de Superfície: forças axiais finais calculadas (C) e do Wellcat (W). 150

Figura 10.7 - Revestimento de Superfície: fatores de segurança ao colapso (API), em azul, e ruptura (Barlow), em vermelho. . . . . . . . . . . . . . 151

Figura 10.8 - Revestimento de Superfície: fatores de segurança à falha triaxial (von Mises). . . 152

Figura 10.9 - Revestimento Intermediário: forças axiais na condição inicial e pós-cimentação. . 154

Figura 10.10 - Revestimento Intermediário: fatores de segurança ao colapso (API) e ruptura (Barlow) . . . . . . . . . . . . . . . . . 155

Figura 10.11 - Revestimento Intermediário: fatores de segurança à falha triaxial (von Mises). . . 156

Figura 10.12 - Revestimento de Produção: forças axiais iniciais e durante a exploração do poço. 158

Figura 10.13 - Revestimento de Produção: fatores de segurança ao colapso (API) e ruptura (Barlow).159

Figura 10.14 - Revestimento de Produção: fatores de segurança à falha triaxial (von Mises). . 160

Figura 10.15 - Revestimento de Superfície: FS e $\beta$ dos critérios de resistência à ruptura e ao colapso. . . . . . . . . . . . . . . . . . 162

Figura 10.16 - Revestimento de Superfície: FS e $\beta$ do modo de falha triaxial. . . . . . . . . 163

Figura 10.17 - Revestimento Intermediário: FS e $\beta$ dos critérios de resistência à ruptura e ao colapso. . . . . . . . . . . . . . . . 163

Figura 10.18 - Revestimento Intermediário: FS e $\beta$ do modo de falha triaxial. . . . . . . . . 164

Figura 10.19 - Revestimento de Produção: FS e $\beta$ dos critérios de resistência à ruptura e ao colapso.165

Figura 10.20 - Revestimento de Produção: FS e $\beta$ do modo de falha triaxial. . . . . . . . . . . 165

Figura 10.21 - Fatores de sensibilidade relativos à evacuação total do revestimento de produção. 166

Figura 10.22 - Fatores de sensibilidade relativos à ocorrência de um kick no revestimento de produção. . . . . . . . . . . . . . . . . . . . 166

Figura 10.23 - Índices de confiabilidade calculados para o cenário de tubing leak: FORM e MCI. 168

Figura 10.24 - Índices de confiabilidade calculados para o cenário de tubing leak: FORM e MCS. 169

Figura 10.25 - Índices de confiabilidade do modelo de Klever-Tamano para caso de evacuação total.169 
Figura 10.26 - Configurações ótimas do revestimento de superfície para valores distintos de FS. 171

Figura 10.27 - Configurações ótimas do revestimento de superfície para cenário de kick considerando um único modo de falha / múltiplos modos de falha. . . . . . . . . . . . 173

Figura 10.28 - Configurações ótimas do revestimento de superfície para cenário de perda de circulação considerando um único modo de falha / múltiplos modos de falha. . 173

Figura 10.29 - Configuração ótima do revestimento de superfície e respectivos cenários de carga críticos ao seu dimensionamento. . . . . . . . . . . . . . . . . . 174

Figura 10.30 - Comparativo das soluções ótimas determinísticas do revestimento intermediário. 175

Figura 10.31 - Fatores de segurança dos modos de falha triaxial e de ruptura para cenário de kick de gás no revestimento intermediário. . . . . . . . . . . . . 176

Figura 10.32 - Comparativo das soluções ótimas determinísticas do revestimento de produção. 177

Figura 10.33 - Comparativo das soluções ótimas do revestimento de superfície. . . . . . . . . 178

Figura 10.34 - Comparativo das configurações do revestimento intermediário. . . . . . . . . 179

Figura 10.35 - Configurações ótimas probabilísticas do revestimento de produção. . . . . . . . 180

Figura 10.36 - Configurações ótimas probabilísticas e determinísticas do poço de referência. . . 181

Figura C.1 - Menu "Revestimentos"para definição dos tubulares de cada fase. . . . . . . . . 206

Figura C.2 - Opções de customização para carregamento de kick durante a perfuração do poço. 207

Figura C.3 - Cenários de carregamento de ruptura e colapso na etapa de produção. . . . . . . 208

Figura C.4 - Fatores de segurança ao colapso calculados pelo solver determinístico. . . . . . 209 



\section{Lista de tabelas}

Tabela 3.1 - Tipos de revestimento. . . . . . . . . . . . . . . . . 39

Tabela 3.2 - Diâmetro externo e tolerâncias de fabricação. . . . . . . . . . . . . 45

Tabela 3.3 - Resistências das classes de aço normatizadas pelo API (2006b). . . . . . . . . 46

Tabela 6.1 - Fatores de segurança usuais no campo de petróleo. . . . . . . . . . . . . . 81

Tabela 6.2 - Critérios de resistência ao colapso do API (1994) . . . . . . . . . . . . . 90

Tabela 7.1 - Índices de confiabilidade alvo $\beta$ (e respectivas taxas de falha associadas) relacionadas a um período de referência de um ano (JCSS, 2001) . . . . . . . . . . 98

Tabela 7.2 - Probabilidades de falha anuais indicadas para o projeto de revestimentos (CSA, 2008). . . . . . . . . . . . . . . . . 100

Tabela 7.3 - Índices de confiabilidade alvo $\left(\beta_{T}\right)$ para a vida útil da estrutura (ISO 2394:1998). 101

Tabela 7.4 - Propriedades do revestimento de superfície. . . . . . . . . . . . . . . 114

Tabela 7.5 - Índices de confiabilidade e probabilidades de falha do sistema e do componente crítico. . . . . . . . . . . . . . . . . . . 115

Tabela 8.1 - Dados estatísticos das variáveis de resistência (ISO 10400:2011). . . . . . . . 118

Tabela 8.2 - Dados estatísticos da pressão de poros ～. . . . . . . . . . . . . . 121

Tabela 8.3 - Dados estatísticos das variáveis de solicitação. . . . . . . . . . . . . 128

Tabela 10.1 - Revestimento de Superfície: propriedades mecânicas dos tubulares. . . . . . . . 147

Tabela 10.2 - Revestimento Intermediário: propriedades mecânicas dos tubulares. . . . . . . . 153

Tabela 10.3 - Revestimento de Produção: propriedades mecânicas dos tubulares. . . . . . . . 157

Tabela 10.4 - Temperaturas no topo e na base do poço. . . . . . . . . . . . . . . . . 158

Tabela 10.5 - Revestimento Intermediário (OD 9 5/8"): propriedades mecânicas e preço dos tubos das soluções ótimas obtidas. . . . . . . . . . . . . . . . . . 176

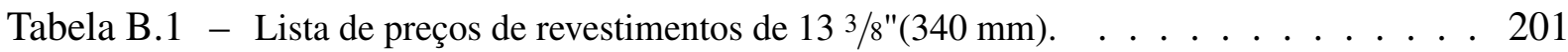

Tabela B.2 - Lista de preços de revestimentos de $95 / 8 "(245 \mathrm{~mm})$. . . . . . . . . . . . . 202

Tabela B.3 - Lista de preços de revestimentos de 7"(178 mm) . . . . . . . . . . . . . 203 



\section{Lista de abreviaturas e siglas}

\begin{tabular}{|c|c|}
\hline ALARP & As Low as Reasonably Practicable \\
\hline API & American Petroleum Institute \\
\hline ARCO & Atlantic Richfield Company \\
\hline $\mathrm{B} \& \mathrm{~B}$ & Branch and Bound \\
\hline BOP & Blowout Preventer \\
\hline C.V. & Coeficiente de Variação \\
\hline CRS & Alinhamento a frio (Cold Rotary Straightened) \\
\hline DDO & Deterministic Design Optimization \\
\hline EW & Tubo formado por soldagem elétrica (Eletric Welded) \\
\hline FORM & First Order Reliability Method \\
\hline FS & Fator de Segurança \\
\hline HRS & Alinhamento a quente (Hot Rotary Straightened) \\
\hline HTHP & Altas temperaturas e altas pressões (High Temperature High Pressure) \\
\hline ISO & International Organization for Standardization \\
\hline JCSS & Joint Committee on Structural Safety \\
\hline KS & Klever-Stewart \\
\hline KT & Klever-Tamano \\
\hline LHS & Amostragem por hipercubo latino (Latin Hypercube Sampling) \\
\hline MCI & Simulações de Monte Carlo por importância usando pontos de projeto \\
\hline MCS & Simulações de Monte Carlo simples \\
\hline MV-OPT & Problemas de otimização de variáveis mistas \\
\hline OCTG & Oil Country Tubular Goods \\
\hline PDF & Função de densidade de probabilidades \\
\hline Q\&T & Aço temperado e revenido (Quenched and Tempered) \\
\hline QRA & Análise quantitativa de risco (Quantitative Risk Analysis/Assessment) \\
\hline RBDO & Reliability-based Design Optimization \\
\hline SITP & Pressão de fechamento do poço (Shut-in Tube Pressure) \\
\hline SORM & Second Order Reliability Method \\
\hline SPDC & Shell Petroleum Development Company \\
\hline StRAnD & Structural Reliability Analysis and Design \\
\hline TOC & Cota de topo do cimento \\
\hline
\end{tabular}





\section{Sumário}

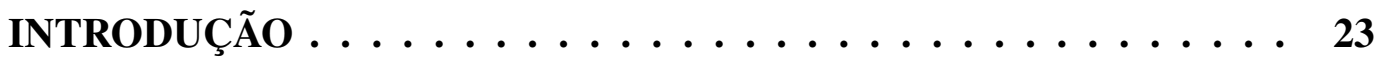

$1.1 \quad$ Motivação do Projeto $\ldots \ldots \ldots \ldots \ldots \ldots \ldots$

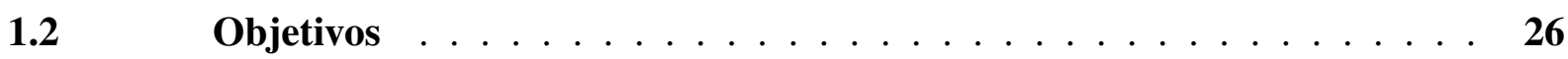

$1.3 \quad$ Organização do trabalho e síntese dos capítulos $\ldots \ldots \ldots \ldots \ldots$

2 ESTADO DA ARTE DA CONFIABILIDADE DE POÇOS . . . . . 31

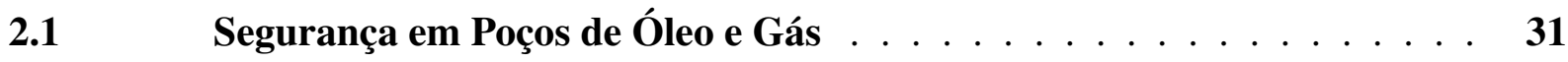

2.2 Filosofias de Projeto de Revestimentos de Poços . . . . . . . . . . . . 33

2.2.1 Projetos determinísticos de revestimentos e suas limitações . . . . . . . 33

2.2.2 Projetos probabilísticos de revestimentos e QRA _ . . . . . . . . 34

2.2.3 Aplicações bem-sucedidas de métodos probabilísticos de projeto . . . . 35

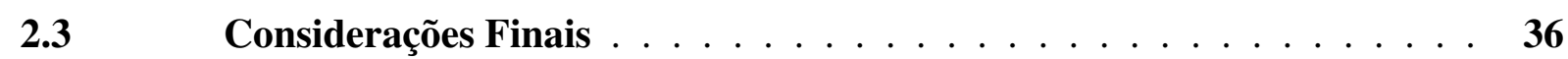

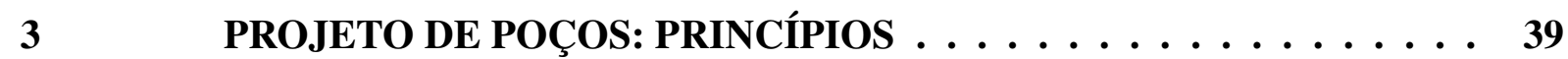

$3.1 \quad$ Número de Fases e Profundidade das Sapatas $\ldots \ldots \ldots \ldots$

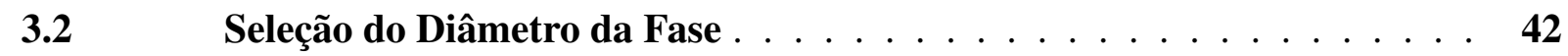

3.3 Casos de Carregamento $\ldots \ldots \ldots \ldots \ldots \ldots$

3.4 Geometria e Material dos Revestimentos . . . . . . . . . . . . . 44

3.4.1 Diâmetro externo, diâmetro interno e espessura da parede . . . . . . . 45

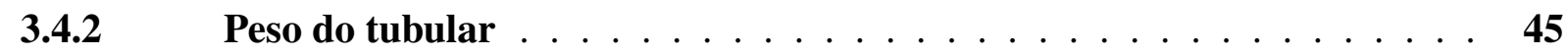

3.4.3 Classe de aço $\ldots \ldots \ldots \ldots \ldots \ldots \ldots \ldots \ldots \ldots \ldots$

3.5 Delimitação do trabalho $\ldots \ldots \ldots \ldots \ldots \ldots \ldots$

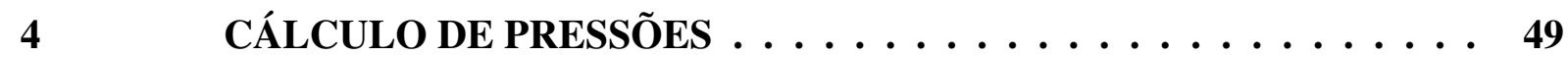

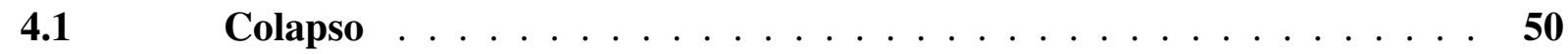

4.1.1 Instalação do Revestimento $\ldots \ldots \ldots \ldots \ldots \ldots \ldots \ldots$

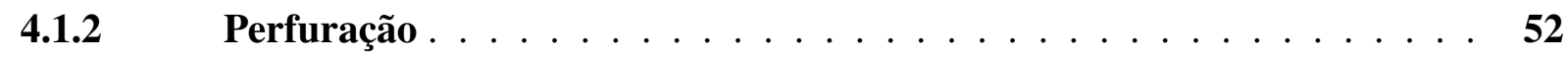

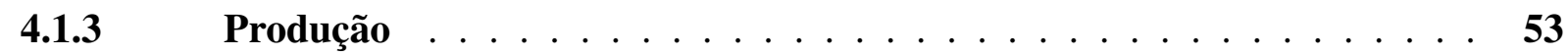

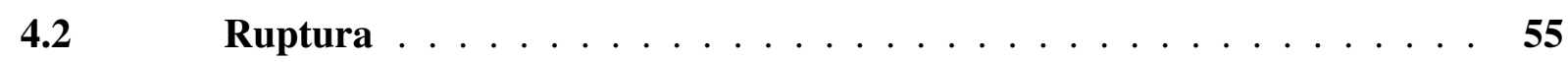

4.2.1 Instalação do Revestimento $\ldots \ldots \ldots \ldots \ldots \ldots \ldots \ldots$

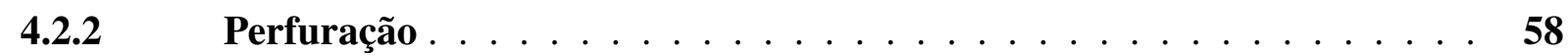

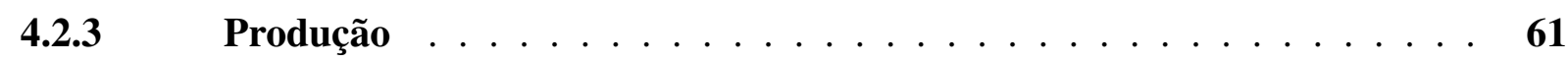

$4.3 \quad$ Annular Pressure Buildup (APB) $\ldots \ldots \ldots \ldots$

5 CÁLCULO DE FORÇAS AXIAIS $\ldots \ldots \ldots \ldots \ldots \ldots$

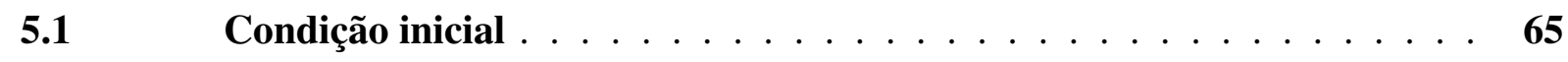

$5.2 \quad$ Metodologia para cálculo da força axial efetiva $\ldots \ldots \ldots \ldots$ 
5.3 Deslocamento devido ao efeito da temperatura $\ldots \ldots \ldots$. . . . . . 70

$5.4 \quad$ Deslocamento devido ao efeito pistão $\ldots \ldots \ldots \ldots \ldots$

5.4.1 Variação do esforço axial devida ao efeito pistão . . . . . . . . . . . . 73

$5.5 \quad$ Deslocamento devido ao efeito ballooning $\ldots \ldots \ldots \ldots$

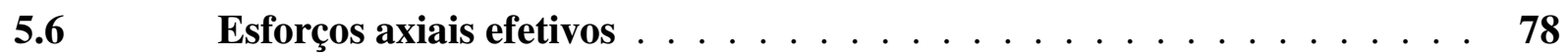

$5.7 \quad$ Outras fontes de esforços axiais $\ldots \ldots \ldots \ldots$

5.7.1 Tensão axial de flexão $\ldots \ldots \ldots \ldots \ldots$

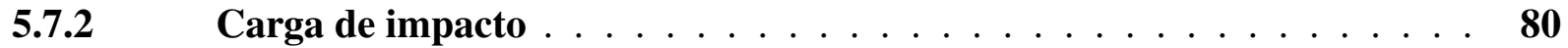

5.7.3 Força de arraste $\ldots \ldots \ldots \ldots \ldots \ldots$

6 DIMENSIONAMENTO DE REVESTIMENTOS . . . . . . . . . 81

$6.1 \quad$ Modelos de resistência da norma ISO/TR $10400 \ldots \ldots \ldots$

$6.2 \quad$ Critério de resistência à tração $\ldots \ldots \ldots \ldots$

$6.3 \quad$ Critério de resistência à ruptura $\ldots \ldots \ldots \ldots$

6.3.1 Critério de ruptura dúctil - ISO/TR $10400 \ldots \ldots \ldots \ldots$

$6.4 \quad$ Critério de resistência ao colapso $\ldots \ldots \ldots \ldots \ldots$

6.4.1 Colapso Plástico: equação de Lamé . . . . . . . . . . . . . . . . . . . 88

6.4.2 Colapso Plástico: equação empírica . . . . . . . . . . . . . . . . . 88

6.4.3 Colapso Elástico $\ldots \ldots \ldots \ldots \ldots$

6.4.4 Colapso no domínio de transição elasto-plástico . . . . . . . . . . . . . . 89

6.4.5 Efeito da pressão interna . . . . . . . . . . . . . . . . . . 89

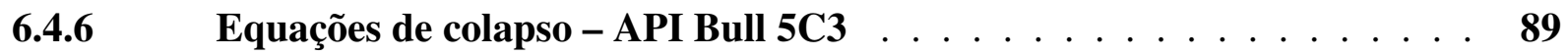

6.4.7 Critério de Klever-Tamano - ISO/TR $10400 \ldots \ldots \ldots$

$6.5 \quad$ Estado triaxial de tensões: critério de von Mises . . . . . . . . . . . . . 94

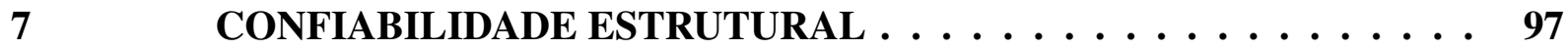

$7.1 \quad$ Níveis de confiabilidade alvo $\ldots \ldots \ldots \ldots \ldots$

$7.2 \quad$ Estados limites $\ldots \ldots \ldots \ldots \ldots 1 \ldots \ldots \ldots$

7.2.1 Equações de Estado Limite . . . . . . . . . . . . . . . . . . . . 102

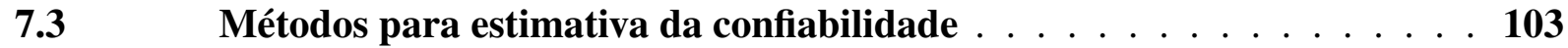

7.3.1 Método de confiabilidade de primeira ordem - FORM . . . . . . . . . 104

7.3.1.1 Índices de sensibilidade . . . . . . . . . . . . . . . . . . 105

7.3.2 Gradientes com respeito às variáveis de resistência $\ldots \ldots \ldots$

7.3.3 Simulações de Monte Carlo . . . . . . . . . . . . . . . . . . 107

7.3.3.1 Técnicas de amostragem $\ldots \ldots \ldots \ldots \ldots$

7.3.3.2 Monte Carlo Bruto . . . . . . . . . . . . . . . . . . . . . . . . 109

7.3.3.3 Monte Carlo por Importância usando pontos de projeto ～. . . . . . . . . . 110

7.4 Confiabilidade de sistemas estruturais $\ldots \ldots \ldots 11$

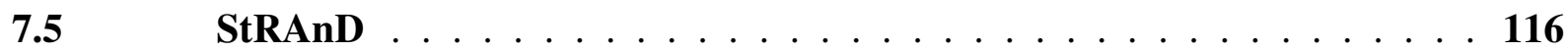


8.1 Dados Estatísticos das Variáveis de Resistência . . . . . . . . . . . 117

8.2 Dados Estatísticos das Variáveis de Solicitação . . . . . . . . . . . . 119

8.2.1 Caracterização de variáveis de solicitação: estado da arte $\ldots \ldots$. . . . 120

8.2.2 Considerações Gerais . . . . . . . . . . . . . . . . . . 126

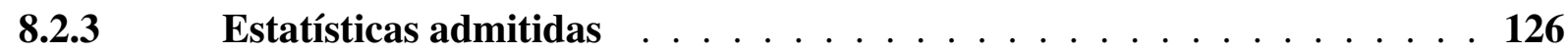

9 OTIMIZAÇÃO BASEADA EM CONFIABILIDADE . . . . . . . . . . 129

9.1 Otimização Matemática de Variáveis Discretas . . . . . . . . . . . 129

9.1.1 Problemas de otimização de variáveis mistas: definição e classes . . . . . 130

9.2 Otimização e Confiabilidade Estrutural . . . . . . . . . . . . 131

9.3 Otimização de Revestimentos de Poços . . . . . . . . . . . . . . . . 133

9.3.1 Conflito custo $v$ s. peso . . . . . . . . . . . . . . . . . . . 134

9.3.2 Formulação matemática do problema de otimização . . . . . . . . 135

9.3.2.1 Otimização baseada no custo mínimo . . . . . . . . . . . . . . . . . . 135

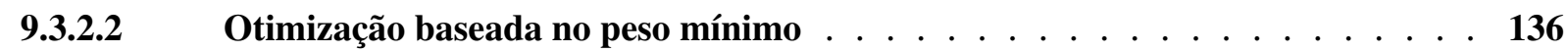

9.3.2.3 Formulação probabilística do problema de otimização $\ldots \ldots \ldots \ldots$

9.4 Métodos para solução de problemas MV-OPT . . . . . . . . . . . 137

9.4.1 Algoritmo branch-and-bound (B\&B) . . . . . . . . . . 138

9.4.2 Otimização probabilística de revestimentos usando algoritmo B\&B . . . 140

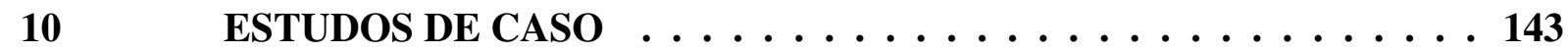

10.1 Validação do Módulo Determinístico . . . . . . . . . . . . 143

10.1.1 Revestimento Condutor . . . . . . . . . . . . . . . . . 145

10.1.2 Revestimento de Superfície . . . . . . . . . . . . . . . . 147

10.1.3 Revestimento Intermediário . . . . . . . . . . . . . . . . . 153

10.1.4 Revestimento de Produção . . . . . . . . . . . . . . . . . . . 156

10.2 Verificação do Módulo Estocástico . . . . . . . . . . . . . . . . . 161

10.2.1 Análise Qualitativa: verificação de tendências . . . . . . . . . . . 161

10.2.2 Análise da Precisão do FORM . . . . . . . . . . . . . . . . . . . . 167

10.3 Projeto Ótimo de Revestimentos . . . . . . . . . . . . . . 170

10.3.1 Otimização determinística (DDO) . . . . . . . . . . . . . . 171

10.3.2 Otimização Baseada em Confiabilidade (RBDO) . . . . . . . . . . . 177

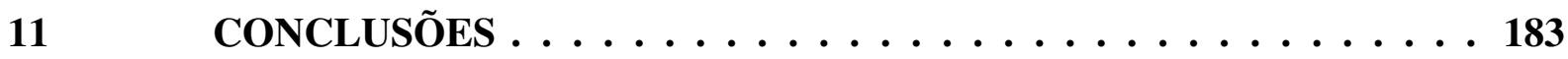

11.1 Sugestões para trabalhos futuros $\ldots \ldots \ldots \ldots$ 
APÊNDICE A - GRADIENTES DAS EEL . . . . . . . . . 195

A.1 Gradientes do critério de Klever-Stewart . . . . . . . . . . . . . . 195

A.2 Gradientes do critério de Klever-Tamano . . . . . . . . . . . . . . . 197

A.3 Gradientes do critério de von Mises . . . . . . . . . . . . . . . . . . . . . 199

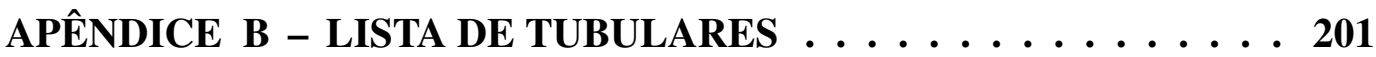

APÊNDICE C - CÓDIGO COMPUTACIONAL PARA O PROJETO ÓTIMO DE REVESTIMENTOS . . . . . . . . 205

C.1 Módulo Determinístico e Interface Gráfica . . . . . . . . . . . . . 205

C.1.1 Interface para entrada dos dados . . . . . . . . . . . . . . . 206

C.1.2 Descrição do solver determinístico $\ldots \ldots \ldots \ldots$

C.1.3 Interface para visualização de resultados . . . . . . . . . . . . 209

C.2 Módulo Estocástico . . . . . . . . . . . . . . . . . . . . . . . . . 209

C.2.1 Métodos de confiabilidade aproximativos (FORM e SORM) . . . . . 210

C.2.2 Método de simulação de Monte Carlo $\ldots \ldots \ldots \ldots$ 


\section{Introdução}

No último século, empresas petrolíferas deram preferência à exploração de petróleo em desertos, áreas continentais e em águas rasas, devido à facilidade de produção em tais locais. À medida que estes reservatórios foram se esgotando e as reservas já não eram suficientes para suprir a demanda mundial por muitos anos, a cadeia exploratória foi guiada para áreas de exploração mais complexas, que demandam mais investimentos e tecnologias, culminando no desenvolvimento da indústria marítima offshore (SIQUEIRA; BATISTA; OLIVEIRA, 2012).

As reservas de petróleo de pré-sal são grandes reservas de óleo e gás encontradas em áreas profundas dos oceanos, que atingem profundidades de até $7 \mathrm{~km}$ abaixo do nível da água (Figura 1.1). São consideradas as reservas de petróleo menos exploradas do mundo, em virtude da dificuldade envolvida em todas as etapas de planejamento e operação (PETROBRAS, 2018a).

Figura 1.1 - Formação geológica do pré-sal.

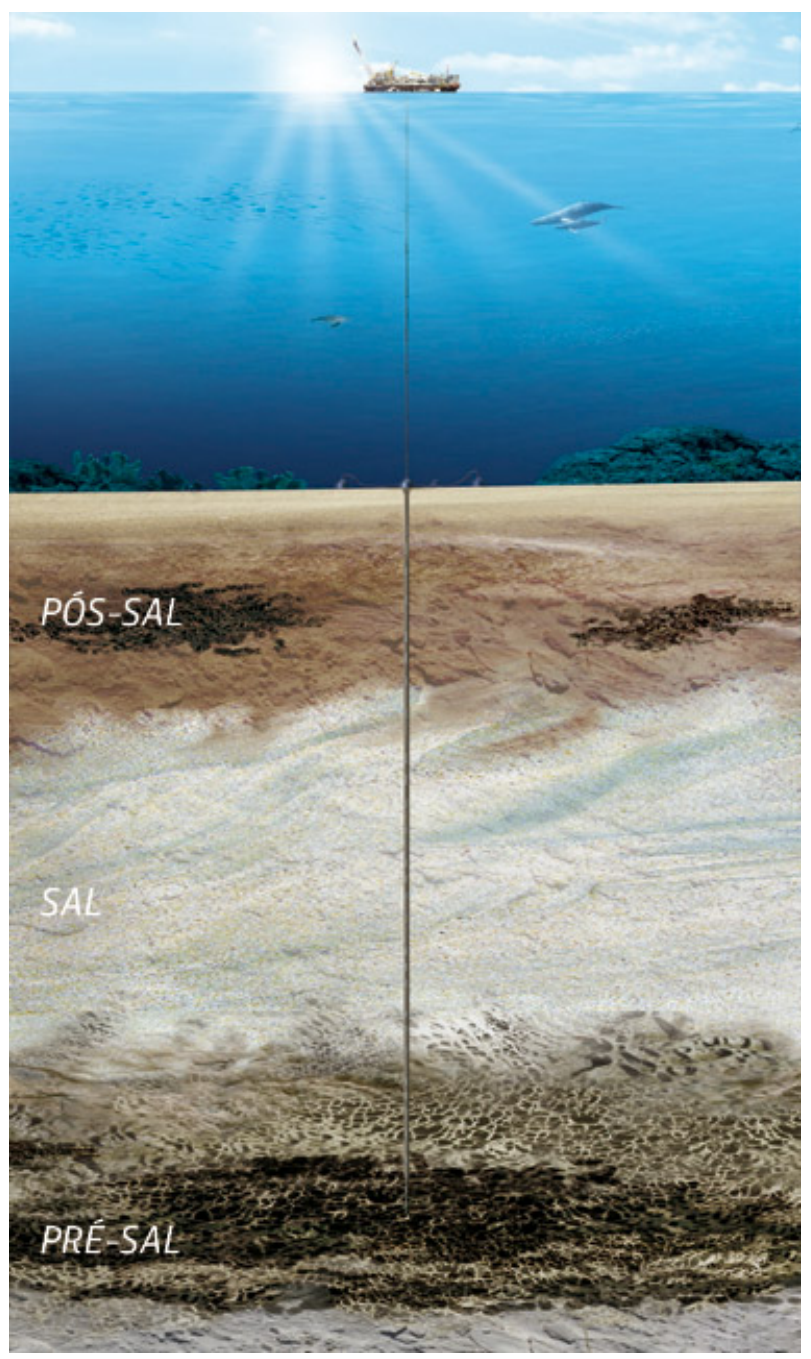

Fonte: (ADAMS, 1995)

Quando o pré-sal foi descoberto, há pouco mais de uma década, o cenário de preço do 
petróleo era o melhor já experimentado pela indústria e os custos para ultrapassar a camada de sal, apesar de altos, não eram motivos de maiores preocupações. Entretanto, após o preço do petróleo despencar em 2014, a viabilidade do pré-sal passou a ser questionada. Os investimentos em pesquisa afastaram as dúvidas sobre a viabilidade de se retirar volumes extraordinários de petróleo debaixo da camada de sal, de modo que hoje tem-se a visão nítida de que, além de viável, esse é um dos melhores negócios do mundo (NUNES; LUNA, 2017).

No Brasil, as jazidas de petróleo do pré-sal estão localizadas na região Sudeste, em um polígono de aproximadamente $800 \mathrm{~km}$ de extensão por $200 \mathrm{~km}$ de largura, situado a uma distância de $300 \mathrm{~km}$ da costa brasileira. Se estendendo a partir do norte do estado do Espírito Santo e descendo até o litoral de Santa Catarina, as reservas do pré-sal são compostas por grandes acumulações de óleo leve, de excelente qualidade e com alto valor comercial. Seu volume potencial já ultrapassa os 35 bilhões de barris de óleo equivalente (boe), estimativa esta que cresce à medida que novas jazidas são descobertas (PETROBRAS, 2016) .

A Petróleo Brasileiro S/A - Petrobras, principal companhia brasileira de exploração de petróleo, continua quebrando recordes a cada ano: em 2017, a empresa atingiu uma produção média de 2,65 milhões de barris de óleo equivalente por dia (boed), o que corresponde a um crescimento de quase 65 vezes em relação à produção média inicial de 41 mil barris por dia, em 2010 (PETROBRAS, 2018b) . A principal razão para o sucesso da estatal está nos altos investimentos em pesquisas, que possibilitaram a otimização do tempo de construção de poços marítimos no pré-sal: com o avanço no conhecimento da geologia, a introdução de tecnologias de ponta e o aumento da eficiência dos projetos, o tempo médio para construção baixou de 310 dias, em 2010, para 89 dias, em 2016. Com essa redução, estima-se que a empresa economize em média US\$ 66 milhões por poço no pré-sal somente com a atividade de perfuração, a qual tem um custo aproximado de US\$ 1 milhão por dia (PETROBRAS, 2014, 2016) .

A exploração dessa nova fonte de petróleo configura um grande desafio para o Brasil, já que quase toda a tecnologia é nova, experimental ou ainda está em desenvolvimento. As altas cifras envolvidas no processo fazem com que qualquer economia alcançada, seja na fase de perfuração ou completação de poços do pré-sal, gere grande impacto, visto que ainda são muitos os poços a serem perfurados. Por outro lado, o ambiente hostil de exploração dificulta qualquer operação, de modo que o projeto destes poços deve ser meticuloso para que sua perfuração seja realizada de forma segura.

\subsection{Motivação do Projeto}

Poços de exploração e produção de óleo e gás são estruturas complexas, de custo elevado e de alta responsabilidade. Falhas no revestimento ou na coluna de produção têm potencial para causar enormes prejuízos econômicos e ambientais, como perda total da sonda de perfuração, do poço ou até mesmo da plataforma de produção, além de sérios danos ambientais ocasionados pelo vazamento de hidrocarbonetos. 
As consequências de falhas estruturais em um poço crescem potencialmente com o aumento da lâmina d'água e/ou da profundidade total do poço, em função da complexidade da operação. Portanto, a exploração de petróleo em águas ultra-profundas ou em condições de alta temperatura e alta pressão (HTHP ou High Temperature High Pressure) demanda novos procedimentos para superar os desafios da exploração do petróleo nestas condições.

Essencialmente, um poço é composto por diferentes colunas de revestimento, também denominadas fases. Cada coluna, por sua vez, é constituída por uma série de tubulares conectados entre si, tal como os elos que compõem uma corrente. O objetivo principal do projeto de revestimentos de poços é selecionar os tubulares (elos) que irão formar cada coluna de revestimento, de modo a garantir a segurança do poço frente às solicitações que podem ocorrer ao longo de sua vida útil. $O$ projeto deve ainda ser capaz de atender a requisitos de natureza construtiva, sob a pena de se tornar inexequível.

Durante as etapas de perfuração, completação e produção, os tubulares das diferentes colunas de revestimento estão sujeitos a múltiplos modos de falha. A depender da fase a que pertencem, um mesmo modo de falha pode ainda se manifestar devido a carregamentos de origem diversa: revestimentos de superfície, por exemplo, são susceptíveis ao colapso por perda de circulação do fluido de perfuração durante sua construção, enquanto o colapso dos revestimentos de produção é governado por sua evacuação total (BYROM, 2015). Ademais, à medida que a profundidade do poço aumenta, a pressão de poros e a pressão de fratura da rocha se alteram, exigindo características distintas para os tubulares que compõem uma mesma fase. Assim, o projetista pode optar por selecionar conjuntos de tubulares com propriedades mecânicas e geométricas distintas entre si para uma mesma coluna de revestimento.

Este conjunto de particularidades torna a elaboração do projeto difícil e trabalhosa, forçando a adoção de uma série de simplificações durante as etapas de cálculo, dentre as quais está o emprego de coeficientes (muitas vezes arbitrários) para imposição de uma margem de segurança ao projeto. Prática comum entre as empresas do ramo, a adoção de fatores de segurança sem uma validação estatística rigorosa impossibilita o real controle da probabilidade de falha da estrutura do poço, dando ao projetista uma falsa sensação de segurança em alguns casos (ADAMS; GLOVER, 1998).

Em decorrência dos grandes acidentes observados recentemente, regulamentos para a exploração e produção de petróleo têm se tornado mais exigentes ao longo dos anos, especialmente para a exploração em ambiente marinho. Na Noruega, por exemplo, passou-se a exigir uma análise quantitativa de riscos (QRA), individual para cada empreendimento, após o acidente com a sonda Alexander Kielland em 1980. Em 1992, após o acidente com a plataforma Piper Alpha, foi introduzido no Reino Unido o Safety Case Regulation, que também passou a exigir análises quantitativas de risco dos empreendimentos novos e dos já existentes. Nos Estados Unidos não há atualmente exigência regulatória para a elaboração de análises de risco, sendo os regulamentos para operações off-shore principalmente prescritivos. No entanto, a comissão que investigou a explosão da plataforma de perfuração Deepwater Horizon, ocorrida em 2010, recomendou ao 
Departamento do Interior a adoção de uma nova regulamentação, exigindo dos operadores uma QRA específica para cada empreendimento, semelhante ao "Safety Case" adotado no Mar do Norte (SKOGDALEN; VINNEM, 2012).

Em alinhamento com o recente movimento para a análise quantitativa de risco em empreendimentos de exploração e produção de petróleo, observa-se um crescente consenso para a adoção do projeto probabilístico da estrutura de poço (revestimentos externos e coluna de produção). Vários artigos publicados na literatura apontam caminhos para a realização de QRA (HINTON, 1998; PAYNE; SATHUVALLI; CRABTREE, 1998; ADAMS; GLOVER, 1998; ERIVWO; ADELEYE, 2012) ou abordam questões específicas relacionadas ao projeto probabilístico de revestimentos (ADAMS; HODGSON, 1999; DEDENUOLA et al., 2003; ADAMS; MOORE; PAYNE, 2003; VALIGURA; TALLIN, 2005). Desta forma, a adoção do projeto probabilístico de revestimento de poços está de acordo com tendências mundiais e atuais.

Apesar dos avanços alcançados nos últimos anos, referenciados acima, há uma série de soluções técnicas e teóricas que precisam ser desenvolvidas para se alcançar o objetivo da realização do projeto ótimo de revestimentos de poços baseado em confiabilidade. A alta complexidade do projeto de poços em sua maneira atual (determinística), atrelada à dificuldade em quantificar as probabilidades de falha dos revestimentos configuram um grande desafio em si, porém a otimização dos revestimentos configura uma tendência futura que se pretende antecipar e desenvolver no presente trabalho.

Cabe ainda registrar que o tema desta tese derivou de um projeto de Pesquisa e Desenvolvimento fomentado pela Petrobras (BECK et al., 2017) e reflete uma necessidade emergente de uma empresa de ponta do setor de exploração de óleo e gás.

\subsection{Objetivos}

A presente tese objetiva o desenvolvimento de uma metodologia para otimização do projeto de revestimentos de poços de petróleo e gás com base em requisitos (ou restrições) expressos em termos de probabilidades de falha (RBDO - Reliability-based Design Optimization).

Para atingir o objetivo proposto, o trabalho foi dividido em uma série de etapas. São elas:

a) Delinear os princípios que regem o projeto determinístico de revestimentos de poços e o procedimento básico de cálculo praticado na indústria para estimativa de pressões e forças axiais;

b) Identificar as variáveis sobre as quais o projetista do poço tem efetivo controle e definir quais deverão ser otimizadas na busca pelo projeto ótimo de revestimento de poços;

c) Identificar e equacionar os modos de falha admissíveis a cada uma das fases de revestimento;

d) Caracterizar as variáveis que afetam os diferentes modelos de resistência, realizando a descrição estatística daquelas que exibem comportamento aleatório;

e) Investigar os métodos de confiabilidade e otimização adequados ao projeto de poços. 
Paralelamente, objetiva-se desenvolver um código computacional capaz de realizar o cálculo do diferencial de pressão, da força axial e do estado de tensão em cada ponto do revestimento ao longo de sua profundidade, para todas as fases do poço. A este código (determinístico) serão integradas rotinas específicas para estimativa de probabilidades de falha e índices de confiabilidade - que irão compor o módulo estocástico -, além de rotinas de otimização. $\mathrm{O}$ software passará por um processo de validação síncrono ao seu desenvolvimento e servirá de ferramenta para a realização de estudos de caso a fim de ilustrar a aplicabilidade da metodologia proposta, bem como quantificar seu desempenho.

\section{Metodologia}

A metodologia empregada neste trabalho corresponde a uma adaptação do procedimento adotado por Adams e Hodgson (1999) para a calibração de critérios de projeto de revestimentos com base em técnicas de confiabilidade estrutural.

\section{Projeto de Poços: Estado da Arte}

Para melhor compreender o problema estudado, o estudo tem início com uma revisão bibliográfica que procura relatar o estado da arte da aplicação de técnicas de QRA ao revestimento de poços. São elencadas as principais vantagens conferidas pelo emprego de métodos probabilísticos de projeto, legitimadas por meio de aplicações reais conduzidas por empresas do setor de exploração de óleo e gás.

Ainda nesta etapa de revisão são estudados os princípios que regem o projeto determinístico de revestimentos. Abordam-se questões referentes à definição do número de fases do poço e da profundidade de cada uma delas, aspectos normativos/regulamentares envolvidos, casos de carregamentos aplicáveis, dentre outros. São elencadas as propriedades mecânicas e geométricas dos tubulares sobre as quais o projetista do revestimento exerce efetivo controle (tomada de decisão) e que irão delimitar o escopo da otimização que se pretende realizar.

\section{Estimativa da Confiabilidade Estrutural}

Análises de confiabilidade estrutural são parte integrante de uma análise de risco e buscam estimar a probabilidade de falha de um dado componente ou sistema. Para proceder com a estimativa de tal probabilidade, são percorridas as etapas propostas por Sorensen (2004), descritas a seguir.

Inicialmente identificam-se as variáveis aleatórias pertinentes ao problema de poços e faz-se a caracterização estatística das mesmas. Em seguida, definem-se os possíveis mecanismos de falha dos revestimentos e selecionam-se as equações de estado limite que melhor predizem o nível de tensão máximo resistido por eles. Tal seleção é baseada na qualidade da predição em comparação com resultados de campo ou com testes em escala real para um número estatisticamente significativo de casos. Nestas duas primeiras etapas, recorre-se às informações 
apresentadas pela norma ISO/TR 10400:2011 (ISO, 2011).

As equações de estado limite escolhidas são então implementadas dentro de um programa de confiabilidade estrutural capaz de estimar a probabilidade de falha de cada componente (tubular) e/ou do sistema (colunas de revestimento) por meio de métodos de confiabilidade de primeira e segunda ordem (FORM/SORM) ou de técnicas de simulação de Monte Carlo (MELCHERS, 1999). Nesta etapa, um ponto importante corresponde à definição do modelo mais apropriado para a realização das análises de confiabilidade de revestimentos. Dois modelos são possíveis: um modelo de componente, que considera a falha de cada tubular de maneira isolada; e um modelo de sistema, que considera a associação dos tubulares na composição de cada fase do poço (ADAMS; HODGSON, 1999). São discutidas as peculiaridades de cada modelo e define-se qual o mais recomendado, tendo em vista o contexto mais amplo de otimização em que as análises de confiabilidade estão inseridas.

Finalmente, em posse das probabilidades de falha dos tubulares e/ou do sistema, a análise de confiabilidade se encerra com a comparação dos resultados obtidos a um valor de referência (probabilidade de falha alvo). Cada uma das etapas ora descritas será melhor explorada em capítulos específicos.

\section{Otimização sob Incertezas}

Após a estimativa da confiabilidade estrutural, a metodologia tem sequência com a otimização do poço. Com base nas probabilidades de falha calculadas, a configuração inicial de cada coluna de revestimento é modificada de modo que a seleção dos tubulares que a compõem seja aperfeiçoada. A otimização é realizada de modo a proporcionar uma margem de segurança mais homogênea ao longo da profundidade de cada fase, procurando estreitar a distância entre o índice de confiabilidade do modo de falha dominante e o índice alvo, considerado aceitável, cuja escolha caberá ao analista do projeto.

Para que esta etapa seja bem sucedida, é necessário primeiramente construir um modelo matemático que descreva o desempenho de revestimentos de poços, de modo que o problema seja bem definido em termos de objetivos e restrições. Este modelo será implementado no código computacional desenvolvido e integrado às rotinas de confiabilidade.

\section{Desenvolvimento do Código Computacional}

Paralelamente à evolução deste trabalho foi feita a programação de um código computacional capaz de realizar a otimização de revestimentos sob presença de incertezas. O algoritmo é composto por três módulos de cálculo (solvers) relativamente independentes entre si: um módulo determinístico, um módulo estocástico e um módulo de otimização.

O solver determinístico foi desenvolvido em parceria com uma empresa privada como parte de um contrato de Projeto de Pesquisa e Desenvolvimento (BECK et al., 2017). Tal empresa contribuiu também para a criação de uma interface gráfica que permite a entrada de dados do poço. Simplificadamente, o módulo determinístico engloba todo o conjunto de equações necessárias à 
determinação das forças axiais e das pressões externa e interna atuantes ao longo das colunas de revestimento do poço, para cada caso de carregamento. Sua concepção fundamenta-se nos princípios da Hidrostática e da Mecânica dos Sólidos. Adicionalmente, permite o cálculo dos coeficientes de segurança atrelados aos modos de falha por ruptura, colapso e estado triaxial de tensões.

O módulo estocástico, por sua vez, calcula as probabilidades de falha das várias fases do poço, para todos os casos de carregamento aplicáveis. Para isso, utiliza os dados nominais de pressões e esforços axiais fornecidos pelo módulo determinístico. Faz uso das mesmas equações de resistência utilizadas para o cálculo dos coeficientes de segurança, contudo emprega parâmetros adicionais em sua avaliação para levar em conta a natureza aleatória das variáveis e a diferença entre a previsão dos modelos matemáticos em relação aos dados de campo ou testes em escala real (erro de modelo).

A concepção do módulo estocástico baseou-se no software acadêmico StRAnD (Structural Reliability Analysis and Design), desenvolvido junto ao Departamento de Engenharia de Estruturas da EESC/USP ao longo da última década (BECK, 2007; BECK, 2009; SANTOS, 2014a; KROETZ, 2015; TESSARI, 2016). O módulo foi completamente adaptado e integrado ao solver determinístico para a realização de análises de confiabilidade ao longo da profundidade de cada fase.

Por fim, o módulo de otimização inclui uma técnica de enumeração parcial, ideal para problemas envolvendo variáveis discretas. Foi implementada de modo a permitir a otimização dos revestimentos do poço segundo dois critérios de desempenho distintos: custo mínimo absoluto e menor peso.

Com exceção da interface gráfica, implementada em linguagem C\#, os demais módulos estão implementados em linguagem FORTRAN 2003 utilizando conceitos de orientação a objetos. Estratégias de programação em paralelo foram utilizadas nos laços das técnicas de simulação de Monte Carlo, reduzindo significativamente o tempo de processamento.

\section{Verificação do Código Computacional}

Uma vez concluída a implementação de cada um dos módulos de cálculo, o código computacional deve ser verificado. Para isso, análises são realizadas com base em uma configuração típica de um poço HTHP extraída da literatura, especificada conforme recomendações normativas e procedimentos usuais (determinísticos) de projeto.

Inicialmente é efetuada a validação do módulo determinístico, mais especificamente das rotinas para cálculo das pressões internas e externas, forças axiais e coeficientes de segurança. Em seguida, com base nos revestimentos escolhidos para cada fase, são calculadas as probabilidades de falha para cada cenário de carregamento e para cada modo de falha aplicável (ruptura, colapso ou estado triplo de tensões), ao longo de toda a profundidade do poço. O módulo estocástico é averiguado apenas qualitativamente, em virtude da não existência de softwares comerciais similares ou da impossibilidade de aquisição de softwares de ponta. 
Por fim, o módulo de otimização é aferido separadamente em duas etapas. Primeiramente são simulados problemas determinísticos para avaliar a correta implementação das rotinas de otimização e, em seguida, os mesmos exemplos sofrem nova otimização, porém agora baseada em confiabilidade. Os resultados de ambos são comparados entre si, demonstrando a diferença entre as abordagens.

\subsection{Organização do trabalho e síntese dos capítulos}

O presente trabalho está dividido em onze capítulos, incluindo este introdutório. No Capítulo 2, é feita uma exposição sobre o estado da arte do projeto probabilístico de revestimentos. Em seguida, os princípios básicos para o projeto de poços são apresentados no Capítulo 3. Os Capítulos 4 e 5 dedicam-se à descrição dos cálculos envolvidos na estimativa das pressões de colapso e ruptura, bem como das forças axiais atuantes no revestimento nos casos de carregamento considerados críticos ao dimensionamento do poço. No Capítulo 6 apresentam-se os modelos de resistência tradicionalmente empregados em projetos determinísticos e são introduzidos critérios de resistência mais modernos, preconizados pela norma ISO/TR 10400, adequados à realização de análises de confiabilidade. A teoria da confiabilidade estrutural é brevemente explanada no Capítulo 7, o qual se encerra com uma discussão a respeito do modelo mais indicado ao projeto de revestimentos. A descrição das variáveis aleatórias de resistência e solicitação é realizada no Capítulo 8 e o conjunto de conceitos teóricos se encerra no Capítulo 9, quando a metodologia para o projeto ótimo de revestimentos baseado em confiabilidade é delineada. Por fim, nos Capítulos 10 e 11 estão documentados os estudos de caso conduzidos e as principais conclusões observadas, respectivamente. 


\section{Estado da Arte da Confiabilidade de Poços}

Este capítulo apresenta uma visão geral e sucinta a respeito da segurança em poços de óleo e gás, com foco na aplicação de análises quantitativas de risco no contexto específico dos revestimentos de poços. O interesse é mantido especialmente no caso de poços em águas profundas (profundidade maior que $300 \mathrm{~m})$ e ultraprofundas $(>1500 \mathrm{~m})$ sob condições severas de pressão e temperatura (poços HTHP). Este enfoque é dado devido ao aumento expressivo de atividades de exploração de petróleo em áreas de águas profundas que vem ocorrendo ao longo dos últimos anos em vários países, inclusive no Brasil. Uma revisão mais extensa sobre o tema pode ser encontrada em Beck et al. (2015).

\subsection{Segurança em Poços de Óleo e Gás}

Perfurações de poços offshore, especialmente em águas profundas, são operações complexas nas quais erros de engenharia podem custar centenas de milhões de dólares. Trata-se, portanto, de atividades que envolvem altos riscos e altos custos.

Em águas profundas, muitos fatores de alto risco podem estar presentes, tais como: programas de revestimento complexos, altas pressões, altas temperaturas, formações de elevada complexidade, incertezas geológicas e falta de pessoal experiente (SKOGDALEN; VINNEM, 2012). A ocorrência de janelas de perfuração estreitas (definidas basicamente pela diferença entre a pressão de poros e a pressão de fratura da formação) também torna mais difícil a execução das operações de perfuração. Assim, o gerenciamento eficiente dos riscos é importante ao longo de todo o ciclo de vida do poço.

De maneira geral, as fases do ciclo de vida para atividades de perfuração podem ser divididas em: fase de planejamento do poço; fase de perfuração (que consiste na perfuração em si, descida do revestimento, cimentação, circulação, deslocamento de fluido e limpeza); e fase de completação (SKOGDALEN; VINNEM, 2012).

De acordo com Skogdalen, Utne e Vinnem (2011), há, em geral, três categorias de incidentes indesejados que podem ocorrer durante operações de poços: kick, vazamento do poço e blowout. A primeira categoria consiste em uma instabilidade causada pelo fluxo do fluido originalmente contido na formação (gás, óleo ou água) para dentro do poço. O vazamento do poço, por sua vez, é caracterizado pelo transbordamento do fluido da formação pelo topo do poço através do Blowout Preventer (BOP) por um período limitado de tempo até que o fluxo seja interrompido pelo equipamento existente no poço ou por meios operacionais definidos (API, 2006a; API, 2010). Finalmente, um blowout consiste em um fluxo descontrolado de fluidos da formação subterrânea para a atmosfera ou para dentro de outra formação. São resultado de uma perda de controle do poço, que pode acontecer quando a pressão da formação excede a pressão a ela aplicada pela coluna de fluido de perfuração ou de completação (API, 2010). 
Blowouts estão entre os mais sérios acidentes envolvendo plataformas de perfuração e suas tripulações. Como exemplo, o blowout ocorrido no poço em Macondo e os subsequentes incêndios e explosões, evento conhecido como acidente da plataforma Deepwater Horizon, levou a 11 fatalidades, à perda de uma plataforma de perfuração e causou o maior vazamento de óleo em ambiente marinho da história da indústria do petróleo (XUE et al., 2013).

A probabilidade de ocorrência de kicks depende das condições operacionais e geológicas. Entretanto, eles podem ser evitados por meio de planejamento adequado do poço, monitoramento da performance e gerenciamento de mudanças. As consequências de kicks podem ser eliminadas ou reduzidas por repostas adequadas a determinados eventos. Procedimentos de controle de poço têm por objetivo prevenir ou lidar de maneira segura com tais eventos e reestabelecer o controle primário do poço, evitando a ocorrência de vazamentos e blowouts (SKOGDALEN; UTNE; VINNEM, 2011).

Assim, é fundamental a aplicação de soluções técnicas, operacionais e organizacionais para reduzir o risco de liberação descontrolada de fluidos da formação ao longo da vida útil do poço (NORSOK, 2004). Os meios utilizados na indústria do petróleo para redução de riscos são comumente chamados de barreiras de segurança. Tais barreiras podem ser passivas ou ativas, sistemas físicos, técnicos ou operacionais e têm por função prevenir, controlar ou mitigar eventos indesejados e acidentes (MIURA et al., 2006; HUDSON et al., 1994; SKLET, 2006).

A norma norueguesa NORSOK D-010 (2004) define barreira de poço como sendo um envelope de um ou mais elementos de barreira dependentes, que previnem o fluxo não intencional de fluidos ou gases de uma formação para outra ou para a superfície. As barreiras de poço são divididas em primárias e secundárias e, segundo a referida norma, duas barreiras devem estar disponíveis durante todas as atividades e operações de poço nas quais houver pressão diferencial que possa causar fluxo descontrolado do poço para o ambiente externo. Se uma barreira vier a falhar, nenhuma outra atividade deve ser executada no poço até que a mesma seja recuperada. $\mathrm{O}$ princípio das duas barreiras é seguido por várias empresas ao redor do mundo.

Xue et al. (2013) apresentam uma teoria de controle de poço em três níveis, em que a operação de controle de poço pode ser dividida em:

1. Controle primário de poço: consiste em utilizar a coluna de fluido de perfuração para controlar a pressão do reservatório durante perfuração normal ou perfuração por zonas que possuam hidrocarbonetos sob alta-pressão. O objetivo do controle primário de poço é manter a integridade do poço durante a perfuração;

2. Controle secundário de poço: é o processo de reestabelecimento da pressão balanceada por meio de operações de fechamento (shut-in) e circulação do poço, quando a integridade do poço é quebrada devido à ocorrência de um kick;

3. Controle terciário de poço: consiste nas tecnologias de recuperação do controle da cabeça de poço após um vazamento ou blowout.

Um kick no poço ocorrerá quando a barreira de controle primário falhar. Se o kick não for desviado ou parado por meio do fechamento do poço a tempo, poderá se transformar/desenvolver 
em um blowout.

Na prática, há dependências entre algumas barreiras, o que é positivo do ponto de vista de controle de eventos indesejáveis. Entretanto, independentemente disto, o modo mais simples e seguro para prevenir acidentes e suas consequências é manter todas as barreiras intactas.

\subsection{Filosofias de Projeto de Revestimentos de Poços}

O revestimento de poço é uma das barreiras físicas relevantes para a manutenção da integridade do poço, constituindo, portanto, uma das barreiras primárias de controle. A função essencial das barreiras primárias é prevenir a ocorrência de kicks no poço e limitar suas consequências.

Conforme será apresentado nas próximas subseções, o projeto de revestimentos de poços pode ser conduzido essencialmente de duas maneiras: determinística ou probabilisticamente. A segunda alternativa faz uso, basicamente, de análises quantitativas de riscos ou QRA (Quantitative Risk Analysis/Assessment). A seguir, apresentam-se ambas as filosofias para projeto de revestimentos de poços e aborda-se a questão relacionada à tolerância ao kick. A seção se encerra com a apresentação de alguns exemplos de aplicação prática encontrados na literatura, seguidos de comentários finais a respeito do tema.

\subsubsection{Projetos determinísticos de revestimentos e suas limitações}

Projetos convencionais de revestimentos utilizam métodos determinísticos para comparar um máximo carregamento a uma propriedade mínima de desempenho (MILLER, 1998). Este procedimento se baseia no método das tensões admissíveis que, para este caso específico, consiste em comparar o valor de tensão calculado para o pior caso de carregamento com a tensão de escoamento do revestimento, envolvendo ainda coeficientes de segurança para incorporar uma margem de segurança à comparação (HINTON, 1998).

Segundo Adams e Glover (1998), critérios de projeto têm sido tradicionalmente baseados em experiência e precedentes históricos. Contudo, esta abordagem apresenta muitas limitações, tais como:

- Frequentemente conduz a projetos muito conservadores que geram custos excessivos;

- Não orienta quanto ao projeto de novos tipos de poços (os HTHP, por exemplo);

- Não informa o real nível de segurança do projeto; e

- Não permite ao projetista controlar o nível de segurança.

Segundo estes autores, projetos de poços requerem a seleção de cargas de projeto e coeficientes de segurança adequados. A segurança depende do quão correta é esta seleção, mas métodos determinísticos de projeto não ajudam a fazê-la. Além disso, os métodos determinísticos ou semi-probabilítiscos não endereçam as consequências de falha.

De acordo com Hinton (1998), os riscos não podem ser quantificados nesta metodologia, dificultando, portanto, a comparação objetiva e direta de projetos alternativos. Propicia também 
situações nas quais é impossível produzir um projeto passível de ser construído, o que pode ocorrer, por exemplo, devido a diferenciais de pressão extremos no fundo do poço. Miller (1998) afirma ainda que coeficientes de segurança são capazes apenas de fornecer uma sensação geral de aceitabilidade. No entanto, em alguns casos tal sensação pode não ser justificada.

\subsubsection{Projetos probabilísticos de revestimentos e QRA}

Segundo Skogdalen e Vinnem (2012), a análise quantitativa de riscos (QRA) pode ser utilizada como uma ferramenta para definir quais cargas devem ser consideradas no projeto do revestimento e quais barreiras de segurança são necessárias à segurança do poço. De maneira geral, tais análises são empregadas para determinar condições de operação e classificar áreas, sistemas e equipamentos com relação aos riscos identificados.

Projetos probabilísticos utilizando técnicas de QRA podem superar algumas das limitações inerentes aos projetos determinísticos, de maneira que sua aplicação no contexto de sistemas de tubulares e de revestimentos de poços tem experimentado rápido desenvolvimento nos últimos anos (ADAMS; HODGSON, 1999). Como exemplos de projetos nesta área, elaborados há quase duas décadas, podem-se citar: concepção de metodologia e software para aplicação de QRA, incluindo um estudo piloto (ADAMS; GLOVER, 1998); definição de critérios de projeto baseados em confiabilidade para poços HTHP (ADAMS, 1995); calibração de código de projeto utilizando o Método dos Estados Limites (ou LRFD) (BRAND; WHITNEY; LEWIS, 1995; LEWIS et al., 1995a); e preparação de equações de projeto melhoradas para colapso de revestimento (ADAMS et al., 1998).

Em 1998, projetos baseados em risco já eram aplicados para o dimensionamento de dutos não usuais, porém vieram a tornar-se um padrão na engenharia civil quando o conceito de risco foi utilizado para a calibração de coeficientes de segurança de várias normas relacionadas à engenharia de estruturas (HINTON, 1998). Em 1999, tanto os modelos de análise quanto os programas computacionais necessários já estavam razoavelmente maduros (ADAMS; HODGSON, 1999).

A utilização de técnicas de QRA não é necessária para projetos usuais de revestimento, casos nos quais coeficientes de segurança devidamente calibrados podem desempenhar bem seu papel. Porém, métodos de QRA podem fornecer informações adicionais úteis, por exemplo, em situações que envolvam poços de exploração HTHP, nos quais os materiais são levados aos seus limites, ou em otimizações de campo em larga escala, em que uma pequena redução nos custos de revestimento é multiplicada por centenas de poços (MILLER, 1998).

Considerando que não existe operação livre de risco, há necessidade de garantir que os riscos à segurança e à saúde das pessoas sejam controlados adequadamente e reduzidos para um nível tão baixo quanto possível (HINTON, 1998). Neste sentido, um princípio amplamente adotado e discutido na indústria do petróleo é o chamado princípio ALARP (As Low as Reasonably Practicable, ou tão baixo quanto razoavelmente praticável).

Projetar via ALARP significa balancear custos contra riscos. Uma avaliação via ALARP 
para um revestimento de poço envolve, geralmente, admitir diferentes valores para os coeficientes de segurança - e, portanto, vários custos de revestimento e tubulações -, calcular probabilidades de falha para cada caso e obter curvas de custo do poço contra o respectivo risco. Adams e Glover (1998) afirmam que é necessário mudar de padrões prescritivos para critérios mais objetivos, utilizando o princípio ALARP.

A confiabilidade estrutural está inserida neste contexto, sendo aplicada para a avaliação da probabilidade de falha estrutural de um determinado projeto ou para a calibração de normas de projeto, quando se definem os coeficientes de segurança em função do risco de falha de classes genéricas de estruturas. Conforme ressaltam Adams e Glover (1998), o cálculo das probabilidades de falha é somente uma parte da QRA, sendo a outra a avaliação das consequências de falha.

Na presente pesquisa, o foco da confiabilidade estrutural é essencialmente a estimativa da probabilidade de falha de revestimentos, aplicada em um âmbito mais geral de otimização. As consequências de falha não serão estudadas devido à enorme complexidade envolvida na estimativa de tempos e custos, que estão intrinsecamente atrelados ao local de implantação do poço, às políticas ambientais aplicáveis e às técnicas construtivas empregadas. Segundo Domingues (2013), se realizada da maneira mais detalhada e precisa possível, a estimativa de custo de um poço pode exigir tanto esforço quanto o próprio projeto do poço.

\subsubsection{Aplicações bem-sucedidas de métodos probabilísticos de projeto}

As análises quantitativas de risco têm ganhado aceitação em muitas companhias como um meio de otimizar colunas de revestimento em relação ao custo e à segurança, especialmente para o caso de poços críticos. Miller (1998) apresenta três situações reais de poços submetidos a altas pressões, nas quais se utiliza QRA para justificar a utilização de colunas de revestimento que não satisfazem requisitos convencionais de projeto.

No primeiro exemplo, o revestimento foi projetado utilizando hipóteses convencionais de carregamento e coeficientes de segurança convencionais. Entretanto, após a perfuração, verificouse que a pressão no fundo do poço era bem maior do que a considerada no projeto original. Mostrou-se então como empregar a QRA para decidir quanto a reforçar ou não a estrutura com um tieback, o que corresponderia a decidir quanto a uma taxa de produção mais baixa ou um maior custo de falha. $\mathrm{Na}$ QRA foram considerados carregamentos determinísticos, calculados com base em dados medidos, e resistência estocástica, descrita a partir dos resultados de testes em 14 corpos de prova do material do revestimento e de outros dados disponíveis.

No segundo caso, uma metodologia similar de QRA é aplicada a um poço exploratório HTHP, com o intuito de ilustrar como lidar com mais de uma variável aleatória e como endereçar incertezas no carregamento. Por se tratar de um poço exploratório, a pressão no fundo do poço não é conhecida e a pressão de fechamento do poço (SITP) pode ser tão alta quanto 14600 psi (100 MPa). No exemplo, probabilidades de falha são calculadas para vários valores de SITP, de maneira que o engenheiro pode determinar qual a pressão admissível no revestimento que corresponde a um valor aceitável da probabilidade de falha. 
A terceira situação discute como combinar distribuições de carregamento e resistência em um caso envolvendo um revestimento de produção. Simplificadamente, gera-se uma distribuição dos coeficientes de segurança a partir das distribuições do carregamento e da resistência e computa-se a probabilidade de falha a partir da distribuição obtida, sendo que a ocorrência de falha está relacionada a valores do coeficiente de segurança menores que um.

As aplicações apresentadas por Miller (1998) podem ser consideradas simples do ponto de vista computacional, mas ilustram a aplicabilidade da análise quantitativa de risco e o fato dela possibilitar projetos mais arrojados que os convencionais.

Outros projetos de sucesso desenvolvidos pela companhia ARCO (Atlantic Richfield Company) também foram apresentados por Payne, Sathuvalli e Crabtree (1998). Os exemplos ilustram métodos probabilísticos utilizados na tomada de decisão envolvendo a substituição ou não de revestimentos sujeitos a carregamentos reais superiores àqueles previstos na situação de projeto, o que poderia afetar negativamente a segurança durante a completação e produção do poço. Nos casos reportados, estudos estatísticos baseados em testes experimentais foram realizados para descrever as propriedades mecânicas e geométricas dos tubulares e, com isso, efetuar novo cálculo da resistência apresentada por eles. Verificou-se então uma margem suficientemente grande entre a carga de projeto e a carga máxima real suportada pelos revestimentos de interesse, de modo que não foi necessário realizar substituições e economias substanciais foram feitas.

Por meio destes exemplos, torna-se evidente que métodos probabilísticos de projeto permitem conceber estruturas mais econômicas e com nível real de segurança passível de ser quantificado. Dentre outros fatores, seu sucesso pode ser explicado pela melhor descrição das propriedades dos materiais envolvidos e das condições de máximo carregamento de campo assumidas, bem como pela adoção de medidas corretivas mais apropriadas. Ressalta-se que a economia de recursos não se deve exclusivamente à aplicação de técnicas de QRA, sendo resultado direto também de um maior entendimento das causas de falhas nos tubulares e do consequente aprimoramento dos modelos de resistência empregados.

\subsection{Considerações Finais}

A maioria dos comentários apresentados a seguir estão relacionados às discussões levantadas em Hinton (1998). No artigo, afirma-se que o projeto baseado em risco (Risk Based Design) por si só não significará poços mais seguros e precisa ser justificado como sendo parte de um sistema mais amplo, que inclui controle de qualidade melhorado e equações de falha mais precisas. Além disso, é fundamental que o usuário de modelos e programas de computador sofisticados entenda as hipóteses e princípios sobre os quais os mesmos foram elaborados para que possa utilizá-los corretamente.

Outro questionamento levantado por Hinton (1998) é o seguinte: os carregamentos no revestimento podem ser previstos com tanta precisão quanto a resistência? A resposta apresentada é a de que os carregamentos (que envolvem pressões de formação e volumes de kick, por exemplo) 
raramente serão tão previsíveis quanto a resistência de produtos manufaturados. Mesmo em situações nas quais kicks são mais prováveis de acontecer (como em poços HTHP e dolomitas altamente pressurizadas dentro de sais maciços) pode haver outros fatores complicadores, como perda massiva de circulação. Além disso, os bancos de dados relacionados aos carregamentos são bem menores, de maneira que seria importante que companhias compartilhassem esse tipo de informação para melhorar sua previsibilidade.

Outro ponto discutido é que a resistência apresentada por um duto é geralmente maior que seus valores nominais API. Porém, uma coluna de revestimento é somente tão resistente quanto seu elo mais fraco. Se o projeto baseado em risco é utilizado para justificar revestimentos de menor resistência, isto deve ser garantido por um melhor controle de qualidade do revestimento.

Como conclusão, o autor afirma que projetos baseados em risco significarão poços mais seguros, mesmo levando a tubos mais leves e com menores classes de aço. Mas isso somente ocorrerá se:

- Os padrões de qualidade forem melhores;

- Esta metodologia de projeto for utilizada por pessoas que entendam o sistema e considerem-no em sua totalidade (não fazendo somente análises pontuais);

- Os dados de carregamento puderem ser adequadamente estimados, especialmente em casos de poços HTHP.

Desde a publicação do artigo de Hinton (1998), muitas mudanças já ocorreram. Como exemplo, as equações para colapso e ruptura de revestimento presentes na norma ISO/TR 10400 (2007) sofreram várias melhorias e conseguem representar com grande fidelidade os fenômenos aos quais estão relacionadas. Tais equações servem, inclusive, para descrever estados limites últimos em avaliações probabilísticas, como feito em Liao, Guan e Long (2012).

Outra mudança significativa que pode ser citada é aquela descrita em Adams, Moore e Payne (2003), que aborda um novo tratamento para colapso de tubos Q\&T (Quenched \& Tempered), isto é, tubos que passam por processo térmico no qual são temperados e resfriados rapidamente. Este artigo descreve o projeto desenvolvido por um dos grupos de trabalho que constituíram o comitê responsável por reescrever as equações de resistência do Boletim API 5C3 (2004). Este projeto deu origem à norma ISO/TR 10400 (2007), a qual foi integralmente transcrita na norma API/TR 5C3 (2018). A necessidade de atualizar o documento estava relacionada ao fato que as equações para determinação do desempenho de tubulares estavam conduzindo a valores muito diferentes em função do intervalo de variação da razão entre diâmetro externo e espessura $(O D / t)$. Em meio ao processo, percebeu-se que a diferença nos valores observados estava relacionada também à utilização das mesmas equações para tubos Q\&T e não Q\&T, que apresentam comportamentos de colapso significativamente diferentes.

Grandes avanços tecnológicos na fabricação do aço também têm resultado em melhorias significativas na qualidade dos tubulares. Adicionalmente, inspeções permitem localizar e eliminar defeitos ocorridos na fabricação, garantindo que o corpo dos tubos esteja livre de defeitos. Portanto, tecnologias de fabricação e inspeção atuais devem ser mais cuidadosamente levadas 
em conta, para que se possa usufruir das vantagens das mesmas no projeto e na utilização de tubulares.

Logicamente, ainda há muitos desafios a serem superados e melhorias a serem feitas, principalmente no âmbito das águas profundas. Neste tipo de ambiente, o controle do poço se torna mais complicado devido às margens estreitas de perfuração, às altas temperaturas e pressões no fundo do poço, além da presença de fluidos de produção muitas vezes ácidos e corrosivos (SHAUGHNESSY et al., 2003). Neste contexto, o presente trabalho busca contribuir para o avanço do projeto de poços de petróleo, mais especificamente para a otimização probabilística de revestimentos empregados em águas profundas. 


\section{Projeto de Poços: Princípios}

Durante a perfuração de poços de petróleo e gás torna-se necessário revestir as paredes do poço com tubos de aço, denominados revestimentos. As funções do revestimento durante as etapas de perfuração e produção incluem: prevenir o colapso de formações fracas; servir como condutor dos fluidos de perfuração e produção para a superfície; servir de suporte para equipamentos de cabeça de poço e BOPs (Blowout Preventors); dentre outras.

Poços são perfurados e revestidos em várias etapas para que seja possível selar zonas problemáticas e atingir a profundidade total requerida. Assim, diferentes colunas de revestimento são necessárias em diferentes profundidades. Os principais tipos de revestimento para poços offshore, suas funções e características são apresentados na Tabela 3.1. Uma configuração típica de revestimentos para um poço profundo é ilustrada na Figura 3.1.

Tabela 3.1 - Tipos de revestimento.

\begin{tabular}{|c|c|c|c|c|}
\hline $\begin{array}{l}\text { Tipo de } \\
\text { revestimento }\end{array}$ & $\begin{array}{c}\text { Diâmetro } \\
\text { externo } \\
\text { in. }(\mathrm{mm})\end{array}$ & $\begin{array}{l}\text { Profundidade de } \\
\text { assentamento }\end{array}$ & $\begin{array}{c}\text { Comprimento } \\
\text { ft. }(\mathrm{m})\end{array}$ & Funções principais \\
\hline $\begin{array}{l}\text { Revestimento } \\
\text { Condutor }\end{array}$ & $\begin{array}{c}95 / 8 \text { a } 36 \\
(244 \text { a } 914)\end{array}$ & $\begin{array}{l}\text { Coluna de } \\
\text { revestimento mais } \\
\text { externa fixada no } \\
\text { leito do mar. }\end{array}$ & $\begin{array}{l}40 \text { a } 1000 \\
(12 \text { a } 305)\end{array}$ & $\begin{array}{l}\text { Conter formações não } \\
\text { consolidadas de superfície. } \\
\text { Suportar revestimentos } \\
\text { subsequentes e equipamen- } \\
\text { tos de cabeça de poço. }\end{array}$ \\
\hline $\begin{array}{l}\text { Revestimento } \\
\text { de Superfície }\end{array}$ & $\begin{array}{c}7 \text { a } 16 \\
(178 \text { a } 406)\end{array}$ & $\begin{array}{c}\text { Estende-se do } \\
\text { leito do mar até } \\
\text { profundidades de } \\
5000 \mathrm{ft} .\end{array}$ & $\begin{array}{l}2000 \text { a } 5000 \\
(610 \text { a } 1524)\end{array}$ & $\begin{array}{l}\text { Conter formações rasas. } \\
\text { Proteger aquíferos naturais. } \\
\text { Servir de base para BOPs. }\end{array}$ \\
\hline $\begin{array}{l}\text { Revestimento } \\
\text { Intermediário }\end{array}$ & $\begin{array}{c}7 \text { a } 113 / 4 \\
(178 \text { a } 300)\end{array}$ & $\begin{array}{l}\text { Situado entre os } \\
\text { revestimentos de } \\
\text { superfície e de } \\
\text { produção. }\end{array}$ & $\begin{array}{l}7000 \text { a } 15000 \\
(2133 \text { a } 4572)\end{array}$ & $\begin{array}{l}\text { Isolar zonas problemáticas } \\
\text { que impeçam o poço de ser } \\
\text { perfurado até sua profundi- } \\
\text { dade total (e.g. zonas corro- } \\
\text { sivas ou com pressões de } \\
\text { formação anormais) }\end{array}$ \\
\hline Liners & - & $\begin{array}{c}\text { Suspenso na parte } \\
\text { inferior da coluna } \\
\text { de revestimento } \\
\text { precedente. }\end{array}$ & - & $\begin{array}{l}\text { Selar zonas problemáticas do } \\
\text { poço. Adentrar zonas de } \\
\text { produção com menores custos } \\
\text { associados. }\end{array}$ \\
\hline $\begin{array}{l}\text { Revestimento } \\
\text { de Produção }\end{array}$ & $\begin{array}{l}41 / 2 \text { a } 95 / 8 \\
(114 \text { a } 244)\end{array}$ & $\begin{array}{l}\text { Posicionado } \\
\text { através das zonas } \\
\text { produtivas } \\
\text { potenciais. }\end{array}$ & - & $\begin{array}{l}\text { Suportar pressões induzidas } \\
\text { durante operações de comple- } \\
\text { tação e pressões exercidas } \\
\text { pelas formações da zona de } \\
\text { produção. Permitir o reparo e } \\
\text { substituição do tubo de } \\
\text { produção. }\end{array}$ \\
\hline
\end{tabular}

Fonte: Adaptado de Rahman e Chilingarian (1995). 
Figura 3.1 - Configuração típica de um poço com 19000 ft (5790 m) de profundidade.

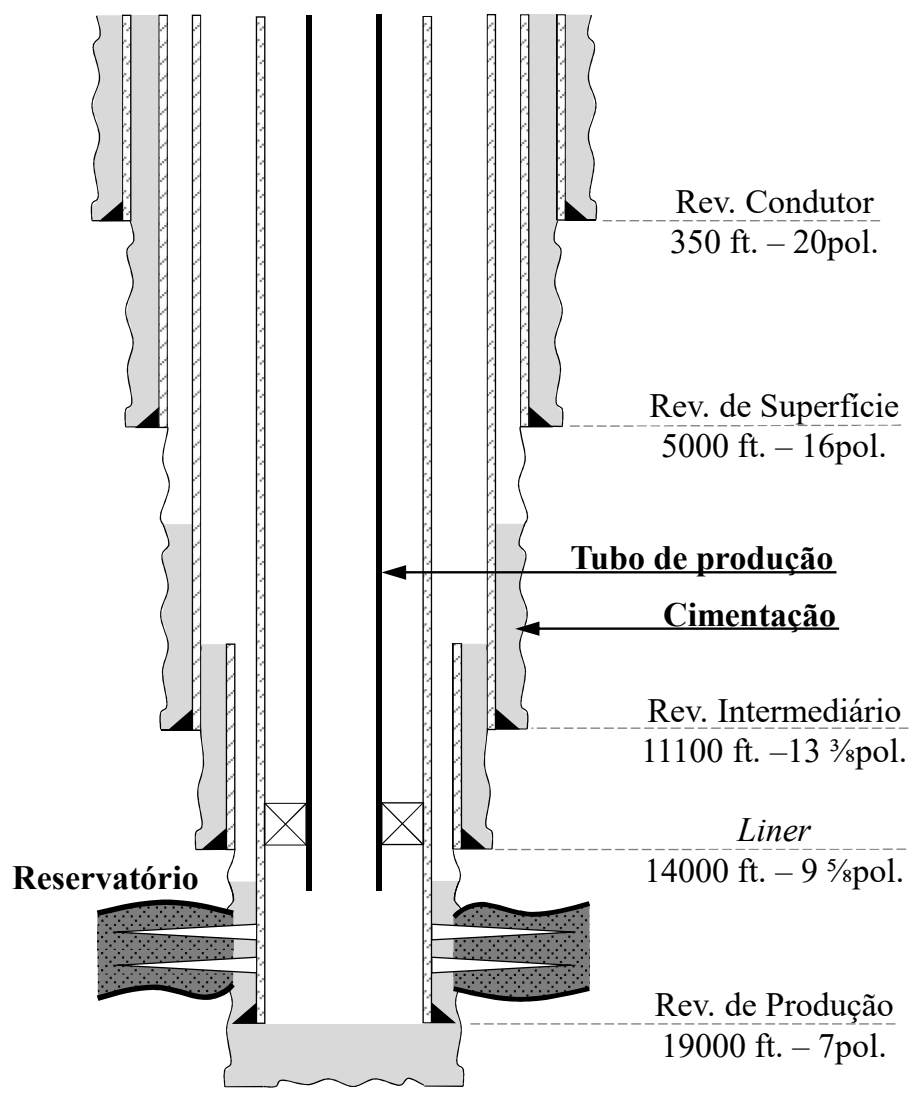

Fonte: Adaptado de Rahman e Chilingarian (1995).

Basicamente, o projeto dos revestimentos de um poço de petróleo compreende: a definição do número de escalonamentos da coluna "telescópica" (também denominado por número de fases); a determinação das profundidades de instalação das sapatas; o levantamento dos carregamentos atuantes; e a seleção do diâmetro, espessura e material de cada segmento de revestimento. A seguir, cada um destes tópicos será investigado em detalhe.

\subsection{Número de Fases e Profundidade das Sapatas}

A primeira etapa da elaboração do projeto de um poço corresponde à definição do número de fases a serem perfuradas e à seleção das profundidades nas quais as sapatas dos revestimentos serão assentadas e cimentadas. Baseia-se nas características da formação a ser perfurada e em registros históricos de poços perfurados anteriormente na mesma região (DOMINGUES, 2013).

O número de fases de um poço depende das condições geológicas do maciço a ser perfurado. Deve assegurar, por exemplo, que aquíferos não sejam contaminados por fluidos presentes em outras regiões da formação. Pode ser também determinado tendo em vista o isolamento de zonas suscetíveis à perda de circulação (regiões de baixa pressão de poros) ou para evitar o aprisionamento da broca durante a perfuração. Em poços profundos, a seleção do número de fases é feita com o objetivo de controlar zonas de pressões anormais, isolar formações 
superficiais mais fracas ou em função das pressões de esmagamento provocadas por camadas de sal, que tendem a fluir plasticamente sob altas pressões.

A definição do escalonamento dos revestimentos e das profundidades de instalação das suas sapatas é realizada a partir da observação dos perfis de pressão de poros e de pressão de fratura da formação a ser perfurada (Figura 3.2). O controle das geopressões ou da estanqueidade da perfuração é feito por meio da pressão hidrostática exercida pelo fluido de perfuração. Seu peso específico é escolhido de forma a exercer uma pressão ligeiramente maior que a pressão de poros da formação (impedindo que fluidos nela contidos migrem para dentro do poço), sem contanto ultrapassar a pressão de fratura do maciço (o que provocaria perda de circulação para a formação).

Figura 3.2 - Definição da profundidade de assentamento das sapatas dos revestimentos de um poço com base na pressão de poros e na pressão de fratura.

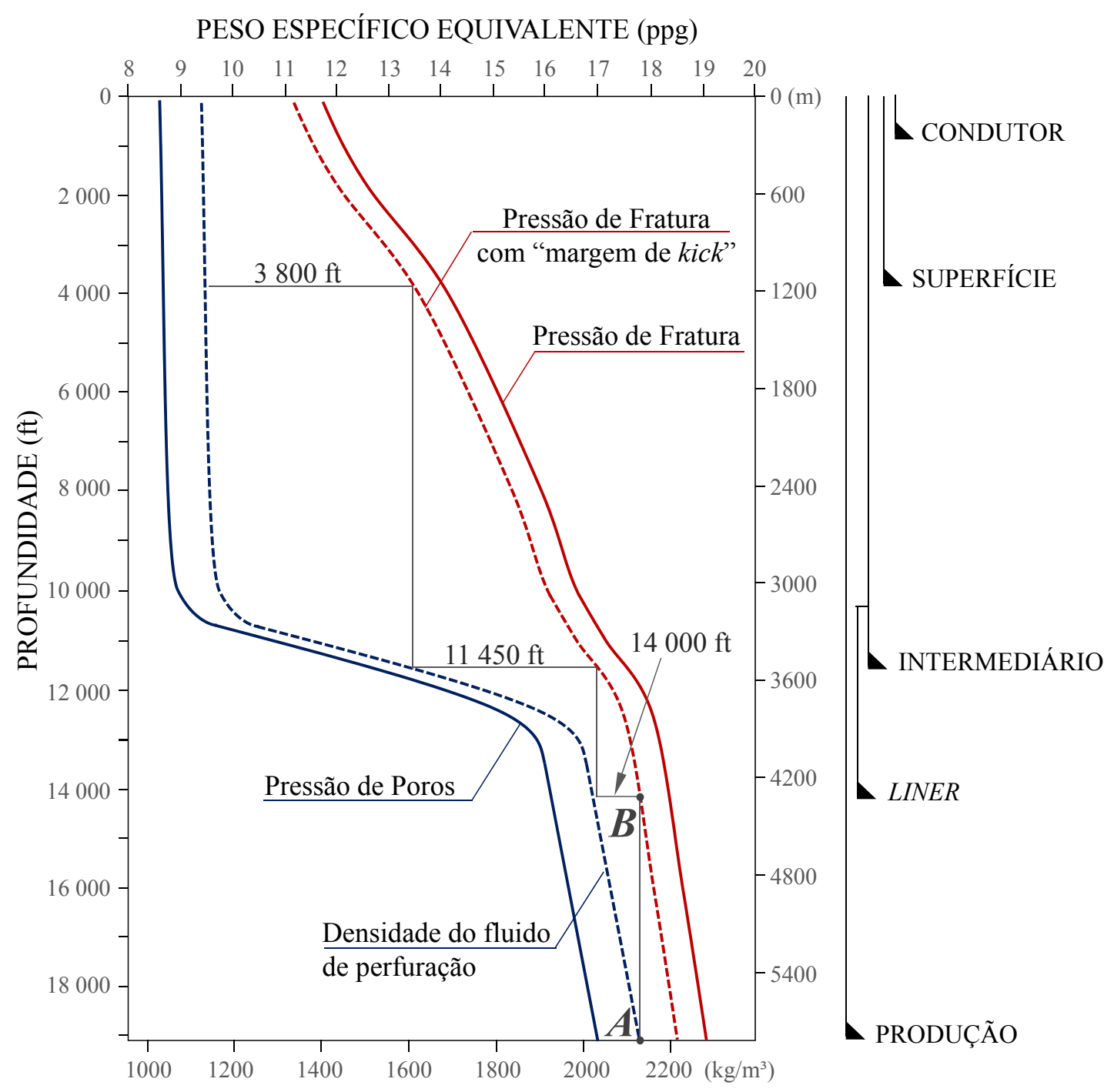

Fonte: Adaptado de Byrom (2015) 
Na prática, é usual considerar uma margem de segurança para levar em conta as pressões diferenciais causadas pela descida ou subida da broca ou das colunas de revestimento. $\mathrm{O}$ valor desta margem varia de acordo com a política interna de cada empresa, do tipo e da localização do poço, girando em torno de 0,5 a 0,9 lb/gal (60 a $\left.108 \mathrm{~kg} / \mathrm{m}^{3}\right)$ (RAHMAN; CHILINGARIAN, 1995). Incorporando esta margem de segurança às curvas de pressão de poros e pressão de fratura, obtém-se as curvas tracejadas de "Densidade do fluido de perfuração"e de "Pressão de fratura com margem de kick", ilustradas na Figura 3.2. Com base nestes novos perfis de pressão, definem-se as profundidades em que serão instaladas as sapatas dos revestimentos.

Há duas maneiras possíveis de definir as cotas de assentamento das sapatas a partir da Figura 3.2: utilizando uma abordagem de projeto dita "de baixo para cima"(Bottom-Up Design) ou "de cima para baixo"(Top-Down Design). A primeira consiste na abordagem padrão para a seleção da profundidade dos revestimentos em poços de desenvolvimento. A segunda é mais indicada para poços exploratórios, quando se dispõe de pouca ou nenhuma informação a respeito da geologia, das pressões de poros e das pressões de fratura da formação (MITCHELL, 2006). Devido à sua natureza especial, poços exploratórios não são alvo de economia de custos e, consequentemente, de otimização. Por esse motivo apenas a primeira abordagem será explicitada a seguir.

Conforme o próprio nome diz, o Bottom-Up Design parte do fundo do poço em direção à superfície. Naturalmente, a sapata do revestimento de produção é instalada na cota mais profunda, de onde será realizada a extração do petróleo. Em seguida, são definidas as profundidades dos revestimentos intermediários, de superfície e condutor. A título de exemplo, pode-se ilustrar o procedimento de seleção da profundidade dos revestimentos por meio da Figura 3.2. Inicialmente, a densidade do fluido de perfuração é definida como o menor valor de pressão de poros (já incluída a margem de segurança) na cota de fundo do poço - ponto A. A partir deste ponto, traça-se uma linha vertical até que ela intercepte a linha marginal de pressão de fratura - ponto $B$. Horizontalmente a este ponto, traça-se uma nova reta, cuja cota definirá a profundidade da sapata do revestimento de diâmetro imediatamente superior ao revestimento de produção (neste caso, definido como sendo um liner). O processo se repete até que sejam determinados por completo o número de revestimentos e a profundidade de instalação de cada um deles.

\subsection{Seleção do Diâmetro da Fase}

Uma vez definidas as profundidade de assentamento das sapatas e, consequentemente, o número de colunas de revestimento necessárias à exploração do poço, o projeto tem sequência com a seleção do diâmetro externo de cada coluna de revestimento e do furo a ser perfurado. A definição é amparada no programa de perfuração, em função dos diâmetros nominais das brocas a serem usadas, e especialmente no diâmetro do tubo de produção desejado.

Não há fórmulas para determinar o tamanho ideal do furo. Contudo, algumas diretrizes gerais auxiliam na seleção (BYROM, 2015): 
i. O furo deve ser grande o suficiente para que o revestimento passe livremente com pouca chance de ficar preso;

ii. Deve haver suficiente folga em torno do revestimento para permitir um bom trabalho de cimentação;

iii. Quanto maior o diâmetro do revestimento final, maior a possibilidade de instalar um tubo de produção de grande diâmetro e, consequentemente, aumentar a produção resultante; e

iv. Quanto maior o furo, mais cara é a operação de perfuração.

Com base nisto, o projetista define inicialmente o diâmetro externo do revestimento de produção, cujo valor usual é de 7 in. (177,8 mm) para poços profundos (RAHMAN; CHILINGARIAN, 1995). À dimensão externa do revestimento deve ser acrescida uma folga anular média de 0,75 in. (19 mm), para o posicionamento de centralizadores e escareadores, por exemplo. Deste modo garante-se, naturalmente, o cumprimento da segunda diretriz.

O processo continua com a definição do tamanho do furo. Esta etapa se baseia principalmente em práticas de sucesso em áreas com litologia similar, porém há uma série de gráficos e tabelas disponíveis na literatura que mostram algumas opções em função do tipo de rocha. A Figura 3.3 ilustra um gráfico típico utilizado em formações rochosas. Embora o uso de gráficos deste tipo seja intuitivo, Byrom (2015) adverte que o melhor conselho é usar o que é prática comum na empresa, a menos que haja um bom motivo para fazer o contrário.

Figura 3.3 - Diâmetros típicos (em polegadas) de furos e revestimentos para formações rochosas.

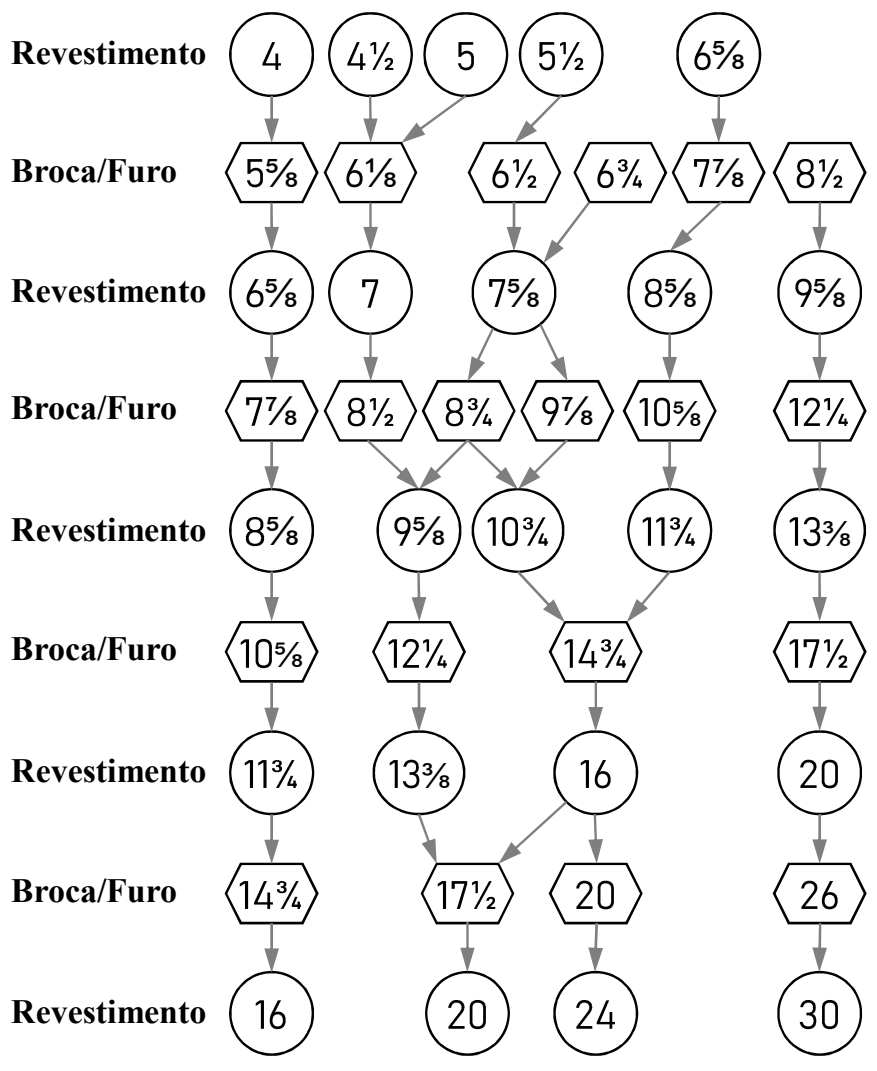

Fonte: Adaptado de Byrom (2015). 
A leitura do gráfico é feita de cima para baixo e se inicia a partir da linha que apresenta o diâmetro externo do revestimento de produção. Seguem-se então as setas indicadas rumo à coluna de revestimento mais externa do poço. Nota-se que alguns revestimentos permitem a seleção de mais de um diâmetro de fase ou broca. Ainda que exibidas no gráfico, algumas destas opções podem não ser factíveis: em função dos carregamentos atuantes, pode ser necessário utilizar tubos mais pesados ${ }^{1}$ em determinado trecho da coluna de revestimento e, quanto mais pesado for o tubo, menor será o espaço interno para passagem da broca.

\subsection{Casos de Carregamento}

Depois de concluídas as etapas precedentes, o projeto prossegue com o levantamento dos possíveis casos de carregamento que podem solicitar a estrutura do poço ao longo de sua vida útil.

A magnitude das ações que uma determinada coluna de revestimento experimenta em serviço é na maior parte do tempo desconhecida. Em geral, é possível predizê-la quando tudo está em perfeitas condições ou quando as coisas fogem completamente ao controle, mas entre essas duas situações é uma grande incógnita. Logo, a abordagem mais lógica (e segura) é investigar o pior cenário que pode vir a acontecer, dentro de um limite de razoabilidade, e utilizá-lo para dimensionar o revestimento.

O capítulo seguinte é dedicado exclusivamente à descrição dos cenários de carregamento usualmente considerados no dimensionamento dos tubulares das várias fases de um poço. Os carregamentos mais importantes estão relacionados à tração/compressão, ruptura e colapso do revestimento, de maneira que as resistências mínimas associadas a estes eventos são definidas pelo American Petroleum Institute (API) por meio de propriedades mínimas de desempenho (API, 1999; API, 1994).

\subsection{Geometria e Material dos Revestimentos}

Uma vez estimados os piores casos de carregamento em cada fase do poço, o projetista deve definir o peso nominal, o diâmetro interno e o grau do aço dos tubulares que irão compor cada coluna de revestimento, de modo que apresentem resistência suficiente para suportar as solicitações a eles impostas. A fim de amparar projetistas e padronizar os produtos oferecidos no mercado, por volta de 1990 o API desenvolveu um conjunto de especificações para a fabricação de tubulares utilizados no revestimento de poços. Tais especificações se referem a propriedades geométricas do tubular e propriedades físicas do material empregado em sua confecção. Valores nominais e tolerâncias admissíveis estipuladas pelo órgão incluem: diâmetro externo, espessura da parede, diâmetro interno máximo, peso, classe de aço, dentre outros (API, 2006b).

\footnotetext{
1 Tubos mais pesados são aqueles com parede de maior espessura.
} 


\subsubsection{Diâmetro externo, diâmetro interno e espessura da parede}

O diâmetro externo (OD) dos revestimentos podem variar de $41 / 2$ a 42 polegadas (de 114,3 a 1066,8 mm), devendo respeitar as tolerâncias indicadas na Tabela 3.2. Fabricantes geralmente tentam evitar que o tubo seja subdimensionado, de maneira que a maioria dos revestimentos se encontra ligeiramente dentro do limite superior de tolerância.

Tabela 3.2 - Diâmetro externo e tolerâncias de fabricação.

\begin{tabular}{|c|c|c|c|}
\hline \multicolumn{2}{|c|}{$\begin{array}{c}\text { Diâmetro externo } \\
\text { in. (cm) }\end{array}$} & \multicolumn{2}{c|}{$\begin{array}{c}\text { Tolerâncias } \\
\text { in. (mm) }\end{array}$} \\
\hline$\geq 3^{1 / 2}$ & $(88,9)$ & $+3 / 32(2,38)$ & $-1 / 32(0,79)$ \\
4 a 5 & $(101,6$ a 127$)$ & $+7 / 64(2,78)$ & $-0.75 \%$ OD \\
$5^{1} / 2$ a $85 / 8$ & $(139,7$ a 219,1$)$ & $+1 / 8(3,175)$ & $-0.75 \%$ OD \\
$\geq 8^{5} / 8$ & $(219,1)$ & $+5 / 32(3,97)$ & $-0.75 \%$ OD \\
\hline
\end{tabular}

Fonte: Adaptado de API (2006b).

O diâmetro interno (ID) é especificado em termos da espessura da parede e do chamado drift diameter, que se refere ao diâmetro pelo qual pode-se passar livremente o tubo quando este encontra-se perfeitamente na vertical. Seu valor mínimo é controlado pelas tolerâncias combinadas do diâmetro externo e da espessura nominal da parede, tal que a espessura de parede mínima admissível para tubulares é de $87.5 \%$ do valor nominal, correspondente a uma tolerância de $-12.5 \%$. Por outro lado, seu valor máximo é governado pelo diâmetro da broca especificada para a perfuração da próxima fase.

\subsubsection{Peso do tubular}

O peso do tubular pode ser definido por meio de seu peso nominal, peso de extremidade livre (plain-end weight) ou peso roscado e acoplado (threaded and coupled weight). É geralmente expresso em libras por pés (lb/ft) e está sujeito a tolerâncias de $+6.5 \%$ e $-3.5 \%$, de acordo com a especificação API (2006b).

O peso nominal baseia-se no peso teórico por unidade de comprimento para um tubo de $20 \mathrm{ft}$ (6,1 m), já incluindo roscas e conexões em ambas as extremidades. Apesar de não se tratar do peso exato do tubo, o peso nominal é utilizado com o propósito de identificação de classes de revestimento. É calculado por:

$$
W_{n}=k_{w}\left(d_{0}-t\right) t+0.0722 d_{0}^{2}
$$

onde:

$W_{n}$ : peso nominal por unidade de comprimento;

$k_{w}$ : fator de conversão de massa por unidade de comprimento, igual a 0.0246615 para unidades $\mathrm{SI}(\mathrm{kg} / \mathrm{m})$ ou 10.69 para unidades USC (lb/ft);

$d_{0}$ : diâmetro externo, em milímetros ou polegadas;

$t$ : espessura da parede, em milímetros ou polegadas. 
O peso de extremidade livre inclui apenas o peso do revestimento, desprezando roscas e conexões, enquanto o peso roscado e acoplado corresponde à soma do peso médio do tubular (já com rosca em ambas as extremidades) com o peso de uma conexão instalada em uma das pontas.

\subsubsection{Classe de aço}

A classe de aço do revestimento está relacionada à resistência do aço utilizado para confeccioná-lo e é expressa por meio de um código que consiste em letra e número, por exemplo, K-55. A letra é escolhida arbitrariamente, para que haja uma designação única para cada classe de revestimento. O número designa a mínima tensão de escoamento do aço em milhares de libras por polegada quadrada (ksi). Resistências das classes de aço são apresentadas na Tabela 3.3.

Tabela 3.3 - Resistências das classes de aço normatizadas pelo API (2006b).

\begin{tabular}{|c|c|c|c|c|}
\hline \multirow{2}{*}{ Classe API } & \multicolumn{2}{|c|}{$\begin{array}{c}\text { Tensão de escoamento } \\
f_{y}(\mathrm{ksi})^{1}\end{array}$} & $\begin{array}{c}\text { Mín. resistência } \\
\text { última à tração } \\
f_{u}(\mathrm{ksi})^{1}\end{array}$ & $\begin{array}{c}\text { Alongamento } \\
\text { mínimo }^{2} \\
\varepsilon(\%)\end{array}$ \\
\cline { 2 - 3 } & Mínima & Máxima & 60 & 29.5 \\
\hline H-40 & 40 & 80 & 75 & 24.0 \\
\hline J-55 & 55 & 80 & 95 & 19.5 \\
\hline K-55 & 55 & 80 & 95 & 19.5 \\
\hline L-80 & 80 & 95 & 100 & 18.5 \\
\hline N-80 & 80 & 110 & 100 & 18.5 \\
\hline C-90 & 90 & 105 & 105 & 18.0 \\
\hline C-95 & 95 & 110 & 105 & 18.0 \\
\hline T-95 & 95 & 110 & 125 & 15.0 \\
\hline P-110 & 110 & 140 & 135 & 14.0 \\
\hline Q-125 & 125 & 150 & & \\
\hline
\end{tabular}

${ }^{1}$ Conversão de unidades para SI: $1,0 \mathrm{ksi}=6,894757 \mathrm{MPa}$.

${ }^{2}$ Alongamento mínimo em 2 polegadas, calculado para um corpo de prova com área $A$ maior ou igual a $0.75 \mathrm{in}^{2}$ através da fórmula: $\varepsilon=625000\left(A^{0.2} / f_{u}{ }^{0.9}\right)$.

Outras classes de aço não padronizadas pelo API (que não constam nesta tabela) estão disponíveis no mercado e são utilizadas na indústria. Tais aços são empregados em aplicações especiais que requerem, por exemplo, alta resistência à tração ou resistências maiores ao ataque por $\mathrm{H}_{2} \mathrm{~S}$, um composto químico altamente corrosivo encontrado no gás natural e nos tipos de petróleo que contêm enxofre.

\subsection{Delimitação do trabalho}

Além dos fatores até aqui elencados, o projeto de poços de petróleo depende ainda de um grande número de elementos sobre as quais o projetista estrutural não exerce efetivo 
controle. Dentre estes fatores, pode-se citar as condições geológicas de perfuração (geopressões, gradientes de fratura, zonas de pressão anormal), tipo de equipamento de instalação, políticas da companhia e regulamentação governamental.

Desta forma, o presente trabalho será desenvolvido tendo como limite o uso exclusivo de variáveis passíveis de manipulação e otimização por parte do projetista do poço, sendo elas:

- Propriedades geométricas do tubular (diâmetro externo e espessura);

- Propriedades do material do tubular (classe do aço e peso);

- Número de fases e profundidade das sapatas.

A rigor, para proceder com uma análise quantitativa de riscos completa do projeto de poços, deve-se ainda contabilizar a probabilidade de vazamento das conexões. Isto é de especial importância em poços HTHP, em que as conexões estão sujeitas a condições extremas e devem apresentar um alto desempenho.

A probabilidade de falha de uma coluna de tubulares aumenta significativamente em virtude do grande número de conexões presente. Cada rosca constitui um caminho de vazamento em potencial e a falha de uma única rosca compromete a integridade e a segurança de toda a coluna. Para gerenciar esse risco é necessário que a probabilidade de falha de cada conexão seja inferior à de uma falha no corpo do tubo, pois se a conexão apresentar desempenho superior ao do tubular, deixa de ser crítica para o projeto do poço (VALIGURA; TALLIN, 2005).

Na prática, companhias do setor avaliam a segurança das conexões por meio de testes padronizados. As normas API 5C5 (API, 2003) e ISO 13679:2002, idênticas entre si, são os documentos de referência neste tópico e estabelecem procedimentos para o ensaio de conexões para os principais tipos de cargas primárias às quais colunas de revestimentos são submetidas em poços: pressão do fluido (externa e interna), força axial (tensão ou compressão), flexão (flambagem e/ou desvio do poço) e torque de aperto. No entanto, as referidas normas não apresentam uma base estatística para a análise de riscos, de modo que cada empresa acaba por desenvolver seu próprio modelo.

Um modelo simplificado adotado pela Shell ${ }^{\mathrm{TM}}$ para a determinação da probabilidade de vazamento de conexões em uma coluna de tubulares corresponde a (VALIGURA; TALLIN, 2005):

$$
P_{v c}=1-\left(1-P_{L}\right)\left(1-P_{i s}^{k}\right)^{2 n}
$$

O primeiro termo entre parenteses considera a falha decorrente de modos comuns a todas as conexões. É dado em função de uma probabilidade de falha latente, $P_{L}$, que surge de fatores alheios ao projeto estrutural. Conceitualmente, os chamados "modos de falha comuns" são atribuídos a erros sistemáticos de fabricação e inspeção da qualidade e que, se presentes em uma única conexão, têm grandes chances de estar presentes em todas as conexões. $\mathrm{O}$ valor de $P_{L}$ é, portanto, constante ao longo da coluna, sendo tanto menor quanto maior for o controle de qualidade dos processos. 
O segundo termo considera a probabilidade de ocorrência de vazamentos causados por defeitos aleatórios não detectados durante a inspeção e manuseio do produto, cujo valor é igual a $P_{i s}$ para cada selo. Na equação, $2 n$ é o número de conexões roscadas e acopladas que compõem a coluna de revestimento analisada (cada conexão tem duas roscas) e $k$ é o número de selos inspecionados. A expressão assume que a inspeção de cada selo é realizada de maneira independente, logo a probabilidade de haver um caminho de vazamento através de ambos os selos na mesma conexão é igual à probabilidade de ambos falharem simultaneamente.

O modelo proposto presume ainda que o vazamento de cada selo seja um evento mutuamente independente e que as conexões em uma coluna se comportem de modo análogo a elos de uma corrente: se um elo (conexão) falhar, a corrente falhará (a coluna de tubulares perderá sua estanqueidade). Conceitualmente, o modelo configura um sistema em série (ANG; TANG, 1975).

Ainda que esse modelo seja aplicável, faltam estimativas rigorosas para o valor de $P_{L} \mathrm{e}$ $P_{i s}$. Somado a isso, o modelo considera apenas a probabilidade de vazamento das conexões, que, apesar de importante, não configura um estado-limite último do revestimento (URIBE, 2017). Sendo assim, no presente trabalho optou-se por desprezar a influência das conexões na estimativa da probabilidade de falha do poço em virtude da carência de modelos probabilísticos rigorosos para o cálculo da resistência de conexões. 


\section{Cálculo de Pressões}

Antes de definir as propriedades físicas e geométricas dos tubulares que irão compor o revestimento estrutural do poço, o projetista deve elencar os casos de carregamento que podem vir a solicitá-lo ao longo de sua vida útil. Na prática, cada coluna de revestimento é projetada para suportar as cargas máximas previstas durante as operações de perfuração, assentamento, cimentação e produção.

As cargas a serem consideradas no projeto de revestimentos costumam ser baseadas em normativas internas das empresas, exigências governamentais, considerações operacionais e experiências em perfurações passadas. Cargas internas são calculadas e combinadas com cargas externas para dar origem às cargas efetivas. Com base nelas, são selecionados tubulares com resistência suficiente para garantir uma margem de segurança ao projeto.

Em virtude do efeito das cargas efetivas sobre o revestimento, é possível agrupá-las em três tipos básicos (BYROM, 2015):

1. Cargas de colapso: ocasionadas por pressões diferenciais, tal que a pressão externa excede a pressão interna ao revestimento e tende a comprimi-lo radialmente, provocando sua implosão, $\Delta p=p_{i}-p_{e}<0$.

2. Cargas de ruptura: ocasionadas por pressões diferenciais, tal que a pressão interna excede a pressão externa e tende a expandir o revestimento radialmente, provocando sua explosão, $\Delta p=p_{i}-p_{e}>0$.

3. Cargas axiais: são esforços de tração ou compressão que podem provocar o escoamento ou a flambagem do tubular.

Cargas de colapso e ruptura são governadas pelas condições geológicas e de operação no poço. São calculadas em função das pressões de poros, pressões de fratura da formação, pressões do fluido de perfuração, pressões de cimento e pressões de teste. Os cálculos realizados envolvem basicamente a avaliação de pressões hidrostáticas para várias combinações de fluidos dentro e fora do revestimento.

Cargas axiais, por outro lado, são induzidas majoritariamente pelo peso próprio da coluna de revestimento, pela ação do empuxo de fluidos, pelo efeito pistão e por variações de temperatura. Cargas de menor intensidade podem ainda ser provocadas pela flexão do corpo do tubo e por forças de atrito, porém estas parcelas são pouco significativas no caso de poços verticais. O cálculo das cargas axiais é mais complexo e por este motivo será visto em detalhes no Capítulo 5.

A seguir, procura-se detalhar os cenários de carregamento usualmente considerados no dimensionamento de revestimentos, seja por sua elevada probabilidade de ocorrência, seja pelas severas consequências associadas. Os primeiros cenários são classificados como de serviço, enquanto os últimos são ditos cenários de sobrevivência (API, 2013). 


\subsection{Colapso}

Carregamentos de colapso são provocados pela pressão hidrostática da coluna de fluido fora da coluna de revestimento (em geral, fluido de perfuração ou pasta de cimento). Revestimentos podem também estar sujeitos a pressões severas de colapso durante a perfuração de formações problemáticas, tais como argilas plásticas e sais.

A pior carga de colapso é determinada a partir de diferentes cenários de carregamento em que o revestimento apresenta o maior diferencial de pressão possível (baixa pressão interna e elevada pressão externa), durante as fases de assentamento, perfuração e produção. Em geral, a pressão de colapso é máxima na base da coluna e nula na superfície.

\subsubsection{Instalação do Revestimento}

A fase de instalação compreende a descida da coluna de revestimento no poço, sua posterior cimentação e a execução de testes de pressão. Apenas um cenário de colapso pode ocorrer durante a descida da coluna: a coluna estar vazia ou pacialmente vazia.

Já na fase de cimentação, é imperativo que se examine o caso de carregamento ilustrado na Figura 4.1: para que o cimento seja conduzido até a sapata do revestimento, utiliza-se um fluido de deslocamento (displacement fluid). A densidade deste fluido é quase sempre menor do que a do cimento, de maneira que a pressão diferencial resulta máxima quando o cimento está devidamente posicionado no espaço anular e o interior do tubo está preenchido com fluido de deslocamento.

Figura 4.1 - Cenário de colapso durante a cimentação do revestimento.

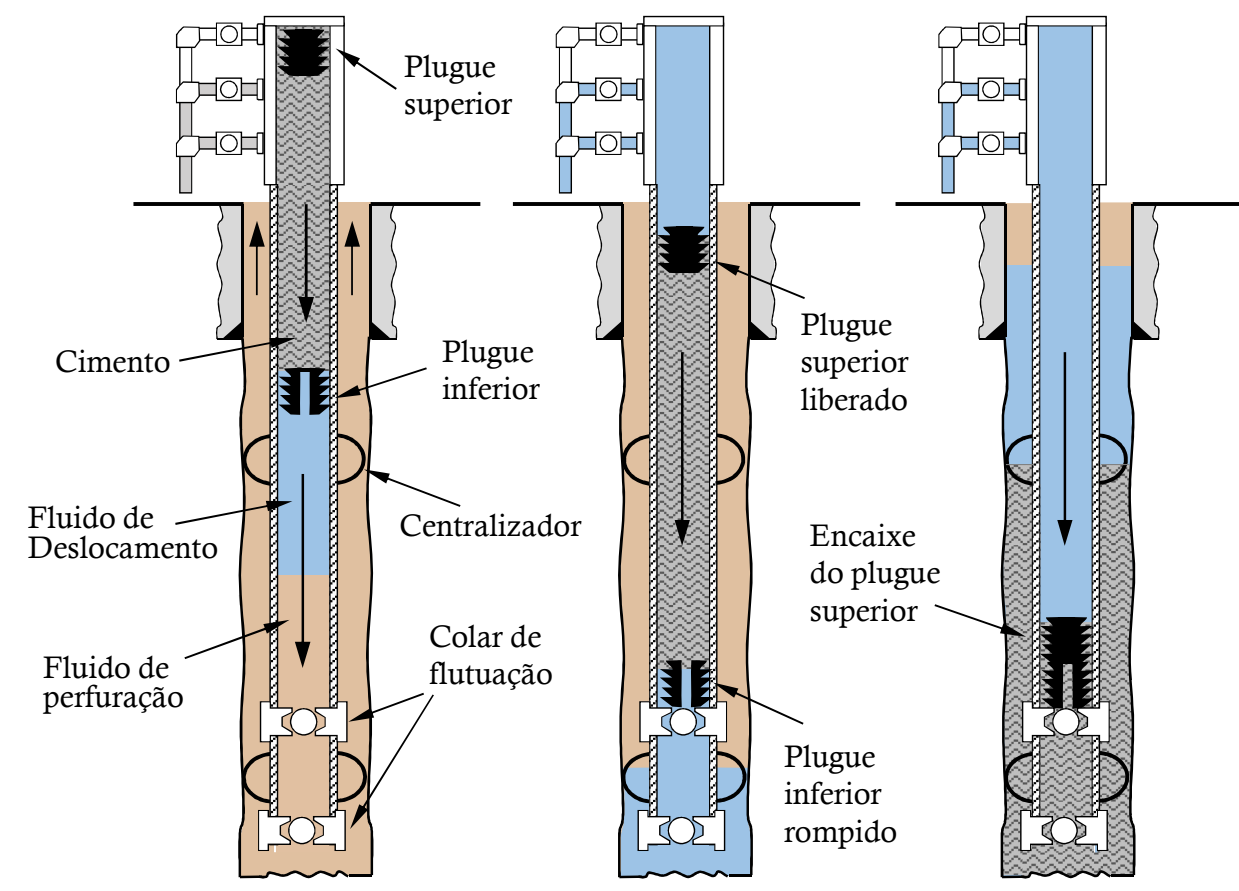

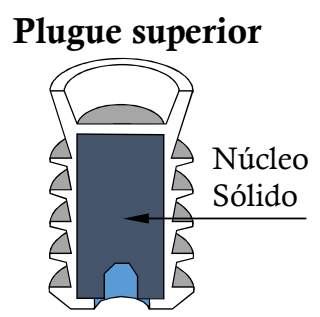

Plugue inferior

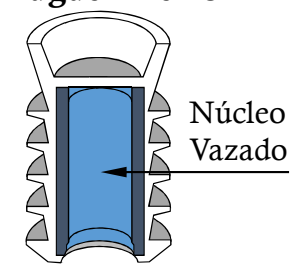


Neste tipo de carregamento, o perfil no anular deve ser calculado com base na densidade da(s) pasta(s) de cimento utilizada(s) durante a cimentação do revestimento, enquanto o perfil de pressões internas corresponde à pressão hidrostática do fluido de deslocamento. A Figura 4.2 ilustra os perfis de pressão considerados no cenário de cimentação.

Figura 4.2 - Perfis de pressão para cenário de colapso durante operação de cimentação.

Adaptado de Souza (2015).

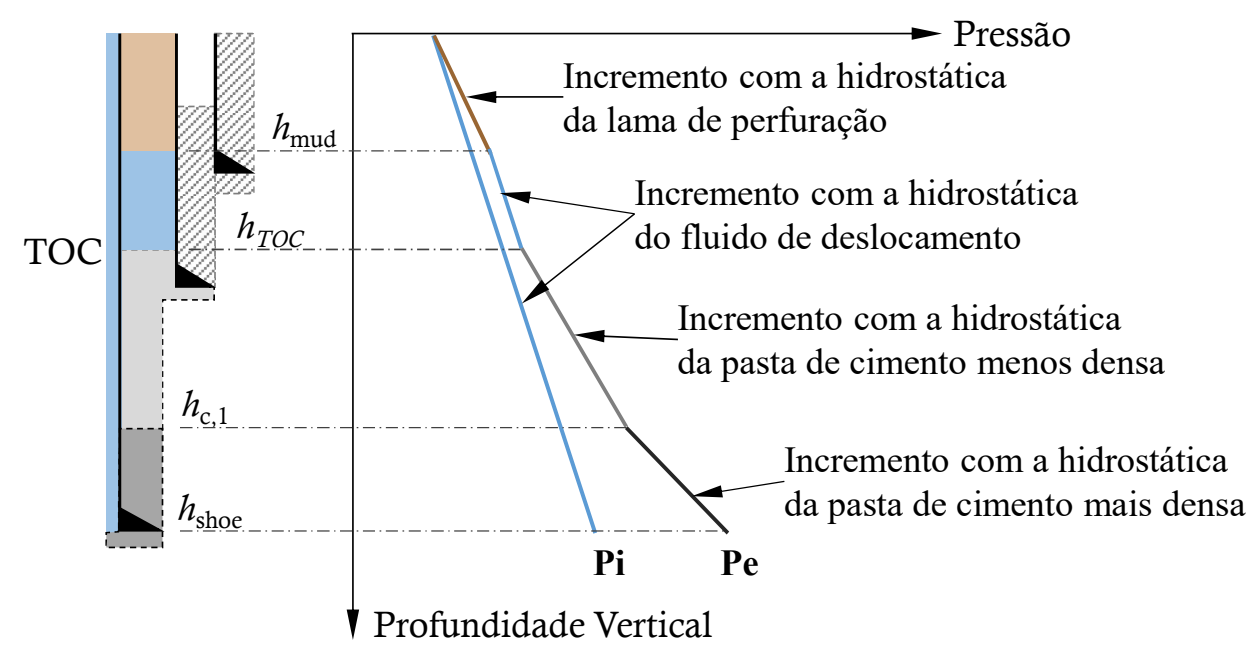

Para este cenário, o incremento de pressões no anular e no interior do poço pode ser equacionado simplificadamente como:

$$
\begin{gathered}
\Delta P_{i}=\rho_{\text {disp }} \cdot h_{v} \text { para } 0<a \leq h_{v}>3 \geq h_{\text {shoe }} \\
\Delta P_{i}=\rho_{\text {disp }} \cdot h_{v} \\
\Delta P_{e}=\left\{\begin{array}{crr}
\rho_{\text {mud }} \cdot h_{v} & \text { para } & 0 \leq h_{v} \leq h_{\text {shoe }} \\
\rho_{\text {displ }} \cdot\left(h_{v}-h_{\text {mud }}\right) & \text { para } & h_{\text {mud }} \leq h_{v} \leq h_{\text {TOC }} \\
\rho_{\text {cim }, 1} \cdot\left(h_{v}-h_{\text {TOC }}\right) & \text { para } & h_{\text {TOC }} \leq h_{v} \leq h_{c, 1} \\
\vdots & & \vdots \\
\rho_{\text {cim }, k} \cdot\left(h_{v}-h_{c, k-1}\right) & \text { para } & h_{c, k-1} \leq h_{v} \leq h_{\text {shoe }}
\end{array}\right.
\end{gathered}
$$

onde:

- $\Delta P_{i}, \Delta P_{e}$ : incremento de pressão interna e externa (no anular), respectivamente;

- $\rho_{\text {disp }}, \rho_{\text {mud }}, \rho_{\text {cim }}$ : peso específico do fluido de deslocamento, do fluido de perfuração e da(s) pasta(s) de cimento, respectivamente;

$\Delta h_{v}$ : profundidade vertical;

$h_{\text {mud }}$ : altura da coluna de fluido de perfuração;

$h_{T O C}:$ cota do topo de cimentação;

$h_{c, i}:$ cota de fundo da pasta de cimento $i(i=1, \ldots, k)$;

$h_{\text {shoe }}$ : cota de fundo (sapata) do revestimento. 
tal que a pressão externa resultante em um ponto situado a uma altura $h_{v}$ arbitrária, equivale à soma de todas as parcelas de incremento de pressão externa acima da cota em questão.

\subsubsection{Perfuração}

A situação mais crítica durante a perfuração do poço ocorre quando uma região fraca da formação sofre fratura e o revestimento da fase anterior perde fluido de perfuração em seu interior, diminuindo drasticamente a pressão hidrostática à qual o revestimento estava submetido. Em profundidades menores, quando uma região destas é encontrada, o nível de fluido dentro da coluna pode cair abaixo da cota de sua sapata, reduzindo a pressão interna a zero (evacuação completa). Em profundidades maiores, a evacuação completa da coluna é menos provável devido às pressões de poros da formação. Neste caso, o nível de fluido cai até equilibrar a pressão da formação da zona de perda. A Figura 4.3 ilustra este cenário de carregamento.

Figura 4.3 - Cenário de evacuação parcial durante a perfuração da próxima fase.

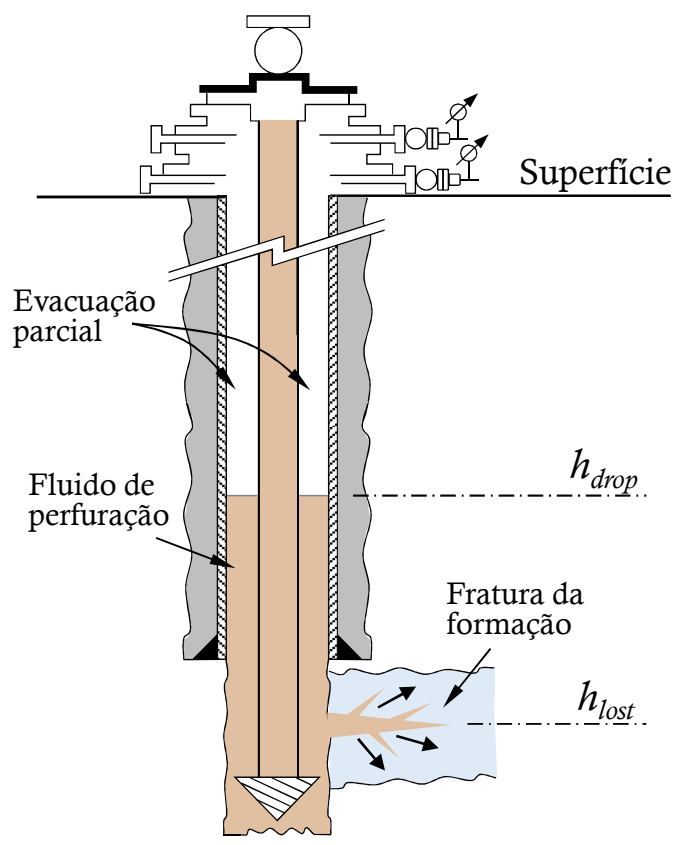

O revestimento de superfície é, em geral, dimensionado para evacuação total, enquanto os revestimentos intermediários e de produção são projetados para evacuação parcial. Nesta última situação, adotam-se as seguintes hipóteses para o cálculo da carga de colapso:

a. Uma zona de perda de circulação é encontrada abaixo da sapata da fase atual, em uma cota vertical $h_{\text {lost }}$;

b. Perde-se fluido para a formação e o interior fica parcialmente preenchido por uma coluna de ar que se estende da superfície até o nível $h_{\text {drop}}$;

c. No anular, admite-se que houve falha na cimentação e que o espaço está preenchido pelo fluido utilizado na instalação do revestimento;

d. Caso se desconheça a profundidade e o gradiente de poros da zona de perda, adota-se, de forma conservadora, que a perda de circulação ocorrerá ao final da fase seguinte e que a 
pressão de poros é igual à pressão hidrostática de uma coluna de água do mar saturada, com peso específico $\rho_{\text {swtr }}=0,465 \mathrm{psi} / \mathrm{ft}\left(\right.$ ou $\left.10,518 \mathrm{kN} / \mathrm{m}^{3}\right)$.

Para estimar a carga de colapso é necessário calcular o nível em que o fluido de perfuração irá equilibrar a pressão da formação:

$$
\left(h_{\text {lost }}-h_{\text {drop }}\right) \cdot \rho_{\text {mud }}=h_{\text {lost }} \cdot \rho_{\text {swtr }} \quad \therefore \quad h_{\text {drop }}=h_{\text {lost }}\left(\frac{\rho_{\text {mud }}-\rho_{\text {swtr }}}{\rho_{\text {mud }}}\right)
$$

Uma vez determinado $h_{d r o p}$, o perfil de pressão interna no revestimento será:

$$
P_{i}=\left\{\begin{array}{llr}
0 & \text { para } \quad 0 \leq h_{v} \leq h_{\text {drop }} \\
\rho_{\text {mud }} \cdot\left(h_{v}-h_{\text {drop }}\right) & \text { para } & h_{\text {drop }} \leq h_{v} \leq h_{\text {shoe }}
\end{array}\right.
$$

A Figura 4.4 ilustra os perfis de pressão considerados no caso de perda de circulação.

Figura 4.4 - Perfis de pressão para cenário de perda de circulação.

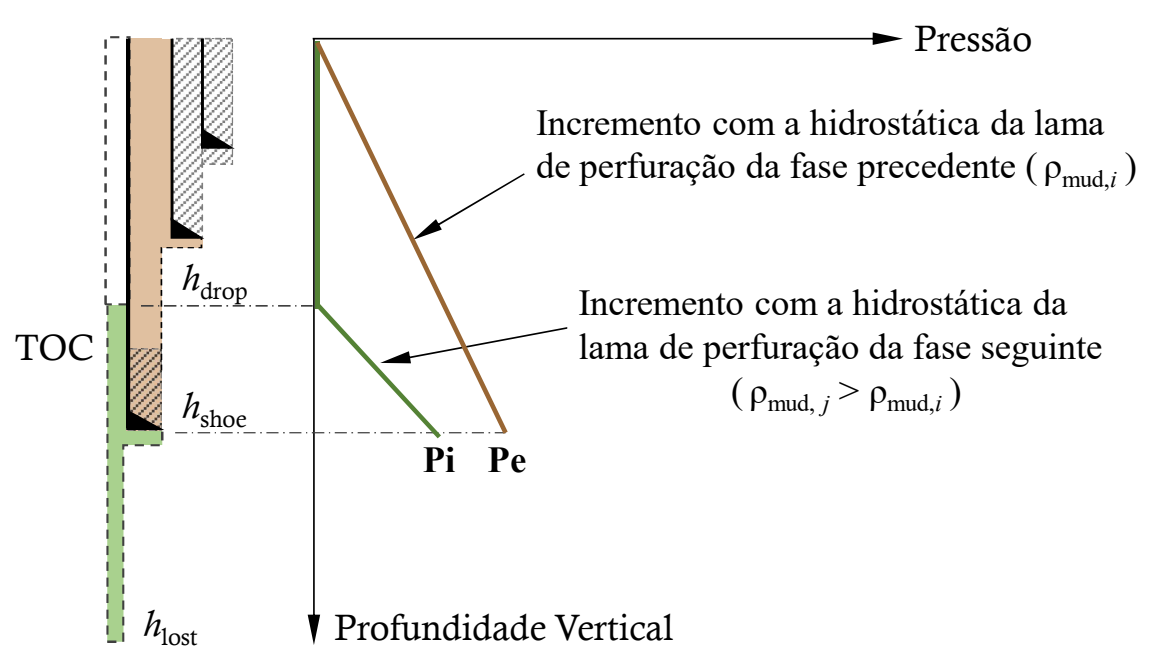

\subsubsection{Produção}

O colapso durante a fase de produção aplica-se exclusivamente ao revestimento de produção. Considera-se que o poço está em sua fase final de exploração e que o reservatório foi esvaziado até uma pressão de abandono. Durante esta fase, qualquer vazamento no dispositivo de vedação (packer) que envolve o tubo de produção pode levar à perda parcial ou total do fluido de completação (packer fluid) contido no espaço anular entre o tubo e o revestimento (Figura 4.5).

A observação deste cenário de colapso em um poço produtor de gás está condicionada a eventos de baixíssima probabilidade de ocorrência. Para que se concretize, a seguinte série de acontecimentos deve se suceder (SOUZA, 2015):

- Perda de vedação do selo do packer por falha mecânica do próprio equipamento ou por corrosão (pilha formada entre sua parede e a do revestimento);

- Substituição gradativa de todo o packer fluid por gás (o fluido de vedação passa ser produzido acidentalmente em conjunto com o gás);

- Entupimento dos canhoneados (canal perfurado com cargas explosivas através do revestimento para interligar o interior do poço ao reservatório); 
Figura 4.5 - Cenário de colapso durante a fase de produção.

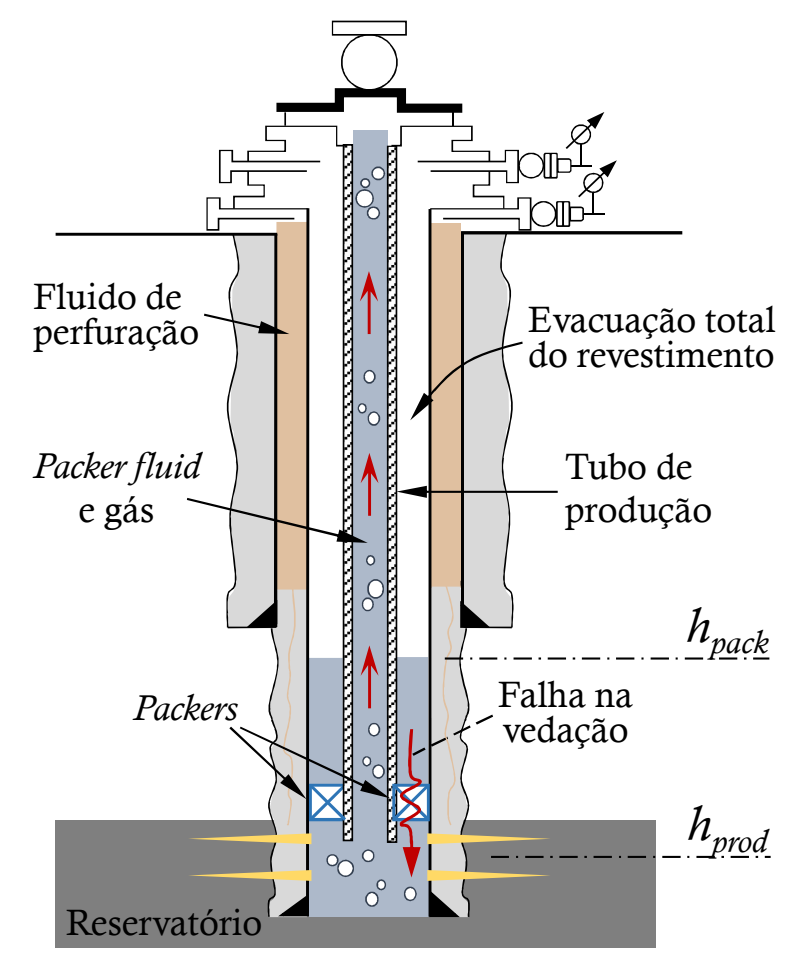

- Comunicação do gás com a atmosfera.

Nesta situação, admite-se que o interior do revestimento está preenchido por gás (pressão hidrostática desprezível) e que o fluido existente do lado de fora do revestimento é o mesmo utilizado na instalação do revestimento. Além disso, efeitos positivos da cimentação são ignorados.

Em poços produtores de óleo, o cenário de esvaziamento total é excessivamente conservador. Assim, costuma-se considerar apenas o esvaziamento parcial do revestimento, caso em que o fluido de completação cai até haver equilíbrio entre as pressões internas e o gradiente de poros da zona produtora depletada. Nesta situação, a queda do nível estático do packer fluid pode ser calculada de forma análoga ao caso de perda de circulação:

$$
\left(h_{\text {prod }}-h_{\text {pack }}\right) \cdot \rho_{\text {pack }}=h_{\text {prod }} \cdot \rho_{\text {swtr }} \quad \therefore \quad h_{\text {pack }}=h_{\text {prod }}\left(\frac{\rho_{\text {pack }}-\rho_{\text {swtr }}}{\rho_{\text {pack }}}\right)
$$

onde:

$h_{\text {prod }}:$ profundidade vertical da zona de produção;

$h_{\text {pack }}$ : profundidade de queda do packer fluid;

$\rho_{\text {pack }}$ : peso específico do packer fluid.

Uma vez determinada $h_{\text {pack }}$, o perfil de pressão interna pode ser construído com o auxílio da Equação 4.7.

$$
P_{i}=\left\{\begin{array}{lrr}
0 & \text { para } & 0 \leq h_{v} \leq h_{\text {pack }} \\
\rho_{\text {pack }} \cdot\left(h_{v}-h_{\text {pack }}\right) & \text { para } & h_{\text {pack }} \leq h_{v} \leq h_{\text {shoe }}
\end{array}\right.
$$




\subsection{Ruptura}

Para o dimensionamento à ruptura, procura-se combinar a pressão interna máxima e a pressão externa mínima que ocorrem simultaneamente em qualquer fase de operação do poço. Logo, a favor da segurança, admite-se em todos os cenários de ruptura que o perfil de pressões no anular é igual ao da pressão de poros ou, caso as pressões de poro sejam desconhecidas, que todo o anular está preenchido com água do mar (Figura 4.6).

Figura 4.6 - Perfis de pressão no anular para cenários de ruptura.

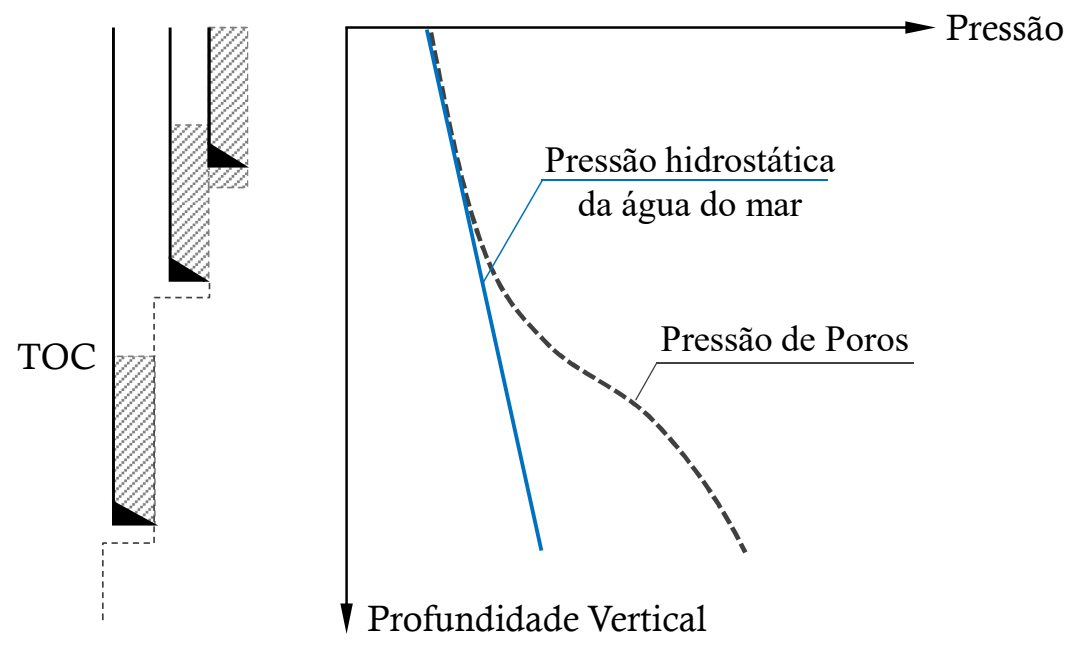

A adoção de um destes perfis de pressão advém de duas hipóteses básicas. A primeira é de que o fluido utilizado na instalação do revestimento pode sofrer degradação com o passar do tempo, sendo contaminada pelo fluido da formação. A segunda diz respeito à qualidade da cimentação, que pode ter sido mal sucedida, permitindo a comunicação do revestimento com os fluidos da formação. Assim, à semelhança do dimensionamento contra o colapso, o confinamento proporcionado pelo cimento é também desconsiderado nos cálculos.

\subsubsection{Instalação do Revestimento}

\section{- Cimentação}

Em operações de cimentação (Figura 4.1), a circulação do fluido de deslocamento é interrompida quando o tampão superior (top plug) entra em contato com o tampão inferior (bottom plug) e observa-se um aumento na pressão interna do revestimento. Contudo, antes que o bombeamento seja interrompido, costuma-se aplicar uma pressão adicional, denominada pressão de plug-bump, para garantir a estanqueidade do poço e o correto encaixe dos tampões. A magnitude desta pressão é uma questão de preferência e de política da empresa, mas geralmente é da ordem de 500-1500 psi (3450-10340 kPa) (BYROM, 2015).

Em decorrência deste procedimento, surgem pressões diferenciais de ruptura na parte superior da coluna de revestimento. Os perfis de pressão interna e externa são idênticos àqueles apresentados na Figura 4.2, exceto pela translação causada pela pressão de plug-bump sobre a 
curva de pressões internas. Para uma pressão $\Delta P_{p b}$ arbitrária, a pressão de ruptura na sapata do revestimento resulta no próprio valor de $\Delta P_{p b}$, enquanto na superfície corresponde a:

$$
P_{\text {burst }}^{\text {top }}=\Delta P_{p b}+P_{e}^{\text {shoe }}-P_{i}^{\text {shoe }}
$$

sendo $\Delta P_{p b}$ a pressão adicional de plug-bump; $P_{b u r s t}^{\text {top }}$ a pressão de ruptura na cabeça do poço; e $P_{e}{ }^{\text {shoe }}$ e $P_{i}^{\text {shoe }}$ as pressões externa e interna na base do revestimento, provocadas pela pressão hidrostática das pastas de cimento e demais fluidos contidos no anular e no interior do poço. Algebricamente, o valor destas pressões pode ser expresso por:

$$
\begin{aligned}
P_{i}^{\text {shoe }}= & \rho_{\text {displ }} \cdot h_{\text {shoe }} \\
P_{e}^{\text {shoe }}= & \rho_{\text {mud }} \cdot h_{\text {mиd }}+\rho_{\text {disp }} \cdot\left(h_{\text {ToC }}-h_{\text {mиd }}\right)+ \\
& +\rho_{\text {cim }, 1} \cdot\left(h_{c, 1}-h_{\text {ToC }}\right)+\cdots+\rho_{\text {cim }, k} \cdot\left(h_{\text {shoe }}-h_{c, k-1}\right)
\end{aligned}
$$

A Figura 4.7 ilustra os perfis de pressão para o presente caso de carregamento.

Figura 4.7 - Perfis de pressão interna e externa para cenário de ruptura durante a cimentação.

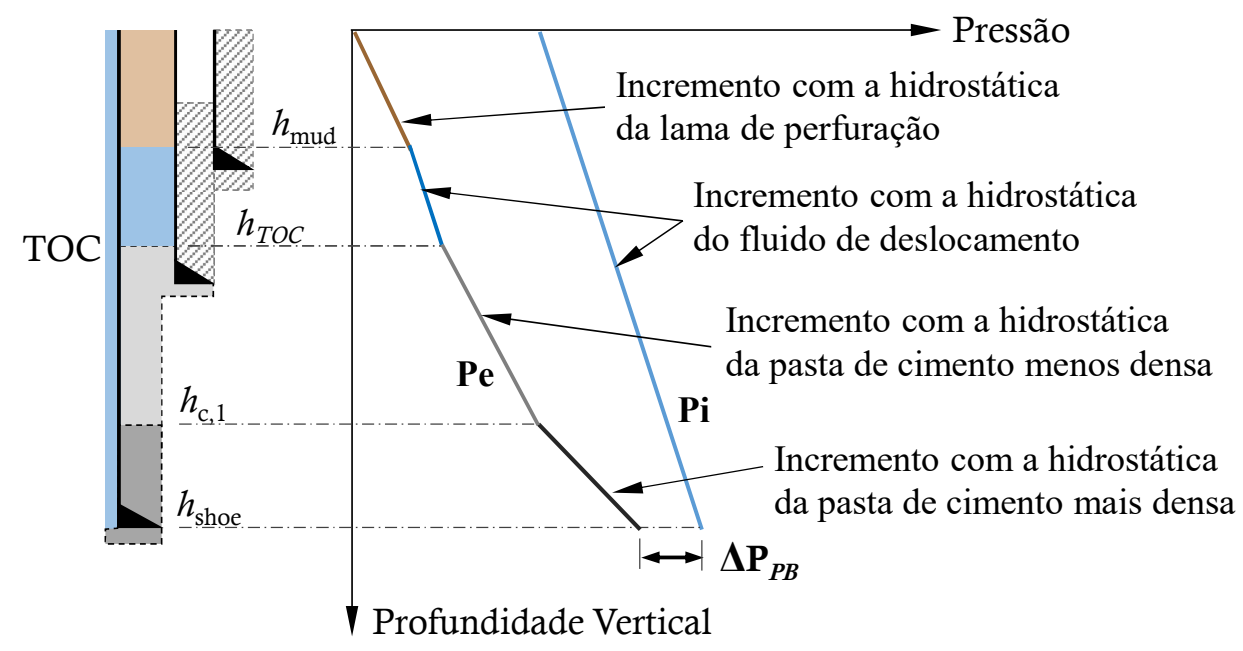

\section{- Teste de Pressão}

Ainda na fase de instalação, muitas normas e regulamentos exigem que um teste de pressão seja realizado após o revestimento estar posicionado e o cimento curado. Contudo, vários operadores contestam que a sobrepressão aplicada ao final da cimentação tem exatamente a mesma função e que, caso o revestimento mantenha-se estanque com a aplicação da pressão de plug-bump, então não há motivo para que apresente vazamentos posteriormente. Argumentos à parte, quando a realização do teste de pressão é mandatória, costuma-se considerar que o espaço anular está preenchido por fluido de deslocamento com densidade igual ao fluido de perfuração e a pressão interna é o valor indicado por norma.

A título de exemplo, a versão antiga da N-2752 (2007), norma interna da Petrobras, preconizava que a pressão de teste fosse tomada como $70 \%$ da resistência do tubular à pressão interna. A aplicação deste critério acabava gerando valores de teste excessivamente elevados 
no caso de revestimentos robustos, equiparando-se a uma carga de sobrevivência. Contudo, a filosofia da API-RP 96 (2013) preconiza que a execução de testes de pressão deve apenas ser feita para avaliar cargas antecipadas de serviço. Assim, na versão atual da N-2752 (2014), um novo critério passou a vigorar. O teste de pressão se limita agora a verificar a estanqueidade das conexões frente aos seguintes carregamentos:

a) pressão necessária para perfurar a próxima fase;

b) pressão necessária para garantir a circulação de um kick;

c) pressão de acionamento de dispositivos hidráulicos e picos de pressão de operação.

No primeiro caso, o teste simula a pressão exercida pelo fluido de perfuração da fase seguinte na região próxima à base do revestimento (Figura 4.8). Este teste é geralmente realizado após a cimentação estar concluída e poucos metros terem sido escavados, para que possíveis medidas corretivas sejam tomadas com uma perda mínima de fluido de perfuração. Caso contrário, um vazamento durante a operação de perfuração resultaria na perda de fluido mais denso e mais caro.

Figura 4.8 - Pressão de teste para carga de serviço de perfuração da próxima fase.

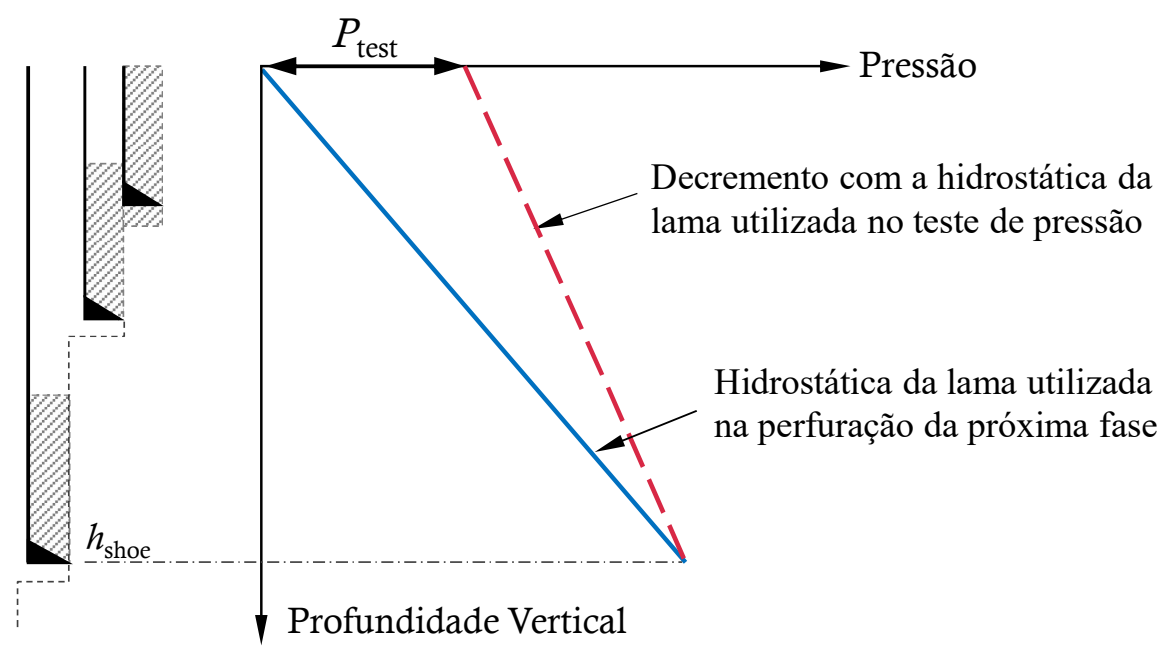

A pressão de teste pode ser equacionada como:

$$
P_{\text {test }}=\left(\rho_{\text {mud }, 2}-\rho_{\text {mud }, 1}\right) h_{\text {shoe }}
$$

onde:

$P_{\text {test }}$ : sobrepressão de teste a ser aplicada na superfície $\left(h_{v}=0\right)$;

$\rho_{m u d, 1}$ : peso específico do fluido de perfuração utilizado na instalação da fase atual;

$\rho_{m u d, 2}$ : peso específico do fluido de perfuração utilizado na perfuração da próxima fase.

No caso de circulação de um kick, o teste de pressão visa garantir a integridade do revestimento frente às pressões geradas por um influxo de gás com volume inferior ao valor admissível de projeto. Para fins operacionais, a normativa N-2752 (2014) especifica um volume máximo de $25 \mathrm{bbl}\left(3,98 \mathrm{~m}^{3}\right)$ de gás para poços com diâmetros superiores a 12 1/4" (311 mm); ou $20 \mathrm{bbl}\left(3,18 \mathrm{~m}^{3}\right)$ nos demais casos. 
Nesta situação, a pressão de teste equivale ao incremento de pressão gerado na cabeça do poço pelo gás invasor, cuja expressão de cálculo pode ser consultada em Souza (2015). A determinação das pressões internas na ocorrência de um kick será vista mais detalhadamente adiante no texto.

Finalmente, testes podem ser também aplicados para avaliar eventuais picos de pressão operacionais (decorrentes do bombeio de fluidos e pastas de cimento, rompimento de plugs, etc.), bem como assegurar o correto funcionamento de dispositivos hidráulicos. Sugere-se adotar um incremento de $300 \mathrm{psi}(\approx 2 \mathrm{MPa})$ sobre a máxima variação de pressão apresentada pelo fluido no momento do teste (PETROBRAS, 2017):

$$
P_{\text {test }}=\max \left\{\Delta P_{\text {pico }} ; \Delta P_{\text {disp }}\right\}+300 \quad \text { [em psi] }
$$

tal que $\Delta P_{\text {pico }}$ representa o maior pico de pressão estimado e $\Delta P_{\text {disp }}$ a maior variação de pressão para acionar um dispositivo hidráulico.

\subsubsection{Perfuração}

Durante a perfuração da próxima fase, o projeto de um revestimento deve considerar a pressão interna máxima que pode resultar do influxo indesejado de fluidos da formação (kick). Kicks de gás correspondem ao pior cenário possível, sendo por esse motivo utilizados para o dimensionamento dos revestimentos de superfície e intermediários. O revestimento de produção dispensa essa verificação.

Admite-se que o kick tem origem na zona de mais alta pressão a ser perfurada (em geral, na profundidade da sapata da próxima fase) e que o fluido invasor preenche o interior da coluna parcialmente ou em sua totalidade (Figura 4.9). Em revestimentos pouco profundos, considera-se que o fluido preenche todo o espaço interno. Nos demais casos, parte da coluna permanece ocupada por fluido de perfuração. Vale ressaltar que a posição relativa entre o gás invasor e o fluido de perfuração no interior do revestimento é importante: a hipótese de fluido de perfuração acima do gás resulta nas maiores pressões de projeto, sendo portanto adotada (RAHMAN; CHILINGARIAN, 1995).

Independente da profundidade do revestimento, existem duas principais abordagens para determinar o perfil de pressões internas na ocorrência de um kick:

$i$. Se a pressão da coluna de gás não exceder a pressão de fratura na base do revestimento $\left(P_{\text {frac }}\right)$, então a pressão exercida pelo gás é calculada a partir da zona de origem do kick até a superfície (Figura 4.9a);

ii. Caso contrário, a fratura da rocha serve como válvula de alívio, de modo que a pressão interna na base do revestimento é admitida como o próprio valor de $P_{\text {frac }}$ (Figura $4.9 \mathrm{~b}$ ). 
Figura 4.9 - Cenários de ruptura durante a fase de perfuração.

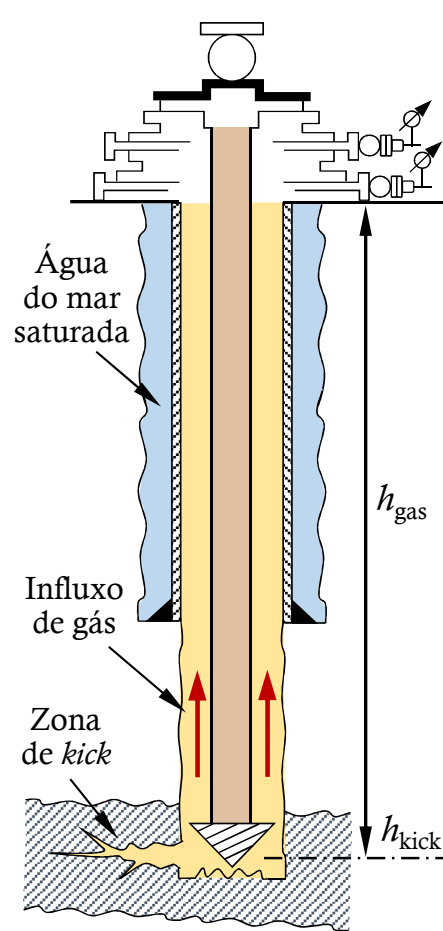

(a) Coluna de gás da zona de kick até a superfície

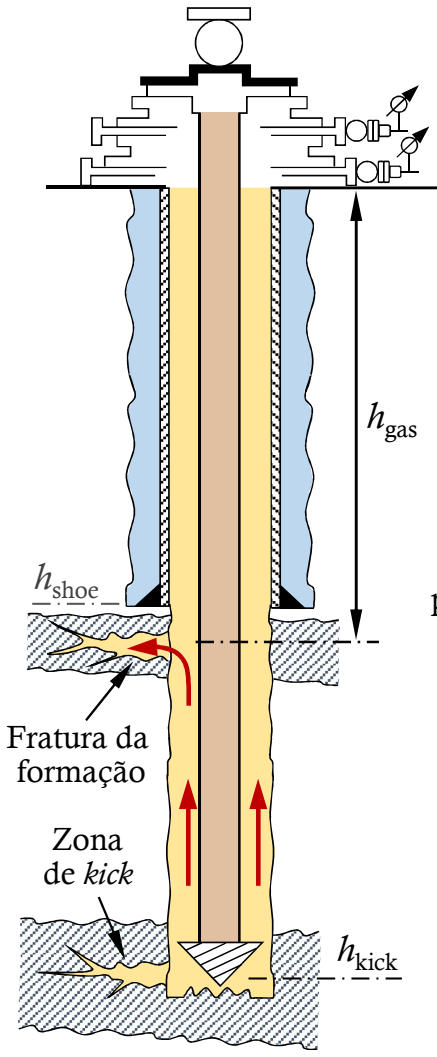

(b) Kick de gás com alívio de pressão na base da coluna de revestimento

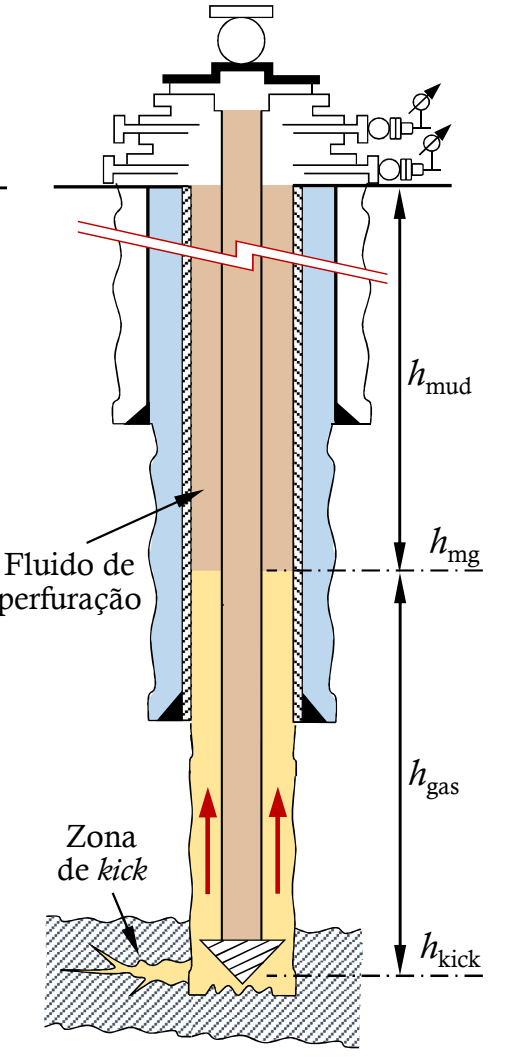

(c) Kick controlado pelo BOP

Valendo-se destas abordagens, a pressão interna na sapata $P_{i, \text { shoe }}$ pode ser determinada pelo menor valor de pressão encontrado em cada situação, isto é:

$$
P_{i, s h o e}=\min \left\{P_{\text {frac }} ; P_{\text {gas }}\left(h_{\text {kick }}, h_{\text {shoe }}\right)\right\}
$$

sendo:

$P_{\text {frac }}:$ pressão de fratura da formação na sapata do revestimento;

$P_{\text {gas }}$ : pressão exercida pelo gás após migrar da profundidade $h_{k i c k}$ para $h_{\text {shoe }}$.

Devido à compressibilidade dos gases, há várias abordagens para calcular a pressão do gás definida na Eq. (4.13). A mais simples corresponde à aplicação da lei dos gases ideais em sua forma original, enquanto fórmulas mais avançadas incorporam também fatores de compressibilidade. A complexidade crescente deve-se ao fator de compressibilidade ser em si uma função da temperatura, pressão e composição do gás. Além disso, em poços profundos, a temperatura quase nunca é uma constante. Assim, quando for necessário um maior grau de precisão, é imprescindível recorrer a métodos mais sofisticados.

A prática comum, no entanto, consiste em admitir que o gás encontrado seja metano puro, cuja massa molar é $16 \mathrm{~g} / \mathrm{mol}$ (ou $16 \mathrm{lb} / \mathrm{mol}$ em unidades USC). Uma vez que o metano é o menos denso dos componentes do gás natural, obtém-se resultados mais conservadores para o projeto de revestimentos. Além disso, seu fator de compressibilidade $Z$ é constante para um 
intervalo bastante grande $(Z \approx 1)$, o que conduz a uma equação simples para aplicação direta ao projeto de revestimentos (BYROM, 2015):

$$
P\left(h_{0}, h\right)=P_{0} \cdot \exp \left[\frac{M g\left(h-h_{0}\right)}{Z R T_{\text {med }}}\right]
$$

onde:

$P, P_{0}$ : pressão do gás a uma altura $h$ e $h_{0}$, respectivamente;

$h, h_{0}$ : profundidade vertical de interesse e de referência, respectivamente (em metros);

$M$ : massa molar do gás (em $\mathrm{g} / \mathrm{mol}$ );

$g:$ aceleração da gravidade $\left(\mathrm{em} \mathrm{m} / \mathrm{s}^{2}\right) ;$

$Z$ : fator de compressibilidade do gás;

$R$ : constante universal dos gases perfeitos $(R=8314.462 \mathrm{~mJ} / \mathrm{K} \cdot \mathrm{mol})$;

$T_{m e d}:$ temperatura absoluta média, $T_{m e d}=\left(T+T_{0}\right) / 2$.

Nos casos representados nas Figuras 4.9a e 4.9b, admite-se que o volume de gás ocupa todo o interior do revestimento. No entanto, um terceiro cenário de carregamento (Figura 4.9c) está relacionado ao máximo volume admissível de fluido invasor no interior do poço, cujo valor pode ser calculado por meio de critérios de tolerância ao kick (JIN; LI; WU, 2016; CHEN; GUAN, 2000).

Critérios de tolerância ao kick são estabelecidos em função das pressões internas ao longo do revestimento, as quais são limitadas pela pressão de fratura da formação na base do revestimento e pela pressão de trabalho do equipamento posicionado na cabeça do poço (BOP ou choke valve). Valores típicos de pressão de operação destes equipamentos variam de 5 a 20 ksi (cerca de 35 a $140 \mathrm{MPa}$ ) (RAHMAN; CHILINGARIAN, 1995).

No terceiro cenário, a pressão na superfície do poço, $P_{\text {sup }}$, fica limitada à pressão de trabalho do equipamento posicionado na cabeça do poço, $P_{B O P}$, ou seja:

$$
P_{\text {sup }}=P_{\text {gas }}\left(h_{\text {shoe }}, h_{\text {mud }}\right)-\rho_{\text {mud }} \cdot h_{\text {mud }} \leq P_{\text {BOP }}
$$

Para o cálculo da pressão exercida pelo gás, considera-se que a pressão interna na base do revestimento seja igual ao valor de $P_{i, \text { shoe, }}$, conforme a Eq. (4.13), e que o gás migra da profundidade $h_{\text {shoe }}$ até a base da coluna de fluido de perfuração. Logo, a equação anterior pode ser reescrita como:

$$
P_{\text {sup }}=P_{i, \text { shoe }} \cdot \exp \left[\frac{M g\left(h_{\text {mud }}-h_{\text {shoe }}\right)}{Z R T_{\text {med }}}\right]-\rho_{\text {mud }} \cdot h_{\text {mud }} \leq P_{\text {BOP }}
$$

Pelo fato da Eq. (4.16) ser não linear, é necessário recorrer a métodos numéricos para determinar a altura da coluna de fluido de perfuração e assim definir o máximo volume admissível de gás no interior do revestimento. Em posse do valor de $h_{m u d}$, é possível traçar o perfil de pressões internas ao revestimento.

As Figuras 4.10 e 4.11 ilustram os perfis de pressão de cada um dos cenários a serem considerados em projeto. 
Figura 4.10 - Perfis de pressão interna para coluna de revestimento completamente preenchida por gás.

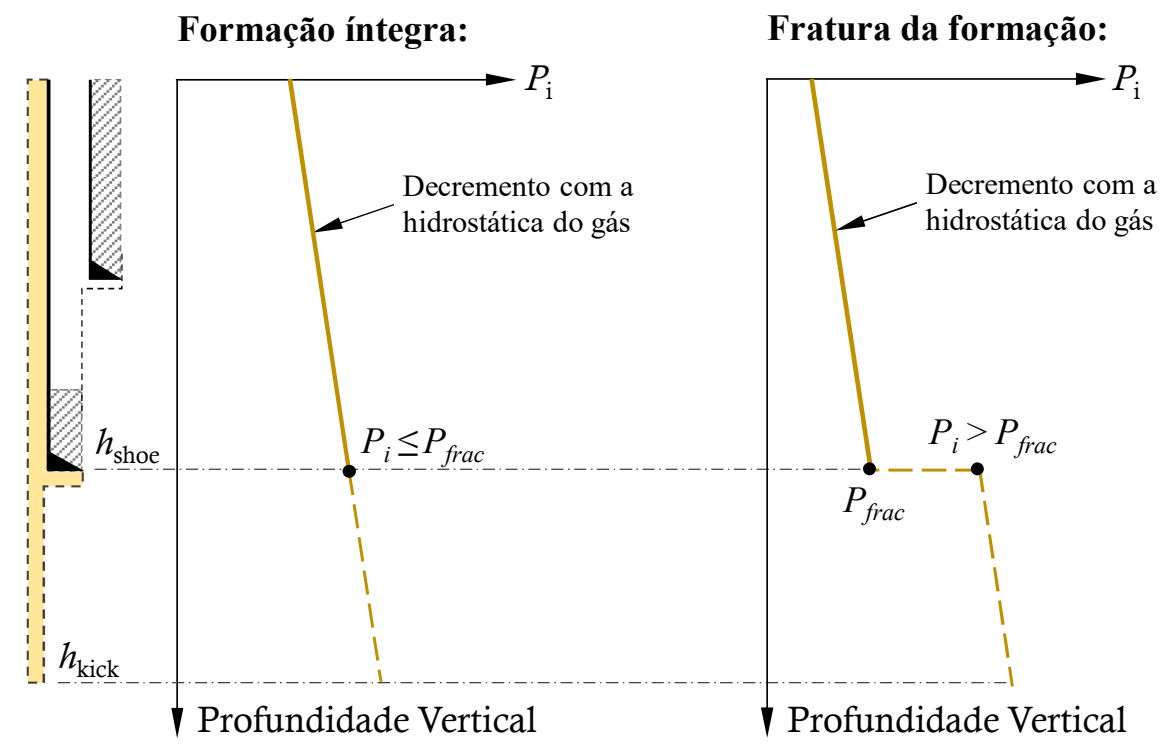

Figura 4.11 - Perfis de pressão interna para coluna de revestimento parcialmente preenchida por fluido de perfuração.

Formação íntegra:

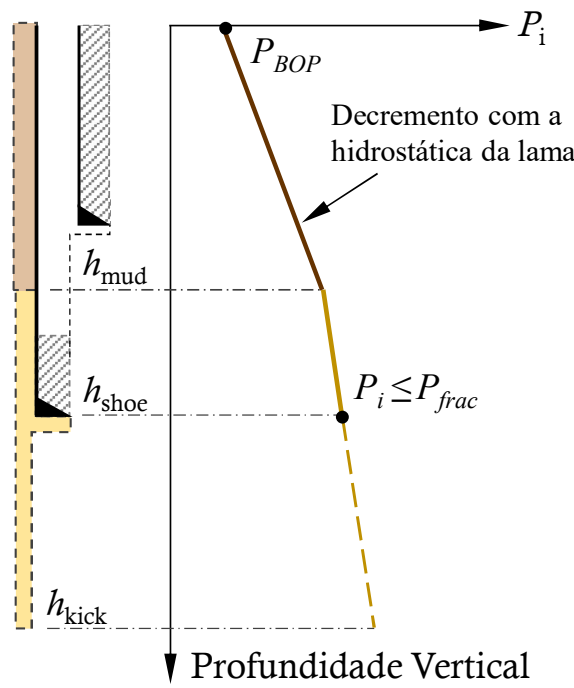

Fratura da formação:

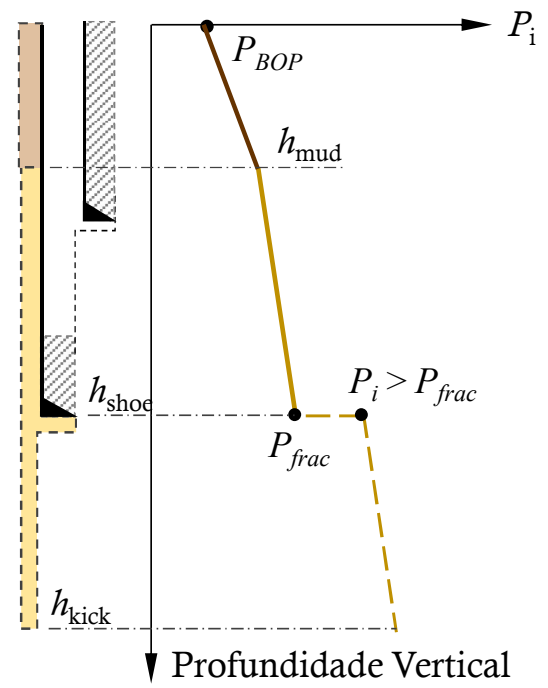

\subsubsection{Produção}

A produção de hidrocarbonetos ocorre através do tubo de produção, o qual é selado pelo packer fluid. Este fluido tem a função de reduzir a pressão diferencial suportada pelo elemento de vedação (packer) e pelo revestimento por meio de sua pressão hidrostática, além de proteger metais e elastômeros da corrosão.

Sob condições ideais, apenas o revestimento situado na região entre a sapata e o packer estará sujeito a uma pressão de ruptura. No entanto, o revestimento de produção deve ser capaz de resistir às pressões de ruptura causadas por uma eventual falha do tubo de produção (API, 2013). Assim, uma das cargas de ruptura mais severas em um poço é resultado de um vazamento de gás no tubo de produção (tubing leak) a uma altura próxima à superfície, como mostra a 
Figura 4.12.

Figura 4.12 - Cenário de ruptura durante a fase de produção.

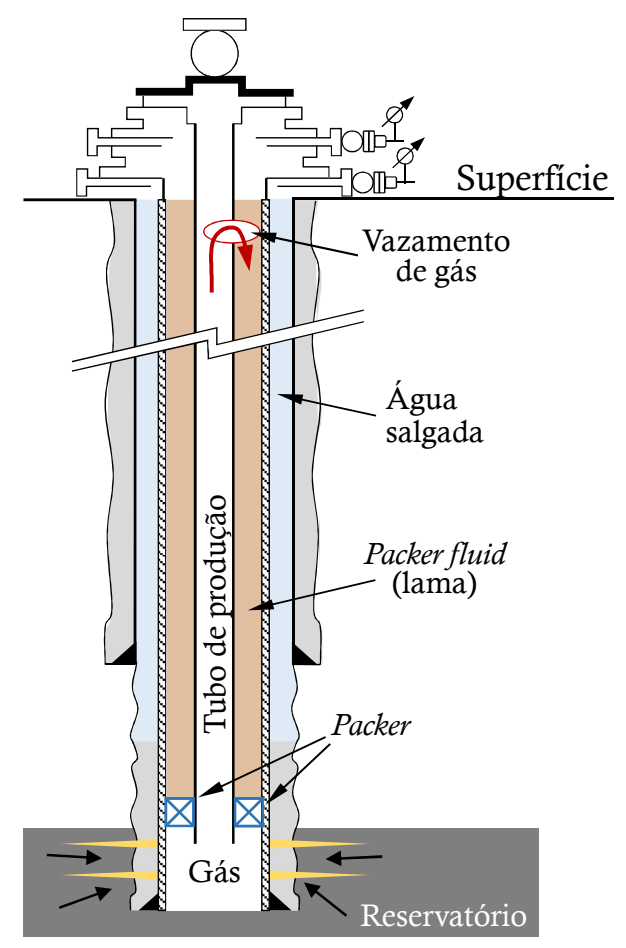

O projeto do revestimento de produção é realizado para esta condição, com base nas seguintes hipóteses:

a. O revestimento de produção tem pressão de fundo igual à pressão de poros da formação;

b. Admite-se que o espaço anular entre o tubo e o revestimento de produção estava originalmente preenchido pelo fluido utilizado na instalação da coluna;

c. Na parede externa do revestimento há presença de água salgada saturada.

A pressão interna no topo do revestimento de produção num evento de tubing leak corresponde à pressão exercida por uma coluna de gás que se estende da zona produtora até a superfície do poço $\left(h_{\text {sup }}\right)$, ou seja:

$$
P_{t b l}=P_{\text {gas }}\left(h_{\text {prod }}, h_{\text {sup }}\right)
$$

A este valor soma-se a pressão hidrostática exercida pelo fluido de completação para finalmente se obter o perfil de pressões internas ao revestimento:

$$
P_{i}=P_{t b l}+\rho_{\text {pack }} \cdot h_{v} \text { para } h_{\text {sup }} \leq h_{v} \leq h_{\text {prod }}
$$




\subsection{Annular Pressure Buildup (APB)}

O crescimento de pressão em anulares confinados, ou Annular Pressure Buildup (APB), corresponde a um cenário especial de carregamento que pode provocar tanto o colapso quanto a ruptura de revestimentos. É originado por aumentos de temperatura após a instalação (cimentação da base) do revestimento, que causam a expansão térmica dos fluidos aprisionados no espaço anular da coluna, provocando acréscimos de pressão significativos em certos casos.

Segundo Mitchell (2006), na maioria das vezes essas cargas adicionais não precisam ser incluídas no projeto, pois as pressões podem ser reduzidas por meio de mecanismos de alívio de pressão. No entanto, em poços situados em águas profundas, o espaço anular torna-se inacessível após a instalação dos revesimentos, de modo que torna-se necessário estimar o crescimento de pressão nos anulares confinados.

O APB geralmente ocorre durante a fase de produção, devido à circulação do óleo ou gás produzido. No entanto, também pode ocorrer durante etapas de perfuração, quando fluidos confinados em anulares rasos sofrem aumento de pressão devido a uma expansão térmica ocasionada pela circulação do fluido de perfuração, que retorna do fundo de poços de alta temperatura.

Segundo a N-2752 (2014), a possibilidade de ocorrência de APB deve ser avaliada nos seguintes casos:

a) Topos de cimento acima das sapatas dos revestimentos anteriores;

b) Possibilidade de tamponamento das sapatas anteriores devido a decantação de sólidos, quando forem utilizados fluidos com alto teor de sólidos;

c) Anulares com o topo de cimento abaixo das sapatas anteriores cujas formações apresentam elevados gradientes de fratura.

Ainda que não haja anulares confinados, a norma N-2752 (2014) recomenda que, em poços de alta temperatura, sejam realizados estudos para avaliar o impacto do aumento de temperatura oriundo da produção na queda da resistência dos aços e dos esforços axiais compressivos induzidos nas colunas de revestimento. Este último tópico será visto em maior detalhe no capítulo seguinte.

Em caso de ocorrência de APB, o acréscimo de pressão produzido pela expansão térmica deve ser calculado por meio de análises termodinâmicas de modo a equilibrar a variação do volume do fluido com a mudança do volume anular. Por se tratar de um assunto de elevada complexidade, este cenário de carregamento não será considerado no presente trabalho. No entanto, recomenda-se a leitura de Halal e Mitchell (1994) para maiores detalhes a respeito do tema. 



\section{Cálculo de Forças Axiais}

Antes de proceder com o levantamento das cargas axiais, o projetista deve realizar o pré-dimensionamento dos tubulares que irão compor cada coluna de revestimento com base nos carregamentos críticos de colapso e ruptura estimados. O procedimento consiste na seleção da classe de aço, do diâmetro externo e da espessura (ou peso) dos tubulares conforme a resistência oferecida pelos mesmos a cada um destes modos de falha. Somente após esta etapa torna-se possível calcular as forças axiais (em virtude da influência do peso próprio e da geometria do arranjo estrutural) e proceder com ajustes no projeto, se necessário.

As principais fontes de força axial são o peso próprio do revestimento, a ação do empuxo de fluidos, variações de temperatura, o efeito pistão e o efeito de Poisson. A soma de todas estas forças resulta no que se denomina força axial efetiva. A seguir, apresenta-se uma metodologia para levantamento das cargas axiais atuantes em colunas de revestimento, fundamentada nos trabalhos de Rahman e Chilingarian (1995) e Souza (2015). Contudo, antes de avançar para os cálculos, é importante definir o conceito de condição inicial.

\subsection{Condição inicial}

Quando o revestimento é posicionado e o cimento ainda está fluido, a carga axial em qualquer ponto da coluna equivale à soma de todas as cargas atuando abaixo deste ponto. Se não houver mudanças nas densidades dos fluidos e nas pressões atuantes, após a cura do cimento a carga axial em todos os pontos do revestimento permanecerá igual à do momento de sua instalação. Contudo, operações subsequentes de perfuração e produção com fluidos de diferentes densidades provocam alterações nos diferenciais de pressão e, por conseguinte, nas cargas axiais. Mudanças também ocorrem quando a temperatura média no tubular varia.

Assim, para o cálculo das forças axiais atuantes ao longo do revestimento, é necessário definir a priori as condições iniciais em termos de pressão, temperatura e força axial. Esta é uma etapa de suma importância, pois os esforços axiais efetivos são resultado da sobreposição da condição inicial à variação de esforços provocada por um determinado efeito.

\section{Condição inicial de temperatura}

Para fins de projeto, a condição inicial de temperatura deve ser tomada como sendo o próprio perfil de temperatura decorrente do gradiente geotérmico (condição não perturbada). Esta é uma premissa robusta que visa maximizar as variações de temperatura no revestimento e, consequentemente, os esforços de origem térmica.

Em retroanálises, no entanto, é razoável considerar um perfil de temperatura diferente da condição não perturbada, valendo-se do histórico operacional do poço (SOUZA, 2015). 


\section{Condição inicial de pressão}

Quando um tubo é submetido a uma variação de pressão externa e/ou interna, tende a contrair ou expandir radialmente. Como resultado do efeito de Poisson, observa-se também o aumento ou diminuição de seu comprimento. No entanto, caso ambas as extremidades do tubo estejam impedidas de se deslocar, seu alongamento ou encurtamento longitudinal provoca tensões axiais adicionais de tração ou compressão. O mesmo ocorre com as colunas de revestimento antes e após a cimentação de sua sapata. Caso a pasta de cimento ainda esteja fluida, o revestimento é livre para expandir/contrair axialmente. Uma vez que o cimento esteja curado, eventuais mudanças de pressão induzem esforços axiais no revestimento em virtude do aprisionamento da coluna em sua base.

Portanto, a condição inicial de pressão depende do estado da pasta de cimento no anular e deve ser pensada como sendo o cenário de pressões aplicadas ao revestimento imediatamente antes da cura do cimento. Com base nisto pode-se elencar dois perfis distintos de pressão, cuja escolha fica a critério do projetista. $\mathrm{O}$ primeiro corresponde às pressões exercidas no revestimento após o completo deslocamento do cimento (Figura 4.2). O segundo corresponde à condição em que se aplica a pressão de plug-bump (Figura 4.7). Em geral, seleciona-se o perfil que provoca o maior acréscimo dos esforços axiais.

\section{Condição inicial de força axial}

A condição inicial de força axial provém do peso próprio do revestimento e das forças de pressão que agem nos ombros dos tubulares que o compõem. Denominam-se por ombros as áreas expostas ao empuxo de fluidos nos pontos em que ocorre mudança na geometria dos tubulares (Figura 5.1).

Figura 5.1 - Forças de empuxo nos ombros do revestimento.
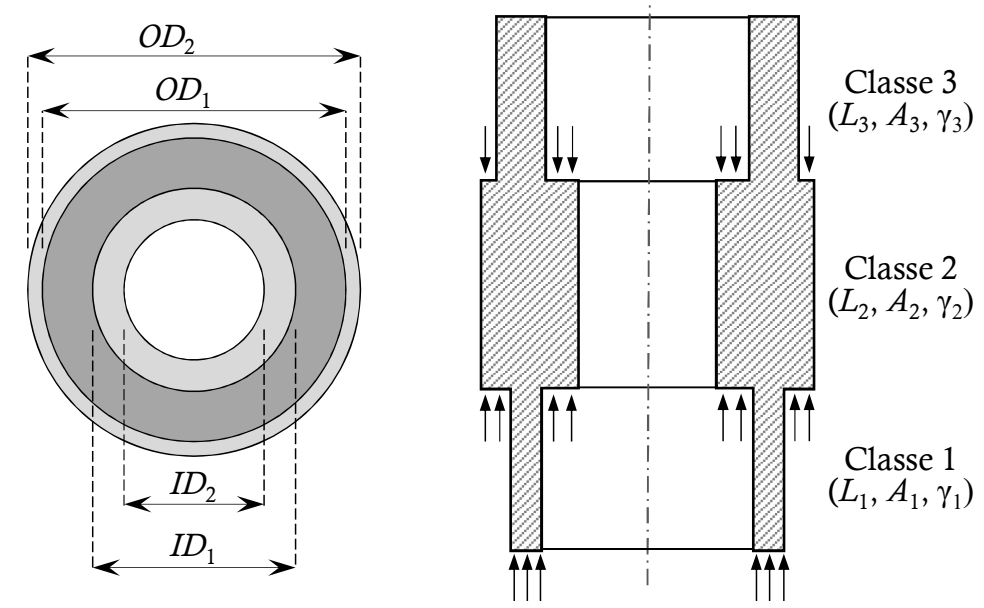

Fisicamente, a condição inicial de forças corresponde ao diagrama de esforços axiais do revestimento. Para traçá-lo, recorre-se a um procedimento simples:

1. Primeiramente, divide-se a coluna de revestimento em $n$ segmentos, de comprimento $L_{i}$, com peso específico $\gamma_{i}$ e geometria constantes ao longo de sua extensão; 
2. Enumeram-se os segmentos sequencialmente, iniciando pela base do revestimento rumo à superfície;

3. Computa-se a área interna $A_{\text {int }}$, a área externa $A_{\text {ext }}$ e a área de aço da seção transversal $A$ de cada segmento $i$ por meio das relações:

$$
\left\{\begin{array}{l}
A_{\text {int }}=\pi \cdot I D^{2} / 4 \\
A_{\text {ext }}=\pi \cdot O D^{2} / 4 \\
A=\left(A_{\text {ext }}-A_{\text {int }}\right)
\end{array}\right.
$$

onde ID e OD são o diâmetro interno e externo do segmento, respectivamente;

4. Calcula-se o peso próprio (não flutuante) de cada segmento: $W_{i}=A_{i} \gamma_{i} L_{i}$;

5. Determinam-se as pressões interna e externa, $P_{i n t}$ e $P_{\text {ext }}$, em cada um dos pontos de aplicação das forças de empuxo com base na condição inicial de pressão;

6. Calculam-se as forças concentradas que agem nos ombros do revestimento por meio da expressão:

$$
F_{i}=P_{\text {ext }, i} \cdot\left(A_{\text {ext }, i}-A_{\text {ext }, i+1}\right)-P_{\text {int }, i} \cdot\left(A_{\text {int }, i}-A_{\text {int }, i+1}\right), \quad \text { para } i=1, \ldots, n-1 .
$$

7. Na base do revestimento, a força de empuxo é dada pela expressão:

$$
F_{0}=-P_{\text {ext }} \cdot A_{\text {ext }, 1}+P_{\text {int }} \cdot A_{\text {int }, 1}
$$

8. Iniciando pela sapata do revestimento, calcula-se a força axial na base do segmento $i, F_{i}^{\text {base }}$, e em seguida em seu topo, $F_{i}^{\text {topo }}$. Para o caso particular do primeiro segmento tem-se:

$$
\left\{\begin{array}{l}
F_{1}^{\text {base }}=F_{0} \\
F_{1}^{\text {topo }}=F_{1}^{\text {base }}+W_{1}
\end{array}\right.
$$

Nos demais segmentos, a seguinte expressão pode ser aplicada:

$$
\left\{\begin{array}{l}
F_{i}^{\text {base }}=F_{i-1}^{\text {topo }}+F_{i-1} \\
F_{i}^{\text {topo }}=F_{i}^{\text {base }}+W_{i}
\end{array} \quad \text { para } i=2, \ldots, n\right.
$$

A Figura 5.2 ilustra a condição inicial de forças axiais para uma coluna composta por três segmentos de revestimento. Nota-se que a força de empuxo atuante na base do revestimento provoca esforços de compressão neste ponto. À medida que se avança em direção à superfície, a força compressiva diminui em função do peso próprio, até que ocorre uma inversão de esforços. A condição inicial na coluna passa então a ser de tração, apresentando máxima intensidade na cabeça do poço. Observam-se ainda descontinuidades no diagrama em virtude das forças de empuxo que agem pontualmente nos ombros do revestimento.

No caso de trajetória direcional, deve-se discretizá-la em trechos retilíneos e trabalhar com a decomposição do peso próprio e das forças de empuxo segundo a direção axial do trecho. Para o cômputo das pressões, é suficiente trabalhar com profundidades verticais. 
Figura 5.2 - Condição inicial de forças axiais.

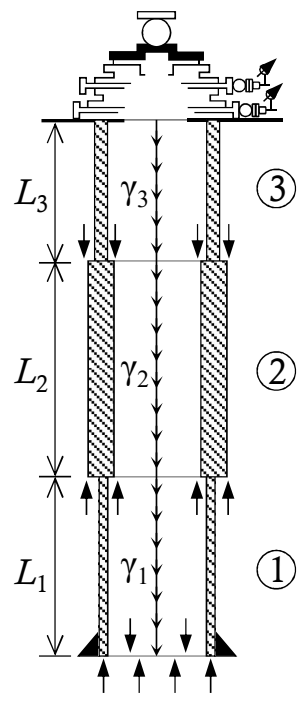

(a) Revestimento composto

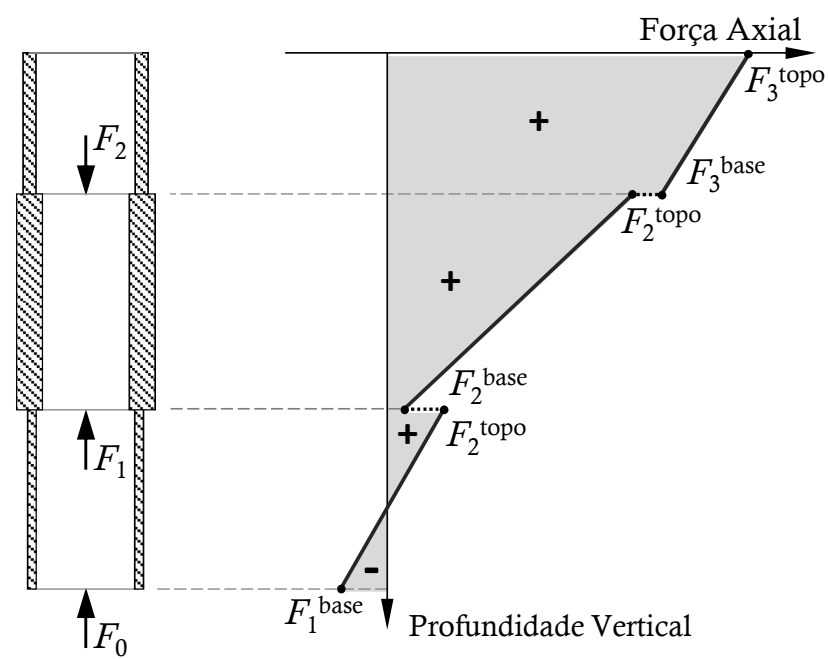

(b) Forças de empuxo (c) Diagrama de esforços axiais (condição inicial)

\subsection{Metodologia para cálculo da força axial efetiva}

Quando o cimento ainda está fluido, a força axial efetiva no revestimento corresponde à própria força axial calculada conforme o procedimento descrito na seção anterior. No entanto, uma vez que haja cura da pasta, o revestimento fica impedido de se mover e surgem esforços axiais adicionais para qualquer perturbação nas condições iniciais de pressão e temperatura.

O cálculo destes esforços e da força axial efetiva segue uma metodologia que consiste em determinar o deslocamento que um dado efeito ou carga produziria caso o revestimento não estivesse aprisionado e então encontrar a força axial necessária para zerar este deslocamento (SOUZA, 2015). O valor obtido corresponde então ao esforço axial que deverá ser sobreposto à condição inicial para formar o diagrama final do revestimento.

Matematicamente, pode-se expressar a metodologia como:

$$
\Delta L_{\text {efeito }}+\Delta L_{F}=0 \quad \therefore \quad \Delta L_{F}=-\Delta L_{\text {efeito }}
$$

onde $\Delta L_{\text {efeito }}$ é o deslocamento produzido por certo efeito e $\Delta L_{F}$ é o deslocamento que será contraposto pela força axial que se deseja determinar. $\mathrm{O}$ deslocamento proveniente do efeito, por sua vez, é constituído de três parcelas, a saber:

$$
\Delta L_{\text {efeito }}=\Delta L_{T}+\Delta L_{P i s}+\Delta L_{B}
$$

sendo $\Delta L_{T}$ provocado por mudanças de temperatura, $\Delta L_{P i s}$ devido ao efeito pistão e $\Delta L_{B}$ gerado por variações de pressão, denominado efeito ballooning. O cálculo de cada parcela de deslocamento será exposto nas seções 5.3, 5.4 e 5.5 . 
A aplicação da Eq. (5.6) deve ser realizada de modo diferenciado para o trecho livre e para o trecho cimentado do revestimento. A Figura 5.3 ilustra o procedimento recomendado para cada caso.

Figura 5.3 - Metodologia para cálculo de deslocamentos nos trechos livre e cimentado.

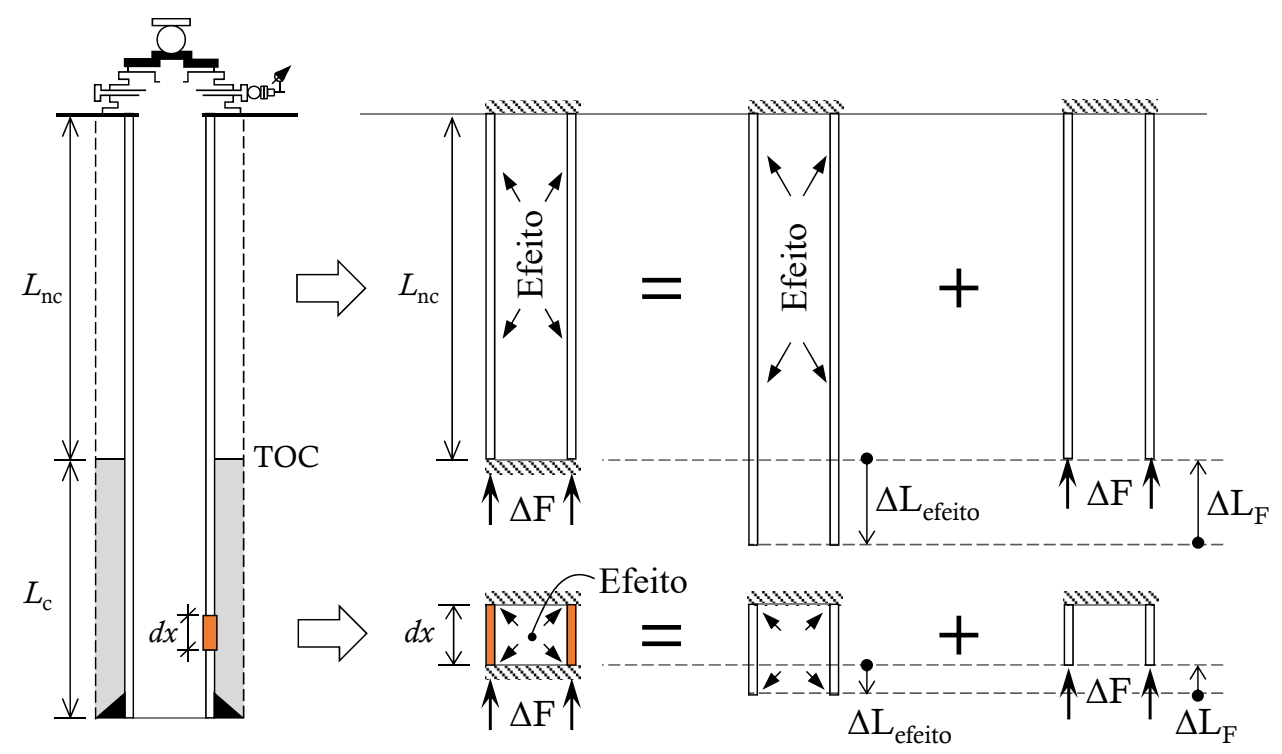

No trecho livre, deve-se retirar o vínculo decorrente da cimentação na cota de topo do cimento (TOC) e calcular o deslocamento causado por um determinado efeito em todo o comprimento não cimentado $\left(L_{n c}\right)$. Como em realidade a coluna é impedida de se mover, a força de reação no vínculo $(\Delta F)$ deve proporcionar deslocamento de igual módulo, mas em sentido oposto, de modo a retornar a extremidade do trecho livre para sua posição original.

Numa coluna de revestimento composta por tubulares de mesma classe e igual geometria (um único segmento), o encurtamento $\Delta L_{F}$ pode ser obtido facilmente pela aplicação da Lei de Hooke:

$$
\Delta L_{F}=\frac{\Delta F L_{n c}}{E A_{s}}
$$

onde $\Delta F$ é variação do esforço axial que se deseja determinar, $E$ representa o módulo de Young e $A_{s}$ a área de aço da seção transversal.

Para o caso geral de colunas compostas, a aplicação da Lei de Hooke deve ser realizada sistematicamente para cada segmento $i$ com propriedades constantes, ou seja:

$$
\Delta L_{F}=\Delta F \sum_{i}^{n} \frac{L_{i}}{E_{i} A_{i}}
$$

O equacionamento para o trecho cimentado é praticamente o mesmo, porém deve ser calculado pontualmente para cada elemento de comprimento infinitesimal $d x$ (Figura 5.3). Devese escolher um número suficiente de pontos ao longo do comprimento cimentado para aplicação das Eqs. (5.7) e (5.8), de modo a possibilitar a construção de uma curva por interpolação.

Recomenda-se que pontos de discretização sejam adotados sempre que forem identificadas descontinuidades na geometria do poço e nos perfis de pressão e de temperatura. 


\subsection{Deslocamento devido ao efeito da temperatura}

Operações de perfuração e produção causam mudanças na temperatura do revestimento ao longo de sua extensão. Durante a perfuração da fase seguinte, o fluido de perfuração circulante é aquecido à medida que se desloca para o fundo do poço e é arrefecido pelo revestimento circundante enquanto retorna para a superfície. No decorrer da produção, um fenômeno similar de transferência de calor se desenvolve. O fluido extraído, inicialmente com a mesma temperatura da zona de exploração, cede calor ao revestimento conforme ascende à superfície. Como resultado, observa-se o aquecimento do revestimento como um todo, contudo a porção superior fica submetida a uma maior variação de temperatura (em relação à condição inicial de instalação do revestimento).

O cálculo do deslocamento devido ao efeito térmico será realizado de forma aproximada, considerando trechos de revestimento submetidos a perfis lineares de temperatura nas condições inicial e de produção. Caso algum destes perfis seja não linear, deverá ser convenientemente discretizado, como mostra a Figura 5.4. Com esta sistemática, o deslocamento total da coluna passa a ser dado pela contribuição de cada trecho. Logo, a qualidade da solução obtida será tão melhor quanto maior for o número de trechos considerados.

Figura 5.4 - Perfis de temperatura usuais e discretização do problema.

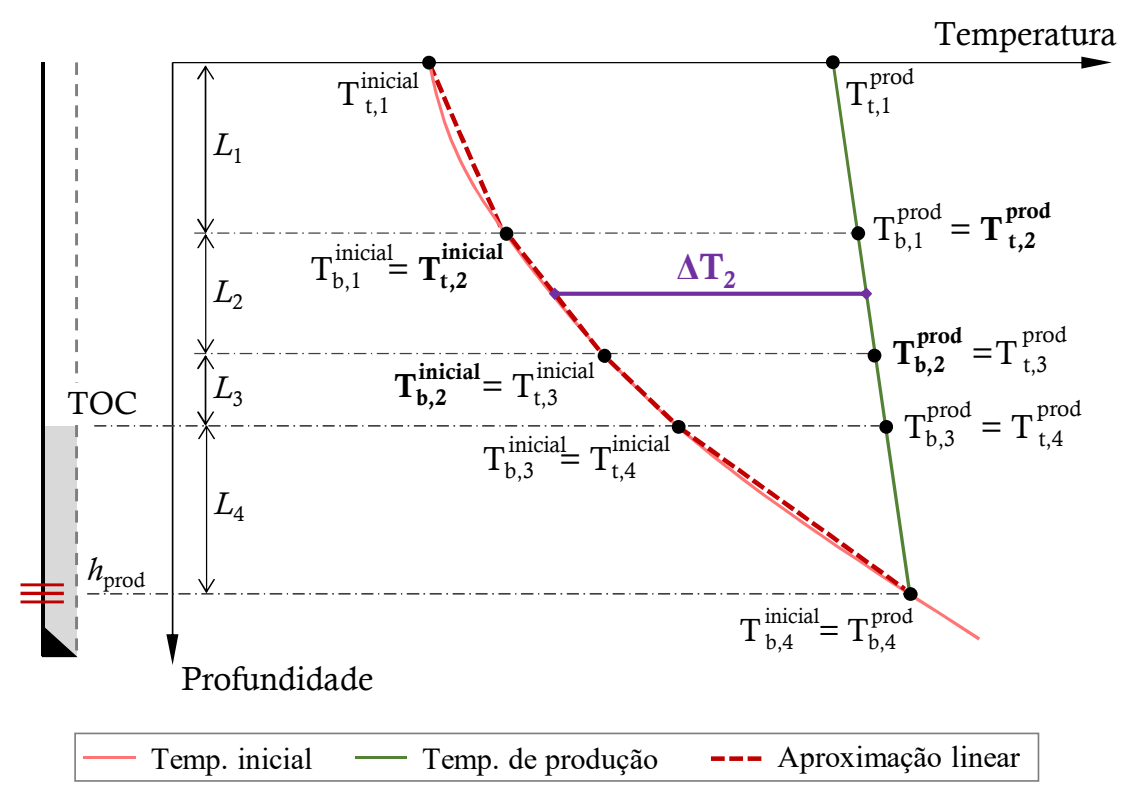

Para um segmento de comprimento $L$, a elongação causada por uma variação de temperatura pode ser expressa como:

$$
\Delta L=\alpha L \Delta T
$$

sendo $\alpha$ o coeficiente de dilatação térmica (cujo valor característico é de $1,242.10^{-5}$ para o aço) e $\Delta T$ a variação média de temperatura no segmento, dada pela diferença entre a temperatura 
média nas condições final e inicial:

$$
\Delta T=\frac{T_{t}^{\text {final }}+T_{b}^{\text {final }}}{2}-\frac{T_{t}^{\text {inicial }}+T_{b}^{\text {inicial }}}{2}
$$

onde $T_{t}$ e $T_{b}$ são temperatura no topo e na base do segmento, respectivamente.

\section{Trecho Livre}

Considerando inicialmente a extensão não cimentada do revestimento discretizada em um número arbitrário de trechos de comprimento $L_{i}$, a elongação por efeito da temperatura corresponde a:

$$
\Delta L_{T}=\alpha \sum_{i} L_{i} \Delta T_{i}
$$

No caso de uma coluna de revestimento com seção transversal constante, a força axial de origem térmica $\left(\Delta F_{T}\right)$ resulta da combinação da equação anterior às Eqs. (5.6) e (5.8), tal que:

$$
\Delta L_{F}=-\Delta L_{T} \quad \therefore \quad \frac{\Delta F_{T} L_{n c}}{E A}=\alpha \sum_{i} L_{i} \Delta T_{i}
$$

Isolando $\Delta F_{T}$, obtém-se a força axial no comprimento não cimentado do revestimento:

$$
\Delta F_{T}=-\frac{E A \alpha}{L_{n c}} \sum_{i} L_{i} \Delta T_{i} \quad \text { (seção constante) }
$$

Já para seção variável, a Eq. (5.12) deve ser combinada com a Eq. (5.9), tal que:

$$
\Delta F_{T}=-\alpha \sum_{i}\left(L_{i} \Delta T_{i}\right) \cdot\left(\sum_{j} \frac{L_{j}}{E_{j} A_{j}}\right)^{-1} \quad \text { (seção variável) }
$$

onde o índice $i$ provém da discretização adotada para aproximação da temperatura, enquanto $j$ corresponde ao número de segmentos da coluna de revestimento com seções transversais distintas.

\section{Trecho Cimentado}

Para a extensão cimentada do revestimento, o alongamento de um elemento de comprimento $d x$ pode ser calculado por meio de uma versão simplificada da Eq. (5.14), a saber:

$$
\Delta L_{F}=-\Delta L_{T} \quad \therefore \quad \frac{\Delta F_{T} d x}{E A}=\alpha d x \Delta T
$$

que resulta em:

$$
\Delta F_{T}=-E A \alpha \Delta T \quad \text { (trecho cimentado) }
$$

A variação de temperatura para o comprimento $d x$ é o próprio incremento de temperatura do ponto considerado $\left(\Delta T=T^{\text {final }}-T^{\text {inicial }}\right)$, pois o comprimento é tomado com seu limite tendendo a zero.

Salienta-se que todas as expressões para a força axial por efeito da temperatura ora deduzidas são precedidas de um sinal negativo, indicando que a força é compressiva para variações positivas de temperatura. 


\subsection{Deslocamento devido ao efeito pistão}

O efeito pistão é um fenômeno provocado por mudanças nas pressões hidrostáticas que agem nos ombros interno e externo da coluna de revestimento (Figura 5.1) em relação à condição inicial de pressões. Tais variações ocorrem principalmente em virtude de mudanças na densidade dos fluidos dentro e fora do revestimento, como consequência dos seguintes eventos:

- Aumento do peso específico do fluido de perfuração antes da perfuração da próxima fase;

- Contaminação do fluido de deslocamento contido no anular por água do mar ou fluidos leves da formação, reduzindo seu peso específico;

- Ocorrência de kick ou perda de circulação durante operações de perfuração, provocando alterações na pressão interna do revestimento.

O efeito pistão se manifesta por meio de forças de empuxo incrementais que promovem a variação dos esforços axiais em todo o revestimento. A força do efeito pistão, $F_{P i s}$, que atua em um ponto $k$ de mudança de geometria pode ser obtida por meio da seguinte expressão:

$$
F_{P i s, k}=\Delta P_{\text {ext }, k} \cdot\left(A_{\text {ext }}^{\text {inf }}-A_{\text {ext }}^{\text {sup }}\right)-\Delta P_{\text {int }, k} \cdot\left(A_{\text {int }}^{\text {inf }}-A_{\text {int }}^{\text {sup }}\right)
$$

onde:

$\Delta P_{\text {ext }, k}, \Delta P_{\text {int }, k}$ : variação de pressão externa e interna no ponto $k$, respectivamente;

$A_{\text {ext }}^{\text {inf }}, A_{\text {ext }}^{\text {sup }}$ : área externa da seção inferior e superior ao ponto $k$, respectivamente;

$A_{\text {int }}^{\text {inf }}, A_{\text {int }}^{\text {sup }}$ : área interna da seção inferior e superior ao ponto $k$, respectivamente.

Em geral, o diâmetro externo é constante ao longo de toda a extensão do revestimento, de modo que as forças de pistão externas se cancelam e restam apenas as forças internas.

Para o cálculo do deslocamento causado pelo efeito pistão considere os segmentos de revestimento representados nas Figuras 5.5a e 5.5b.

Figura 5.5 - Deslocamento devido ao efeito pistão.

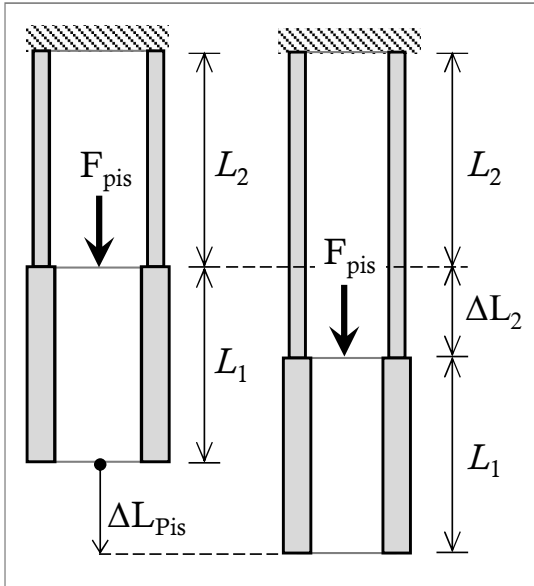

(a) coluna com apenas uma transição

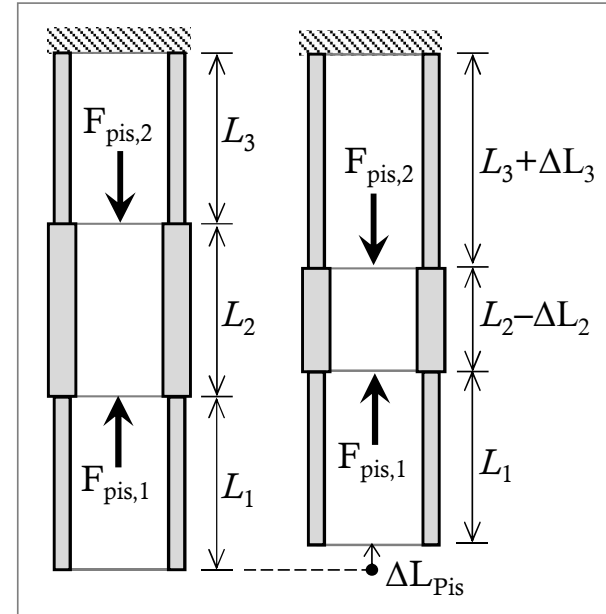

(b) coluna com várias transições

Conforme mostram as Figuras 5.5a e 5.5b, apenas os segmentos situados acima do ponto de atuação da força de pistão $F_{P i s}$ sofrem alongamento. Os trechos abaixo deste ponto 
apresentam apenas movimento de corpo rígido. Logo, para o caso da coluna com uma única seção de transição de geometria (Figura 5.5a), o deslocamento total devido ao efeito pistão equivale a:

$$
\Delta L_{\text {Pis }}=\frac{F_{\text {Pis }} L_{\text {sup }}}{E_{\text {sup }} A_{\text {sup }}}=\frac{F_{\text {Pis }} L_{2}}{E_{2} A_{2}}
$$

Para o caso geral de uma coluna com várias seções de transição, a elongação por efeito pistão de cada força $F_{P i s, k}$ é igual a:

$$
\Delta L_{P i s, k}=F_{P i s, k} \sum_{i}\left(\frac{L_{i}}{E_{i} A_{i}}\right), \quad \text { para } i=k+1, \ldots, n
$$

sendo $n$ o número de segmentos de revestimento com propriedades geométricas e de material constantes.

Finalmente, o deslocamento total da base da coluna corresponde à soma do alongamento produzido por cada uma das forças $F_{P i s, k}$ agindo ao longo da extensão do revestimento, ou seja:

$$
\Delta L_{P i s}=\sum_{k} \Delta L_{P i s, k}
$$

Alternativamente, pode-se calcular o valor de $\Delta L_{P i s}$ com base nos esforços internos solicitantes em cada segmento da coluna, segundo a expressão:

$$
\Delta L_{P i s}=\sum_{i=1}^{n} \frac{N_{i} L_{i}}{E_{i} A_{i}}
$$

sendo $N_{i}$ o esforço axial do segmento $i$, dado por:

$$
N_{i}=\sum_{k=1}^{i-1} F_{P i s, k}
$$

\subsubsection{Variação do esforço axial devida ao efeito pistão}

A variação do esforço axial devida ao efeito pistão deve ser determinada separadamente para o trecho livre e para o trecho cimentado do revestimento. Em ambos os casos, aplica-se a sistemática exposta na seção 5.2.

$\mathrm{O}$ trecho de revestimento, inicialmente engastado em ambas as extremidades, é analisado separadamente em três etapas: primeiramente, remove-se o vínculo existente em sua base e calcula-se o deslocamento deste ponto em virtude das forças do efeito pistão; em seguida, recupera-se a condição de vinculação por meio de uma força reativa aplicada na base do segmento analisado; por fim, encontra-se o valor de tal força por meio da imposição de que o deslocamento deste ponto seja nulo.

\section{$\underline{\text { Trecho Livre }}$}

No caso do trecho livre, o resultado da primeira etapa corresponde às Eqs. (5.21) e (5.22). Por sua vez, a força necessária para consumir a elongação do efeito pistão pode ser calculada por meio da Eq. (5.9), abaixo replicada por conveniência:

$$
\Delta L_{F}=\Delta F \sum_{i}^{n} \frac{L_{i}}{E_{i} A_{s i}}
$$


A última etapa consiste em combinar a expressão anterior com a Eq. (5.21) e impor a nulidade do deslocamento da base do trecho livre. Fazendo isto, obtém-se o valor da reação $\Delta L_{F}$ :

$$
\Delta L_{F}+\Delta L_{P i s}=0 \quad \therefore \quad \Delta F=-\sum_{i}^{n}\left(\frac{E_{i} A_{i}}{L_{i}}\right) \cdot \sum_{k}\left(F_{P i s, k} \cdot \sum_{i=k+1}^{n} \frac{L_{i}}{E_{i} A_{i}}\right)
$$

Em posse do valor de $\Delta F$, determina-se a variação de esforço axial devida ao efeito pistão em cada segmento de revestimento:

$$
\Delta N_{P i s}=N_{i}+\Delta F
$$

\section{Trecho Cimentado}

No trecho cimentado, o efeito pistão tende a causar descontinuidades no diagrama de esforços axiais somente nos pontos onde há variação de diâmetro interno da coluna de revestimento. Em virtude da cimentação do anular, não há variação de pressão externa, de modo que a força do efeito pistão pode ser calculada simplificadamente por:

$$
F_{\text {Pis }}=\Delta P_{\text {int }, k} \cdot\left(A_{\text {int }}^{\text {sup }}+A_{\text {int }}^{\text {inf }}\right)
$$

Para o cálculo do deslocamento produzido por esta força, considere o elemento de comprimento infinitesimal $2 d x$ ilustrado na Figura 5.6.

Figura 5.6 - Deslocamento devido ao efeito pistão.

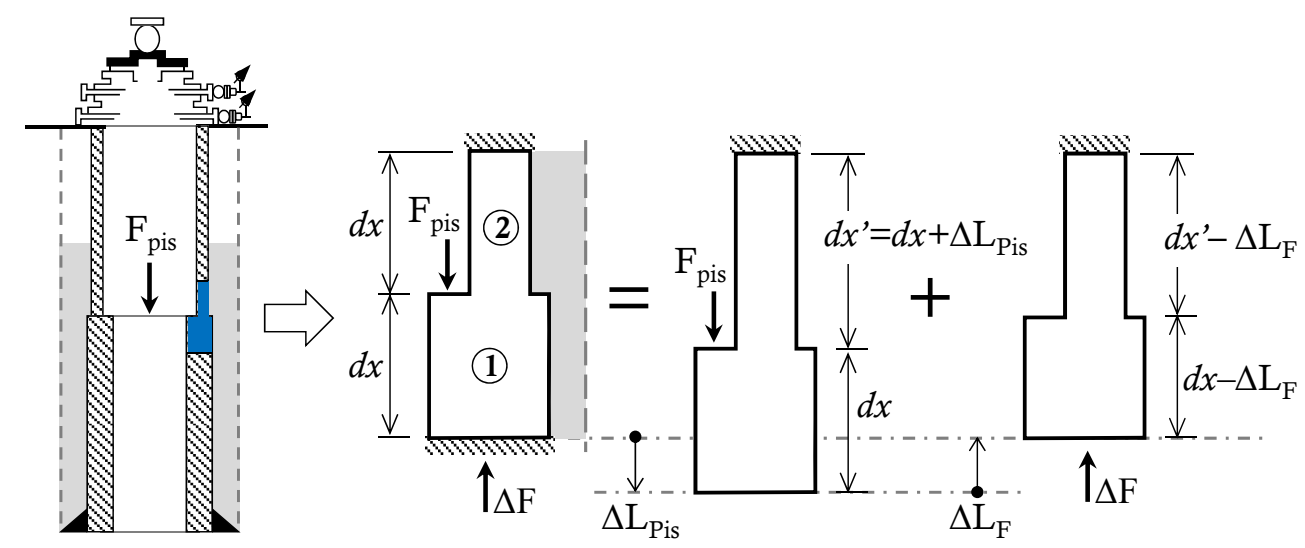

O deslocamento devido ao efeito pistão, após retirada a influência do cimento, é igual a:

$$
\Delta L_{P i s}=\frac{F_{P i s} d x}{E_{2} A_{2}}
$$

Por sua vez, a força reativa $\Delta F$ provoca encurtamento do revestimento em um comprimento igual a:

$$
\Delta L_{F}=-\Delta F \sum_{i} \frac{L_{i}}{E_{i} A_{s i}}=-\Delta F\left(\frac{d x}{E_{1} A_{1}}+\frac{d x}{E_{2} A_{2}}\right)
$$

Igualando as Eqs. (5.27) e (5.28), determina-se o valor da força $\Delta F$ :

$$
\Delta F=-\frac{F_{P i s}}{E_{2} A_{2}} \cdot\left(\frac{1}{E_{1} A_{1}}+\frac{1}{E_{2} A_{2}}\right)^{-1}
$$


Finalmente, com base no valor de $\Delta F$, calcula-se a variação de esforço axial acima e abaixo do ponto de pistoneio:

$$
\left\{\begin{array}{l}
\Delta N_{P i s, 1}=\Delta F \\
\Delta N_{P i s, 2}=F_{P i s}+\Delta F
\end{array}\right.
$$

\subsection{Deslocamento devido ao efeito ballooning}

Do ponto de vista da mecânica, um tubo pode se comportar como viga, como coluna ou ainda como vaso de pressão. Uma coluna de revestimento, de certo modo, apresenta características híbridas a estes três elementos. Ao todo, três componentes de tensão são de especial interesse para aplicações em poços: a tensão axial e as tensões radial e tangencial. Estas componentes são convenientemente orientadas segundo um sistema de coordenadas cilíndrico, conforme mostra a Figura 5.7.

Figura 5.7 - Sistema de coordenadas cilíndrico e componentes de tensão no corpo do tubo.

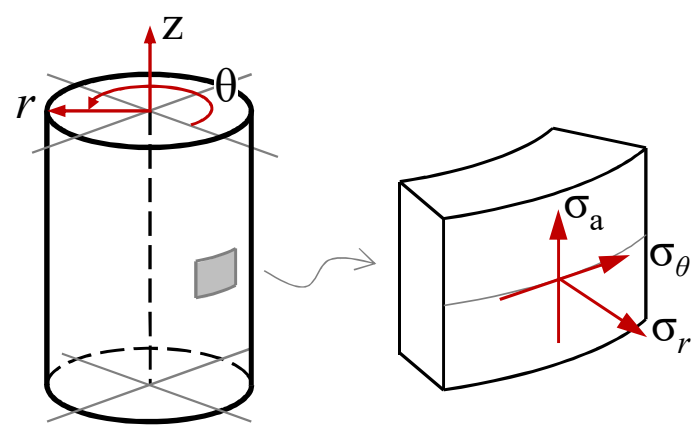

A tensão axial em um tubo reto corresponde à carga axial dividida pela área da seção transversal do tubo, ou seja:

$$
\sigma_{a}=\frac{F_{z}}{A}=\frac{F_{z}}{\left(O D^{2}-I D^{2}\right) \cdot \pi / 4}
$$

onde:

$\sigma_{a}:$ componente de tensão axial;

$F_{z}$ : força axial;

$O D, I D$ : diâmetro externo e interno, respectivamente.

As componentes de tensão radial e tangencial, por sua vez, podem ser fornecidas pelas equações de Lamé para o caso de cilíndros de parede espessa $(O D / t<20)$ :

$$
\begin{gathered}
\sigma_{r}=\left[\frac{P_{\text {int }} r_{i}^{2}-P_{\text {ext }} r_{e}^{2}}{r_{e}^{2}-r_{i}^{2}}\right]-\left[\frac{P_{\text {int }}-P_{\text {ext }}}{r_{e}^{2}-r_{i}^{2}}\right] \cdot\left[\frac{r_{e}^{2} r_{i}^{2}}{r^{2}}\right] \\
\sigma_{\theta}=\left[\frac{P_{\text {int }} r_{i}^{2}-P_{\text {ext }} r_{e}^{2}}{r_{e}^{2}-r_{i}^{2}}\right]+\left[\frac{P_{\text {int }}-P_{\text {ext }}}{r_{e}^{2}-r_{i}^{2}}\right] \cdot\left[\frac{r_{e}^{2} r_{i}^{2}}{r^{2}}\right]
\end{gathered}
$$

onde: 
$\sigma_{r}$ : componente de tensão radial;

$\sigma_{\theta}$ : componente de tensão tangencial;

$P_{\text {int }}, P_{\text {ext }}$ : pressão externa e interna ao tubo, respectivamente;

$r_{i}, r_{e}$ : raio externo e interno, respectivamente;

$r$ : raio do ponto em análise $\left(r_{i} \leq r \leq r_{e}\right)$.

A soma das tensões radial e tangencial é uma invariante de tensão através da parede do tubo, dada por:

$$
\sigma_{r}+\sigma_{\theta}=2 \frac{P_{\text {int }} r_{i}^{2}-P_{\text {ext }} r_{e}^{2}}{r_{e}^{2}-r_{i}^{2}}=\frac{P_{\text {int }} A_{\text {int }}-P_{\text {ext }} A_{\text {ext }}}{A}
$$

Em um vaso de pressão cilíndrico, qualquer alteração na pressão interna ou externa faz com que o vaso se contraia ou expanda radialmente. Como resultado, observa-se o seu alongamento ou encurtamento na direção longitudinal. No entanto, a coluna de revestimento deixa de ser livre para se mover quando cimentada em sua sapata, de modo que movimentos de contração ou alongamento produzem tensões axiais incrementais. Assim, usando a Lei de Hooke generalizada, a deformação axial $\varepsilon_{a}$ induzida por mudanças de pressão pode ser expressa da seguinte forma:

tal que

$$
\begin{gathered}
\varepsilon_{a}=\frac{\Delta L}{L}=\frac{-v}{E}\left[\Delta\left(\sigma_{r}+\sigma_{\theta}\right)\right] \\
\Delta\left(\sigma_{r}+\sigma_{\theta}\right)=\left(\sigma_{r}+\sigma_{\theta}\right)_{\text {final }}-\left(\sigma_{r}+\sigma_{\theta}\right)_{\text {inicial }}
\end{gathered}
$$

Substituindo na equação anterior a expressão da invariante de tensão, Eq. (5.34), obtémse:

$$
\Delta\left(\sigma_{r}+\sigma_{\theta}\right)=2\left[\frac{\Delta P_{i n t} A_{i n t}-\Delta P_{\text {ext }} A_{\text {ext }}}{A}\right]
$$

Finalmente, isolando o termo do alongamento na Eq. (5.35), obtém-se uma expressão para o deslocamento devido ao efeito ballooning:

$$
\Delta L=\frac{-2 v L}{E}\left[\frac{\Delta P_{i n t} A_{i n t}-\Delta P_{e x t} A_{\text {ext }}}{A}\right]
$$

\section{Trecho Livre}

Para calcular o deslocamento devido ao efeito ballooning, deve-se dividir o comprimento livre $L_{n c}$ em segmentos de comprimento $L_{j}$, com propriedades constantes ao longo de sua extensão. O número de segmentos, no entanto, será função não apenas da geometria da coluna, mas também de mudanças na inclinação dos perfis de pressão interna e externa, nas condições inicial e final (Figura 5.8). 
Figura 5.8 - Discretização do trecho livre para cálculo do deslocamento devido ao efeito ballooning.

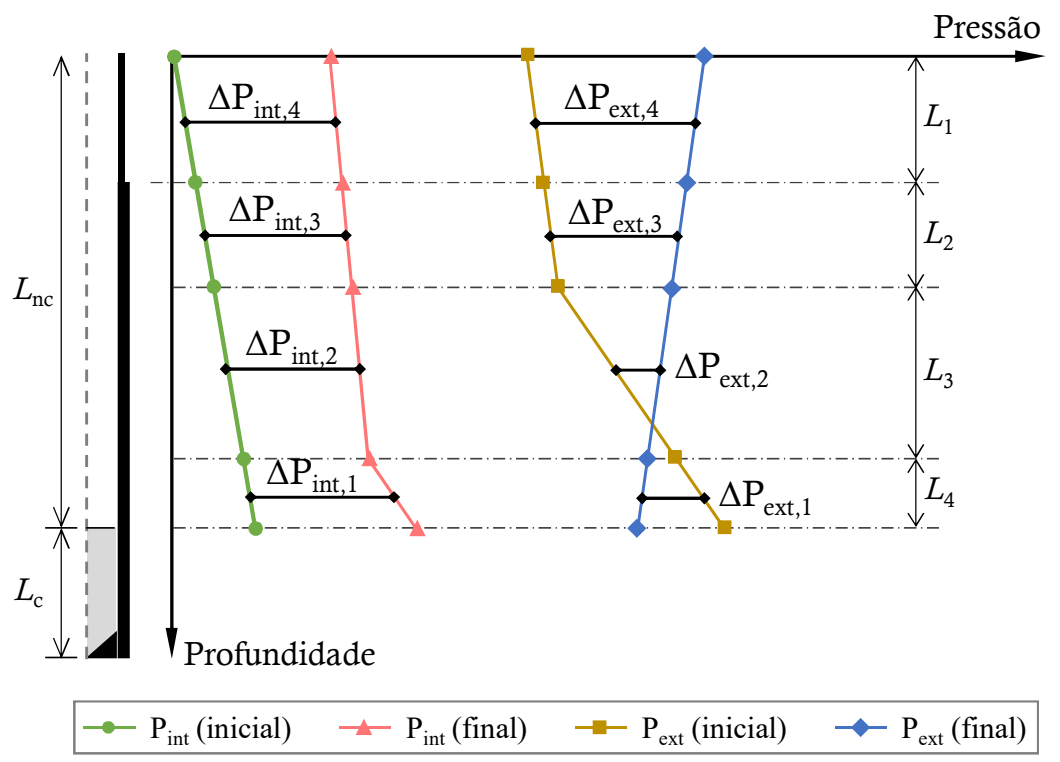

Assim sendo, para um número arbitrário de trechos, a elongação pode ser obtida da seguinte Equação:

$$
\Delta L_{B}=\sum_{j} \frac{-2 v L_{j}}{E_{j}}\left[\frac{\Delta P_{\text {int }, j} A_{\text {int }, j}-\Delta P_{\text {ext }, j} A_{\text {ext }, j}}{A_{j}}\right]
$$

sendo as variações de pressão $\Delta P_{i n t, j}$ e $\Delta P_{i n t, j}$ dadas pela diferença entre a condição final e inicial na metade do segmento, ou seja:

$$
\begin{aligned}
& \Delta P_{\text {int }}=\left[\frac{P_{\text {int }, b}^{\text {final }}+P_{\text {int }, t}^{\text {final }}}{2}\right]-\left[\frac{P_{\text {int }, b}^{\text {inicial }}+P_{\text {int }, t}^{\text {inicial }}}{2}\right] \\
& \Delta P_{\text {ext }}=\left[\frac{P_{\text {ext }, b}^{\text {final }}+P_{\text {ext }, t}^{\text {final }}}{2}\right]-\left[\frac{P_{\text {ext }, b}^{\text {inicial }}+P_{\text {ext }, t}^{\text {inicial }}}{2}\right]
\end{aligned}
$$

tal que os índices $b$ e $t$ designam o valores medidos na base e no topo do trecho, respectivamente.

A força em virtude do efeito ballooning é obtida combinando-se as Eqs. (5.39) e (5.9), o que resulta em:

$$
\Delta L_{B}=-\Delta L_{F} \quad \therefore \Delta F_{B}=\sum_{j}\left[\frac{2 v L_{j}}{E_{j} A_{j}}\left(\Delta P_{\text {int }, j} A_{\text {int }, j}-\Delta P_{\text {ext }, j} A_{\text {ext }, j}\right)\right] \cdot\left(\sum_{i} \frac{L_{i}}{E_{i} A_{i}}\right)^{-1}
$$

onde o índice $j$ provém da discretização adotada para cálculo do efeito ballooning, enquanto $i$ corresponde ao número de segmentos da coluna de revestimento com seções transversais distintas. 


\section{$\underline{\text { Trecho Cimentado }}$}

No trecho cimentado, a variação de pressão no anular é nula, uma vez que se admite isolamento hidráulico devido à operação de cimentação. Desta forma, a elongação proveniente do efeito ballooning para um trecho de comprimento $d x$ e propriedades constantes simplifica-se para:

$$
\Delta L_{B}=\frac{-2 v d x}{E A}\left(\Delta P_{i n t} \cdot A_{\text {int }}\right)
$$

tal que a variação de pressão no interior do tubular, $\Delta P_{i n t}$, corresponde à própria variação de pressão do ponto considerado, pois o comprimento é tomado com seu limite tendendo a zero.

Impondo a condição de deslocamento nulo no trecho, obtém-se:

$$
\Delta L_{B}=-\Delta L_{F} \quad \therefore \frac{-2 v d x}{E A}\left(\Delta P_{\text {int }} \cdot A_{\text {int }}\right)=-\frac{\Delta F_{B} d x}{E A}
$$

Por fim, isolando $\Delta F$ na equação acima, a variação na força axial do trecho resulta:

$$
\Delta F_{B}=2 v \cdot \Delta P_{\text {int }} \cdot A_{\text {int }}
$$

\subsection{Esforços axiais efetivos}

Nas seções anteriores explicou-se a metodologia para cálculo da variação de esforços axiais provocada por cada um dos efeitos em separado (termperatuda, efeito pistão e ballooning). Isso posto, os esforços axiais efetivos podem ser obtidos somando-se a parcela referente à condição inicial aos esforços axiais decorrentes destes efeitos. A Figura 5.9, a seguir, ilustra esquematicamente este procedimento.

Figura 5.9 - Determinação do diagrama de esforços axiais efetivos.

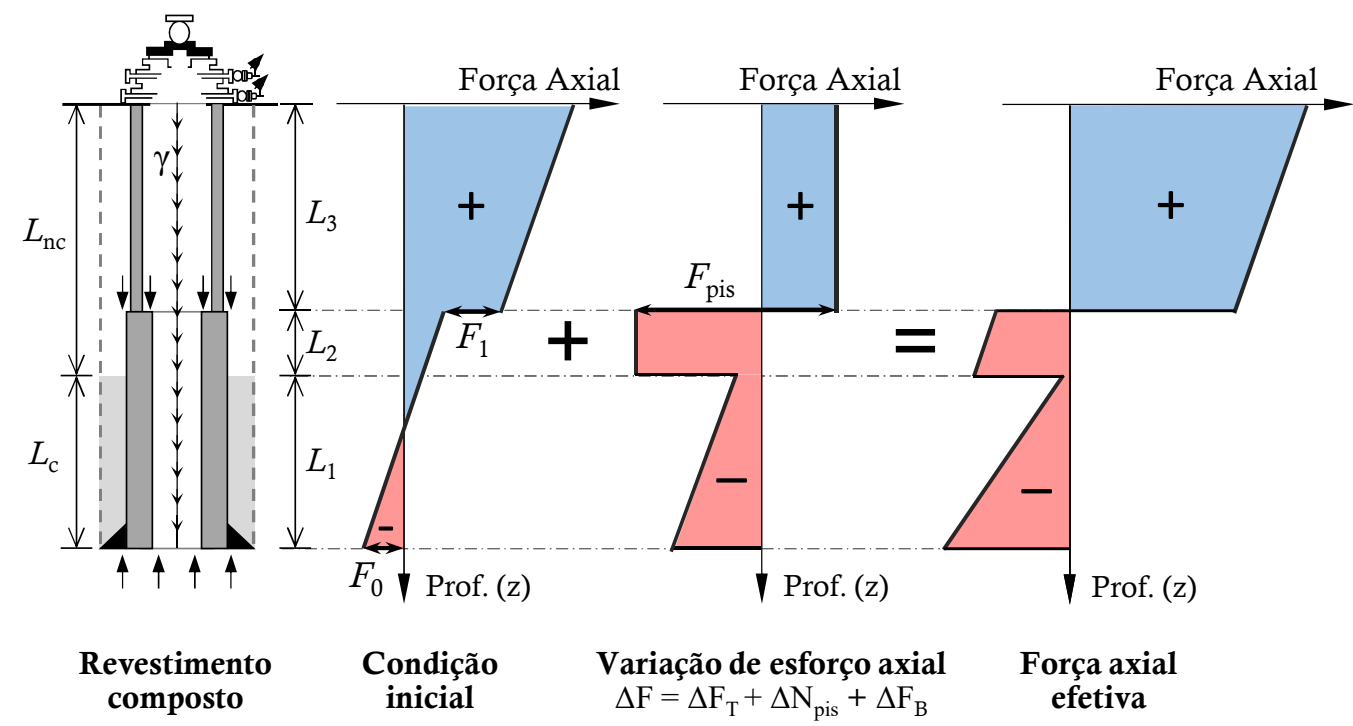

Fonte: Adaptado de (SOUZA, 2015). 


\subsection{Outras fontes de esforços axiais}

Além das forças axiais listadas, tensões induzidas pela flexão do corpo do tubo, cargas de impacto e forças de arraste podem provocar esforços axiais adicionais, de especial importância para poços direcionais. A seguir, estes carregamentos são abordados apenas de maneira superficial. Para maiores informações a respeito do tema, recomenda-se a leitura dos trabalhos de Rahman e Chilingarian (1995) e Byrom (2015).

\subsubsection{Tensão axial de flexão}

O revestimento é sujeito a tensões axiais de flexão quando executado em poços inclinados ou horizontais. Na prática, a taxa de inclinação do poço (dogleg severity) costuma ser expressa por meio do ângulo, em graus, para cada $100 \mathrm{ft}$ (30 m) de extensão do poço (SCHLUMBERGER, 2019). Por questões operacionais, esta taxa deve ser limitada a $3^{\circ} / 100 \mathrm{ft}$ (SOUZA, 2015). Esta limitação operacional deve-se aos requisitos para descida do tubo de produção (completação) do poço.

Como resultado da mudança de declividade do poço, parte da seção transversal do tubo é tracionada e se alonga, enquanto parte é comprimida e sofre encurtamento. O plano que delimita estas duas regiões não apresenta mudança de comprimento, sendo denominado superfície neutra. A deformação do revestimento induz tensões axiais internas, que podem ser determinadas segundo a teoria clássica de vigas de Euler-Bernulli. Para o equacionamento apresentado a seguir, considere o esquema representado na Figura 5.10.

Figura 5.10 - Tensões axiais de flexão.
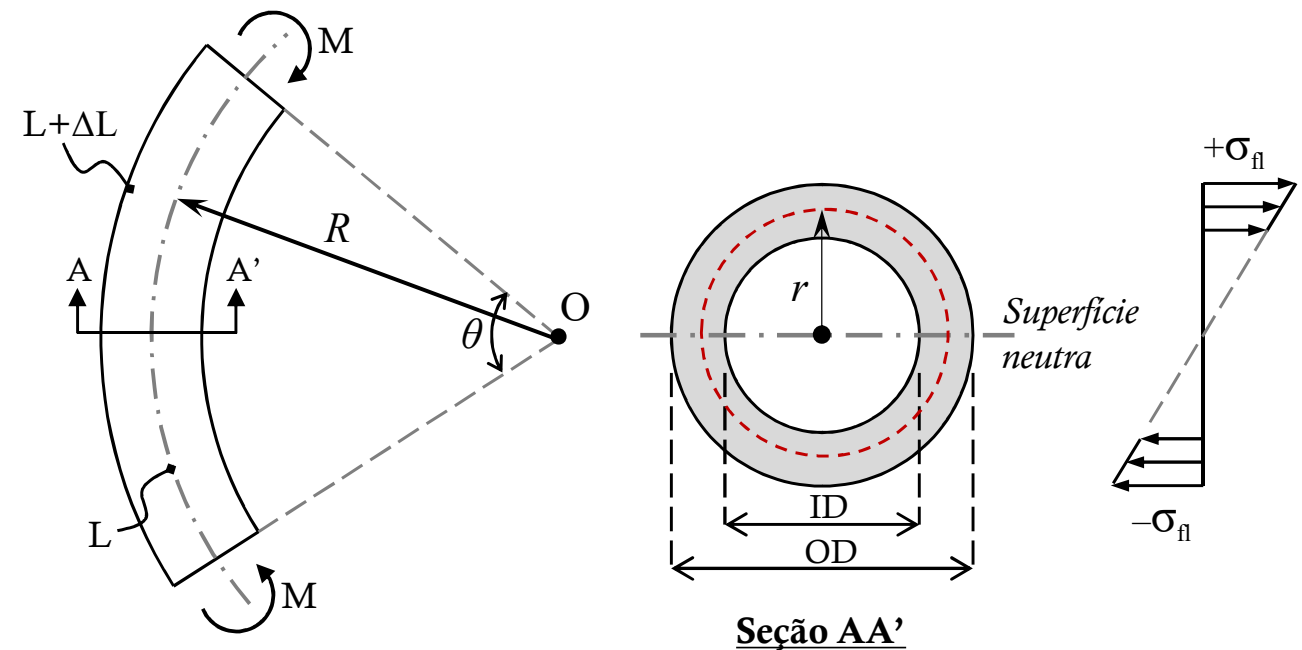

Seção AA'

Para uma trajetória inclinada com raio de curvatura $R$, um tubular de comprimento $L$, compreendido por um ângulo $\theta$ a partir do centro de curvatura (ponto $\mathrm{O}$ ), apresenta a seguinte deformação específica numa seção $A A^{\prime}$ genérica:

$$
\varepsilon_{f l}=\frac{\Delta L}{L}=\frac{(R+r) \cdot \theta-R \cdot \theta}{R \cdot \theta}=\frac{r}{R}
$$


tal que $r$ mede a distância entre o ponto analisado e a superfície neutra (ID/2 $\leq r \leq \mathrm{OD} / 2$ ). Aplicando a Lei de Hooke, a tensão interna no ponto resulta:

$$
\sigma_{f l}=E \varepsilon_{f l} \quad \therefore \quad \sigma_{f l}=E \cdot \frac{r}{R}
$$

Com base na equação anterior, observa-se que as tensões máximas de tração e compressão ocorrem na parede externa do tubo $(r= \pm \mathrm{OD} / 2)$. Porém, para verificação da resistência de tubulares, é de interesse o cálculo das tensões axiais de flexão na parede interna do revestimento, de modo que basta fazer $r= \pm \mathrm{ID} / 2$.

\subsubsection{Carga de impacto}

Durante a sua instalação, o revestimento fica sujeito a carregamentos compressivos relacionados à sua desaceleração devido ao travamento da coluna por cunhas. Ao contrário do peso suspenso do tubo e das tensões de flexão, as cargas de impacto atuam somente em regiões localizadas da coluna e por um curto período de tempo. Entretanto, os efeitos combinados da carga de impacto, peso suspenso e força de flexão podem levar à ruptura do tubo, de modo que recomenda-se a análise específica dos pontos de fixação e travamento da coluna de revestimento.

\subsubsection{Força de arraste}

Colunas de revestimento são usualmente alternadas ou rotacionadas no sentido axial durante operações de assentamento e cimentação, o que resulta em um carregamento axial adicional devido ao atrito mecânico entre o tubo e a parede do poço. Esta força, denominada força de arraste, é geralmente expressa como uma fração do peso flutuante do revestimento, $P_{n e t}$, tal que:

$$
F_{\text {drag }}=-\alpha_{\text {drag }} \cdot\left\|P_{\text {net }}\right\|
$$

onde $F_{d r a g}$ é a força de arraste, cujo sentido é oposto ao da movimentação da coluna, e $\alpha_{d r a g}$ é fator de atrito da parede do poço, cujo valor depende da geometria e das irregularidades do poço, além da lubrificação provida pelo fluido de perfuração (API, 2013). 


\section{Dimensionamento de Revestimentos}

Após terem sido esclarecidos os princípios que norteiam o projeto de poços, partindo da definição do número de fases rumo ao levantamento dos piores casos de carregamento aplicáveis a cada coluna de revestimentos, será investigado o processo de dimensionamento em si. Em geral, o dimensionamento dos revestimentos segue um procedimento determinístico no qual fatores de segurança são utilizados para levar em conta as incertezas inerentes aos carregamentos, às tolerâncias de fabricação, à resistência dos tubulares e aos modelos de cálculo. São aplicados sobre os valores nominais das ações (pressões de colapso, ruptura e tensões axiais), sendo então comparados com a resistência de determinada classe de tubular.

Os fatores de segurança aplicados variam conforme o operador e estão fortemente baseados na experiência e em práticas de sucesso. Valores usuais na indústria para o projeto de poços são apresentados na Tabela 6.1 .

Tabela 6.1 - Fatores de segurança usuais no campo de petróleo.

\begin{tabular}{|c|c|c|}
\hline Colapso & Ruptura & Tração \\
\hline 1.0 a 1.125 & 1.0 a 1.35 & 1.6 a 2.0 \\
\hline
\end{tabular}

Fonte: Byrom (2015).

Na ocorrência de colapso, o principal risco envolvido consiste na perda de uma seção do poço, enquanto a eventual ruptura do revestimento apresenta risco em potencial à vidas humanas. Por este motivo, o segundo modo de falha apresenta mais altos fatores de segurança em relação ao primeiro. A falha do revestimento por tração, por sua vez, tem como consequência apenas a queda da coluna de revestimento, porém o mais alto fator de segurança está relacionado à variabilidade da força de aperto das conexões (KING, 1998). A seguir, a Figura 6.1 ilustra a manifestação física dos modos de falha por colapso e por ruptura.

Figura 6.1 - Modos de falha de revestimentos.

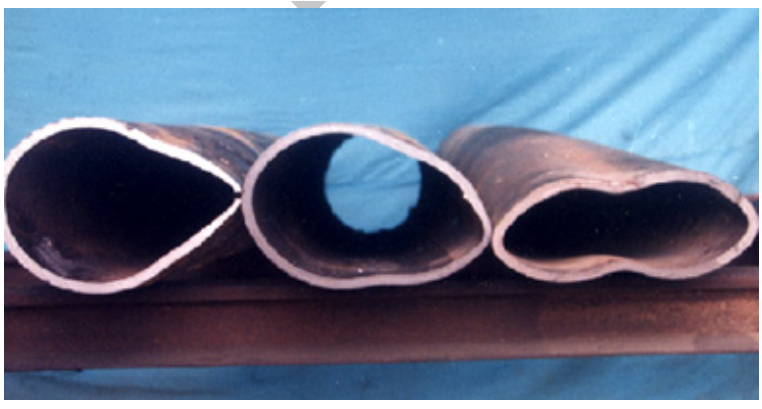

(a) Colapso (LIU et al., 2014).

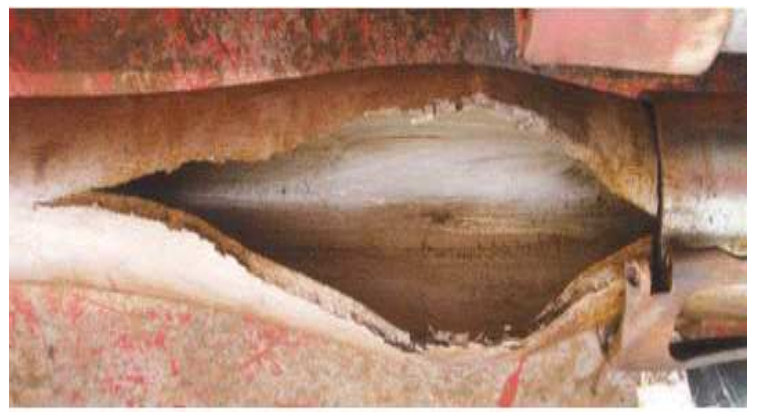

(b) Ruptura (SUN et al., 2012).

Após majorar o valor das ações, os tubulares devem ser dimensionados de modo a apresentar resistência suficiente para atender com segurança a todos os critérios de resistência 
(também denominados critérios de falha). A seleção dos revestimentos é feita por projetistas com base nos valores de resistência publicados no Boletim API Bull 5C2 (API, 1999). Tal documento é essencialmente uma coleção de tabelas em que estão listadas as resistências de vários tamanhos e classes de revestimento padronizados, calculadas com base nas fórmulas do API Bull 5C3 (API, 1994).

Apesar de terem sido utilizadas por muitos anos com resultados satisfatórios, as equações do API Bull 5C3 permaneceram inalteradas desde sua primeira edição, em 1968. Devido aos avanços significativos na fabricação de $\mathrm{OCTG}^{1}$, a comunidade de projetistas de poços reconheceu a necessidade de revisar as equações de dimensionamento. Um grupo de especialistas do API/ISO foi incumbido desta missão, que resultou nas novas diretrizes publicadas nas normas gêmeas ISO/TR 10400:2007 e API TR 5C3:2008 (PAYNE; SIMPSON; LIVESAY, 2004).

\subsection{Modelos de resistência da norma ISO/TR 10400}

A norma ISO TR 10400:2011 é o instrumento normativo no qual estão reunidas as mais atuais recomendações a respeito do dimensionamento de tubulares utilizados em poços. Em seus anexos, apresenta um amplo estudo estatístico sobre a qualidade de modelos de previsão da resistência à ruptura e ao colapso de OCTG. Para isso, utiliza-se de uma variável denominada erro de modelo $\left(M_{E}\right)$ :

$$
M_{E}=\frac{p_{\text {exp }}}{p_{R}}
$$

onde $p_{R}$ é a pressão resistente segundo o modelo de cálculo (ruptura ou colapso), e $p_{\text {exp }}$ é a pressão resistente observada experimentalmente.

Como não existe modelo perfeito, a variável $M_{E}$ é, por natureza, uma variável aleatória, sendo caraterizada por um valor médio, uma variância e uma distribuição de probabilidades. Um modelo é dito não tendencioso quando a média de seu erro é unitária e considerado preciso quando, além de média próxima da unidade, possui variância aproximadamente nula. Em se tratando de modelos de resistência, uma média maior que a unidade representa um modelo conservador.

Em seu anexo B, a norma ISO 10400:2011 apresenta um estudo da qualidade de seis modelos para previsão da pressão de ruptura de tubulares: ad-hoc Barlow, ad-hoc von Mises, Klever-Stewart, ad-hoc Paslay, ad-hoc Moore e Nadai. O estudo é baseado na comparação entre resultados experimentais e resultados de previsão dos modelos para o caso de ruptura de tubos fechados (capped-end condition) sob ação exclusiva de pressão interna.

Amostras da variável aleatória erro de modelo são obtidas para cada resultado experimental conhecido. Apresentam-se os dados relativos a 106 testes de ruptura, fornecidos por três fabricantes industriais. Os resultados mostram que, dentre todos os modelos considerados, o de Klever e Stewart (1998) é o mais preciso (média de 1,004 e C.V. de 4,7\%) para todo o conjunto

1 A sigla OCTG (Oil Country Tubular Goods) refere-se a todos os tubulares, revestimentos e tubos de perfuração fabricados de acordo com a Especificação API 5CT (API, 2006b). 
de dados analisado, sendo, portanto, recomendado para a previsão da pressão de ruptura de tubulares.

Procedimento semelhante é adotado para avaliar a qualidade de onze modelos para estimativa da pressão de colapso de tubulares. No anexo F da norma ISO 10400:2011 constam os resultados de cada conjunto de testes de ruptura conduzidos por diferentes empresas, totalizando mais de 3 mil ensaios. A análise realizada conclui que, dentre todos os modelos considerados, o de Klever e Tamano (2004) possui a melhor combinação entre uma média próxima da unidade e um coeficiente de variação próximo de zero (média de 0,9991 e C.V. de 6,7\%). Recomenda-se, portanto, sua adoção para a previsão da pressão de colapso de tubulares.

A seguir, os principais critérios de resistência de tubulares serão investigados: tração, colapso, ruptura e estado triaxial de tensões. Em virtude de sua importância histórica, cada seção trará a princípio as equações de projeto recomendadas pelo API Bull 5C3, seguidas dos novos critérios de resistência propostos pela norma ISO/TR 10400.

\subsection{Critério de resistência à tração}

A resistência à tração da coluna de revestimento é especificada tanto pelo API quanto pela ISO por meio de dois critérios: resistência ao escoamento do corpo do tubo e resistência da conexão.

A resistência ao escoamento do corpo do tubo equivale à força axial necessária para provocar o início do escoamento do material na ausência de pressão interna e externa, flexão e torção. É expressa em função da tensão de escoamento mínima do material, $\sigma_{y}$, e da área líquida da seção transversal, $A$ :

$$
N_{t R}=\sigma_{y} \cdot A=\sigma_{y} \cdot \frac{\pi\left(O D^{2}-I D^{2}\right)}{4}
$$

onde $N_{t R}$ é o máximo esforço normal de tração resistido pelo tubular.

A resistência da conexão, por sua vez, corresponde à mínima força de tração capaz de provocar a sua falha. É calculada por meio de fórmulas de caráter semi-empírico, que dependem do tipo específico de acoplamento, da tensão de escoamento e/ou da tensão última do aço, do passo da rosca, do número de passos na conexão, etc. As equações para o cálculo da resistência de conexões podem ser consultadas em ambas as normas API 5C3 e ISO/TR 10400. Elas não serão aqui reproduzidas pois, em geral, costuma-se utilizar os valores de resistência publicados pelos próprios fabricantes das conexões.

\subsection{Critério de resistência à ruptura}

A resistência à ruptura de um revestimento é definida pelo API como sendo a mínima pressão interna que provoca o escoamento da parede interna do tubular. $\mathrm{O}$ cálculo do valor nominal da pressão de ruptura é baseado na fórmula de Barlow para tubos de paredes finas 
$(O D / t>20)$, obtida a partir da teoria de membranas para reservatórios cilíndricos:

$$
P_{i R, \mathrm{API}}=2 \sigma_{y} \cdot \frac{0,875 t}{O D}
$$

sendo $P_{i R, \mathrm{API}}$ a máxima pressão interna resistida pelo tubular, segundo determinação do API 5C3. O fator de 0,875 considera uma tolerância de fabricação de $-12,5 \%$ sobre a espessura nominal da parede do revestimento, conforme as especificações API 5C2 e ISO 11960.

Este critério de resistência é útil para o pré-dimensionamento do revestimento, porém é baseado em hipóteses simplificadoras que conduzem a um projeto excessivamente conservador. Descreve matematicamente o início da deformação plástica do corpo do tubo e não a perda de integridade em si, havendo, portanto, uma parcela adicional de resistência não aproveitada. Fisicamente, tal diferença se dá em virtude do encruamento do aço, que faz com que a tensão última suportada pelo material seja ligeiramente maior que sua tensão de escoamento.

Por fim, uma grave limitação da fórmula recomendada pelo API é que ela considera exclusivamente a solicitação do revestimento por pressões internas. Enquanto as pressões externas podem ser consideradas indiretamente por meio da pressão diferencial atuante $\left(\Delta p=p_{i}-p_{e}>0\right)$, sob tensões axiais a Eq. (6.3) deixa de ser válida.

\subsubsection{Critério de ruptura dúctil - ISO/TR 10400}

Equações de resistência à pressão interna se diferenciam entre escoamento e ruptura do corpo do tubular. O API Bull 5C3 trata do primeiro caso, em que a falha do tubular não é precisamente representada. No segundo caso, há distinção entre o comportamento frágil ou dúctil do material.

A ruptura dúctil, caso no qual o modelo de Klever e Stewart (1998) se aplica, é tipificada pela falha do tubo dentro do intervalo de deformações plásticas. Ou seja, o tubo entra em colapso devido ao desenvolvimento de deformações plásticas e não ao aparecimento e propagação de trincas. Isto é uma característica de tubos com tenacidade adequada ao ambiente a que será exposto.

As equações para ruptura dúctil dependem de vários fatores (STEWART; KLEVER, 1998): da mínima espessura real da parede do tubo e de seu diâmetro externo; da tenacidade à fratura do material; do encruamento do material; da resistência última à tração do tubo; e da máxima profundidade de imperfeições que tenha uma probabilidade razoável de não ser detectada durante o processo de inspeção. A tensão de escoamento do material não está diretamente relacionada à pressão de ruptura dúctil, exceto por meio da correlação com o parâmetro de encruamento $n$.

As equações de Klever-Stewart, recomendadas pela norma ISO/TR 10400, derivam da mecânica do equilíbrio de reservatórios cilíndricos, em combinação com um modelo de plasticidade do material e um modelo para quantificar o efeito de imperfeições. A fórmula primária de ruptura dúctil admite a condição de vaso de pressão cilíndrico com extremidades fechadas, de maneira que a pressão interna atuante nas extremidades do vaso induz tensão axial 
no material. Este é um caso particular de uma situação mais geral em que um tubo pode estar sujeito a ação simultânea de pressão externa e esforço axial de tração ou compressão arbitrários. Na prática, a condição de extremidades fechadas raramente é observada em revestimentos, exceto no final da cimentação quando aplica-se a sobrepressão de plug-bump. Durante a maior parte de sua vida útil, o revestimento encontra-se biengastado devido à cimentação (BYROM, 2015).

Isto posto, o critério de ruptura dúctil da norma ISO para projeto de tubulares na condição de extremidades fechadas é:

$$
P_{i R}=2 k_{d r} f_{u} \cdot\left(\frac{t_{d r}}{O D-t_{d r}}\right)
$$

com

$$
t_{d r}=t_{\min }-k_{a} \delta_{\text {ins }}
$$

onde:

$P_{i R}:$ pressão interna de ruptura dútil;

$f_{u}$ : resistência última à tração do material;

$t_{\min }$ : espessura mínima da parede;

$k_{d r}, k_{a}:$ fatores de correção, dados por:

$$
\begin{aligned}
k_{d r} & =\left(\frac{1}{2}\right)^{n+1}+\left(\frac{1}{\sqrt{3}}\right)^{n+1} \\
k_{a} & =\left\{\begin{array}{l}
1,0 \text { para aços Q\&T ou } 13 \mathrm{Cr} \\
2,0 \text { para os demais casos (valor padrão) }
\end{array}\right.
\end{aligned}
$$

$\delta_{\text {ins }}$ : máxima profundidade de uma fissura não detectada durante o processo de inspeção;

$n$ : coeficiente de encruamento da curva real de tensão/deformação obtido a partir de ensaio uniaxial de tração.

A Eq. (6.4) é uma equação de estado limite que prediz a ruptura de um lote cujos dados amostrais de espessura mínima $t_{\min }$ e resistência última $f_{u}$ foram obtidos por meio de ensaios, mas que pode também ser aplicada para o projeto determinístico de revestimentos. Neste último caso, a norma ISO/TR 10400 determina a adoção do valor mínimo da tensão última do aço $\left(f_{u} m n\right)$ em lugar de $f_{u}$ e a substituição da espessura mínima do revestimento $\left(t_{\min }\right)$ pela relação $k_{\text {wall }} t$, onde $k_{\text {wall }}$ é o fator que incorpora a tolerância de fabricação especificada da parede do tubo (sendo igual a 0,875 para uma tolerância de $-12,5 \%$, por exemplo) e $t$ é a espessura nominal do corpo do tubo.

Um segundo critério de ruptura é estabelecido para uma situação mais geral, na qual o tubo pode atingir um valor máximo de pressão interna, enquanto sujeito à ação simultânea de pressão externa e carregamento axial arbitrários. Sua formulação é governada pelas equações das superfícies de escoamento de von Mises e de Tresca, sendo expressa por:

$$
P_{i R, \mathrm{KS}}=P_{\text {ext }}+\min \left[\left(p_{M}+p_{\text {ref T }}\right) / 2, p_{M}\right]
$$


com:

$$
\begin{aligned}
& p_{M}=p_{\text {ref M }} \cdot \sqrt{1-k_{R}\left(F_{\text {ef }} / F_{\mathrm{u}}\right)^{2}} \\
& F_{\text {ef }}=F_{a}+P_{\text {ext }} A-p_{M} A \cdot \frac{\left(O D-2 t_{d r}\right)^{2}}{4 t_{d r}\left(O D-t_{d r}\right)} \\
& F_{a}=\sigma_{a} A \\
& F_{\mathrm{u}}=f_{u} A \\
& p_{\mathrm{u}}=2 f_{u} \cdot\left(\frac{t_{d r}}{O D-t_{d r}}\right) \\
& p_{\text {ref }}=\frac{p_{\text {ref M }}+p_{\text {ref T }}}{2} \\
& p_{\text {ref M }}=p_{\mathrm{u}} \cdot\left(\frac{1}{2}\right)^{n} \cdot\left(\frac{2}{\sqrt{3}}\right)^{n+1} \\
& p_{\text {ref T }}=p_{\mathrm{u}} \cdot\left(\frac{1}{2}\right)^{n} \\
& k_{R}=\frac{4^{(1-n)}-1}{3^{(1-n)}}
\end{aligned}
$$

onde $P_{i R, \mathrm{KS}}$ é a pressão interna máxima resistida pelo tubular segundo o critério geral de KleverStewart e $F_{\text {ef }}$ é a força axial efetiva que se desenvolve no tubular, cujo valor é zero para o caso de extremidades fechadas, reduzindo a Eq. (6.6) à Eq. (6.4).

Se a força axial efetiva for não nula, a pressão diferencial $p_{M}$ não pode ser calculada

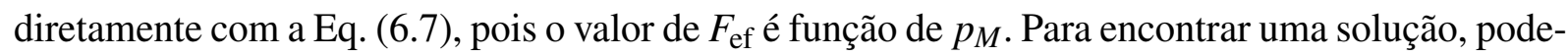
se reescrevê-la como uma equação quadrática em termos da variável $p_{M}$. Para isso, inicialmente eleva-se ambos os lados da Eq. (6.7) ao quadrado e isola-se $F_{\text {ef }}$, tal que:

$$
\frac{p_{M}^{2}}{p_{\text {ref M }}^{2}}=1-k_{R}\left(\frac{F_{\text {ef }}}{F_{\mathrm{u}}}\right)^{2} \quad \therefore \quad\left(1-\frac{p_{M}^{2}}{p_{\text {ref M }}^{2}}\right) \cdot \frac{F_{\mathrm{u}}^{2}}{k_{R}}=F_{\text {ef }}^{2}
$$

Efetuando a seguinte troca de variáveis na Eq. (6.8):

$$
K_{a u x}=\frac{\left(O D-2 t_{d r}\right)^{2}}{4 t_{d r}\left(O D-t_{d r}\right)}
$$

e substituindo a Eq. (6.8) na Eq. (6.9), temos:

$$
\frac{F_{\mathrm{u}}^{2}}{k_{R}}-\frac{F_{\mathrm{u}}^{2}}{k_{R} p_{\text {ref M }}^{2}} \cdot p_{M}^{2}=\left(F_{a}+P_{\text {ext }} A-p_{M} A \cdot K_{\text {aux }}\right)^{2}
$$

Desenvolvendo a equação anterior e agrupando os termos constantes, lineares e quadráti$\cos$ de $p_{M}$, a expressão simplifica-se para:

$$
\begin{aligned}
p_{M}^{2}\left(A^{2} K_{\text {aux }}^{2}+\frac{F_{\mathrm{u}}^{2}}{k_{R} p_{\text {ref M }}^{2}}\right)+ & p_{M}\left(-2 F_{a} A K_{\text {aux }}-2 P_{\text {ext }} A^{2} K_{\text {aux }}\right)+ \\
+ & \left(F_{a}^{2}+P_{\text {ext }}^{2} A^{2}+2 F_{a} P_{\text {ext }} A-F_{\mathrm{u}}^{2} / k_{R}\right)=0
\end{aligned}
$$


Denominando por $a_{1}, b_{1}$ e $c_{1}$ os coeficientes da Eq. (6.12) e aplicando a regra de Bháskara, encontramos as possíveis raízes para $p_{M}$ :

$$
p_{M}=\frac{-b_{1} \pm \sqrt{b_{1}^{2}-4 a_{1} c_{1}}}{2 a_{1}}
$$

Dentre as possíveis soluções para a Eq. (6.13), deve ser adotada a solução de valor positivo que resulta da adição da raiz do discriminante da fórmula de Bháskara. Valores negativos de $p_{M}$, ainda que possíveis matematicamente, representariam fisicamente que o tubo está sujeito a uma pressão de colapso ao invés de ruptura, violando as hipóteses básicas do modelo de Klever-Stewart.

Por fim, destaca-se que a ruptura será o mecanismo predominante de falha somente se a tensão axial não for muito grande. Para tensões axiais elevadas e pressões internas pequenas, um fenômeno de estricção e separação axial do tubo ocorre. Sendo assim, a Eq. (6.6) é valida desde que a seguinte condição seja respeitada:

$$
\frac{F_{\mathrm{ef}}}{F_{\mathrm{u}}} \leq \frac{3}{2} \frac{\left(P_{i n t}-P_{\text {ext }}\right)}{p_{\mathrm{u}}}
$$

Além disso, para valores negativos da força axial (compressão), o tubo pode sofrer flambagem como uma coluna, dependendo de como o mesmo está apoiado lateralmente. Se a flambagem for adequadamente suprimida, então a equação de ruptura sob carregamentos combinados permanece válida. Entretanto, para altos valores de compressão axial efetiva, o mecanismo predominante de falha passa a ser o fenômeno de flambagem localizada da parede do tubo.

\subsection{Critério de resistência ao colapso}

Admitindo um comportamento elasto-plástico perfeito para o aço, a resistência de revestimentos ao colapso pode ser calculada de acordo com as fórmulas publicadas no API Bull 5C3 para dois modos de falha principais: colapso plástico e colapso elástico. A manifestação física de um ou outro modo de falha depende da razão entre o diâmetro externo e a espessura da parede do revestimento, $O D / t$, da tensão de escoamento do material e do nível de tensão axial a que está submetido.

Revestimentos de paredes finas $(O D / t>20)$ e alta resistência atingem o valor crítico de colapso para tensões internas inferiores à tensão de escoamento do material. A falha é causada por deformações puramente elásticas e resulta na ovalização do tubo. A capacidade resistente deste tipo de revestimento é limitada pela ocorrência de flambagem localizada, como no caso de estruturas muito esbeltas sob compressão.

O colapso plástico, por outro lado, ocorre assim que o material começa a escoar sob ação da pressão externa, sendo observado em revestimentos espessos de baixa resistência. Neste caso, o mecanismo de colapso é idealmente plástico e a falha ocorre no chamado "patamar de escoamento". É idealizado por meio de dois critérios de resistência distintos, vistos a seguir. 


\subsubsection{Colapso Plástico: equação de Lamé}

Pressões externas podem induzir tensões tangenciais superiores à tensão de escoamento do material na parede interna de revestimentos espessos, desencadeando sua falha. Logo, o API estabelece um primeiro critério de resistência ao colapso plástico com base na equação de Lamé expresso por:

$$
P_{\mathrm{p}, \mathrm{L}}=2 f_{\mathrm{ym}} \frac{(O D / t)-1}{(O D / t)^{2}}
$$

tal que $f_{\text {ym }}$ representa a tensão de escoamento modificada do material, que serve de artifício para a consideração indireta das tensões axiais às quais o revestimento está solicitado. Seu valor é baseado na teoria plana da máxima energia de distorção de Hencky-von Mises, sendo expresso por:

$$
f_{\mathrm{ym}}=f_{y}\left[1-\frac{3}{4}\left(\frac{\sigma_{a}+P_{i n t}}{f_{y}}\right)^{2}\right]^{1 / 2}-\frac{\sigma_{a}+P_{i n t}}{2}
$$

onde:

$\sigma_{a}$ : tensão axial solicitante (positiva para tração);

$f_{y}$ : tensão de escoamento do tubo.

\subsubsection{Colapso Plástico: equação empírica}

Um segundo critério para estimativa da pressão de colapso plástico foi estabelecido com base em uma análise de regressão estatística dos resultados de quase 2500 testes de colapso realizados em corpos de prova das classes K-55, N-80 e P-110. A fórmula baseia-se na concepção de que há uma probabilidade de $95 \%$ de que a pressão de colapso suportada pelo revestimento excederá o valor mínimo declarado com não mais de 0,5\% de falhas (API, 1994):

$$
P_{\mathrm{p}, \mathrm{E}}=f_{\mathrm{ym}}\left[\frac{A_{c}}{O D / t}-B_{c}\right]-C_{c}
$$

tal que os valores dos parâmetros $A_{c}, B_{c}$ e $C_{c}$ são dados em função da tensão de escoamento do material, a fim de permitir a aplicação da Eq. (6.17) a classes de aço distintas àquelas originalmente ensaiadas.

\subsubsection{Colapso Elástico}

O critério de resistência ao colapso elástico, $P_{\mathrm{el}}$, de revestimentos de parede fina é expresso em função da razão $O D / t$, do módulo de Young e do coeficiente de Poisson do material. Foi originalmente proposto por Clinedinst (1939 apud RAHMAN; CHILINGARIAN, 1995), sendo expresso por:

$$
P_{\mathrm{el}}=\frac{2 E}{1-v^{2}} \frac{1}{(O D / t) \cdot[(O D / t)-1]^{2}}
$$


A fórmula para projeto recomendada pelo API introduz um fator de correção na Eq. (6.18) que diminui o valor da pressão externa para 71,25\% do valor teórico calculado. Para valores do módulo de Young $E=30 \cdot 10^{6} \mathrm{lbf} / \mathrm{in}^{2}$ e coeficiente de Poisson $v=0,3$, a resistência ao colapso elástico de tubulares é igual a:

$$
P_{\mathrm{el}, \mathrm{API}}=\frac{46,95 \cdot 10^{6}}{(O D / t) \cdot[(O D / t)-1]^{2}} \quad[\mathrm{em} \mathrm{psi}]
$$

\subsubsection{Colapso no domínio de transição elasto-plástico}

As curvas que representam os critérios de colapso plástico se cruzam à medida que o valor da razão $O D / t$ do revestimento é acrescido - Eqs. (6.15) e (6.17). No entanto, a equação empírica de colapso plástico não chega jamais a interceptar a curva de mínima pressão de colapso elástico, independentemente de qual for a razão $O D / t$ utilizada. Isto impossibilita representar de maneira satisfatória o comportamento de revestimentos com média resistência e esbeltez intermediária. Este problema de descontinuidade foi matematicamente resolvido por meio de um domínio de transição elasto-plástico artificial. A determinação da resistência ao colapso neste intervalo é realizada por meio da seguinte equação:

$$
P_{\text {tran }}=f_{\text {ym }}\left[\frac{F_{c}}{O D / t}-G_{c}\right]
$$

tal que a aplicação da Eq. (6.20) é limitada ao seguinte intervalo de valores da razão $O D / t$ :

$$
\frac{f_{\mathrm{ym}}\left(A_{c}-F_{c}\right)}{C_{c}+f_{\mathrm{ym}}\left(B_{c}-G_{c}\right)} \leq \frac{O D}{t} \leq \frac{2+B_{c} / A_{c}}{3 B_{c} / A_{c}}
$$

\subsubsection{Efeito da pressão interna}

Caso o revestimento esteja sujeito a ação simultânea de pressões internas e externas, o API Bull 5C3 determina que o efeito da pressão interna seja considerado por meio de um diferencial de pressão de colapso, $\Delta P_{c o l}$, com valor igual a:

$$
\Delta P_{c o l}=P_{\text {ext }}-P_{\text {int }} \cdot\left(\frac{I D}{O D}\right)
$$

\subsubsection{Equações de colapso - API Bull 5C3}

A Tabela 6.2 a seguir reúne o conjunto de equações para previsão do colapso de revestimentos e o domínio para o qual são válidas, segundo as recomendações do API Bull 5C3. Deve-se ter atenção ao fato de que estas equações não são aplicáveis para valores de tensão de escoamento modificada $\left(f_{\mathrm{ym}}\right)$ inferiores a $24 \mathrm{ksi}(165 \mathrm{MPa})$. 
Tabela 6.2 - Critérios de resistência ao colapso do API (1994).

\begin{tabular}{lc}
\hline Mecanismo de falha & Intervalo $O D / t$ aplicável \\
\hline 1. Colapso Plástico: equação de Lamé & $\quad \frac{O D}{t} \leq\left[\frac{\left[\left(A_{c}-2\right)^{2}+8\left(B_{c}+C_{c} / f_{\mathrm{ym}}\right)\right]^{1 / 2}+\left(A_{c}-2\right)}{2\left(B_{c}+C_{c} / f_{\mathrm{ym}}\right)}\right]$
\end{tabular}

2. Colapso Plástico: equação empírica

$$
P_{\mathrm{p}, \mathrm{E}}=f_{\mathrm{ym}}\left[\frac{A_{c}}{O D / t}-B_{c}\right]-C_{c}
$$

$$
\begin{array}{r}
{\left[\frac{\left[\left(A_{c}-2\right)^{2}+8\left(B_{c}+C_{c} / f_{\mathrm{ym}}\right)\right]^{1 / 2}+\left(A_{c}-2\right)}{2\left(B_{c}+C_{c} / f_{\mathrm{ym}}\right)}\right] \leq} \\
\leq \frac{O D}{t} \leq \frac{f_{\mathrm{ym}}\left(A_{c}-F_{c}\right)}{C_{c}+f_{\mathrm{ym}}\left(B_{c}-G_{c}\right)}
\end{array}
$$

3. Colapso: transição elasto-plástica

$$
P_{\text {tran }}=f_{\mathrm{ym}}\left[\frac{F_{c}}{O D / t}-G_{c}\right]
$$

$$
\frac{f_{\mathrm{ym}}\left(A_{c}-F_{c}\right)}{C_{c}+f_{\mathrm{ym}}\left(B_{c}-G_{c}\right)} \leq \frac{O D}{t} \leq \frac{2+B_{c} / A_{c}}{3 B_{c} / A_{c}}
$$

4. Colapso elástico

$$
P_{\mathrm{el}}=0,7125 \frac{2 E}{1-v^{2}} \frac{1}{(O D / t) \cdot[(O D / t)-1]^{2}} \quad \frac{O D}{t} \geq \frac{2+B_{c} / A_{c}}{3 B_{c} / A_{c}}
$$

Como a maioria das fórmulas do API estão escritas em unidades USC com dimensões em polegadas e tensões em psi, as constantes $A_{c}, B_{c}, C_{c}, F_{c}$ e $G_{c}$ devem ser calculadas por meio das Equações (6.24) a (6.27).

$$
\begin{aligned}
A_{c}= & 2,8762+0,10679 \cdot 10^{-5} f_{\mathrm{ym}}+0,21301 \cdot 10^{-10} f_{\mathrm{ym}}^{2}-0,53132 \cdot 10^{-16} f_{\mathrm{ym}}^{3} \\
B_{c}= & 0,026233+0,50609 \cdot 10^{-6} f_{\mathrm{ym}} \\
C_{c}= & -465,93+0,030867 f_{\mathrm{ym}}-0,10483 \cdot 10^{-7} f_{\mathrm{ym}}^{2}+0,36989 \cdot 10^{-13} f_{\mathrm{ym}}^{3} \\
F_{c}= & \frac{46,95 \cdot 10^{6}\left(\frac{3 B_{c} / A_{c}}{2+B_{c} / A_{c}}\right)^{3}}{f_{\mathrm{ym}}\left(\frac{3 B_{c} / A_{c}}{2+B_{c} / A_{c}}-B_{c} / A_{c}\right)\left(1-\frac{3 B_{c} / A_{c}}{2+B_{c} / A_{c}}\right)^{2}} \\
G_{c}= & \left(F_{c} \cdot B_{c}\right) / A_{c}
\end{aligned}
$$

Para unidades SI, a tensão de escoamento é expressa em MPa e as dimensões em mm. As fórmulas de colapso e as equações que exprimem o intervalo $O D / t$ aplicável são as mesmas, porém as constantes devem ser calculadas a partir das seguintes fórmulas:

$$
\begin{aligned}
& A_{c}=2,8762+0,15489 \cdot 10^{-3} f_{\mathrm{ym}}+0,44809 \cdot 10^{-6} f_{\mathrm{ym}}^{2}-0,16211 \cdot 10^{-9} f_{\mathrm{ym}}^{3} \\
& B_{c}=0,026233+0,73402 \cdot 10^{-4} f_{\mathrm{ym}} \\
& C_{c}=-3,2125+0,030867 f_{\mathrm{ym}}-0,15204 \cdot 10^{-5} f_{\mathrm{ym}}^{2}+0,77810 \cdot 10^{-9} f_{\mathrm{ym}}^{3}
\end{aligned}
$$




$$
\begin{aligned}
& F_{c}=\frac{3,237 \cdot 10^{5}\left(\frac{3 B_{c} / A_{c}}{2+B_{c} / A_{c}}\right)^{3}}{f_{\mathrm{ym}}\left(\frac{3 B_{c} / A_{c}}{2+B_{c} / A_{c}}-B_{c} / A_{c}\right)\left(1-\frac{3 B_{c} / A_{c}}{2+B_{c} / A_{c}}\right)^{2}} \\
& G_{c}=\left(F_{c} \cdot B_{c}\right) / A_{c}
\end{aligned}
$$

\subsubsection{Critério de Klever-Tamano - ISO/TR 10400}

O modelo proposto por Klever e Tamano (2004), ao qual as equações de resistência ao colapso da norma ISO 10400:2011 fazem referência, consiste em uma generalização do modelo proposto anteriormente por Tamano, Mimaki e Yanagimoto (1985). Ele foi desenvolvido com base nos resultados de numerosos testes de colapso, além de análises teóricas e paramétricas, com o intuito de descrever a falha de tubos por colapso com um grau satisfatório de precisão por meio de equações aproximadas. Um objetivo adicional do modelo é abordar o efeito combinado de carregamentos, o que para poços muito profundos tem implicações econômicas significativas.

Assim como outros modelos disponíveis na literatura, o modelo de Klever-Tamano consiste em um conjunto de conceitos interligados:

- Uma equação de colapso elástico para tubos perfeitos, relevante para tubos de paredes finas;

- Uma equação de colapso plástico para tubos perfeitos, no qual ocorre escoamento ao longo de toda a parede do tubo, relevante para tubos de paredes muito espessas;

- Uma equação que fornece uma transição entre colapso elástico e colapso plástico, capaz de prever a resistência para todos os tamanhos, pesos e classes de tubos padronizados;

- Funções de minoração para incorporar a influência negativa de imperfeições, tais como ovalidade, formato da curva tensão-deformação, tensões residuais e excentricidade.

As equações apresentadas na norma ISO 10400:2011 são basicamente as mesmas apresentadas por Klever e Tamano (2004), exceto por alguns coeficientes de projeto introduzidos. A calibração destes coeficientes permite empregar o modelo tanto em análises de confiabilidade estrutural quanto no projeto determinístico de revestimentos. Neste último caso, os valores são ajustados de modo a estabelecer uma margem entre o valor real e o valor de cálculo da resistência ao colapso, assumindo, portanto, um papel semelhante ao de fatores parciais de segurança. Com este artifício, a norma ISO avança em direção ao projeto probabilístico de poços, sem no entanto deixar de cumprir com seu papel prescritivo.

A seguir, são apresentadas as equações de projeto e as equações de estado limite (adequadas a análises de confiabilidade) do modelo de Klever-Tamano.

\section{- Equação de projeto para carregamentos combinados}

Segundo o modelo de Klever-Tamano, a máxima pressão externa de colapso suportada pelo revestimento é dada por:

$$
P_{\text {ext,clp }}=\Delta P_{\text {des }}+P_{\text {int }}
$$


com

$$
\Delta P_{\mathrm{des}}=\frac{\left(P_{\mathrm{el}}+P_{\mathrm{y}}\right)-\sqrt{\left(P_{\mathrm{el}}-P_{\mathrm{y}}\right)^{2}+4 P_{\mathrm{el}} P_{\mathrm{y}} H_{\mathrm{t}, \mathrm{des}}}}{2\left(1-H_{\mathrm{t}, \mathrm{des}}\right)}
$$

tal que $P_{\mathrm{el}}$ representa a pressão de colapso elástico

$$
P_{\mathrm{el}}=k_{\mathrm{el}, \mathrm{des}} \frac{2 E}{\left(1-v^{2}\right)} \frac{1}{(O D / t) \cdot[(O D / t)-1]^{2}}
$$

enquanto $P_{\mathrm{y}}$ representa a pressão de colapso plástico, cujo valor é dado em função da pressão de escoamento segundo os critérios de von Mises, $P_{\mathrm{yM}}$, e de Tresca, $P_{\mathrm{yT}}$ :

$$
P_{\mathrm{y}}=\min \left\{\left(P_{\mathrm{yT}}+P_{\mathrm{yM}}\right) / 2 ; P_{\mathrm{yM}}\right\}
$$

A pressão de escoamento segundo o critério de Tresca vale:

$$
P_{\mathrm{yT}}=2 k_{\mathrm{y}, \mathrm{des}} f_{y}\left(\frac{t}{D-t}\right)
$$

Por sua vez, a pressão de escoamento de von Mises é calculada por:

$$
P_{\mathrm{yM}}=\frac{4}{\sqrt{3}} k_{\mathrm{y}, \mathrm{des}} f_{y}\left(\frac{t}{D-t}\right) \cdot \sqrt{1-\left(F_{\mathrm{ef}} / F_{y}\right)^{2}}=P_{\text {ext }}-P_{\text {int }}
$$

onde

$$
\begin{aligned}
& F_{\mathrm{ef}}=F_{a}+P_{\mathrm{ext}} A_{\mathrm{ext}}-P_{\mathrm{int}} A_{\mathrm{int}} \\
& F_{y}=k_{\mathrm{y}, \mathrm{des}} \cdot f_{y} A_{s}
\end{aligned}
$$

sendo o valor de $F_{\text {ef }}$ dado em função de $P_{\text {ext }}$, de modo que a Eq. (6.38) deve ser resolvida iterativamente.

Nas equações de projeto apresentadas, os coeficientes $k_{\mathrm{el} \text {,des }}$ e $k_{\mathrm{y} \text {,des }}$ possuem valores tabelados de acordo com a classe do aço e do processo industrial aplicado para endireitar os tubos (Tabela F.9 da ISO/TR 10400:2011), sendo ambos inferiores à unidade. Além disso, o fator de decréscimo $H_{\mathrm{t}, \text { des }}$ considera o efeito negativo de excentricidades, da ovalização do tubo e de tensões residuais para a resistência do revestimento, sendo igual a 0,22 para tubos alinhados a frio (CRS - cold rotary straightened) e 0,20 para tubos endireitados a quente (HRS - hot rotary straightened).

\section{- Equação de estado limite último de colapso}

As expressões para o cálculo da pressão de colapso segundo o modelo probabilístico de Klever-Tamano simplificam-se sobremaneira em relação ao projeto determinístico. Nesta condição, a pressão última resistida pelo revestimento é dada por:

$$
P_{\mathrm{uls}}=\frac{\left(P_{\mathrm{el}, \mathrm{uls}}+P_{\mathrm{y}, \mathrm{uls}}\right)-\sqrt{\left(P_{\mathrm{el}, \mathrm{uls}}-P_{\mathrm{y}, \mathrm{uls}}\right)^{2}+4 P_{\mathrm{el}, \mathrm{uls}} P_{\mathrm{y}, \mathrm{uls}} H_{\mathrm{t}, \mathrm{uls}}}}{2\left(1-H_{\mathrm{t}, \mathrm{uls}}\right)}
$$


onde

$$
\begin{aligned}
P_{\mathrm{el}, \mathrm{uls}} & =k_{\mathrm{el}, \mathrm{uls}} \frac{2 E}{\left(1-v^{2}\right)} \frac{1}{\left(D_{m} / t_{m}\right) \cdot\left[\left(D_{m} / t_{m}\right)-1\right]^{2}} \\
P_{\mathrm{y}, \mathrm{uls}} & =k_{\mathrm{y}, \mathrm{uls}} 2 f_{y} \cdot\left(t_{m} / D_{m}\right) \cdot\left[1+t_{m} /\left(2 D_{m}\right)\right] \\
H_{\mathrm{t}, \mathrm{uls}} & =0,127 o v+0,0039 e c-0,440\left(r s / f_{y}\right)+h_{n} \geq 0
\end{aligned}
$$

sendo

$H_{\mathrm{t}, \mathrm{uls}}:$ fator de decréscimo;

$k_{\mathrm{el}, \mathrm{uls}}=1,089:$ fator de calibração para o colapso elástico último;

$k_{\mathrm{y}, \mathrm{uls}}=0,9911:$ fator de calibração para o colapso plástico último;

$f_{y}$ : tensão de escoamento real de uma amostra de tração representativa;

$D_{m}$ : diâmetro externo real médio;

$D_{m}$ : espessura real média.

Nota-se grande semelhança entre as Eqs. (6.42) e (6.35). De fato, a única diferença entre estas expressões está no valor do coeficiente $k_{\mathrm{el}}$. Quando aplicado ao projeto de revestimentos, o coeficiente $k_{\text {el,des }}$ tem a finalidade de minorar a resistência do tubo, sendo igual a 0,825 . Em análises de confiabilidade, entretanto, seu valor é calibrado de modo que a equação de estado limite último represente de maneira mais acurada possível a resistência real do revestimento.

Em contrapartida, uma grande diferença existe entre as Eqs. (6.41) e (6.34). Quando se dispõe de dados estatísticos e deseja-se realizar uma avaliação mais precisa da real capacidade resistente do revestimento, o fator de decremento $H_{\mathrm{t}}$ deixa de apresentar valores exatos e passa a representar uma função de variáveis aleatórias:

$$
H_{\mathrm{t}, \mathrm{uls}}=0,127 o v+0,0039 e c-0,440\left(r s / f_{y}\right)+h_{n} \geq 0
$$

sendo

$o v=100\left(D_{\max }-D_{\min }\right) / D_{m}:$ ovalidade, em porcentagem;

$e c=100\left(t_{\max }-t_{\min }\right) / t_{m}:$ excentricidade, em porcentagem;

rs: tensão residual (negativa para compressão e positiva para tensão na face interna)

$h_{n}$ : fator de forma da curva tensão-deformação do material, igual a zero para aços com regime de transição elasto-plástico bem definido (pontiagudo), ou igual a 0,017 para transição suave entre os regimes de deformação;

$D_{\max }, D_{\min }$ : diâmetro externo real máximo e mínimo, respectivamente;

$t_{\max }, t_{\min }:$ espessura real máxima e mínima, respectivamente.

As grandezas geométricas da Eq. (6.45) são calculadas com base em dados amostrais aferidos de um único lote ou fornecedor. 


\subsection{Estado triaxial de tensões: critério de von Mises}

Um terceiro modelo de resistência deve ser estabelecido para a situação em que os modelos de ruptura e colapso não conseguem descrever com precisão a condição que leva à falha estrutural do revestimento: quando os esforços axiais produzem tensões de magnitude semelhante ou superior àquelas induzidas pelas pressões solicitantes. Neste caso, fica configurado um estado triaxial de tensões no material.

Um dos primeiros critérios de resistência utilizados para a previsão da falha de materiais dúcteis foi proposto por Tresca, em 1868. Neste tipo de material, a falha é caracterizada pelo aparecimento de deformações permanentes (indesejáveis sob o ponto de vista estrutural), sendo frequentemente observada nos planos onde as tensões de cisalhamento são máximas.

Também conhecido por Teoria da Máxima Tensão Cisalhante, o critério expressa a resistência do material em função da tensão de cisalhamento que causa o escoamento do material quando submetido a um ensaio uniaxial de tração $\left(\tau_{R}\right)$. Esta tensão é comparada ao valor absoluto da máxima tensão de cisalhamento que pode ser observado em um estado geral de tensão, sendo matematicamente expresso por meio das tensões principais $\left(\sigma_{1}, \sigma_{2}, \sigma_{3}\right)$ atuantes no material:

$$
|\tau|_{\max } \leq \tau_{R} \Rightarrow \max \left\{\frac{\left|\sigma_{1}-\sigma_{2}\right|}{2}, \frac{\left|\sigma_{1}-\sigma_{3}\right|}{2}, \frac{\left|\sigma_{2}-\sigma_{3}\right|}{2}\right\} \leq \frac{\sigma_{y}}{2}
$$

onde $\sigma_{y}$ é a tensão de escoamento do material, obtida por meio de ensaio de tração simples.

Caso as componentes de tensão principais sejam ordenadas de modo decrescente $\left(\sigma_{1}>\right.$ $\sigma_{2}>\sigma_{3}$ ), verifica-se que o máximo valor absoluto da tensão de cisalhamento corresponderá simplesmente a:

$$
|\tau|_{\max }=\frac{\left|\sigma_{1}-\sigma_{3}\right|}{2}
$$

A representação gráfica do critério de Tresca corresponde a um polígono hexagonal para estados planos de tensão $\left(\sigma_{3}=0\right)$ e, no caso tridimensional, descreve o formato de uma superfície hexagonal no espaço, segundo um sistema de eixos cartesianos definidos pelas tensões principais, como indicado na Figura 6.2. Para que a Eq. (6.46) seja atendida, os pontos representativos do estado de tensão atuante no material deverão encontrar-se no interior ou sobre o contorno da superfície hexagonal. Caso contrário, o estado de tensão terá causado a falha do material.

Figura 6.2 - Representação gráfica do critério de Tresca para o caso plano e tridimensional.
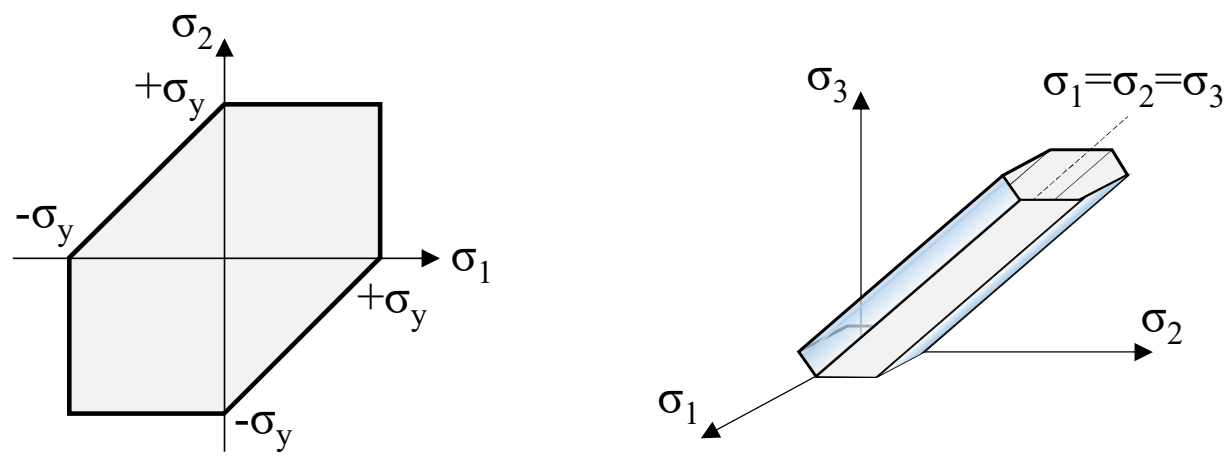
Um segundo critério de ruptura, concebido décadas mais tarde por Richard von Mises, veio a substituir o critério de Tresca para a previsão da falha de materiais dúcteis. Com a realização de ensaios experimentais, observou-se a influência da tensão principal intermediária $\sigma_{2}$ (desconsiderada pelo critério anterior - Eq. 6.47), além de relações não lineares entre as componentes principais do estado de tensão que formam a envoltória de falha.

Com base nestas evidências, foi proposta uma superfície elíptica em substituição à superfície hexagonal de Tresca, que está relacionada à energia de distorção por unidade de volume do material. A equação do critério de von Mises (também conhecido por Teoria da Máxima Energia de Distorção) é dada por:

$$
\left(\sigma_{1}-\sigma_{2}\right)^{2}+\left(\sigma_{1}-\sigma_{3}\right)^{2}+\left(\sigma_{2}-\sigma_{3}\right)^{2} \leq 2 \sigma_{y}^{2}
$$

Para problemas planos de tensão, a Eq. (6.48) é representada simplificadamente por uma elipse. Para um caso mais geral, a fronteira entre os domínios de falha e segurança é delimitada pela superfície cilíndrica indicada na Figura 6.3.

Figura 6.3 - Representação gráfica do critério de von Mises para o caso plano e tridimensional.

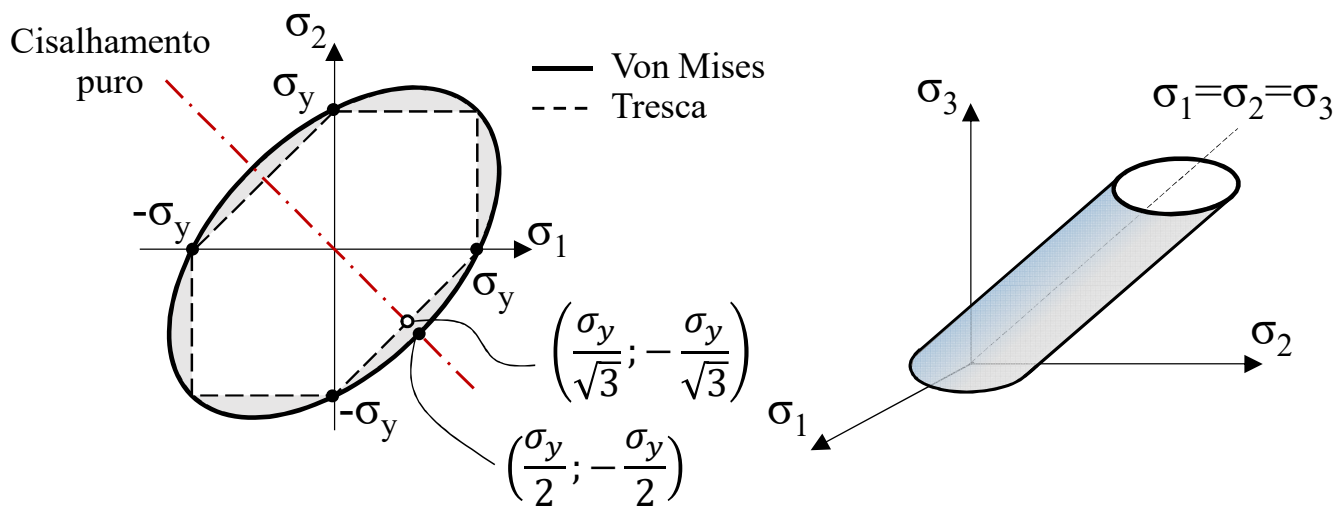

Embora os critérios de Tresca e de von Mises tenham sido propostos para prever a resistência de materiais dúcteis, existe uma pequena diferença entre a previsão de ambos os critérios. Por meio do caso plano representado na Figura 6.3, observa-se que os critérios concordam entre si sobre a previsão da falha quando uma das tensões principais no plano é nula $\left(\sigma_{1}=0\right.$ ou $\sigma_{2}=0$ ). Porém, para os demais pontos existem pequenas diferenças, em especial quando um estado de cisalhamento puro atua sobre o corpo em análise. Nessa condição, constata-se que o critério de von Mises admite um estado de tensão aproximadamente 15\% mais elevado que o previsto pelo critério de Tresca. Resultados experimentais em corpos de prova submetidos à torção pura indicam que o critério de von Mises é mais preciso na previsão de falha, sendo, portanto, recomendado para a estimativa da resistência de materiais submetidos a um estado triaxial de tensões.

O modelo adotado pela norma ISO 10400:2011 para o cálculo da resistência de revestimentos sujeitos a estados triaxiais de tensões é uma adaptação do critério de von Mises. Consiste na combinação de cinco componentes de tensão: 
$i$. tensão radial $\left(\sigma_{r}\right)$ e tangencial $\left(\sigma_{t}\right)$, determinadas pelas equações de Lamé para um cilindro de paredes espessas;

ii. tensão axial uniforme $\left(\sigma_{a}\right)$ devida a todas as fontes, exceto flexão;

iii. tensão axial de flexão $\left(\sigma_{b}\right)$, determinada pela teoria de vigas de Timoshenko;

$i v$. tensão de cisalhamento $\left(\tau_{t}\right)$ causada pela torção do eixo do tubo.

O critério representa o estado limite associado ao início do escoamento do corpo do tubo. Em virtude disso, cada componente de tensão pode ser definida com base em equações que admitem comportamento elástico-linear do revestimento. A resistência de tubulares a um estado geral de tensões é dada por:

$$
\sigma_{r}^{2}+\sigma_{t}^{2}+\left(\sigma_{a}+\sigma_{b}\right)^{2}-\sigma_{r} \sigma_{t}-\sigma_{r}\left(\sigma_{a}+\sigma_{b}\right)-\sigma_{t}\left(\sigma_{a}+\sigma_{b}\right)+3 \tau_{T}^{2} \leq \sigma_{y}^{2}
$$

Comparativamente à formulação original proposta por von Mises, a superposição das tensões axiais $\left(\sigma_{a}\right.$ e $\left.\sigma_{b}\right)$ resulta na tensão principal atuante no sentido longitudinal do corpo do tubo que, juntamente com $\sigma_{r}$ e $\sigma_{t}$, constituem as componentes de tensões principais na ausência de torção do tubo.

Da forma como foi apresentado (Eq. 6.49), o critério de von Mises pode ser empregado na verificação da confiabilidade de poços. Pode ainda ser utilizado para o projeto determinístico de revestimentos, porém neste caso deve-se substituir a espessura nominal $t$ do revestimento por uma espessura reduzida (igual a $0,875 t$ ) para o cálculo das tensões radiais e tangenciais, bem como a tensão real de escoamento do material $f_{y}$ deve ser substituída pela mínima tensão de escoamento especificada por norma (correspondente à classe do aço).

Juntamente com os modelos de resistência à ruptura e ao colapso, o modelo de resistência a estados triaxiais de tensão completa o grupo de equações utilizadas para verificação da segurança de revestimentos. Nos cálculos determinísticos, faz-se pequenos ajustes para que se obtenha a pior configuração admissível para as propriedades de resistência do tubular. Nos cálculos probabilísticos, modelam-se as propriedades dos tubulares por meio de variáveis aleatórias e avalia-se a confiabilidade dos revestimentos utilizando os modelos originais, que passam a representar equações de estados limites, conforme será visto em maior detalhe no Capítulo 7. 


\section{Confiabilidade Estrutural}

A análise de confiabilidade é uma das partes integrantes da análise de riscos. É o processo responsável pela quantificação da probabilidade de que um componente ou sistema encontre-se em um estado adverso, ficando impossibilitado de cumprir com a função para a qual foi projetado.

Faber (2006) diferencia as análises de confiabilidade em dois grupos distintos. O primeiro corresponde àquelas ditas clássicas, que preocupam-se sobretudo com a estimativa de características estatísticas sobre a vida útil de sistemas formados por uma série de componentes do mesmo tipo, submetidos aos mesmos carregamentos e com comportamento estatístico independente (e.g. sistemas eletrônicos). Estatísticas como taxa de falha esperada, expectativa de vida e tempo médio entre falhas estão entre os principais resultados buscados por tais análises.

O segundo grupo é formado pelas análises de confiabilidade estrutural. Estas são fundamentalmente diferentes das clássicas devido ao fato de que falhas estruturais são muito raras e geralmente ocorrem como consequência de algum evento extremo. Somado a isso, pouca informação útil pode ser coletada a partir da falha de sistemas precedentes, pois quase todos os componentes e sistemas estruturais são únicos em virtude de sua geometria, do material empregado ou do carregamento a que estão sujeitos. Consequentemente, o objetivo principal de tais análises corresponde ao cálculo e previsão da probabilidade de ocorrência de desempenho indesejável para um sistema estrutural durante a sua vida de projeto (MELCHERS, 1999).

Para proceder com a estimativa de tal probabilidade, geralmente percorrem-se os seguintes passos (SORENSEN, 2004):

1. Seleção de um índice de confiabilidade alvo;

2. Identificação dos possíveis modos de falha da estrutura (ou de seus elementos) e formulação das funções de falha (equações de estado limite) correspondentes a cada um deles;

3. Especificação das variáveis determinísticas e aleatórias do problema, com a subsequente caracterização estatística das últimas;

4. Estimativa da probabilidade de falha individual de cada modo, dos componentes e do sistema (quando esta última for desejável);

5. Adicionalmente, é possível avaliar a influência de cada variável na composição da probabilidade de falha da estrutura por meio dos seus respectivos coeficientes de sensibilidade.

Em análises simples de confiabilidade, as probabilidades calculadas são utilizadas como parâmetro de comparação entre configurações alternativas para a mesma estrutura ou entre a configuração estudada e a probabilidade de falha alvo. Em um procedimento mais rigoroso de projeto, realiza-se o ajuste da solução estrutural adotada (redimensionamento) de modo a garantir simultaneamente que: (a) todos os índices de confiabilidade obtidos sejam superiores ao índice alvo; e (b) que a configuração estrutural projetada seja a mais econômica possível.

A seguir, os itens listados serão brevemente discutidos, com exceção do item 3 , que será abordado com maior profundidade no Capítulo 8. 


\subsection{Níveis de confiabilidade alvo}

Níveis de confiabilidade alvo estão associados ao risco aceitável de um projeto específico. Entende-se como risco aceitável a frequência de ocorrência de falhas e as consequências decorrentes das mesmas que um proprietário está disposto a admitir (e arcar com os prejuízos) e a sociedade está disposta a permitir (LEWIS et al., 1995a).

Para sistemas estruturais em geral, valores de referência são estabelecidos com base em dois fatores: o primeiro está relacionado ao impacto financeiro, humano e ambiental decorrente de uma falha estrutural (isto é, ao potencial de prejuízo econômico, de perda de vidas e de poluição); o segundo está atrelado às despesas e ao esforço necessários para reduzir o risco de falha. Índices de confiabilidade alvo e suas respectivas probabilidades de falha são apresentados na Tabela 7.1 com base nas recomendações propostas pela Comissão Conjunta sobre Segurança Estrutural (JCSS) e pelo Comitê Europeu de Normatização (CEN, 2002). Os valores prescritos são referentes a um período de retorno de um ano e consideram exclusivamente estados limites últimos desencadeados por eventos de natureza estrutural, excluindo falhas ocasionadas por motivos alheios, como erro humano ou sabotagem.

Tabela 7.1 - Índices de confiabilidade alvo $\beta$ (e respectivas taxas de falha associadas) relacionadas a um período de referência de um ano (JCSS, 2001).

\begin{tabular}{|c|c|c|c|}
\hline $\begin{array}{c}\text { Custo relativo das } \\
\text { medidas de segurança }\end{array}$ & Pequenas & $\begin{array}{c}\text { Consequências de falha } \\
\text { Moderadas }\end{array}$ & Grandes \\
\hline Alto (A) & $\begin{array}{c}\beta=3.1 \\
\left(P_{f}=9,7.10^{-4}\right)\end{array}$ & $\begin{array}{c}\beta=3.3 \\
\left(P_{f}=4,8.10^{-4}\right)\end{array}$ & $\begin{array}{c}\beta=3.7 \\
\left(P_{f}=1,1.10^{-4}\right)\end{array}$ \\
\hline Normal (B) & $\begin{array}{c}\beta=3.7 \\
\left(P_{f}=1,1.10^{-4}\right)\end{array}$ & $\begin{array}{c}\beta=4.2 \\
\left(P_{f}=1,3.10^{-5}\right)\end{array}$ & $\begin{array}{c}\beta=4.4 \\
\left(P_{f}=5,4.10^{-6}\right)\end{array}$ \\
\hline Baixo (C) & $\begin{array}{c}\beta=4.2 \\
\left(P_{f}=1,3.10^{-5}\right)\end{array}$ & $\begin{array}{c}\beta=4.4 \\
\left(P_{f}=5,4.10^{-6}\right)\end{array}$ & $\begin{array}{c}\beta=4.7 \\
\left(P_{f}=1,3.10^{-6}\right)\end{array}$ \\
\hline CEN 1990-2002 & $\beta=4.2$ & $\beta=4.7$ & $\beta=5.2$ \\
$\left(P_{f}=1,3.10^{-5}\right)$ & $\left(P_{f}=1,3.10^{-6}\right)$ & $\left(P_{f}=1,0.10^{-7}\right)$ \\
\hline
\end{tabular}

Para um período de referência arbitrário $T_{r e f}$ (em anos), o respectivo nível de confiabilidade alvo é calculado por (CEN 1990:2002):

$$
\beta\left(T_{r e f}\right)=\Phi^{-1}\left\{\left[\Phi\left(\beta_{1}\right)\right]^{T_{r e f}}\right\}
$$

onde $\Phi(\cdot)$ é a função de distribuição cumulativa normal padrão ( $\Phi^{-1}$ é sua inversa); e $\beta_{1}$ é o índice de confiabilidade relativo a um período de referência de um ano.

$\mathrm{Na}$ Tabela 7.1, as consequências de falha são classificadas em três grupos com base na razão $\rho$ entre os custos totais (isto é, os custos de construção mais os custos diretos de falha) e os custos de construção (JCSS, 2001):

- Classe 1 - Consequências Pequenas $(\rho \leq 2)$ : prejuízos econômicos e ambientais pequenos e risco à vida de pessoas de ordem reduzida ou insignificante (por exemplo, estruturas agrícolas, silos, mastros, torres isoladas); 
- Classe 2 - Consequências Moderadas $(2<\rho \leq 5)$ : prejuízos econômicos e ambientais consideráveis ou risco médio à vida de pessoas (por exemplo, edifícios de escritórios, edifícios industriais, edifícios de apartamentos);

- Classe 3 - Consequências Grandes $(5<\rho \leq 10)$ : prejuízos econômicos ou ambientais elevados ou alto risco à vida de pessoas (por exemplo, pontes principais, teatros, hospitais, prédios altos, centros comerciais).

A coluna de custo relativo, por sua vez, está relacionada aos investimentos feitos ainda na etapa de projeto para garantir uma redução da probabilidade de falha da estrutura. Conforme definição do JCSS (2001), a classe de custo normal (B) está associada a uma vida útil normal da estrutura e a uma média variabilidade dos carregamentos e resistências (entre 10\% e 30\%). Para situações de grande incerteza (ações de natureza acidental ou parâmetros de resistência com variabilidade maior que 40\%), o JCSS recomenda a adoção de uma classe de confiabilidade menor, mais permissiva a falhas. Isto baseia-se no fato de que os custos adicionais para alcançar uma alta confiabilidade são proibitivos nestes casos. Por outro lado, se tanto as variáveis atuantes quanto as resistentes apresentarem coeficientes de variação inferiores a 10\%, um nível de confiabilidade mais alto pode ser alcançado com um mínimo esforço adicional.

O nível de risco apropriado a um projeto particular depende de uma avaliação das consequências de falha associadas à ocorrência de determinado estado limite. Para o caso específico das estruturas de revestimento de poços, o nível de risco ótimo é diferente para cada modo de falha, cenário de carregamento e fase do poço considerada, pois as consequências variam substancialmente de um para outro, especialmente quando há risco de vida envolvido.

A título de ilustração, as consequências de um blowout próximo à superfície superam em muito os custos de uma falha de colapso, de forma que menores probabilidades de falha devem ser admitidas para cenários de carregamento de kick. Por outro lado, uma falha durante a operação de cimentação não tem consequências tão graves, justificando níveis de segurança menores. Da mesma forma, um revestimento de superfície pode dispôr de um índice de confiabilidade menor em relação a um revestimento intermediário profundo, pois ainda que ambos sejam projetados para o mesmo cenário de carregamento, a intensidade das cargas é consideravelmente distinta.

Em virtude da dificuldade envolvida na definição de níveis de risco apropriados, diversos pesquisadores buscaram definir índices de confiabilidade alvo para o projeto de revestimentos de poços. O trabalho de Lewis et al. (1995a) foi um dos pioneiros na área e propôs a adoção de probabilidades de falha da ordem de $10^{-2}$ a $10^{-8}$ de acordo com duas classes de consequência e três níveis de custo. Para modos de falha que não apresentam riscos ao meio ambiente ou à vida, uma probabilidade de falha $P_{f}=10^{-2}$ foi definida, o que corresponde a uma taxa de falha de 1 tubular a cada 100. No outro extremo, fixou-se uma probabilidade de falha de $10^{-8}$ para cenários de falha com consequências severas e custos elevados.

Recomenda-se ter cautela ao utilizar os valores recomendados por Lewis et al. (1995a), pois eles seguem uma lógica contrária à da Tabela 7.1. Diferentemente do JCSS, que faz menção aos custos necessários para implementar medidas de segurança ainda na fase de projeto, a classifi- 
cação proposta por Lewis et al. (1995a) é realizada de acordo com os custos de reparação da falha. Assim, se os custos para restaurar os danos causados à estrutura, às pessoas, a equipamentos e ao meio ambiente forem pequenos, uma maior probabilidade de falha é permitida. A dificuldade envolvida neste processo reside justamente na estimativa dos custos de reparação, o que demanda o desenvolvimento de árvores de eventos específicas para cada evento de falha possível. Os custos relativos das medidas de segurança, por outro lado, são facilmente quantificáveis e sofrem influência de um numero bem menor de fatores externos.

Estendendo a abrangência a plataformas offshore, outros trabalhos buscaram estabelecer níveis de confiabilidade alvo para essas estruturas (BEA, 1989; BEA, 1991; BHATTACHARYA; BASU; MA, 2001; FABER et al., 2012). De maneira geral, os valores recomendados foram estabelecidos com base em probabilidades de falha consideradas aceitáveis em outras áreas da engenharia, tais como aviação comercial, mineração, estruturas de fundação, barragens e plataformas de perfuração.

Para evitar a escolha de valores infundados ou sem uma rigorosa comprovação, optou-se pela adoção de níveis de confiabilidade alvo recomendados por organizações internacionalmente reconhecidas. A norma norueguesa NORSOK D-010 (2004), que estabelece diretrizes para o projeto, execução e operação de poços, estabelece uma probabilidade de falha máxima de $10^{-3,5}$ para revestimentos, porém não dá indicações quanto ao período de referência considerado nem realiza qualquer distinção entre consequências de falha, sendo assim de pouca utilidade prática.

A norma canadense CSA S471 (2008), em contrapartida, prescreve níveis de confiabilidade alvo para estruturas offshore de acordo com duas classes de segurança. A depender das consequências de falha, adota-se um dos valores indicados na Tabela 7.2.

Tabela 7.2 - Probabilidades de falha anuais indicadas para o projeto de revestimentos (CSA, 2008).

\begin{tabular}{lcc}
\hline & Consequências de falha & P $_{\mathbf{f}}$ alvo anual \\
\hline Classe de Segurança 1 & $\begin{array}{c}\text { Grande risco à vida ou alto } \\
\text { potencial de dano ambiental }\end{array}$ & $1 \times 10^{-5}$ \\
Classe de Segurança 2 & $\begin{array}{l}\text { Pequeno risco à vida e baixo } \\
\text { potencial de dano ambiental }\end{array}$ & $1 \times 10^{-3}$ \\
\hline
\end{tabular}

A norma ISO 2394:1998, por sua vez, estabelece níveis de confiabilidade alvo sob duas perspectivas distintas. Do ponto de vista social, a probabilidade de falha admissível a uma estrutura deve ser estipulada com base no risco de morte associado ao seu colapso. Tomando como referência uma taxa média de acidentes letais de 1 a cada 1000 indivíduos por ano, recomenda que a probabilidade de falha da estrutura não ultrapasse $10^{-6} /$ ano. Do ponto de vista econômico, o nível de confiabilidade alvo deve proporcionar o equilíbrio entre as consequências de uma eventual falha e os custos relativos à implementação de medidas de segurança. Os valores sugeridos segundo este prisma são reproduzidos na Tabela 7.3. 
Tabela 7.3 - Índices de confiabilidade alvo $\left(\beta_{T}\right)$ para a vida útil da estrutura (ISO 2394:1998).

\begin{tabular}{|c|c|c|c|c|}
\hline $\begin{array}{c}\text { Custo relativo das } \\
\text { medidas de segurança }\end{array}$ & \multicolumn{4}{|c|}{ Consequências de falha } \\
\hline Alto (A) & 0 & 1,5 & 2,3 & 3,1 \\
\hline Normal (B) & 1,3 & 2,3 & 3,1 & 3,8 \\
\hline Baixo (C) & 2,3 & 3,1 & 3,8 & 4,3 \\
\hline
\end{tabular}

Assim como a norma NORSOK D-010, a norma ISO 2394:1998 não indica o período de referência ao qual estão atrelados os índices de confiabilidade alvo sugeridos (acredita-se, no entanto, se tratar de uma vida útil de 50 anos). Por este motivo e por uma questão de simplicidade, no presente trabalho são adotados os valores apresentados na Tabela 7.2. Para os cenários de ruptura, as probabilidades de falha são admitidas com valor igual a $10^{-5}$, devido ao alto risco imposto à vida dos operadores e ao meio ambiente (especialmente no caso de poços perfurados através de zonas sujeitas a altas temperaturas e altas pressões ou com elevada concentração de $\mathrm{H}_{2} \mathrm{~S}$ ). Para falhas por colapso ou escoamento do tubo provocado por estados triaxiais de tensão, as probabilidades de falha alvo correspondem em sua totalidade a consequências pequenas $\left(P_{f}=10^{-3}\right)$.

\subsection{Estados limites}

Estruturas e seus elementos estruturais devem ser projetadas, executadas e conservadas para que se mantenham adequadas ao seu propósito durante toda a vida útil de projeto. Devem apresentar um nível adequado de segurança à função estrutural que desempenham, mantendo-se economicamente viáveis.

Em especial, uma estrutura deve atender aos seguintes requisitos básicos (JCSS, 2001):

1) Requisito de serviço: deve permanecer apta a cumprir com a função para a qual foi projetada, apresentando durabilidade adequada no ambiente em que será construída;

2) Requisito de segurança: deve resistir a ações extremas e/ou carregamentos repetitivos que ocorram desde o momento de sua construção até o final de sua vida útil;

3) Requisito de robustez: quando sujeita a eventos acidentais, como explosões, impacto ou consequências de erros humanos, a estrutura não deve sofrer danos desproporcionais à intensidade do evento causador.

O primeiro requisito é considerado no projeto por meio da correta especificação dos materiais ou pela substituição de elementos degradados com o tempo, por exemplo. O requisito de segurança, por sua vez, é satisfeito por meio do correto dimensionamento da estrutura e de suas partes. Por fim, o requisito de robustez é atendido ao se projetar caminhos de carga alternativos ou incorporar suficiente redundância e ductilidade ao sistema estrutural.

O desempenho de um sistema estrutural é considerado satisfatório quando este cumpre com os requisitos de serviço e segurança (BECK, 2019). A violação de qualquer um deles 
representa um estado indesejável da estrutura e cada maneira distinta que possa conduzi-la a tal estado é chamada, genericamente, de modo de falha. Cada modo de falha dá origem a um estado limite, que representa um modelo matemático idealizado do fenômeno que antecede a falha estrutural.

Por definição, estado limite é um estado além do qual a estrutura não cumpre mais com a função para a qual foi projetada (CEN, 2002). Classicamente, estados limites são divididos em duas categorias:

- Estados limites de serviço: estão associados à durabilidade e à operacionalização normal da estrutura. Exemplos:

$\triangleright$ Danos locais (fissuras ou trincas) que afetem a durabilidade da estrutura ou comprometam a resistência de elementos estruturais;

$\triangleright$ Danos causados por efeitos dependentes do tempo (fadiga, desgaste, corrosão, etc.);

$\triangleright$ Deformação ou vibração excessiva que comprometa a eficiência de instalações, máquinas ou equipamentos;

- Estados Limites Últimos: estão relacionados à integridade estrutural durante sua vida útil. Exemplos:

$\triangleright$ Superação da capacidade máxima resistente de componentes estruturais, por ruptura ou deformação excessiva;

$\triangleright$ Instabilidade da estrutura ou de componentes estruturais;

$\triangleright$ Ruptura de membros ou conexões por fadiga.

Vale ressaltar que, no caso de poços, a instabilidade por flambagem não constitui um estado limite último. Ao contrário do que ocorre na grande maioria das estruturas, o revestimento tem sua deflexão lateral limitada pela parede do furo, não permitindo o colapso da coluna (REMMEN, 2018). Assim, a flambagem pode ser considerada como um estado limite de serviço, pois afeta a funcionalidade do revestimento e sua capacidade máxima de carga, mas não conduz por si só a estrutura do poço à ruína.

A importância prática de estados limites de serviço limita-se à especificação de classes de aço com resistência adequada ao local de exploração. Estados limites últimos, por outro lado, estão associados à segurança do poço, dos operadores e da vida marinha, governando o processo de dimensionamento.

\subsubsection{Equações de Estado Limite}

É possível descrever analiticamente cada um dos possíveis modos de falha da estrutura por meio de expressões envolvendo as variáveis mais relevantes de resistência e solicitação ${ }^{1}$.

1 Os modos de falha aplicáveis a revestimentos de poços e as equações de estado limite correspondentes a cada caso encontram-se descritas no Capítulo 6. 
Tais funções são denominadas equações de estado limite, sendo expressas genericamente da seguinte forma:

$$
g(\mathbf{R}, \mathbf{S})=0
$$

onde $\mathbf{R}$ e $\mathbf{S}$ representam os conjuntos de variáveis de resistência e solicitação do estado limite em questão.

Em análises de confiabilidade estrutural, costuma-se agrupar todos os parâmetros de carregamento, material e geometria sujeitos a incertezas em um único vetor de variáveis aleatórias $\mathbf{X}$, de modo que a Eq. (7.2) resulta:

$$
g(\mathbf{X})=g\left(X_{1}, X_{2}, \ldots, X_{n}\right)=0
$$

Equações de estado limite são definidas de tal forma que valores negativos representam a falha da estrutura e valores positivos representam a sua sobrevivência (ou não falha). Delimitam, assim, a fronteira entre os domínios desejável e indesejável do problema:

$$
\begin{array}{ll}
\Omega_{f}=\{\mathbf{x} \mid g(\mathbf{x}) \leq 0\} & \text { representa o domínio de falha } \\
\Omega_{s}=\{\mathbf{x} \mid g(\mathbf{x})>0\} & \text { representa o domínio de sobrevivência }
\end{array}
$$

A solução de problemas de confiabilidade envolve a avaliação da probabilidade de que qualquer ponto (x) esteja dentro do domínio que caracteriza a falha, ou seja:

$$
P_{f}=P[g(\mathbf{x}) \leq 0]=\int_{\Omega_{f}} f_{\mathbf{X}}(\mathbf{x}) d \mathbf{x}
$$

tal que $P_{f}$ corresponde à probabilidade de falha da estrutura e representa a propensão à violação de estados limites (MELCHERS; BECK, 2018). Ainda na equação anterior, $\mathbf{x}$ equivale a uma realização de cada variável aleatória que compõe o vetor $\mathbf{X}, f_{\mathbf{X}}(\mathbf{x})$ simboliza a função conjunta de densidade de probabilidades no espaço de projeto e a integral representa o conteúdo de probabilidades contido no domínio de falha.

Nos casos práticos, raramente a integral definida na Eq. (7.5) apresenta solução analítica, devendo ser resolvida numericamente. Para isto, métodos de confiabilidade devem ser empregados.

\subsection{Métodos para estimativa da confiabilidade}

A solução de problemas de confiabilidade estrutural, conforme formulado na Eq. (7.5), envolve a determinação (ou uma aproximação) da função conjunta de densidade de probabilidades, $f_{\mathbf{X}}(\mathbf{x})$, e do domínio de integração, $\Omega_{f}$.

Na maioria dos casos reais, entretanto, não há observações que permitam determinar diretamente $f_{\mathbf{X}}(\mathbf{x})$. Isto significa que esta função deve ser construída com base na informação existente, o que na maioria dos casos se limita a dados sobre as funções de distribuição marginais e, em alguns casos, ao coeficiente de correlação entre pares de variáveis aleatórias (BECK, 2014). 
O domínio de falha também deve ser aproximado, visto que não é possível determinar com exatidão qual o conjunto de fatores que conduzem o sistema à falha.

Aqui se inserem os diferentes métodos de solução, como os métodos de transformação e as simulações de Monte Carlo. Cada um deles envolve diferentes aproximações para $f_{\mathbf{X}}(\mathbf{x})$, utilizando parte ou toda a informação estatística disponível sobre as variáveis de projeto, como também realizam a integração numérica do domínio de falha segundo abordagens distintas. A seguir, os principais métodos utilizados em análises de confiabilidade serão brevemente introduzidos.

\subsubsection{Método de confiabilidade de primeira ordem - FORM}

O método de confiabilidade de primeira ordem ou FORM é um método de confiabilidade estrutural de transformação. Baseia-se em um mapeamento do vetor de variáveis aleatórias do problema, $\mathbf{X}$ - possivelmente correlacionadas e com qualquer distribuição conjunta de probabilidades $f_{\mathbf{X}}(\mathbf{x})$-, em um vetor de variáveis aleatórias independentes, $\mathbf{Y}$, com distribuição normal padrão (média nula e desvio padrão unitário). Tais variáveis apresentam função conjunta de distribuição de probabilidades $f_{\mathbf{Y}}(\mathbf{y})$, chamada de distribuição normal padrão multi-variável ou multi-dimensional, que possui importantes propriedades de simetria e decaimento exponencial em relação à origem (MELCHERS, 1999; BECK, 2014).

Em resumo, a solução de problemas envolvendo equações de estado limite não lineares pelo método de primeira ordem implica na busca pelo ponto de projeto e na aproximação da equação de estado limite por um hiper-plano centrado neste ponto. O nome do método decorre justamente do fato do domínio de falha ser aproximado por uma função linear, o que irá resultar em uma boa aproximação da probabilidade de falha verdadeira quando a equação de estado limite no espaço normal padrão $\mathbb{Y}$ for plana ou razoavelmente plana na vizinhança do ponto de projeto.

Sendo $\beta$ o índice de confiabilidade da estrutura, é possível obter uma estimativa de primeira ordem da probabilidade de falha por meio da função de distribuição cumulativa normal padrão, $\Phi(\cdot)$, mediante a relação:

$$
P_{f}=\Phi(-\beta)
$$

O índice $\beta$ pode ser interpretado como uma medida geométrica da probabilidade de falha, correspondente à mínima distância entre a equação de estado limite e a origem do espaço normal padrão. O ponto sobre a equação de estado limite com menor distância à origem, por conseguinte, é denominado ponto de projeto, sendo habitualmente simbolizado por um asterisco $\left(\mathbf{y}^{*}\right)$. Corresponde ao ponto sobre o domínio de falha com maior probabilidade de ocorrência devido à propriedade de simetria radial do espaço $\mathbb{Y}$, fazendo de si o ponto ideal para a linearização da equação de estado limite. 


\subsubsection{1 Índices de sensibilidade}

Uma propriedade importante obtida com a linearização da equação de estado limite para o cálculo do índice de confiabilidade diz respeito aos índices de sensibilidade (MELCHERS, 1999). Tomando a derivada da aproximação de primeira ordem da probabilidade de falha (Eq. (7.6)) em relação às variáveis de projeto no espaço normal padrão, obtém-se informação acerca da contribuição de cada variável aleatória na composição da $P_{f}$ :

$$
\left.\frac{\partial P_{f}}{\partial \mathbf{y}}\right|_{\mathbf{y}=\mathbf{y}^{*}}=\left.\frac{\partial \Phi(-\beta)}{\partial \beta} \frac{\partial \beta}{\partial \mathbf{y}}\right|_{\mathbf{y}=\mathbf{y}^{*}}=-\left.\phi(-\beta) \frac{\partial \beta}{\partial \mathbf{y}}\right|_{\mathbf{y}=\mathbf{y}^{*}}
$$

O gradiente de $\beta$ com relação ao vetor $\mathbf{y}$ pode ser calculado por meio da avaliação do gradiente da equação de estado limite, $\vec{\nabla} g$, no ponto de projeto $\mathbf{y}^{*}$, ou seja:

$$
\left.\frac{\partial \beta}{\partial \mathbf{y}}\right|_{\mathbf{y}=\mathbf{y}^{*}}=-\frac{\vec{\nabla} g\left(\mathbf{y}^{*}\right)}{\left\|\vec{\nabla} g\left(\mathbf{y}^{*}\right)\right\|}=-\alpha\left(\mathbf{y}^{*}\right),
$$

tal que o cálculo do gradiente é dado por:

$$
\vec{\nabla} g(\mathbf{y})=\left\{\frac{\partial g}{\partial y_{1}}, \frac{\partial g}{\partial y_{2}}, \ldots, \frac{\partial g}{\partial y_{n}}\right\}^{T}
$$

Finalmente, é possível agrupar as Eqs. (7.7) e (7.8):

$$
\left.\frac{\partial P_{f}}{\partial \mathbf{y}}\right|_{\mathbf{y}=\mathbf{y}^{*}}=\phi(-\beta) \cdot \boldsymbol{\alpha}\left(\mathbf{y}^{*}\right)
$$

Na expressão acima, o termo $\phi(-\beta)$ é constante e $\beta$ representa o módulo do vetor que une a equação de estado limite à origem do espaço normal padrão, enquanto o versor $\boldsymbol{\alpha}$ representa os cossenos diretores deste mesmo vetor. Em razão de $\boldsymbol{\alpha}$ ser unitário, suas componentes $\alpha_{i}^{2}$ indicam a contribuição relativa da variável aleatória $Y_{i}$ (e consequentemente de $X_{i}$ ) na composição da probabilidade de falha.

Assim, se um valor $\alpha_{i}^{2}$ é pequeno em comparação à unidade $\left(\alpha_{i}^{2} \approx 0\right)$, a variável $X_{i}$ tem pouca contribuição na probabilidade de falha da estrutura e pode, eventualmente, ser eliminada (substituída por um valor determinístico). Esta informação é muito importante, pois permite reduzir a dimensão do problema por intermédio da eliminação de variáveis sem influência.

\subsubsection{Gradientes com respeito às variáveis de resistência}

O método FORM é, ainda hoje, uma das técnicas mais conhecidas e utilizadas para avaliar a confiabilidade de um sistema estrutural. Sua eficiência, usualmente medida a partir do número de avaliações das equações de estado limite necessárias para a convergência, é o principal atrativo deste método.

A estimativa da probabilidade de falha por meio deste método envolve a busca pelo ponto de projeto de cada equação de estado limite. A procura por este ponto demanda a solução de um sub-problema de otimização, que requer a avaliação do vetor gradiente cujos termos são as derivadas parciais da equação de estado limite em relação às variáveis aleatórias do problema. 
Nos casos em que as derivadas parciais não podem ser obtidas analiticamente, costuma-se recorrer ao método das diferenças finitas para obter uma aproximação numérica do vetor gradiente. Este é um procedimento computacionalmente dispendioso, pois aumenta substancialmente o número de avaliações das equações de estado limite (cada termo do vetor exige ao menos uma avaliação de $g(\mathbf{x})$ ), podendo viabilizar o uso de métodos de simulação alternativos. Felizmente, o problema de poços envolve apenas a avaliação de equações de estado limite analíticas. Sendo assim, para evitar o uso de diferenças finitas pelas rotinas do módulo estocástico, foram calculados algebricamente os gradientes de cada equação de resistência com respeito às variáveis aleatórias pertinentes.

Uma equação de estado limite genérica para falha de tubulares por ruptura (pressão interna) ou colapso (pressão externa) pode ser escrita da seguinte maneira:

$$
g(\mathbf{X})=M_{E} \cdot p_{R}-p_{S}
$$

onde $\mathbf{X}$ é o vetor de variáveis aleatórias do problema, $M_{E}$ é o erro de modelo da pressão resistente, $p_{R}$ é a pressão resistente (ruptura ou colapso) e $p_{S}$ é a pressão solicitante (pressão interna para ruptura e externa para colapso). $\mathbf{O}$ vetor $\mathbf{X}$ contém as variáveis aleatórias de resistência e a variável aleatória de carregamento, $p_{S}$.

Na condição de ruptura, a equação de estado limite aplicável deriva do modelo de KleverStewart e a pressão solicitante $\left(p_{S}\right)$ corresponde à pressão interna atuante. Do ponto de vista da resistência, as variáveis aleatórias que influenciam a capacidade resistente de um tubular são: o erro de modelo $\left(M_{E}\right)$, o diâmetro externo do tubo $(D)$, a espessura da parede $(t)$, a tensão axial $\left(\sigma_{A}\right)$, a pressão externa $\left(p_{o}\right)$, a pressão interna $\left(p_{i}\right)$ e a tensão última de tração do material $\left(f_{u}\right)$. Logo, o vetor $\mathbf{X}$ corresponde a:

$$
\mathbf{X}=\left\{M_{E}, D, t, \sigma_{A}, p_{o}, p_{i}, f_{u}\right\}
$$

e o vetor gradiente é dado por:

$$
\vec{\nabla} g=\left\{\frac{\partial g}{\partial \mathbf{X}}\right\}=\left\{p_{R}, M_{E} \frac{\partial p_{R}}{\partial D}, M_{E} \frac{\partial p_{R}}{\partial t}, M_{E} \frac{\partial p_{R}}{\partial \sigma_{A}}, M_{E} \frac{\partial p_{R}}{\partial p_{o}}, M_{E} \frac{\partial p_{R}}{\partial p_{i}}, M_{E} \frac{\partial p_{R}}{\partial f_{u}},-\frac{\partial p_{S}}{\partial p_{i}}\right\}
$$

O primeiro termo do vetor gradiente é a derivada em relação ao erro de modelo, que é a própria pressão de ruptura avaliada em x. Os demais termos, com exceção do último, são as derivadas da pressão de ruptura, conforme o modelo de Klever-Stewart (Subseção 6.3.1), em relação às variáveis de resistência. $\mathrm{O}$ último termo do vetor gradiente é simplesmente: $-\partial p_{S} / \partial p_{i}=-1$.

A equação de estado limite de colapso também é dada de forma genérica pela Eq. (7.11). Neste caso, a solicitação corresponde à pressão externa atuante, tal que $p_{S}=p_{o}$, e a equação de resistência utilizada decorre do modelo de Klever-Tamano (Subseção 6.4.7). As variáveis aleatórias que exercem influência sobre a resistência ao colapso de um tubular sob pressão externa são basicamente as mesmas da condição de ruptura. No entanto, a tensão última de tração do material deixa de ser relevante, dando lugar a outras variáveis relacionadas à geometria e a propriedades físicas do material, nomeadamente: ovalidade do tubo $(o v)$, excentricidade do furo 
interno em relação ao diâmetro externo $(e c)$, tensões residuais $(r s)$ e tensão de escoamento do aço $\left(f_{y}\right)$. Desta forma, para o modo de falha de colapso, o vetor $\mathbf{X}$ é dado por:

$$
\mathbf{X}=\left\{M_{E}, D, t, o v, e c, r s, f_{y}\right\}
$$

e o vetor gradiente é tal que:

$$
\vec{\nabla} g=\left\{\frac{\partial g}{\partial \mathbf{X}}\right\}=\left\{p_{R}, M_{E} \frac{\partial p_{R}}{\partial D}, M_{E} \frac{\partial p_{R}}{\partial t}, M_{E} \frac{\partial p_{R}}{\partial o v}, M_{E} \frac{\partial p_{R}}{\partial e c}, M_{E} \frac{\partial p_{R}}{\partial r s}, M_{E} \frac{\partial p_{R}}{\partial f_{y}},-\frac{\partial p_{S}}{\partial p_{o}}\right\}
$$

Cada um dos termos do vetor gradiente é calculado de maneira análoga ao caso de ruptura, sendo o primeiro termo igual à pressão de colapso avaliada em $\mathbf{x}$ e o último termo correspondente $\mathrm{a}-\partial p_{S} / \partial p_{o}=-1$.

Por fim, a equação que representa o estado limite último de escoamento de um revestimento submetido a um estado triaxial de tensão é dada por:

$$
g(\mathbf{X})=\sigma_{R}-M_{E} \cdot \sigma_{V M}
$$

onde a tensão resistente, $\sigma_{R}$, é expressa por meio da tensão que causa o escoamento do material quando submetido a um ensaio uniaxial de tração $\left(\sigma_{R}=f_{y}\right)$; a tensão solicitante, $\sigma_{V M}$, é calculada por meio do critério de von Mises (Eq. 6.48); e a variável erro de modelo, $M_{E}$, é considerada determinística e com valor unitário, uma vez que a norma ISO TR 10400:2011 não apresenta dados estatísticos para este critério.

Por tratar de um estado geral de tensão, o critério de von Mises é função das seguintes variáveis aleatórias: diâmetro externo $(D)$, espessura do tubo $(t)$, força axial solicitante $\left(F_{a}\right)$, pressão externa $\left(P_{o}\right)$ e pressão interna $\left(P_{i}\right)$. Sendo assim, o vetor $\mathbf{X}$ é dado por:

$$
\mathbf{X}=\left\{D, t, F_{a}, P_{o}, P_{i}\right\}
$$

e o vetor gradiente é tal que:

$$
\vec{\nabla} g=\left\{\frac{\partial g}{\partial \mathbf{X}}\right\}=\left\{\frac{\partial \sigma_{R}}{\partial f_{y}},-\frac{\partial \sigma_{V M}}{\partial D},-\frac{\partial \sigma_{V M}}{\partial t},-\frac{\partial \sigma_{V M}}{\partial F_{a}},-\frac{\partial \sigma_{V M}}{\partial P_{o}},-\frac{\partial \sigma_{V M}}{\partial P_{i}}\right\}
$$

$\mathrm{O}$ primeiro termo do vetor gradiente corresponde a $\partial \sigma_{R} / \partial f_{y}=1$, sendo os demais multiplicados por $M_{E}$ caso se deseje considerar a incerteza do modelo.

As fórmulas para o cálculo dos demais termos dos vetores gradientes representados nas Eqs. (7.13), (7.15) e (7.18) são descritas no Apêndice A devido à sua complexidade e extensão.

\subsubsection{Simulações de Monte Carlo}

Quando o problema envolve variáveis aleatórias fortemente correlacionadas e/ou suas distribuições de probabilidade são fortemente não-Gaussianas, métodos de transformação podem gerar resultados aproximados muito pobres e, por vezes, não convergir. Nestas situações, uma alternativa é recorrer a técnicas de simulação.

Dentre as técnicas de simulação em confiabilidade, a simulação de Monte Carlo é sem dúvida a mais aplicada. Além de ser utilizada nos casos em que os métodos analíticos falham, é 
também empregada quando se deseja testar a resposta obtida por outros métodos. Isto porque, em teoria, é uma técnica considerada exata na medida em que o seu resultado tende ao valor exato quando o número de simulações tende ao infinito. Além disso, neste tipo de técnica não são feitas quaisquer aproximações do domínio de falha.

Outra grande vantagem das técnicas de simulação está no fato de que não há limite para o número de variáveis do problema ou na complexidade do modelo estudado, resolvendo-se problemas com poucas ou muitas variáveis com a mesma facilidade. A eficiência do método está atrelada majoritariamente à probabilidade de falha esperada, pois dela depende o número de simulações necessários à boa convergência da resposta.

Nas análises estruturais em que as probabilidades de falha admissíveis são muito pequenas (da ordem de $10^{-4}$ ), o custo computacional envolvido na realização das simulações passa a ser um fator limitante e, por vezes, proibitivo. Contudo, a evolução na capacidade de processamento dos computadores combinada à utilização de técnicas de amostragem inteligente permitem suplantar tal barreira.

\subsubsection{Técnicas de amostragem}

Para a realização de simulações de Monte Carlo, é necessário antes gerar amostras de variáveis aleatórias. Para isso, diferentes técnicas de amostragem podem ser empregadas. A seguir, serão explicadas de modo breve as técnicas de amostragem simples e por hipercubo latino, sendo a última utilizada no presente trabalho.

A primeira técnica envolve a geração de um número aleatório, $u_{i}$, com distribuição uniforme de probabilidades e valores compreendidos no intervalo de [0,1]. A partir deste número, obtém-se uma realização da variável aleatória $x$, com função de distribuição cumulativa de probabilidades $F_{X}(x)$, a partir da seguinte relação:

$$
x_{i}=F_{X}^{-1}\left(u_{i}\right),
$$

em que $F_{X}^{-1}$ representa a inversa da função cumulativa de probabilidades da variável $x$.

A utilização da técnica de amostragem simples para a realização de simulações de Monte Carlo constitui a forma mais básica de aplicação do método. A facilidade na geração das amostras é, entretanto, contrabalanceada pela qualidade dos pontos amostrados. Devido ao fato de serem gerados aleatoriamente em todo o domínio, pode ocorrer a concentração de pontos em algumas regiões, deixando outras com pontos esparsos.

Uma técnica de amostragem mais eficiente é a amostragem por hipercubo latino ( $L H S$ - Latin Hypercube Sampling). Ao contrário da amostragem simples, a LHS procura evitar a falta de homogeneidade na cobertura do espaço amostral por meio da divisão do domínio de cada variável aleatória em faixas e da realização de amostragens em cada uma delas uma única vez. A Figura 7.1 ilustra a geração de pontos segundo as técnicas de amostragem simples e por hipercubo latino para duas variáveis aleatórias. Maiores detalhes sobre estas e outras técnicas podem ser consultados em Santos (2014b). 
Figura 7.1 - Amostragem simples e por hipercubo latino.
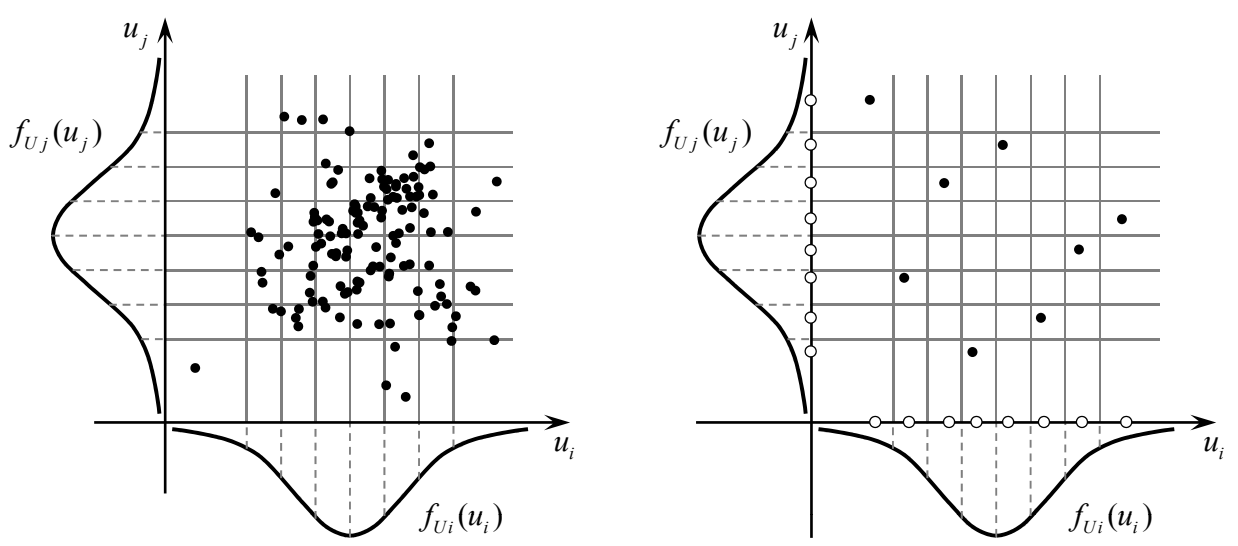

Fonte: Adaptado de Santos (2014b).

\subsubsection{Monte Carlo Bruto}

O modo mais usual e direto de realizar simulações de Monte Carlo é usualmente denominado de Monte Carlo Bruto ou Simples. A solução de problemas de confiabilidade por meio deste método envolve a utilização de uma função indicadora $I[\mathbf{x}]$, definida como:

$$
\begin{aligned}
& I[\mathbf{x}]=1 \quad \text { se } \quad \mathbf{x} \in \Omega_{f} \quad \text { (falha) } \\
& I[\mathbf{x}]=0 \quad \text { se } \quad \mathbf{x} \in \Omega_{s} \quad \text { (sobrevivência) }
\end{aligned}
$$

Substituindo o limite de integração da Eq. (7.5) por todo o domínio do problema $\Omega$, é possível calcular a probabilidade de falha a partir da seguinte expressão:

$$
P_{f}=\int_{\Omega} I[\mathbf{x}] f_{\mathbf{X}}(\mathbf{x}) d(\mathbf{x}) \equiv \mathrm{E}[I[\mathbf{x}]]
$$

Por definição, a Eq. (7.21) equivale ao valor esperado da função indicadora $I[\mathbf{x}]$. Com base em uma amostra de tamanho finito $n$, é possível então estimar a probabilidade de falha como:

$$
\bar{P}_{f}=\frac{1}{n} \sum_{i=1}^{n} I\left[x_{i}\right]=\frac{n_{f}}{n}
$$

onde $n_{f}$ é o número de pontos amostrais no interior do domínio de falha.

Visto que a estimativa obtida pela Eq. (7.22) é computada com base em uma amostra de dimensão finita, está sujeita a um erro estatístico de amostragem correspondente à variância de $I[\mathbf{x}]$, ou seja:

$$
\operatorname{Var}\left[\bar{P}_{f}\right]=\frac{1}{n-1} \sum_{i=1}^{n}\left(I\left[x_{i}\right]-\bar{P}_{f}\right)^{2}
$$

$\mathrm{Na}$ expressão anterior, observa-se que o valor da variância (representativo da incerteza envolvida na simulação) diminui conforme o número de simulações cresce, indo para zero à medida que $n \rightarrow \infty$.

A partir das Eqs. (7.22) e (7.23) é possível então determinar o intervalo de confiança do resultado da simulação:

$$
\bar{P}_{f}-k \sqrt{\operatorname{Var}\left[\bar{P}_{f}\right]} \leq \bar{P}_{f} \leq \bar{P}_{f}+k \sqrt{\operatorname{Var}\left[\bar{P}_{f}\right]}
$$


sendo o parâmetro $k$ determinado com base no nível de confiança desejado, segundo uma distribuição Normal. Para um nível de confiança de 95\%, $k \approx 1,96$.

Para obter uma boa estimativa da probabilidade de falha utilizando o Monte Carlo Bruto, um grande número de simulações torna-se necessário ${ }^{2}$. Nos casos em que a equação de estado limite possui solução analítica, isto não gera maiores problemas. Entretanto, quando a análise de confiabilidade envolve simulações numéricas do comportamento estrutural, técnicas de simulação mais eficientes devem ser utilizadas.

\subsubsection{Monte Carlo por Importância usando pontos de projeto}

O método de Monte Carlo por Importância usando pontos de projeto é uma técnica de simulação inteligente utilizada para estimar a probabilidade de falha de problemas nos quais o Monte Carlo Bruto apresenta dificuldades. Este método faz uso da informação sobre as coordenadas dos pontos de projeto para transladar os pontos de amostragem para regiões importantes do domínio de falha.

A geração dos pontos simulados é feita a partir de uma função de amostragem $h_{\mathbf{X}}(\mathbf{x})$, que os desloca para o domínio de falha. Multiplicando-se numerador e denominador da Eq. (7.21) por $h_{\mathbf{X}}(\mathbf{x})$, obtém-se:

$$
P_{f}=\int_{\Omega} I[\mathbf{x}] \frac{f_{\mathbf{X}}(\mathbf{x})}{h_{\mathbf{X}}(\mathbf{x})} h_{\mathbf{X}}(\mathbf{x}) d(\mathbf{x})
$$

Quando a função de amostragem desloca os pontos para o domínio de falha, o valor esperado da nova função indicadora, $I[\mathbf{x}] \frac{f_{\mathbf{X}}(\mathbf{x})}{h_{\mathbf{X}}(\mathbf{x})}$, será maior do que o valor da função original. Contudo, cada ponto amostrado no interior do domínio de falha não mais estará associado à unidade, e sim a um peso definido por $w_{i}$ :

$$
w_{i}=\frac{f_{\mathbf{X}}\left(x_{i}\right)}{h_{\mathbf{X}}\left(x_{i}\right)}<1
$$

O método de Monte Carlo por Importância usando pontos de projeto apresenta a principal vantagem de ser praticamente independente da ordem de grandeza da probabilidade de falha, visto que praticamente metade do número de pontos amostrados estará dentro do domínio de falha (BECK, 2014). Isto garante a rápida convergência do método e, consequentemente, uma baixa variância da probabilidade de falha, quando comparado com o Monte Carlo Bruto. A amostragem por importância utilizando pontos de projeto pode ainda ser combinada à técnica de geração de amostras por hipercubo latino, aumentando ainda mais a eficiência do processo de simulação.

Para empregar o método, entretanto, deve-se conhecer a priori as coordenadas dos pontos de projeto. Isto em geral é feito através de uma análise inicial com o método FORM e, portanto, está condicionado à sua convergência.

2 Para obter uma probabilidade de falha da ordem de $10^{-p}$ com coeficiente de variação inferior a $10 \%$, é necessária uma amostra de tamanho mínimo $10^{p+2}$ (BECK, 2014). 


\subsection{Confiabilidade de sistemas estruturais}

Cada coluna de revestimento pode ser pensada como um sistema estrutural formado pela associação em série de um grande número de tubulares. Sua falha está condicionada à falha individual de cada um destes tubulares, os quais, por sua vez, estão sujeitos a múltiplos modos de falha.

Tendo em vista o contexto mais amplo de otimização em que as análises de confiabilidade serão realizadas, é importante definir o modelo mais apropriado a tais análises. Dois modelos são possíveis: de componente, que considera a falha de cada tubular de maneira isolada; ou de sistema, que considera a coluna de revestimento como um todo (ADAMS; HODGSON, 1999).

\section{Modelo de componente}

No modelo de componente, a probabilidade de falha do tubular é indicativa da probabilidade de falha do revestimento como um todo. O tubular falha caso um dos estados limites de colapso, ruptura ou escoamento seja violado, sendo todos idealizados como eventos mutuamente exclusivos.

A verificação da segurança da coluna é feita ponto a ponto, ao longo da profundidade do poço. As probabilidades de falha estimadas são utilizadas para otimizar a seleção de cada tubular e adequar o projeto ao índice de confiabilidade alvo. O cômputo da probabilidade de falha neste modelo é muito mais célere computacionalmente, pois a confiabilidade do sistema não é estimada.

\section{Modelo de sistema}

No modelo de sistema, a falha de um único tubular provoca a falha do revestimento, tal como elos de uma corrente. Sendo assim, denotando por $F_{i}$ o evento correspondente à falha do tubular $i$, o evento falha do sistema $(F)$ pode ser representado como:

$$
F=F_{1} \cup F_{2} \cup \ldots \cup F_{n}=\cup_{i=1}^{n} F_{i}
$$

sendo a probabilidade de falha de sistemas em série dada por:

$$
P_{f, s y s}=P[F]=P\left[\cup_{i=1}^{n} F_{i}\right]
$$

A expressão acima é de difícil mensuração no caso de sistemas compostos por um número grande de componentes estatisticamente dependentes, como é o caso das colunas de revestimento. Por essa razão, limites superior e inferior foram desenvolvidos. Na avaliação de $P_{f, s y s}$, deve-se verificar se há correlação entre os eventos $F_{i}$. Caso exista dependência perfeita entre todos os eventos, a probabilidade de falha do sistema é igual à do componente mais fraco (evento de maior probabilidade de ocorrência), isto é:

$$
P_{f, s y s}=\max _{i=1}^{n} P\left[F_{i}\right]
$$

Caso os eventos sejam independentes entre si, a falha do sistema está condicionada à falha de pelo menos um componente (não obrigatoriamente o mais susceptível a falhar). Em 
outras palavras, para que o sistema esteja apto a cumprir com sua função, é necessário que todos os seus componentes estejam funcionando. Assim, se denotarmos por $S_{i}$ o evento de sobrevivência (não-falha) do componente $i$, a probabilidade de sobrevivência $P_{S, s y s}$ do sistema corresponde a:

$$
P\left[S_{1}\right]=1-P\left[F_{1}\right] \therefore P_{S, s y s}=\left(1-P\left[F_{1}\right]\right) \cdot(\ldots) \cdot\left(1-P\left[F_{n}\right]\right)=\prod_{i=1}^{n} P\left[S_{i}\right]
$$

Finalmente, a probabilidade de falha de um sistema formado por componentes independentes será:

$$
P_{f, s y s}=1-P_{S, s y s}=1-\prod_{i=1}^{n} P\left[S_{i}\right]
$$

Para probabilidades de falha individuais pequenas, a Eq. (7.31) pode ser aproximada pelo somatório das probabilidades de falha de todos os componentes, de modo a se obter os seguintes limites para o modelo de sistema (JCSS, 2001):

$$
\max _{i=1}^{n} P\left[F_{i}\right] \leq P_{f, s y s} \leq 1-\prod_{i=1}^{n} P\left[S_{i}\right] \approx \sum_{i=1}^{n} P\left[F_{i}\right]
$$

\section{Escolha do modelo}

Em sistemas de revestimento, as propriedades de resistência variam ao longo do comprimento da coluna e pode haver correlação entre as propriedades de resistência dos tubulares, o que indica a necessidade de modelar o comportamento do sistema (GRANDHI; WANG, 1999). Entretanto, tal modelagem para análise da confiabilidade tem sérias implicações em termos de custo computacional, além de serem necessários dados acerca da dependência real entre os componentes. Logo, é importante ponderar a representatividade do modelo de componente frente ao preço de se realizar uma análise completa.

Embora o modelo de componente seja computacionalmente vantajoso, Grandhi e Wang (1999) argumentam que estimar a confiabilidade estrutural de sistemas estruturais com base apenas na falha de um elemento pode não fornecer uma estimativa segura para o sistema estrutural. Segundo os autores, uma análise probabilística mais precisa deve considerar a correlação entre os múltiplos modos de falha ou entre os elementos que compõem o sistema.

Nos casos em que o modelo de sistema seja o mais indicado, Adams e Hodgson (1999) sugerem que o comportamento da coluna seja idealizado como um sistema em série, no qual a resistência de cada componente é considerada independente dos demais, por uma questão de simplificação. O número de componentes é determinado pelo comprimento de correlação das propriedades de resistência relevantes, definido como sendo o comprimento além do qual suas realizações podem ser efetivamente tratadas como independentes. A cada componente corresponderá então uma realização independente das variáveis de resistência quando se fizer uso de simulações de Monte Carlo.

O conceito de comprimento de correlação recomendado por Adams e Hodgson (1999) é um tanto quanto vago e impreciso. Assim, quando não se dispõe de dados estatísticos suficientes 
para defini-lo com clareza, propõe-se um critério alternativo para determinar o número de componentes de uma coluna: tubulares com iguais propriedades mecânicas e geométricas podem ser admitidos como um único componente, perfeitamente correlacionados entre si, como se fossem amostras de um mesmo lote; enquanto conjuntos de tubulares com propriedades distintas são admitidos como componentes independentes (podendo ser, inclusive, adquiridos de diferentes fabricantes).

Este novo critério fundamenta-se em dois aspectos práticos. Primeiro, é razoável admitir que as resistências de tubulares de igual peso e grau, usinados na mesma fábrica, irão variar em torno de um valor médio semelhante. Afinal, ambos são produzidos a partir dos mesmos materiais, seguindo o mesmo processo, cujo objetivo é produzir tubulares com propriedades idênticas. Segundo, tubulares com iguais propriedades são normalmente comprados de um único fabricante, em virtude das vantagens econômicas atreladas ao volume do pedido (poder de barganha).

Após estabelecer o número total de componentes, calcula-se a probabilidade de falha de cada componente $i$ para o nível médio de carregamento ao longo do comprimento de correlação. Em seguida, computa-se a probabilidade de falha do sistema com base na probabilidade de sobrevivência de todos os $n$ componentes, aplicando a Eq. (7.31) ou a aproximação expressa na Eq. (7.32).

O resultado é então comparado com a probabilidade de falha para um modelo de componente estimada no ponto mais crítico da coluna de revestimento (aquele com a menor margem de segurança observada). Adams e Hodgson (1999) afirmam que três resultados são possíveis:

1) Quando os carregamentos têm alta taxa de variação ao longo do comprimento de correlação, a probabilidade de falha do componente crítico $\left(P_{f, \text { crit }}\right)$ é geralmente conservadora em relação à do sistema $\left(P_{f, s y s}\right)$ e pode ser adotado um modelo de componente;

2) Quando os carregamentos têm taxa de variação moderada, a confiabilidade do modelo de sistema é ligeiramente mais alta e a diferença entre os dois modelos pode ser aplicada como um fator de ponderação;

3) Quando o carregamento é praticamente o mesmo em todos os componentes, pode ser necessário utilizar um modelo de confiabilidade de sistema.

Para verificar o efeito da variabilidade do carregamento sobre a confiabilidade do sistema e estudar a representatividade de cada modelo, um estudo de caso simples foi conduzido. Avaliouse, para os três casos de carregamento mostrados na Figura 7.2, a probabilidade de falha de um revestimento de superfície ao longo de sua profundidade para o modo de falha triaxial. 
Figura 7.2 - Cenários de carregamento analisados.

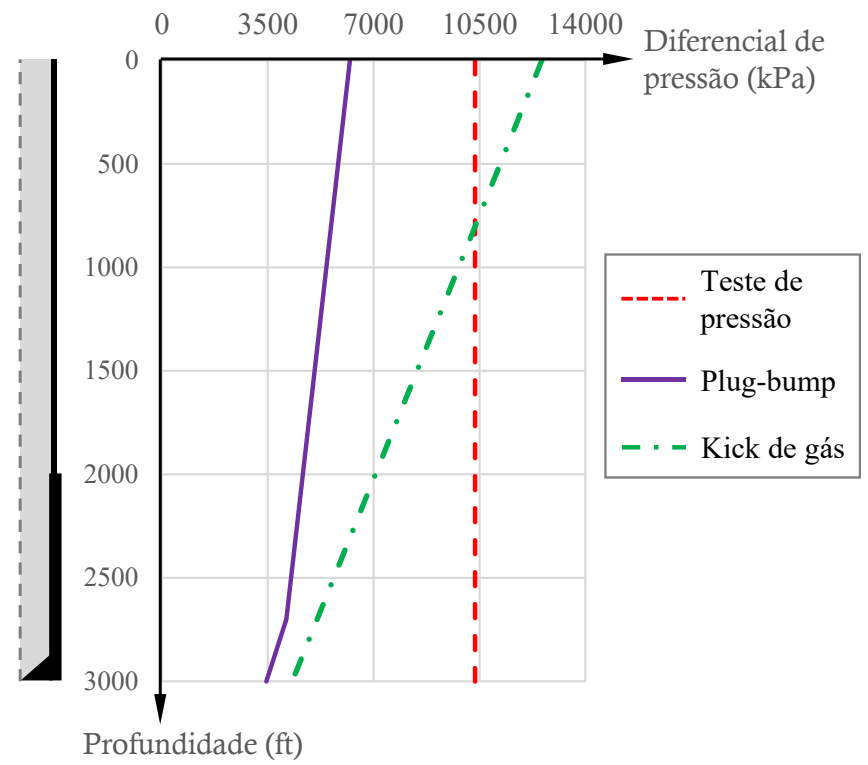

Os cenários de carregamentos considerados foram:

a. Teste de pressão: aplicação de um diferencial de pressão de 1500 psi (10340 kPa) constante ao longo de toda a altura da coluna;

b. Pressão de plug-bump: aplicação de sobrepressão interna para vedação dos tampões após após o término da operação de cimentação;

c. Kick de gás: perfil de pressões diferenciais de ruptura causados por um kick de gás durante a perfuração da próxima fase de revestimento.

Da Figura 7.2, observa-se que o cenário de teste de pressão representa a condição de baixa variabilidade mencionada por Adams e Hodgson (1999), enquanto o carregamento de kick é o que exibe maior taxa de variação ao longo do comprimento de correlação. O cenário (b), por sua vez, representa uma situação entre estes dois extremos.

Para o estudo de caso, admitiu-se um revestimento composto por dois segmentos de propriedades geométricas distintas (modelo com dois componentes) e cimentado ao longo de todo a sua extensão. Os dados de entrada do problema são apresentados na Tabela 7.4.

Tabela 7.4 - Propriedades do revestimento de superfície.

\begin{tabular}{cccccc}
\hline Segmento & $\begin{array}{c}\text { TVD } \\
\text { (ft) }\end{array}$ & $\begin{array}{c}\text { OD } \\
\text { (in) }\end{array}$ & $\begin{array}{c}\text { ID } \\
\text { (in) }\end{array}$ & $\begin{array}{c}\text { Peso Linear } \\
\text { (lb/ft) }\end{array}$ & $\begin{array}{c}\text { Classe } \\
\text { de aço }\end{array}$ \\
\hline 1 & 2000 & $133 / 8$ & 12.615 & 54.5 & K-55 \\
2 & 3000 & $133 / 8$ & 12.415 & 68 & K-55 \\
\hline
\end{tabular}

Os resultados das simulações numéricas são exibidos na Figura 7.3. Foram calculados os índices de confiabilidade em toda a extensão do revestimento, porém os valores de interesse são aqueles em destaque nos gráficos. Segundo a metodologia de Adams e Hodgson (1999), a confiabilidade de cada componente é calculada para o valor médio do carregamento ao longo do comprimento de correlação. Porém, por simplicidade, admitiu-se como sendo igual à confiabilidade do tubular localizado na posição intermediária do componente. 
Figura 7.3 - Índices de confiabilidade para o modo de falha triaxial (critério de von Mises).

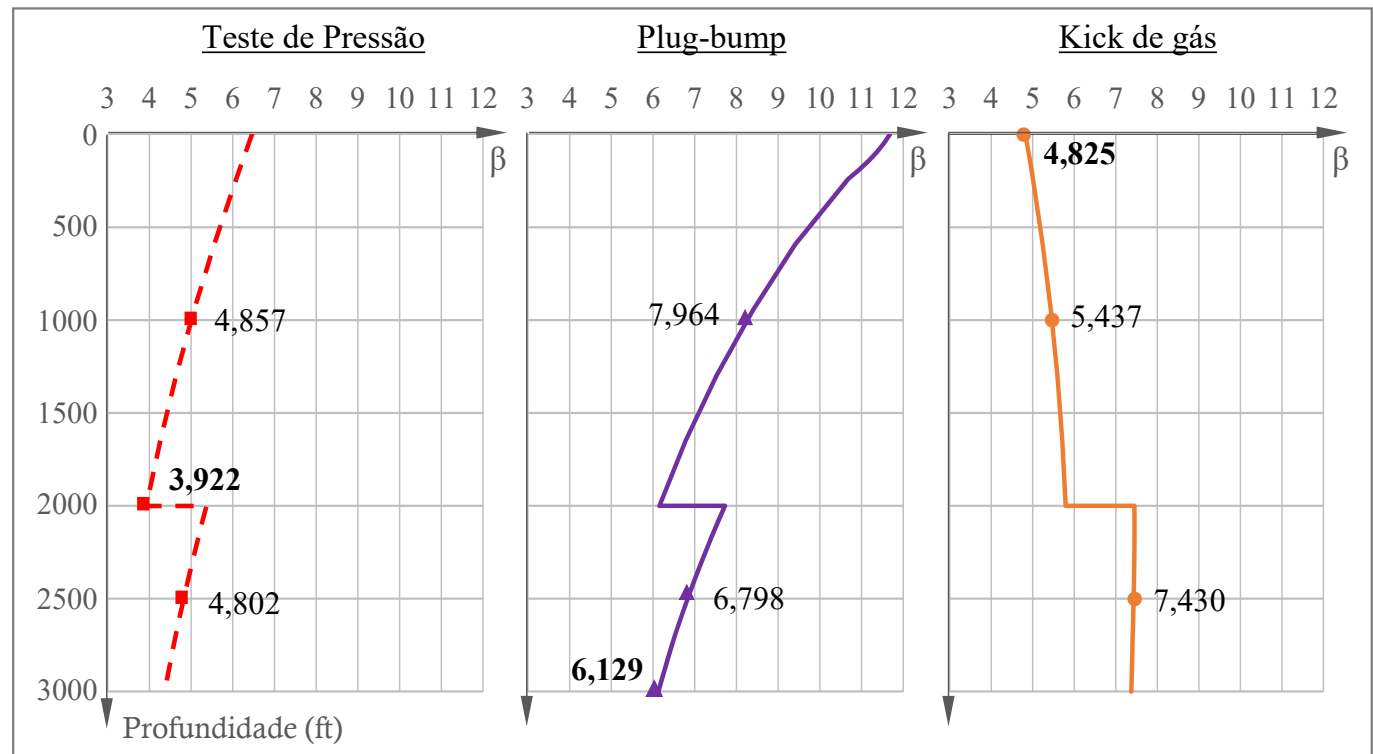

Ao contrário do que os autores da metodologia argumentam, a taxa de variação do carregamento não apresenta relação direta com o aspecto da curva de confiabilidade. O cenário de plug-bump, com taxa de variação moderada, foi o que apresentou a maior amplitude nos resultados $(\beta=6,12 \sim 11,68)$. O cenário de kick, por outro lado, foi o que apresentou menor dispersão ao longo de cada segmento do revestimento, especialmente no caso do segmento 2 $(\beta \approx 7,425)$. Uma possível explicação para o fenômeno talvez esteja relacionada à influência das forças axiais do problema, uma vez que o modo de falha triaxial é igualmente afetado por todas as componentes de tensão.

Dando prosseguimento ao estudo de caso, as probabilidades de falha de cada componente foram combinadas por meio da Eq. (7.32) para obter $P_{f, s y s}$ e então compará-la com $P_{f \text {,crit. Os }}$ valores calculados estão expressos na Tabela 7.5.

Tabela 7.5 - Índices de confiabilidade e probabilidades de falha do sistema e do componente crítico.

\begin{tabular}{|l|cc|cc|cc|}
\cline { 2 - 7 } \multicolumn{1}{c|}{} & \multicolumn{2}{c|}{ Teste de Pressão } & \multicolumn{2}{c|}{ Plug-bump } & \multicolumn{2}{c|}{ Kick de gás } \\
\multicolumn{1}{c|}{} & $\beta$ & $P_{f}$ & $\beta$ & $P_{f}$ & $\beta$ & $P_{f}$ \\
\hline Componente 1 & 4.857 & $5.96 \mathrm{E}-07$ & 7.964 & $8.31 \mathrm{E}-16$ & 5.437 & $2.72 \mathrm{E}-08$ \\
Componente 2 & 4.802 & $7.84 \mathrm{E}-07$ & 6.798 & $5.31 \mathrm{E}-12$ & 7.430 & $5.45 \mathrm{E}-14$ \\
Sistema & & $\mathbf{1 . 3 8 E - 0 6}$ & & $\mathbf{5 . 3 1 E - 1 2}$ & & $\mathbf{2 . 7 2 E - 0 8}$ \\
\hline Crítico & 3.922 & $\mathbf{4 . 3 9 E - 0 5}$ & 6.129 & $\mathbf{4 . 4 1 E - 1 0}$ & 4.825 & $\mathbf{7 . 0 1 E - 0 7}$ \\
\hline
\end{tabular}

Com base nos resultados obtidos, percebe-se que em todos os casos a probabilidade de falha do componente crítico é conservadora em relação à do sistema (isto é, $P_{f \text {,crit }}>P_{f, \text { sys }}$ ), recaindo na situação em que o modelo de componente é recomendado. Sendo assim, no presente trabalho opta-se pela adoção do modelo de componente para as análises de confiabilidade, especialmente devido à sua maior precisão e mais fácil implementação. 


\subsection{StRAnD}

O StRAnD (Structural Risk Analisys and Design) é um programa computacional desenvolvido junto ao departamento de Engenharia de Estruturas da Escola de Engenharia de São Carlos (EESC-USP), escrito em linguagem FORTRAN com conceitos de programação orientada a objeto, cuja especialidade é a realização de análises de risco. Em sua versão atual, o programa é capaz de realizar análises de confiabilidade dependente e independente do tempo, confiabilidade de sistemas e otimização de risco. Apresenta ainda uma interface de acoplamento com o software comercial ANSYS ${ }^{\mathrm{TM}}$ para para solução de problemas estruturais complexos, além de um programa para análise de estruturas reticuladas implementado no interior de seu próprio código fonte (TESSARI, 2016).

Dentre os métodos de confiabilidade disponíveis no StRAnD, estão os métodos de transformação de primeira e segunda ordem (FORM e SORM), superfícies de resposta e simulação de Monte Carlo. Com relação às técnicas de simulação, além do Monte Carlo Simples é possível também realizar simulações com amostragem assintótica, melhorada e por importância usando pontos de projeto, bem como simulação de subconjuntos (SANTOS, 2014a).

Nos estudos de caso realizados adiante neste trabalho, a estimativa da confiabilidade dos revestimentos é calculada majoritariamente por meio do método FORM em virtude de sua eficiência computacional e devido ao fato das equações de estado limite apresentarem gradientes analíticos. O método é também empregado no estudos da sensibilidade de cada variável sobre a resposta do sistema.

Visto que métodos aproximativos não apresentam estimativas de erro, em alguns casos são também realizadas simulações de Monte Carlo bruto e por importância para verificar a qualidade dos resultados obtidos pelo FORM. Ambas as estratégias de simulação estão combinadas à técnica de amostragem por hipercubo latino e permitem calcular a variância da probabilidade de falha estimada. 


\section{Descrição estatística dos parâmetros de interesse}

O problema fundamental da confiabilidade estrutural envolve a avaliação da probabilidade de que a resistência $(R)$ de um determinado sistema seja menor ou igual à solicitação $(S)$ nele atuante ao longo de sua vida útil. Tal probabilidade recebe o nome de probabilidade de falha $\left(P_{f}\right)$ e representa a propensão do sistema à descumprir com a função para a qual foi projetado. Neste caso, o problema envolve apenas duas variáveis aleatórias que, no entanto, podem ser funções de inúmeras outras.

$$
P_{f}=P[R \leq S]
$$

A solução deste tipo de problema é alcançada por meio de uma abordagem probabilística e depende substancialmente da descrição do comportamento aleatório que um sistema pode apresentar tanto no tempo quanto no espaço. Para uma boa descrição, Faber (2006) afirma que devem ser inicialmente definidos os parâmetros de solicitação e resistência que influenciam a resposta estrutural. Em seguida, cada um deles é modelado por meio de uma variável aleatória, cujas estatísticas incorporam as incertezas intrínsecas ao parâmetro.

Este capítulo busca, portanto, elencar as variáveis aleatórias mais relevantes à análise da confiabilidade de revestimentos de poços. A caracterização da resistência é norteada pelas informações publicadas na norma ISO/TR 10400:2011, que reúne os dados estatísticos das propriedades geométricas e de material mais relevantes dos tubulares (distribuição de probabilidades, média e coeficiente de variação). Os dados estatísticos das variáveis de solicitação, por outro lado, são investigados a partir de uma extensa revisão de trabalhos técnicos publicados na área. Em virtude da pequena quantidade de informação disponível e dos dados contraditórios encontrados, optou-se por admitir estatísticas arbitrárias para as principais variáveis de solicitação nas análises realizadas na sequência deste trabalho.

\subsection{Dados Estatísticos das Variáveis de Resistência}

Cada um dos modelos de resistência vistos no Capítulo 6 depende de diferentes propriedades do revestimento que podem ser adequadamente modeladas por meio de variáveis aleatórias com distribuições estatísticas definidas. A caracterização estatística destas variáveis é essencial ao desenvolvimento das análises de confiabilidade e permite a obtenção de resultados mais condizentes com observações físicas.

Nos apêndices B e F, a norma ISO 10400:2011 apresenta estatísticas das principais variáveis aleatórias de resistência para os modelos de ruptura e colapso de tubulares, respectivamente. Ambos incluem propriedades geométricas, como diâmetro externo, espessura da parede, ovalidade e excentricidade, além de propriedades de material. São fornecidos três conjuntos de estatísticas para cada variável: estatísticas de envoltória (ensemble) e dois conjuntos de estatís- 
ticas críticas (governing). As estatísticas de envoltória correspondem aos valores obtidos para toda a base de dados analisada, enquanto aquelas ditas críticas são propriedades observadas para subconjuntos da base de dados (uma classe de tubo ou um fabricante específico) e que podem conduzir a resultados menos seguros.

Na Tabela 8.1 são apresentadas as variáveis de resistência com seus respectivos momentos estatísticos e distribuições de probabilidades. Constam ainda os dados estatísticos das variáveis erro de modelo dos critérios de ruptura (Klever-Stewart) e de colapso (Klever-Tamano). O parâmetro diâmetro externo foi suprimido da tabela e considerado determinístico para fins práticos devido ao baixo nível de incerteza envolvido em sua estimativa (média real/média nominal $=1,0059 ;$ C.V. $=0,181 \%)$, conforme constatado por Gouveia (2014).

Tabela 8.1 - Dados estatísticos das variáveis de resistência (ISO 10400:2011).

\begin{tabular}{|l|c|c|c|c|c|c|c|c|}
\cline { 4 - 9 } \multicolumn{2}{c|}{} & \multicolumn{2}{c|}{$\begin{array}{c}\text { Envoltória } \\
(\text { ensemble })\end{array}$} & \multicolumn{2}{c|}{$\begin{array}{c}\text { Crítica A } \\
(\text { governing A })\end{array}$} & \multicolumn{2}{c|}{$\begin{array}{c}\text { Crítica B } \\
\text { (governing B })\end{array}$} \\
\hline Variável & Símb. & Distribuição & Média & $\begin{array}{c}\text { C.V. } \\
(\%)\end{array}$ & Média & $\begin{array}{c}\text { C.V. } \\
(\%)\end{array}$ & Média & $\begin{array}{c}\text { C.V. } \\
(\%)\end{array}$ \\
\hline $\begin{array}{l}\text { Erro de modelo } \\
\text { (Klever-Stewart) }\end{array}$ & $M_{K S}$ & Normal & 1.004 & 4.70 & - & - & - & - \\
\hline $\begin{array}{l}\text { Erro de modelo } \\
\text { (Klever-Tamano) }\end{array}$ & $M_{K T}$ & Normal & 0.9991 & 6.70 & - & - & - & - \\
\hline $\begin{array}{l}\text { Espessura da } \\
\text { parede }\end{array}$ & $t$ & Normal & 1.0069 & 2.59 & 0.9876 & 0.2 & 0.985 & 0.1 \\
\hline Ovalidade & $o v$ & Weibull min. & 0.217 & 54.1 & 0.660 & 20.0 & 0.795 & 10.0 \\
\hline Excentricidade & $e c$ & Weibull min. & 3.924 & 66.1 & 13.2 & 20.0 & 15.9 & 10.0 \\
\hline Tensão residual & $r s$ & Normal & -0.237 & 33.2 & -0.264 & 20.0 & -0.318 & 10.0 \\
\hline $\begin{array}{l}\text { Tensão de } \\
\text { escoamento }\end{array}$ & $f_{y}$ & Normal & 1.10 & 4.64 & 1.084 & 2.56 & 1.087 & 2.67 \\
\hline Tensão última & $f_{u}$ & Normal & 1.1180 & 9.80 & 1.0849 & 10.96 & 1.1242 & 8.33 \\
\hline
\end{tabular}

${ }^{1}$ Valores exclusivos da classe de aço P110-CRS. Para demais classes, consular Tabela F.3 da ISO-TR 10400 (2011, p. 163).

As estatísticas para a tensão última foram obtidas com base nos dados apresentados na Tabela B.6 da norma ISO 10400:2011. Os dados de envoltória foram calculados considerando os resultados dos 106 ensaios reportados, enquanto as estatísticas críticas foram calculadas admitindo apenas os resultados de tubulares pertencentes às companhias Grant Prideco e Shell, individualmente, devido à maior base de dados destas empresas.

Salienta-se que nenhuma variável da Tabela 8.1 possui unidade de medida. Por definição, a variável erro de modelo é adimensional. Ovalidade e excentricidade, por sua vez, representam o desvio percentual da geometria do tubular em relação ao valor médio aferido do diâmetro externo e da espessura, respectivamente. A tensão residual, ao contrário do que o termo leva a crer, representa a razão entre a tensão residual e a tensão de escoamento real do material (isto é, $\left.\sigma_{r e s} / f_{y}\right)$. Sendo assim, também não apresenta unidade. As demais variáveis $\left(t, f_{y}\right.$ e $\left.f_{u}\right)$ foram adimensionalizadas propositadamente para aplicação direta nas análises de confiabilidade. Isto significa que devem ser multiplicadas pelo valor nominal dos parâmetros que representam para 
que passem a manifestar dimensões físicas.

Observa-se que as variáveis referentes a ovalidade, excentricidade e tensões residuais apresentam grandes coeficientes de variação. Isto deve-se ao fato da ovalidade e excentricidade variarem substancialmente de acordo com o processo de produção do tubular (seamless/EW) e da tensão residual variar de acordo com o método de desempeno (HRS/CRS).

\subsection{Dados Estatísticos das Variáveis de Solicitação}

Os parâmetros de resistência são incertos e aleatórios, mas são basicamente os únicos sobre os quais o projetista exerce algum controle. Enquanto a previsibilidade da resistência de tubulares pode ser aperfeiçoada pelo maior controle de qualidade do processo de fabricação e pela execução de testes em larga escala do produto acabado, a variabilidade dos parâmetros de solicitação dificilmente é conhecida e pode ser controlada.

Dentre as variáveis de solicitação, aquelas com maior nível de incerteza e que afetam diretamente o projeto de revestimentos são (BEP, 2007):

- Perfis de pressão da formação (pressões de poros e pressões de fratura);

- Gradiente de temperatura;

- Pressão no fundo do poço;

- Intensidade e volume de kicks;

- Pressão de fechamento do poço (SITP - shut-in tube pressure); e

- Composição dos fluidos presentes na formação $\left(\mathrm{H}_{2} \mathrm{~S} / \mathrm{CO}_{2}\right)$.

A dificuldade em descrever o comportamento das variáveis associadas aos carregamentos deve-se não apenas a fatores naturais, mas também a práticas de projeto, procedimentos operacionais e erros humanos. As pressões de poros e as pressões de fratura, por exemplo, são estimadas com base em poços de correlação que muitas vezes estão a muitos quilômetros de distância do poço-alvo. Nestes poços, estas pressões são avaliadas por meio de perda de circulação, fratura intencional ou testes de pressão, procedimentos estes também sujeitos a incerteza significativa (LIAO; GUAN; LONG, 2012; WANG; WANG, 2015). Somado a isso, fatores naturais como zonas de pressão e temperatura anormal igualmente afetam a variabilidade das pressões da formação.

Nos cenários de carregamento envolvendo kicks ou perdas de circulação, a influência de fatores operacionais e humanos é ainda mais crítica (HINTON, 1998; SCHWIND et al., 2001). A velocidade de reação dos operadores em fechar o poço após identificarem um kick, por exemplo, afeta diretamente o volume de gás invasor no interior do revestimento. A falta de treinamento do pessoal e a inexistência de contingências no local podem implicar na perda de controle do poço, ocasionando blowouts.

Basicamente, a incerteza nos carregamentos está relacionada à estimativa da probabilidade de ocorrência de um dado carregamento e à variabilidade da magnitude do carregamento, 
caso ele ocorra (LEWIS et al., 1995b). A probabilidade de ocorrência é geralmente controlada por práticas de projeto e operacionais. A primeira inclui os métodos usados para estimar as cargas ao longo do revestimento e a segunda engloba as políticas adotadas para minimizar a probabilidade de ocorrência de cenários críticos, como treinamento de pessoal. Uma vez que o cenário se concretize, a magnitude do carregamento ao qual o tubo será submetido é controlada por fatores naturais, erro humano e procedimentos operacionais.

Cenários de carregamento intencionais (como cimentação e execução de testes de pressão, por exemplo) não são preocupantes à segurança do poço, pois sua ocorrência é certa e a magnitude das pressões no poço podem ser previstas com grande razoabilidade. Cenários acidentais, por outro lado, são críticos ao dimensionamento do revestimento, pois uma enorme incerteza está presente.

Para estimar a variabilidade de um dado carregamento, pode-se optar por modelar a incerteza intrínseca aos atributos que influenciam a magnitude do carregamento ou utilizar como base as estatísticas derivadas a partir de observações reais (dados coletados em campo) do carregamento em questão. A primeira abordagem é frequentemente empregada, uma vez que a quantidade de dados sobre os atributos de controle é geralmente maior do que os dados relativos ao próprio carregamento (MOOS et al., 2003; MASON; CHANDRASEKHAR, 2005).

Um bom exemplo disso é a variabilidade das pressões de kick. Há uma abundância de dados sobre a intensidade e o volume de kicks ocorridos ao redor do mundo. Pressões de ruptura no revestimento podem ser estimadas a partir desses dados usando vários modelos de kick. Infelizmente, os erros associados aos modelos propostos até o momento são considerados grandes demais para serem efetivamente aplicados em análises probabilísticas rigorosas (BEP, 2007).

A seguir, procura-se apresentar, em ordem cronológica, os principais estudos realizados envolvendo a aplicação de técnicas estatísticas, de mineração de dados e de QRA para a caracterização da incerteza intrínseca aos parâmetros de solicitação em poços profundos. Os resultados obtidos por diferentes autores são comparados e as diferenças ou similaridades são evidenciadas.

\subsubsection{Caracterização de variáveis de solicitação: estado da arte}

\section{Wylie e Visram (1990)}

Um dos primeiros trabalhos publicados a respeito da probabilidade de ocorrência de cenários indesejáveis durante a perfuração de poços é de autoria de Wylie e Visram (1990). No estudo conduzido, os autores analisaram os dados de mais de 60 mil poços perfurados na província de Alberta, Canadá, durante um período de dez anos (1979-1988), categorizando ao todo 2457 kicks e 22 blowouts.

Os eventos foram classificados de acordo com a profundidade em que ocorreram, com a profundidade total do poço e com o tipo de poço (exploratório ou de desenvolvimento). A frequência de ocorrência de kicks, definida como a razão entre o número de kicks observada e o número total de poços pertencentes a uma mesma categoria, foi calculada para o conjunto 
total de dados, resultando em um valor médio de 0,039 (equivalente a 1 kick a cada 25 poços perfurados). Exclusivamente para poços de desenvolvimento, a frequência média calculada foi de 1 ocorrência a cada 32 poços, enquanto para poços exploratórios o risco de tomar um kick demonstrou ser 1,8 vezes maior (cerca de 1 em 18).

Filtrando os resultados conforme a profundidade de ocorrência dos kicks, observouse ainda que a frequência de kicks cresce segundo uma progressão geométrica conforme a profundidade perfurada aumenta, sendo igual a 0,018 para perfurações de até $1000 \mathrm{~m}$ e igual a 0,229 para perfurações superiores a $4000 \mathrm{~m}$. Ao filtrar os dados conforme a profundidade total do poço, a diferença entre a frequência de kicks em poços rasos (até $1000 \mathrm{~m}$ ) e poços profundos (> $4000 \mathrm{~m}$ ) demonstrou ser ainda maior: 0,023 para os primeiros versus 0,54 para os últimos. Isto equivale a um risco 23,5 vezes maior para poços profundos, mesmo em profundidades rasas. $\mathrm{O}$ aumento observado é justificado pelo maior tempo que a formação fica exposta (sem revestimento) devido à maior extensão dos trechos perfurados.

Wylie e Visram limitaram-se a caracterizar a variabilidade da probabilidade de ocorrência de kicks, não se atendo à magnitude dos carregamentos nos quase 2500 casos analisados. Seu pioneirismo, no entanto, instigou o desenvolvimento de outros trabalhos na área.

\section{Adams et al. (1993)}

Embora o objetivo do trabalho de Adams et al. (1993) tenha sido mais abrangente e voltado à descrição de um método para análise quantitativa de risco de sistemas de revestimento usando uma abordagem de confiabilidade estrutural, o estudo publicado envolveu também a caracterização estatística de algumas variáveis de solicitação. Em parceria com a companhia de exploração BP, os pesquisadores procuraram quantificar a incerteza dos parâmetros "pressão de poros"e "volume de kick", identificados como sendo os mais importantes às análises de confiabilidade.

Para a pressão dos poros, um grande número de valores de pressão real/pressão prevista foram registrados a partir de vários campos da BP, abrangendo poços exploratórios e de desenvolvimento. Foi admitida distribuição Gaussiana para os dados e calculou-se o coeficiente de variação para cada tipo de poço. A média da distribuição não foi apresentada pelos autores, de modo que apenas especula-se que seja unitária (igual ao valor previsto). As estatísticas derivadas com base nesses dados são exibidos na Tabela 8.2, tendo sido reproduzida também no trabalho de Liang (2002).

Tabela 8.2 - Dados estatísticos da pressão de poros

\begin{tabular}{lc}
\hline Tipo de poço & Pressão de poros (C.V.) \\
\hline Desenvolvimento & 0,01 a 0,05 \\
Exploratório & 0,05 a 0,15 \\
\hline
\end{tabular}

Fonte: Adams et al. (1993).

A caracterização estatística do volume de kick também derivou de dados coletados em campo e compreendeu um total de 28 eventos em poços de exploração e 17 eventos em poços 
de desenvolvimento. O uso de técnicas estatísticas de regressão revelou que o volume de kick é melhor representado por curvas do tipo Weibull, adequada à representação de distribuições de probabilidades de valores extremos.

Entretanto, os parâmetros das distribuições adotadas para cada tipo de poço não foram informados, limitando a aplicabilidade dos resultados encontrados. Além disso, ainda que os dados de kick tenham sido tratados como homogêneos no estudo, os próprios autores comentam que os mesmos foram obtidos de diferentes plataformas, equipes e sistemas de detecção, sem sofrer qualquer tratamento estatístico preliminar.

Finalmente, os autores chegam à conclusão de que a variabilidade dos carregamentos é consideravelmente maior em poços exploratórios $(\mathrm{C} . \mathrm{V} .=0,10-0,22)$ do que em poços de desenvolvimento (C.V. $=0,02-0,04)$. A variabilidade da pressão de poros observada corrobora este resultado.

\section{Adams e Glover (1998)}

Dando sequência ao trabalho iniciado por Adams et al. (1993), Adams e Glover (1998) reportam os resultados alcançados por meio de um grande projeto desenvolvido em conjunto com dezoito empresas de petróleo e dois órgãos reguladores que tratou da aplicação de técnicas de confiabilidade estrutural e análise de risco ao projeto de revestimentos de poços.

Neste contexto, dados de carregamento coletados em campo pelos participantes foram reunidos e analisados a fim de obter distribuições de probabilidade e frequências de ocorrência para os parâmetros volume de kick e intensidade de kick. Verificou-se que ambos são melhor representados pela distribuição de Weibull, segundo uma população dual de kicks "normais" e "agravados". A frequência de kicks de ambos os tipos registrada em poços críticos (HTHP, exploração) foi muito maior do que em poços de desenvolvimento, concordando com os resultados expostos por Wylie e Visram (1990).

As outras variáveis de solicitação analisadas (pressão de poros, gradiente de fratura, pressão do reservatório e densidade do fluido de produção) apresentaram distribuições Gaussianas. Os dados dos poços de exploração tiveram uma dispersão maior do que os de desenvolvimento, mantendo-se em conformidade com os dados passados (ADAMS et al., 1993).

Novamente os momentos estatísticos (média, variância, etc.) de nenhuma das variáveis de solicitação foi apresentado pelos autores, impossibilitando a reprodutibilidade dos dados. Acredita-se que esta omissão seja proposital, uma vez que se trata de dados confidenciais de corporações privadas.

\section{Adams e Hodgson (1999)}

Os principais avanços do trabalho de Adams e Hodgson (1999) com relação à caracterização das variáveis de solicitação são meramente qualitativos e estão relacionados à diferenciação dos dados amostrais de kick em três diferentes categorias, a depender de sua intensidade e volume: 
1. Kicks normais: apresentam volumes de até $60 \mathrm{bbl}\left(9,5 \mathrm{~m}^{3}\right)$ e intensidades potencialmente altas, chegando a $8 \mathrm{ppg}\left(960 \mathrm{~kg} / \mathrm{m}^{3}\right)$. Compõem a grande maioria dos eventos de kick $(80 \mathrm{a}$ 90\%, dependendo do tipo de poço).

2. Kicks agravados: elevados volumes, na faixa de 80 a $400 \mathrm{bbl}\left(12,7-63,6 \mathrm{~m}^{3}\right)$ e intensidades baixas, inferiores a 2 ppg $\left(240 \mathrm{~kg} / \mathrm{m}^{3}\right)$. Constituem 10 a $20 \%$ do total de kicks, dependendo do tipo de poço;

3. Kicks agravados e intensificados: formam um pequeno grupo de kicks com alto volume e alta intensidade (60-200 bbl, 6-8 ppg). São muito pouco frequentes e correspondem ao tipo de kick mais severo. Diferentemente das duas primeiras categorias, ocorrem apenas em poços HTHP, geralmente nos furos de seção 12 1/4". Logo, são apenas um problema para o projeto de revestimentos intermediários.

Com base nesta classificação e nas análises de confiabilidade conduzidas, os autores evidenciam o fato de que os kicks agravados tendem a dominar o risco de falha de poços não críticos, apresentando probabilidades de falha de 4 a 6 ordens de magnitude maiores do que para kicks normais. Portanto, estes últimos podem ser seguramente negligenciados para todos os efeitos práticos.

\section{Tallin et al. (2000)}

Tallin et al. (2000) avaliaram o risco associado ao projeto de poços exploratórios na região sudoeste de Omã com base nas informações concedidas pela Petroleum Development Oman (DOP). O banco de dados compreendeu os registros históricos de 14 poços perfurados na região, contendo um total de 46 testes de pressão de fratura; cerca de 60 medições de permeabilidade; e 33 pontos de dados comparando pressões de poro previstas e reais. Em posse desses dados, os autores estimaram a probabilidade de ocorrência de kicks e a variabilidade em sua magnitude, bem como modelaram uma distribuição de probabilidades adequada ao parâmetro gradiente de fratura.

A probabilidade de ocorrência de kick estimada foi de $12 \%$ e $19 \%$ por poço, variando de acordo com a margem utilizada no ajuste do peso da lama de perfuração $(0,5$ ppg ou 1,0 ppg). Com base nos dados dos poços de correlação, a probabilidade de ocorrência de kick foi considerada quase independente da profundidade, contrapondo os resultados encontrados por Wylie e Visram (1990). Obviamente tratam-se de poços perfurados em perfis geológicos sem qualquer correlação, porém demonstram a especificidade das estatísticas e a dificuldade em sua extrapolação.

Os resultados também mostraram que os kicks com origem no fundo do reservatório raramente irão envolver influxos de gás (probabilidade inferior a $10^{-4}$ ), uma vez que a probabilidade de encontrar gás diminui com o aumento da pressão dos poros. Isto tem implicações diretas sobre as hipóteses de cálculo admitidas em um cenário de tubing leak, o qual constitui a condição mais severa para o projeto do revestimento de produção.

Os autores observaram ainda que existe uma probabilidade significativa de que um kick de gás frature a formação abaixo da sapata do revestimento. As probabilidades estimadas são 
próximas a 30\%, variando muito pouco com a profundidade da sapata ou com a profundidade total do poço. Dada a elevada probabilidade de fratura de formação, é razoável admitirmos os cenários de ruptura (b) e (c) ilustrados na Figura 4.9, durante a fase de perfuração.

Outros parâmetros de interesse modelados estatisticamente pelos autores foram:

- Temperatura: representada por uma variável aleatória normal, com valor médio dado em função da profundidade e desvio padrão constante (momentos estatísticos não informados);

- Tempo para fechamento do poço: o tempo médio necessário para que a tripulação feche o poço quando um kick é detectado foi definido como sendo de 2,5 minutos, com um desvio padrão de 30 segundos. A calda inferior da distribuição foi truncada em 2 minutos.

\section{Dedenuola et al. (2003)}

Neste artigo, os autores apresentam um método de análise estocástica para previsão apropriada do valor de projeto da tolerância ao kick, amplamente dependente de registros históricos.

Para o estudo, foram coletados dados de mais de 2000 poços perfurados pela SPDC (Shell Petroleum Development Company) no Delta do Níger, entre os anos de 1958 e 2001. A intensidade e o volume de gás de todos os eventos de kick foram classificados de acordo com o tipo de hidrocarbonetos envolvidos, configuração do poço, causa operacional dos eventos e período histórico no qual esses eventos ocorreram. O tamanho da amostra final foi definido por meio de técnicas estatísticas e de mineração de dados.

A análise conduzida mostrou que o volume histórico de kick segue uma distribuição Lognormal de probabilidades, resultado esperado pelos autores uma vez que a maioria dos parâmetros de entrada de modelos matemáticos de fluxo de gás seguem distribuições Gaussianas ou Lognormais. A permeabilidade, por exemplo, a mais dominante de todas as variáveis de equações de fluxo de gás, apresenta igual distribuição.

Além disso, verificou-se que as intensidades de kick foram bem representadas por uma distribuição Gaussiana. Novamente o resultado recaiu dentro das expectativas dos autores, pois a pressão de poros, da qual a intensidade do kick depende, é também normalmente distribuída.

Os dois estudos apresentados, ambos embasados em extensivos dados de campo, permitem evidenciar a dificuldade atrelada à seleção de modelos probabilísticos para representação dos carregamentos atuantes em revestimentos. Enquanto Adams e Glover (1998) chegaram à conclusão de que a distribuição de Weibull é a que mais se adequa à representação do volume e intensidade de kicks, Dedenuola et al. (2003) obtiveram distribuições distintas para ambas as variáveis.

\section{Mason e Chandrasekhar (2005)}

Um dos trabalhos mais abrangentes de caracterização estatística de variáveis de solicitação foi realizado por Mason e Chandrasekhar (2005). O estudo envolveu a definição de funções de densidade de probabilidades (PDFs) para os parâmetros com maior influência sobre o modelo 
de kick proposto pelos autores. Resumidamente, as variáveis aleatórias admitidas pelos autores foram:

- Pressão de Poros e Gradiente de Fratura:

Distribuições logísticas descrevem a variabilidade da pressão de poros e gradientes de fratura em função da profundidade.

- Gravidade específica do gás:

Definida como a razão entre a densidade específica do gás e da água $\left(\rho_{\text {gas }} / \rho_{\text {agua }}\right)$, segue uma distribuição normal com média igual a 0,6 e extremos truncados em 0,5 e 0,7.

- Volume de kick observado (pit gain):

Distribuição Lognormal estimada com base em 20 anos de dados de kick. O volume médio de influxo desse conjunto de dados foi de pouco mais de $25 \mathrm{bbl}\left(4 \mathrm{~m}^{3}\right)$. A PDF é truncada na cauda inferior em $5 \mathrm{bbl}\left(0,8 \mathrm{~m}^{3}\right)$ em virtude das limitações dos equipamentos de detecção de kick.

- Perfil de temperatura não perturbado:

Expresso por $T(z)=60+t \cdot z$, onde $T(z)$ é a temperatura $\left[{ }^{\circ} \mathrm{F}\right]$ não perturbada da formação a uma profundidade $z$ [ft], e $t$ é o gradiente de temperatura, considerado uniformemente distribuído entre 0,010 e 0,017 [ $\left.{ }^{\circ} \mathrm{F} / \mathrm{ft}\right]$.

- Intensidade de kick:

O PDF da intensidade de kick é baseado em um artigo publicado por Booth (1994) e assume a forma de uma distribuição Weibull.

- Margem de segurança para "matar" um kick:

Representa a sobrepressão de projeto que pode ser aplicada ao circular um influxo. Um valor médio de 200 psi é admitido (1380 kPa). A incerteza sobre essa média é normalmente distribuída em \pm 100 psi usando um desvio padrão de 50 psi.

Segundo Mason e Chandrasekhar, as PDFs selecionadas promoveram o melhor ajuste aos dados de testes de vazamento e kicks compilados ao longo de 20 anos a partir de fontes em todo o mundo. Contudo, informações específicas a respeito da base de dados utilizada para a caracterização estatística das variáveis não foram informadas pelos autores. Somado a isso, as poucas referências citadas prejudicam a credibilidade dos dados apresentados.

\section{Guan et al. (2018)}

Um dos trabalhos mais recentes publicados a respeito da aplicação de QRA a poços profundos e que lida com a variabilidade dos parâmetros de solicitação é de autoria de Guan et al. (2018). Cientes da enorme incerteza ainda presente em parâmetros geológicos, os autores propõem um método que a incorpora às pressões de formação, admitindo um certo nível de confiança. O valor determinístico (fixo) da pressão de poros e da pressão de fratura é substituído por um intervalo de valores normalmente distribuídos, sendo que os extremos da distribuição correspondem aos valores estimados por diferentes especialistas ou através de técnicas com maior ou menor erro associado, por exemplo. 
O objetivo central do artigo é estabelecer janelas seguras para a densidade do fluido de perfuração, minimizando assim a probabilidade de ocorrência de kicks, perda de circulação e colapso da formação. Esta técnica, no entanto, pode ser incorporada ao dimensionamento de revestimentos, caso se disponha de dados suficientes de poços vizinhos.

\subsubsection{Considerações Gerais}

Dentre os trabalhos citados, dois são particularmente importantes para a aplicação de análises quantitativas de risco ao dimensionamento de revestimentos. O primeiro deles consiste no modelo proposto por Adams e Hodgson (1999) para a estimativa da probabilidade de falha total do revestimento com base em uma árvore de eventos desencadeados pela ocorrência de um kick. Dentre os eventos subsequentes está a falha condicional do revestimento, que pode se suceder com ou sem a fratura da formação. Para calcular tal probabilidade, é interessante utilizar o modelo estocástico proposto por Mason e Chandrasekhar (2005), pois esse descreve os pormenores do cálculo das pressões internas ao longo do revestimento. Conjugando ambos os modelos, o cenário de carregamento na eventualidade de um kick fica probabilisticamente bem definido.

Entretanto, conforme aumenta a complexidade do modelo, cresce o número necessário de dados de entrada. Na ausência de uma base de dados adequada, sua aplicabilidade fica severamente prejudicada, pois pode conduzir a um dimensionamento com nível de segurança inapropriado.

Além disso, o revestimento deve ser capaz de suportar não apenas as pressões internas provocadas por um kick de gás ou óleo, mas também as pressões diferenciais decorrentes de outros eventos extremos, como tubing leak e perda de circulação. Tensões internas causadas pelas forças axiais também podem conduzir o revestimento à falha, de modo que, para caracterizar de maneira completa as variáveis de solicitação, estas não podem ser deixadas de fora.

Com base no que foi exposto, fica evidente a complexidade do assunto. Por este motivo, diversos autores indicam que o modo mais efetivo seria criar uma base de dados de carregamentos integrada entre todas as empresas do setor. No presente trabalho, uma abordagem mais simples será admitida em virtude da carência de dados em quantidade e/ou qualidade razoável. No entanto, o objetivo do trabalho não é prejudicado, visto que a caracterização das variáveis de solicitação está inserida em um contexto mais amplo de otimização probabilística de revestimentos.

\subsubsection{Estatísticas admitidas}

Forças axiais, conforme visto em maior detalhe no Capítulo 5, são causadas predominantemente pelo peso próprio, por variações de temperatura e pelos efeitos balão e pistão. Esforços axiais de menor intensidade podem ser provocados pela flexão do corpo do tubo, por cargas de impacto e forças de arrasto.

Os esforços gerados pelo peso próprio e pela flexão do tubular dependem exclusivamente de propriedades geométricas e físicas do material do revestimento e, consequentemente, 
apresentam uma baixa variabilidade. Cargas de impacto e testes de pressão, por sua vez, estão relacionadas às operações de lançamento e assentamento da coluna de revestimento, suscetíveis a erros humanos. Contudo, se desconsiderarmos esta possibilidade, são carregamentos bem previsíveis. Por fim, as forças de arrasto constituem a fonte de carregamento com maior grau de incerteza neste grupo. Sua magnitude varia em função do fator de atrito, cuja previsão depende de uma grande quantidade de parâmetros: geometria do furo, configuração da superfície do revestimento, fluido de perfuração, propriedades do reboco e irregularidades do furo (BYROM, 2015).

Todas as grandezas ora relacionadas poderiam ser modeladas como variáveis aleatórias. Entretanto, os revestimentos costumam atender naturalmente ao requisito de segurança em termos da tensão axial aplicada, visto que as pressões de colapso e ruptura são críticas ao seu dimensionamento (com exceção do revestimento condutor). Sendo assim, variáveis de solicitação relacionadas a tensões axiais não são diretamente modeladas como variáveis aleatórias, com exceção do peso próprio e das forças de flexão, pois estas dependem de variáveis que afetam também a resistência dos revestimentos. A força de arrasto, quando relevante para a análise estrutural (em poços inclinados ou horizontais, por exemplo), pode ser considerada como um percentual adicional da força axial total solicitante.

Por outro lado, dentre as possíveis variáveis que provocam os piores casos de carregamento de ruptura ou colapso estão:

- a pressão do fluido de perfuração;

- a pressão da pasta de cimento; e

- as geopressões (pressões de poros e de fratura da formação).

A variabilidade da pressão do fluido de perfuração e da pasta de cimento está relacionada à redução da densidade destes fluidos devido a uma possível contaminação por líquidos ou gases contidos na formação. Aferir tal probabilidade de contaminação e sua implicação em termos de pressões é uma tarefa árdua, cujo esforço é questionável sob o ponto de vista da aplicação prática: o fluido contaminante varia de acordo com a litologia de cada poço e com o controle tecnológico de cada operador, de modo que os dados obtidos são muito específicos a cada caso. Logo, é mais racional admitir qual combinação de fluidos no interior e exterior do poço proporciona a pior solicitação de ruptura ou colapso. Por este motivo, em alguns casos de carregamento considera-se como pior hipótese a presença de água salgada no espaço anular entre o furo e o revestimento (deterioração total do fluido de perfuração), além de ser desprezada qualquer resistência adicional provida pelo confinamento do cimento endurecido (RAHMAN; CHILINGARIAN, 1995).

As geopressões, por sua vez, têm fundamental importância em todas as etapas de projeto de um poço, desde a definição da profundidade das colunas de revestimento até o cálculo das pressões de colapso e ruptura. No entanto, ainda não há um modelo estatístico bem definido ou comprovadamente representativo para as pressões de poro e de fratura da formação e, consequentemente, para as pressões internas e externas. Sendo assim, nos estudos de caso posteriormente conduzidos são utilizados valores hipotéticos (arbitrários) de incerteza sobre o valor final das 
pressões, porém esta é uma carência que pode e deve ser estudada em trabalhos futuros. Os valores ora admitidos têm como único objetivo a generalização do código computacional desenvolvido, de maneira a permitir a futura incorporação da incerteza inerente aos parâmetros de carregamento.

A Tabela 8.3 reúne as estatísticas arbitradas para as variáveis de solicitação. Destaca-se que a distribuição lognormal foi escolhida para prevenir que as variáveis apresentem valores negativos (fisicamente uma pressão interna negativa corresponderia a um valor positivo de pressão externa). São admitidas duas variáveis aleatórias adimensionais para representar as pressões interna e externa aos revestimentos, ambas com média unitária e coeficiente de variação de $20 \%$. Essas variáveis passam a multiplicar os valores nominais de pressão calculados ao longo da profundidade de cada fase, proporcionando aleatoriedade aos resultados. Além disso, a tensão axial é enviesada em $10 \%$ para levar em conta a força de arrasto nos tubos, com variabilidade arbitrária.

Tabela 8.3 - Dados estatísticos das variáveis de solicitação.

\begin{tabular}{lccc}
\hline Variável & Distribuição & Média & C.V. \\
\hline Pressão interna & LogNormal & 1,00 & $20 \%$ \\
Pressão externa & LogNormal & 1,00 & $20 \%$ \\
Força axial & LogNormal & 1,10 & $10 \%$ \\
\hline
\end{tabular}




\section{Otimização Baseada em Confiabilidade}

A otimização ou programação matemática objetiva encontrar a melhor solução para um determinado problema a partir de um conjunto de alternativas viáveis. Em geral, problemas de otimização envolvem a minimização ou maximização de uma função que representa o desempenho do sistema, chamada função objetivo, a qual é sujeita a um conjunto de restrições de natureza técnica ou física, também expressas em função das variáveis de projeto.

A solução de problemas de otimização raramente é trivial, pois a função objetivo e as funções de restrição são usualmente conflitantes entre si. No caso específico da otimização estrutural, a solução ótima em geral deve ser capaz de fornecer o melhor compromisso entre custos e segurança.

Matematicamente, um problema de otimização é expresso por (ARORA, 2012):

$$
\begin{aligned}
\text { encontrar: } & \mathbf{d}^{*} \\
\text { que minimiza: } & f(\mathbf{d}) \\
\text { sujeito a: } & c_{i}(\mathbf{d}) \leq 0, i=1, \ldots, m \\
& h_{j}(\mathbf{d})=0, j=1, \ldots, p \\
& \mathbf{d} \in \Omega \subset \mathbb{R}^{n}
\end{aligned}
$$

onde $\mathbf{d}^{*}$ é o valor ótimo do vetor das variáveis de projeto $\mathbf{d} \in \mathbb{R}^{n} ; f(\mathbf{d})$ é a função objetivo; $c_{i}(\mathbf{d}), h_{j}(\mathbf{d})$ são as restrições de desigualdade e igualdade do problema; e $\Omega$ é o subconjunto dos reais que representa todos os pontos viáveis, ou seja, todos os pontos que satisfazem as restrições. Dentre as restrições de desigualdade é usual termos os chamados limites laterais, que representam os valores extremos admitidos pelas variáveis de projeto $\left(\mathbf{d}_{\min } \leq \mathbf{d} \leq \mathbf{d}_{\max }\right)$.

\subsection{Otimização Matemática de Variáveis Discretas}

O modelo matemático de otimização descrito pela Eq. (9.1) permite representar uma vasta gama de problemas ditos contínuos. Tais problemas apresentam como característica fundamental o fato das variáveis de projeto assumirem qualquer valor numérico dentro de seus limites laterais, tal que o conjunto solução pertence ao domínio dos números reais. Em alguns casos, no entanto, as variáveis de projeto só podem assumir valores discretos, de modo que diz-se tratar de um problema de otimização discreta (ARORA, 2012).

Em muitas aplicações práticas, variáveis de projeto discretas ocorrem naturalmente na formulação do problema. Uma variável é chamada de discreta caso seu valor seja atribuído a partir de um determinado conjunto de valores. Por exemplo:

- A espessura de uma chapa deve ser selecionada dentre as disponíveis;

- O diâmetro das barras de aço nos elementos de concreto armado deve ser escolhido dentre aqueles comercializados; 
- As propriedades do material devem corresponder às dos materiais fabricados;

- Perfis estruturais devem ser selecionados com base naqueles catalogados; dentre outros.

Um subconjunto especial das variáveis discretas é o das variáveis inteiras, assim denominadas por só apresentarem valores inteiros. Exemplos incluem a otimização do número de parafusos em uma conexão, do número de barras de aço no concreto, do número de dentes em uma engrenagem, etc.

Quando problemas de otimização envolvem variáveis contínuas e discretas, refere-se a eles como problemas de otimização de variáveis mistas (MV-OPT). Devido à importância desta classe de problemas para aplicações práticas, diversos estudos foram conduzidos objetivando o desenvolvimento de métodos apropriados para sua resolução (ARORA; HUANG, 1996; HUANG; ARORA, 1997a; HUANG; ARORA, 1997b).

\subsubsection{Problemas de otimização de variáveis mistas: definição e classes}

O modelo padrão definido na Eq. (9.1) pode ser estendido à representação de problemas mistos de otimização por meio da incorporação de variáveis discretas à sua definição, como segue:

$$
\begin{aligned}
\text { encontrar: } & \mathbf{d}^{*} \\
\text { que minimiza: } & f(\mathbf{d}) \\
\text { sujeito a: } & c_{i}(\mathbf{d}) \leq 0, i=1, \ldots, m \\
& h_{j}(\mathbf{d})=0, j=1, \ldots, p \\
& d_{k} \in D_{k}, D_{k}=\left(d_{k 1}, d_{k 2}, \ldots, d_{k q_{k}}\right), k=1 \text { a } n_{d} \\
& d_{k L} \leq d_{k} \leq d_{k U}, \quad k=\left(n_{d}+1\right) \text { a } n
\end{aligned}
$$

onde $d_{k i}$ é o $i$-ésimo valor discreto possível para a variável $k ; D_{k}$ é o conjunto dos $q_{k}$ valores possíveis para a $k$-ésima variável; $d_{k L}$ e $d_{k U}$ são os limites laterais inferior e superior das variáveis contínuas e; $n_{d}$ e $n$ são o número de variáveis discretas e de variáveis de projeto, respectivamente.

Dependendo do tipo das variáveis de projeto, das características da função objetivo e das funções de restrição, os problemas MV-OPT podem ser classificados em cinco categorias diferentes, conforme descreve Arora (2012). Para cada categoria, métodos de otimização específicos são recomendados. No caso particular da otimização de revestimentos de poços, o problema pode recair em duas categorias, a depender de sua formulação. A primeira apresenta como características principais:

- A função objetivo ou as funções de restrição não são continuamente diferenciáveis em pelo menos alguns pontos do conjunto viável;

- As variáveis discretas podem ter valores não discretos durante o processo de solução, podendo ser simuladas por meio de variáveis contínuas durante a busca pela solução ótima.

Esta categoria é característica de problemas nos quais o projeto deve atender a restrições impostas por instrumentos normativos. Em geral, essas restrições têm origem empírica ou semiempírica e é comum apresentarem descontinuidades, não sendo diferenciáveis em todo o domínio 
do problema. Uma restrição desta natureza pode ser exemplificada pelo critério de resistência ao colapso do API, o qual abrange um conjunto de quatro equações cujos subdomínios de validade dependem da esbeltez da parede do tubular.

A segunda classe de problemas difere da primeira devido ao comportamento das variáveis discretas. Basicamente lida com variáveis discretas interligadas, de modo que o valor de uma variável está vinculado ao valor atribuído a uma segunda variável. Esse tipo de problema abrange casos práticos em que os elementos estruturais projetados devem ser selecionados dentre uma gama de perfis comercializados e aplicações em que se deseja selecionar o material mais adequado ao projeto. Nestes casos, a escolha de um perfil implica na definição de todas as suas propriedades geométricas (centróide, área, momento de inércia, etc.) e a opção por uma determinada liga de aço em virtude de sua tensão de escoamento, por exemplo, é indissociável das demais propriedades físicas do material (módulo de elasticidade e tensão última, por exemplo).

O problema doravante formulado recai na segunda categoria. A otimização buscará encontrar o tubular com resistência mecânica adequada para suportar as tensões aplicadas, sendo que a resistência mecânica é dada em função das propriedades geométricas e elásticas do material.

\subsection{Otimização e Confiabilidade Estrutural}

Quando a otimização estrutural não leva em consideração as incertezas nas variáveis de projeto (parâmetros de resistência e/ou solicitação), configura-se um problema denominado otimização estrutural determinística ou Deterministic Design Optimization (DDO). A formulação permite encontrar uma configuração estrutural que é ideal em termos de comportamento mecânico ou capacidade de carga, enquanto a segurança da estrutura é garantida indiretamente pelo emprego de coeficientes de segurança (MELCHERS; BECK, 2018). Nesta classe estão incluídos os problemas de otimização com restrições impostas por normas técnicas (projeto semiprobabilístico).

A formulação de um problema DDO típico é:

$$
\begin{aligned}
\text { encontrar: } & \mathbf{d}^{*} \text { que minimiza } f(\mathbf{d}) \\
\text { sujeito a: } & \sigma_{i}(\mathbf{d}) \leq \sigma_{A D M}=\frac{R_{k}}{\mathrm{FS}}, i=1, \ldots, n
\end{aligned}
$$

sendo $\sigma_{i}$ a tensão atuante em um ponto $i$ do material e $\sigma_{A D M}$ sua tensão admissível, que resulta da ponderação da resistência mecânica característica $R_{k}$ por um fator de segurança FS.

Em um cenário determinístico, probabilidades de falhas estruturais são desconsideradas. Desde que a estrutura seja adequadamente projetada e que os fatores de segurança especificados sejam respeitados, admite-se que a falha simplesmente não virá a acontecer. Porém, independentemente de quanto o conhecimento de engenharia e a tecnologia tenham progredido, estruturas eventualmente ainda falham. Várias razões para isso são apresentadas por Petroski (1992), juntamente com alguns exemplos ilustrativos. 
A otimização estrutural baseada em confiabilidade, ou Reliability-based Design Optimization (RBDO), amplia o escopo do problema, abordando explicitamente o efeito das incertezas sobre a segurança estrutural (BECK; GOMES, 2012). Nesta classe de problemas, a viabilidade do projeto está sujeita ao atendimento de restrições expressas em termos de probabilidades de falha admissíveis:

$$
\begin{aligned}
\text { encontrar: } & \mathbf{d}^{*} \text { que minimiza } f(\mathbf{d}) \\
\text { sujeito a: } & P_{f, i}(\mathbf{d}) \leq P_{f, i}^{T}, i=1, \ldots, n_{L S}
\end{aligned}
$$

sendo $P_{f, i}(\mathbf{d})$ a probabilidade de falha estimada do $i$-ésimo modo de falha; $P_{f, i}^{T}$ a probabilidade de falha admissível para o referido modo; e $n_{L S}$ o número de estados limites aplicáveis.

Utilizando o índice de confiabilidade $\beta$ como medida da confiabilidade, a Eq. (9.4) pode ser reescrita como:

$$
\begin{aligned}
\text { encontrar: } & \mathbf{d}^{*} \text { que minimiza } f(\mathbf{d}) \\
\text { sujeito a: } & \beta_{i}(\mathbf{d}) \geq \beta_{i}^{T}, i=1, \ldots, n_{L S}
\end{aligned}
$$

Nas Eqs. (9.4) e (9.5), a formulação do problema de RBDO é realizada a nível de componente, ou seja, as restrições são escritas em termos de probabilidades de falha ou índices de confiabilidade individuais para cada modo de falha. Quando for do interesse do projetista, estas restrições podem ser substituídas por uma única restrição em termos da probabilidade de falha do sistema:

$$
\begin{aligned}
\text { encontrar: } & \mathbf{d}^{*} \text { que minimiza } f(\mathbf{d}) \\
\text { sujeito a: } & P_{f, \text { sist }}(\mathbf{d}) \leq P_{f, \text { sist }}^{T}
\end{aligned}
$$

A solução de problemas de RBDO depende diretamente da avaliação da confiabilidade estrutural, que pode ser feita por meio de métodos aproximativos ou de simulações estocásticas. $\mathrm{O}$ custo computacional para avaliação das restrições é particularmente significativo, uma vez que a análise de confiabilidade é realizada dentro de uma estrutura de otimização, onde os cálculos são repetidos centenas a milhares de vezes (DU; CHEN, 2002). Logo, vários pesquisadores dedicamse ao desenvolvimento de meios práticos para tornar o projeto probabilístico computacionalmente viável para problemas complexos de engenharia (ROYSET; KIUREGHIAN; POLAK, 2001; LOPEZ et al., 2015).

A complexidade envolvida na solução de problemas de otimização baseada em confiabilidade pode ser melhor compreendida com o auxílio da Figura 9.1. No esquema representado, dois laços iterativos são mostrados, sendo o exterior de otimização e o interior de confiabilidade. No laço interno está representado o processo de cálculo do índice de confiabilidade pelo método FORM, que, por si só, corresponde a uma técnica iterativa de minimização.

O laço interno fornece o valor do índice de confiabilidade $\beta$ do componente ou da estrutura e permite apenas avaliar se as restrições do problema foram atendidas ou não. Em um nível mais alto (laço externo de otimização), o projetista tem a opção de modificar a geometria, as propriedades do material e eventualmente as condições de contorno para satisfazer 
Figura 9.1 - Fluxograma da solução de um problema de otimização baseada em confiabilidade.

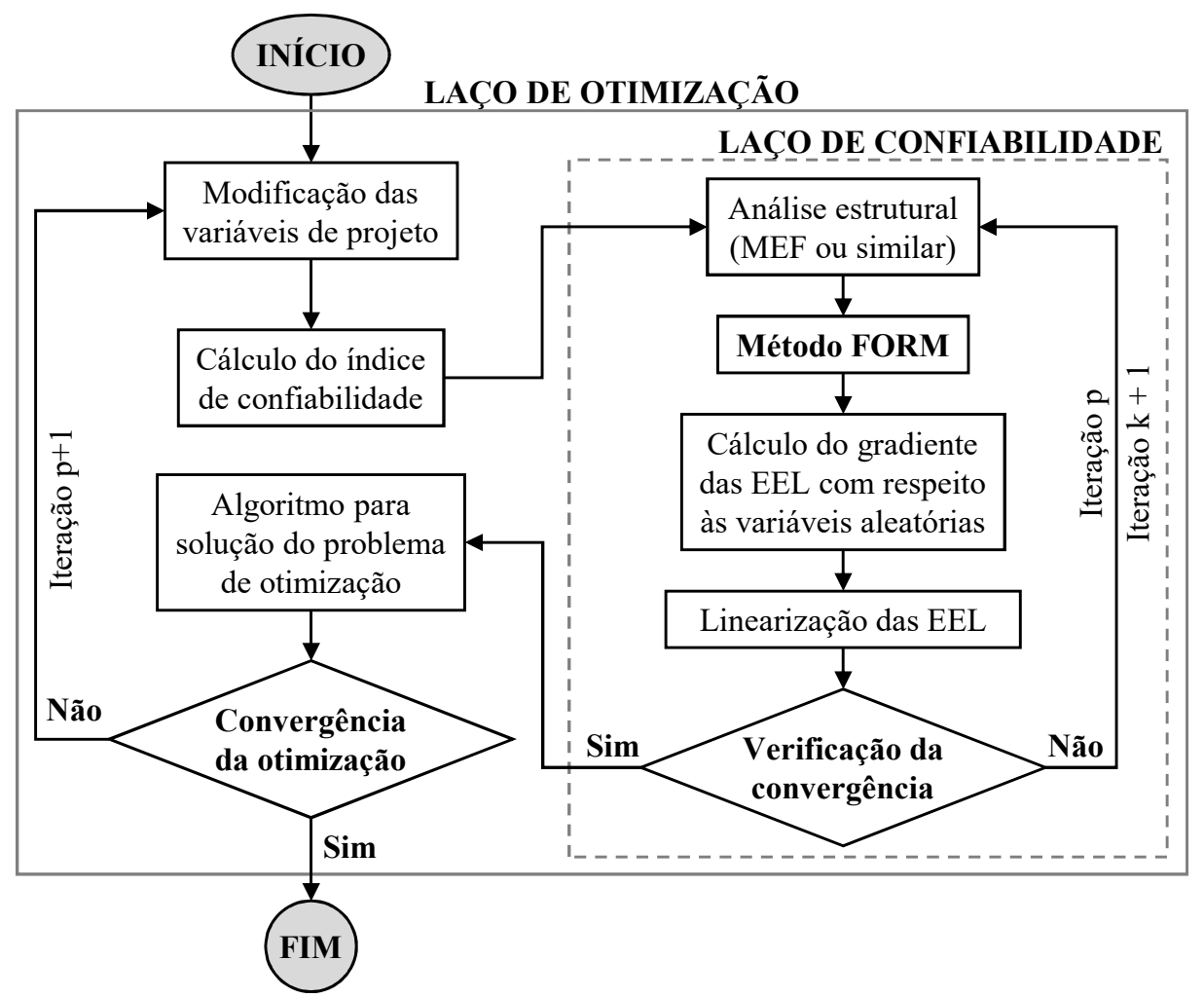

a probabilidade de falha alvo especificada para os estados limites críticos, sempre buscando a minimização ou maximização da função objetivo.

Várias técnicas podem ser empregadas para resolver problemas RBDO, as quais se diferenciam por seguir uma abordagem aproximativa ou "exata". As técnicas consideradas aproximativas baseiam-se no método FORM para solução do problema de confiabilidade (DU; CHEN, 2004; LIANG; MOURELATOS; TU, 2004; AOUES; CHATEAUNEUF, 2010), enquanto as "exatas"utilizam simulações de Monte Carlo (RASHKI; MIRI; MOGHADDAM, 2014; OKASHA, 2016; TESSARI; KROETZ; BECK, 2017).

A técnica mais indicada varia em função do tipo de problema que se pretende solucionar. Portanto, para elaborar um algoritmo capaz de realizar a otimização do revestimento de poços e selecionar as técnicas a serem utilizadas dentro dele, é necessário antes definir matematicamente o problema.

\subsection{Otimização de Revestimentos de Poços}

Ao projetar uma coluna de revestimentos, o engenheiro deve selecionar os tubulares que irão compor a coluna de revestimento e garantir sua segurança. Esta não é uma tarefa fácil, pois qualquer configuração capaz de suportar os carregamentos antecipados é uma solução em potencial. Infinitas soluções podem ser alcançadas por meio da combinação de tubulares com diferentes propriedades físicas e geométricas e, portanto, surge a seguinte pergunta: qual é a melhor escolha? 
Em geral, quando um problema de engenharia apresenta múltiplas soluções, a tomada de decisão é governada pelo fator custo. Para o problema específico do revestimento de poços, no entanto, o custo mínimo pode ser enganoso, porque isso não se traduz necessariamente no preço de mercado do revestimento (BYROM, 2015). O custo também inclui logística, transporte e armazenamento, dentre outras coisas. A depender da disponibilidade de certos tubulares em estoque, pode ser mais econômico para uma empresa utilizar um tubular N-80 de seu inventário do que adquirir um novo tubular K-55, por exemplo. Essas e outras considerações podem afetar o que se costuma denominar como projeto ótimo baseado em uma escala comum de preços. Os estudos de caso posteriores serão pautados nesse princípio, todavia é importante que o leitor tenha em mente que este é um assunto de elevada complexidade.

Segundo Rahman e Chilingarian (1995), o programa de revestimento da maioria dos poços de petróleo representa o item de maior despesa no custo do poço, podendo chegar a $18 \%$ do custo do poço concluído. Logo, mesmo uma pequena redução no custo do revestimento pode proporcionar a economia de uma quantia considerável de dinheiro. Em poços verticais, maior economia costuma ser alcançada por meio da seleção de tubulares com extensão, peso e classe de aço variáveis ao longo da coluna de revestimento. Independentemente do material e da seção transversal escolhidos, a única exigência que se faz é que o tubular seja capaz de suportar com segurança as cargas aplicadas.

Em geral, observa-se que o preço do revestimento cresce conforme aumenta o peso e a classe do aço, e, por consequência, sua resistência. Assim, o menor peso e a classe de aço mais baixa devem fornecer o menor custo. Infelizmente o peso, a classe do aço e o custo do tubular não podem ser minimizados simultaneamente, devido à existência do conflito "custo vs. peso".

\subsubsection{Conflito custo $v s$. peso}

O dilema existente entre o custo e o peso de revestimentos surge da observação de que a decisão tomada em favor do tubular mais barato, particularmente para a seção inferior de uma coluna, pode eventualmente conduzir a uma solução final mais cara. Por outro lado, se a coluna de revestimento apresentar tubulares mais leves em sua porção inferior (ainda que mais caros), a configuração resultante pode ser mais barata devido à redução da carga axial suportada pelos revestimentos superiores.

Estudos realizados por Rahman e Chilingarian (1995) demonstram que o desfecho deste conflito está fundamentalmente ligado aos preços praticados por cada usina siderúrgica. Assim, a depender do valor final do produto comercializado, pode haver ou não discordância entre as soluções obtidas. No estudos de caso conduzidos, os autores verificaram a existência de tal conflito quando apenas tubulares certificados pelo API foram considerados. Quando um banco de dados mais extenso de tubulares (incluindo classes não padronizadas) foi utilizado, a solução visando a minimização do peso da coluna convergiu para o mesmo resultado obtido considerando a minimização do custo.

A seguir, os problemas de minimização do custo e do peso de uma coluna de revesti- 
mento são formulados segundo duas abordagens distintas: determinística (DDO) e probabilística (RBDO).

\subsubsection{Formulação matemática do problema de otimização}

Durante a otimização do revestimento de um poço, as propriedades físicas e geométricas dos tubulares que o compõem sofrem alterações. Embora as pressões externas e internas solicitantes não sejam afetadas por modificações na geometria do revestimento, as forças axiais dependem da configuração do poço. Logo, enquanto as pressões podem ser antecipadamente calculadas, as forças axiais devem ser computadas a cada novo ciclo de otimização.

Dentre as parcelas que compõem a força axial solicitante, as mais afetadas por mudanças de natureza geométrica são as forças devidas ao efeito pistão e as forças decorrentes do peso próprio da coluna. Estas parcelas têm uma característica em comum muito importante à solução do problema de otimização: seu cômputo é feito de baixo para cima, ou seja, avançam do fundo do poço em direção à superfície. Como consequência, a otimização do revestimento deve começar na parte inferior da coluna de revestimento e prosseguir, passo a passo, até o topo.

Além das solicitações externas, há que se considerar uma série de fatores técnicos ao procurar pelo conjunto ótimo de tubulares capazes de suportar as cargas calculadas. Os mais importantes são o peso e a classe do aço (ambos atrelados ao fator custo), bem como a simplicidade da coluna resultante. Com relação ao último quesito, um bom projeto deve sempre considerar as dificuldades inerentes à sua execução. A medida que aumenta a variedade de pesos e classes de tubulares que compõem uma coluna, maior é a chance de ocorrerem erros custosos durante seu lançamento. Sendo assim, quanto mais simples for o projeto, melhor.

Segundo afirma Byrom (2015), a maioria dos operadores raramente executa trechos compostos por diferentes tipos de revestimento com menos de $1000 \mathrm{ft}$ de comprimento. Rahman e Chilingarian (1995) complementam dizendo que é razoável tentar manter o número de segmentos reduzido para três, pois uma coluna simplificada pode proporcionar economia de custos quando as operações de campo são consideradas em conjunto com quantidades mínimas a serem adquiridas, logística, etc. Recai-se, assim, na problemática levantada anteriormente acerca da escala comum de preços. Por este motivo, estas recomendações não serão tratadas como limites laterais do problema de otimização, ficando a cargo do projetista incluí-las em suas análises.

\subsubsection{Otimização baseada no custo mínimo}

Simplificadamente, o problema do custo mínimo absoluto pode ser formulado da seguinte maneira:

$$
C_{t o t}=\min \sum_{i=1}^{n_{t u b}} C_{i} \cdot \Delta \ell_{i}
$$

sendo $C_{t o t}$ o custo total da coluna de revestimentos; $C_{i}$ o custo linear de um segmento $i$ de revestimento, com comprimento $\Delta \ell_{i}$; e $n_{t u b}$ o número total de segmentos que compõem a coluna de revestimentos. O número total $n_{t u b}$ pode ser arbitrariamente definido dividindo-se a coluna em trechos de igual comprimento $\Delta \ell$, por exemplo. 
A Eq. (9.7) deve satisfazer as restrições impostas em termos da pressão externa, da pressão interna e da força axial solicitantes:

onde:

$$
\begin{aligned}
\left(R_{\mathrm{rup}}\right)_{i} & \geq\left(\Delta p_{r}\right)_{i} \cdot \mathrm{FS}_{r} \\
\left(R_{\mathrm{col}}\right)_{i} & \geq\left(\Delta p_{c}\right)_{i} \cdot \mathrm{FS}_{c} \\
\left(R_{\mathrm{vm}}\right)_{i} & \geq f\left(P_{\text {ext }}, P_{\text {int }}, F_{a}\right)_{i} \cdot \mathrm{FS}_{v m}
\end{aligned}
$$

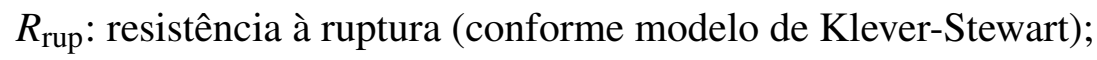

$R_{\mathrm{col}}$ : resistência ao colapso (conforme modelo de Klever-Tamano);

$R_{\mathrm{vm}}$ : resistência a um estado de tensão triaxial (conforme modelo de von Mises);

$\Delta p_{c}$ : pressão diferencial de colapso;

$\Delta p_{r}$ : pressão diferencial de ruptura;

$F_{a}$ : força axial atuante.

Nas Eqs. (9.8) a (9.10), os fatores de segurança $\mathrm{FS}_{c}, \mathrm{FS}_{r}$ e $\mathrm{FS}_{v m}$ incorporam uma margem de segurança contra a falha por colapso, ruptura e estado triaxial de tensões, respectivamente. A força axial $F_{a}$ no segmento $i$ considera o peso próprio do trecho e a contribuição do efeito pistão, além do efeito poisson e da variação de temperatura caso a coluna seja cimentada.

Para cada segmento $i$ da coluna, seleciona-se o melhor tubular disponível dentre uma lista de revestimentos comercializados ou em estoque. A melhor opção de revestimento para qualquer segmento depende de todas as decisões anteriores (ou seja, $i-1, i-2, \ldots, 1$ ) devido à natureza aditiva das cargas axiais.

\subsubsection{Otimização baseada no peso mínimo}

A otimização baseada no peso mínimo fundamenta-se na seleção do revestimento mais barato dentre os mais leves disponíveis. É dada prioridade ao peso sobre o preço. Matematicamente, isso pode ser escrito como:

tal que:

$$
\begin{aligned}
C_{t o t} & =\min \sum_{i=1}^{n_{t u b}} C_{i} \cdot \Delta \ell_{i} \\
C_{i} & =\min _{r \in(a, b)} C_{i}^{r} \\
C_{i}^{r} & =\min _{m \in(c, d)} W_{i}^{m}
\end{aligned}
$$

$r$ : índice do tubular que satisfaz as restrições de segurança;

$a, b$ : menor e maior valor de $r$ para um dado peso $m$, respectivamente;

$m$ : índice do peso do revestimento que satisfaz as restrições de segurança;

$c, d$ : menor e maior valor de $m$ que satisfaz as restrições de segurança, respectivamente;

$W$ : peso linear do segmento $i$

$i$ : índice do segmento que está sendo otimizado.

As restrições do problema se mantêm inalteradas, sendo expressas pelas Eqs. (9.8) a (9.10). 


\subsubsection{Formulação probabilística do problema de otimização}

A diferença entre a formulação determinística recém apresentada e a formulação probabilística da otimização de revestimentos está no equacionamento das restrições. Basicamente, as Eqs. (9.8) a (9.10) são substituídas por um novo conjunto de equações que leva em conta explicitamente a probabilidade de falha do segmento $i$ de revestimento. Sendo assim, as restrições do problema de otimização baseada em confiabilidade (RBDO) são descritas por:

$$
\begin{aligned}
& P\left[g_{1}(\mathbf{x})=R_{\text {rup }}-\Delta p_{r}<0\right] \leq P_{f, 1}^{T} \\
& P\left[g_{2}(\mathbf{x})=R_{\mathrm{col}}-\Delta p_{c}<0\right] \leq P_{f, 2}^{T} \\
& P\left[g_{3}(\mathbf{x})=R_{\mathrm{axl}}-F_{a}<0\right] \leq P_{f, 3}^{T}
\end{aligned}
$$

onde $\mathbf{x}$ representa o vetor de variáveis aleatórias do problema; $P\left[g_{j}(\mathbf{x})\right]$ é a probabilidade de falha associada à $j$-ésima equação de estado limite; $P_{f, j}^{T}$ é a probabilidade de falha admissível para a respectiva equação de estado limite.

De modo alternativo, pode-se utilizar o índice de confiabilidade $\beta$ como medida da confiabilidade. As restrições podem então ser reescritas como:

$$
\begin{aligned}
& \beta_{\text {rup }}(\mathbf{d}) \geq \beta_{\text {rup }}^{T} \\
& \beta_{\mathrm{col}}(\mathbf{d}) \geq \beta_{\mathrm{col}}^{T} \\
& \beta_{\mathrm{axl}}(\mathbf{d}) \geq \beta_{\mathrm{axl}}^{T}
\end{aligned}
$$

sendo $\beta_{\text {rup }}, \beta_{\text {rup }}$ e $\beta_{\text {rup }}$ os índices de confiabilidade associados aos modos de falha por ruptura, colapso e tensões axiais, respectivamente; e $\beta^{T}$ o índice de confiabilidade desejado para o respectivo modo de falha.

\subsection{Métodos para solução de problemas MV-OPT}

Existem muitos algoritmos capazes de resolver problemas de otimização: método de projeção de gradiente, método de direções viáveis, técnica de multiplicadores de Lagrange, penalização interior e exterior, programação quadrática sequencial, etc. Cada algoritmo tem certos méritos para resolver um problema específico, a depender da natureza implícita da função objetivo, das restrições e das variáveis em si (ARORA, 2012).

Para problemas mistos de otimização, os métodos de solução mais usuais são divididos em enumerativos ou estocásticos. No primeiro grupo, a enumeração completa de todas as combinações dos valores das variáveis discretas é uma possibilidade; no entanto, a enumeração parcial é mais comum, baseada em algoritmos branch-and-bound (NARENDRA; FUKUNAGA, 1977). Dentre os métodos classificados como estocásticos (ou meta-heurísticos), os mais comuns são os algoritmos genéticos (GEN; LIN, 2007), o enxame de partículas (KENNEDY, 2010), o simulated annealing (LAARHOVEN; AARTS, 1987), a colônia de formigas (DORIGO; BIRATTARI, 2010), dentre outros algoritmos inspirados na natureza. 
Para o problema de otimização de revestimentos, métodos enumerativos mostram-se adequados à sua solução, pois as variáveis de projeto são exclusivamente discretas e devem ser selecionadas a partir de uma lista finita de valores. Logo, a enumeração parcial permite reduzir suficientemente o custo computacional a ponto de viabilizá-la. Em razão disso, a principal estratégia de enumeração parcial é vista em maior detalhe a seguir.

\subsubsection{Algoritmo branch-and-bound (B\&B)}

É possível resolver qualquer problema de otimização de variáveis discretas por meio da enumeração de todos os valores discretos permitidos para cada uma das variáveis de projeto. $\mathrm{O}$ número de combinações $N_{c o m b}$ a serem avaliadas em tal cálculo é dado por:

$$
N_{\text {comb }}=\prod_{k=1}^{n_{d}} q_{k}
$$

O número de combinações a serem analisadas, no entanto, aumenta rapidamente conforme cresce o número de variáveis de projeto discretas, $n_{d}$, e o número de valores discretos permitidos para cada variável, $q_{k}$. Por esse motivo, a enumeração completa pode levar a um esforço computacional extremamente grande para resolver o problema. Assim, muitos métodos de otimização de variáveis discretas tentam reduzir a procura para apenas uma lista parcial de combinações possíveis empregando várias estratégias de enumeração implícita. A estratégia mais conhecida consiste no método branch-and-bound (B\&B), originalmente desenvolvido para problemas de programação linear (ARORA, 2012).

Existem duas categorias de algoritmos B\&B. Na primeira, valores contínuos para as variáveis discretas não são permitidos (ou não são possíveis) durante o processo de solução. São de implementação bastante simples, de modo que nenhum subproblema é definido ou resolvido. A resolução do problema também não exige a diferenciação de quaisquer funções, sendo ideal para problemas em que não se dispõe de derivadas analíticas da função objetivo ou das restrições.

A segunda categoria de algoritmos B\&B, por sua vez, simula a continuidade das variáveis discretas de projeto, permitindo o uso de técnicas de mais rápida convergência (método de Newton, programação quadrática sequencial, BFGS). Inicialmente, um ponto ótimo é obtido tratando todas as variáveis discretas como contínuas. Se uma das variáveis não tiver um valor discreto, seu valor estará entre dois valores discretos, por exemplo, $d_{k j}<d_{k}<d_{k j+1}$. Forçar uma variável a assumir um valor discreto provoca a ramificação do problema original em dois subproblemas, um com a restrição $d_{k}=d_{k j}$ e o outro com $d_{k}=d_{k j+1}$. Esse processo é chamado de branching: uma a uma as variáveis discretas têm seu valor fixado, eliminando-as de considerações adicionais. Isso reduz a dimensão do subproblema, algo que pode resultar em eficiência. A implementação deste tipo de algoritmo, no entanto, é bem mais complexa.

Dentre as duas categorias existentes, não é possível afirmar qual é a mais adequada ao problema de poços, pois tudo depende da descrição matemática do problema. Entretanto, em virtude de sua simplicidade e da possibilidade de trabalhar com funções não diferenciáveis, recomenda-se a adoção da primeira. A Figura 9.2 reproduz o algoritmo implementado no código 
computacional desenvolvido neste trabalho.

Figura 9.2 - Algoritmo Branch and Bound (B\&B).

Passo 0: Inicialização:

- define-se o limite superior para a função objetivo: $C_{\min }=+\infty$. Caso seja um problema em que se busque maximizar a função objetivo, substitui-se $\circ$ limite superior $C_{\min }$ pelo limite inferior $C_{\max }=-\infty$.

- organiza-se a lista dos $q_{k}$ valores possíveis de $d_{k}$ a depender da influência exercida pela variável na função objetivo. Para isso, calcula-se $\nabla f(\mathbf{d})$ quando possível. Se $\frac{\partial f}{\partial d_{k}}>0$, dispõem-se os $q_{k}$ valores em ordem crescente; caso contrário, em ordem decrescente.

Passo 1: Laços de busca:

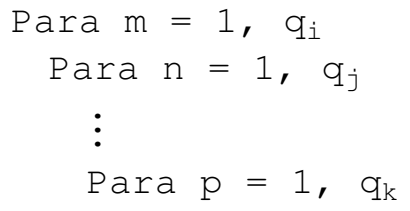

sendo $q_{k}$ o número de valores discretos possíveis da k-ésima variável.

Para acelerar a busca, pode-se ordenar os laços de acordo com os valores de $\frac{\partial f}{\partial d_{k}}$. Em um problema de minimização, o laço mais interno corresponde ao menor valor de $\nabla f(\mathbf{d})$. Por exemplo: $\frac{\partial f}{\partial d_{1}}=-20 ; \frac{\partial f}{\partial d_{2}}=+10$. Nesse caso, tem-se:

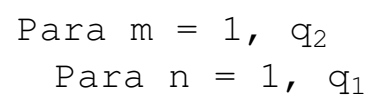

Passo 2: Atribuição de valores às variáveis de projeto e cálculo do valor atual da função objetivo:

$$
\left.\begin{array}{c}
\mathrm{d}_{1}=\mathrm{D}_{1}(\mathrm{n}) \\
\mathrm{d}_{2}=\mathrm{D}_{2}(\mathrm{~m}) \\
\vdots \\
\mathrm{d}_{\mathrm{k}}=\mathrm{D}_{\mathrm{k}}(\mathrm{p})
\end{array}\right\} \mathrm{F}_{\mathrm{obj}}=f\left(\mathrm{~d}_{1}, \mathrm{~d}_{2}, \ldots, \mathrm{d}_{\mathrm{n}_{\mathrm{d}}}\right)
$$

Passo 3: Se $\mathrm{F}_{\text {obj }}>\mathrm{C}_{\mathrm{min}}$, retorna ao Passo 1 e incrementa o contador da variável no laço imediatamente mais externo (nenhum galho subsequente possuirá um valor menor de $\mathrm{F}_{\text {obj }}$ do que o limite atual).

Passo 4: Cálculo do valor das funções de restrição:

$$
g_{j}\left(d_{1}, d_{2}, \ldots, d_{n_{d}}\right)
$$

Passo 5: Se todas as restrições forem atendidas, então:

- atualiza o limite superior: $\mathrm{C}_{\mathrm{min}}=\mathrm{F}_{\mathrm{obj}}$

- salva o ponto candidato a ótimo: $\mathbf{d}^{*}=\left\{\mathrm{d}_{1}, \mathrm{~d}_{2}, \ldots, \mathrm{d}_{\mathrm{n}_{\alpha}}\right\}$

- retorna ao Passo 1 e incrementa o contador da variável no laço imediatamente mais externo (um valor viável foi encontrado e nenhum outro galho subsequente apresentará custo menor ao encontrado).

É importante salientar que o B\&B tem a garantia de encontrar o ótimo global apenas se o problema for linear ou convexo. No caso de problemas não lineares e não convexos, é possível 
que a verdadeira solução global seja descartada no processo.

\subsubsection{Otimização probabilística de revestimentos usando algoritmo B\&B}

Para solucionar o problema de otimização probabilística de revestimentos, deve-se combinar o algoritmo B\&B reproduzido no fluxograma representado na Figura 9.1 e adaptar ambos ao problema em questão. Esse processo dá origem ao fluxograma mostrado na Figura 9.3, que representa a metodologia para o projeto ótimo de poços baseado em confiabilidade proposta no presente trabalho.

Conforme mostra a Figura 9.3, a solução do problema de otimização depende de uma série de dados de entrada. É necessário que o projetista forneça informações acerca da janela operacional do poço, da configuração inicial dos revestimentos (número de fases, extensão de cada fase e tubulares que as compõem, cota de topo da cimentação), dos casos de carregamento considerados, da densidade dos fluidos (lama de perfuração, pasta de cimento, composição do gás invasor), além de parâmetros relacionados ao próprio problema de otimização em si (fatores de segurança e probabilidades de falha admissíveis). Somado a isso, deve-se fornecer a lista de tubulares em estoque ou disponíveis para compra, conforme padrão do Apêndice B, os quais são ordenados de maneira crescente em função de seu custo ou de seu peso.

Para cada uma das fases, a coluna de revestimentos é então dividida em um número arbitrário de trechos, $n_{t}$, cuja contagem segue do topo até a base do revestimento. Caso haja necessidade, esta divisão pode ser feita de modo a respeitar limites laterais em termos de um comprimento mínimo para os segmentos. Isto feito, a otimização têm início na parte inferior da coluna de revestimento (tubular $i=n_{t}$ ) e encerra-se quando o tubular situado no topo da fase $(i=1)$ é otimizado.

Atenção especial deve ser dada à etapa de definição das propriedades do tubular $i$. Nela, o segmento de revestimento $i$ tem suas propriedades físicas e geométricas (classe de aço, diâmetro interno e peso) igualadas ao item $k$ do catálogo ordenado de tubulares. A ordenação é fundamental para o processo de enumeração parcial e garantia de convergência ao ponto de mínimo global (quando atendida a condição de convexidade).(ARORA, 2012).

Na etapa de estimativa dos índices de confiabilidade do tubular, é possível substituir a aplicação do método FORM por simulações de Monte Carlo, caso julgue-se pertinente. No entanto, pelo fato das equações de estado limite do problema de revestimentos apresentarem gradientes analíticos, o método FORM mostra-se o mais adequado devido ao seu baixíssimo custo computacional.

Por fim, vale ressaltar que, independente do método de confiabilidade estrutural utilizado, um ponto forte do algoritmo proposto consiste na verificação antecipada do valor da função objetivo $\left(F_{\text {obj }}>C_{\min }\right.$ ?) com relação ao atendimento das restrições. Com isso, toda alternativa que apresenta custo superior ao valor mínimo encontrado é automaticamente descartada, de modo a dispensar a avaliação de sua viabilidade por meio de análises de confiabilidade onerosas. 
Figura 9.3 - Fluxograma para o projeto ótimo de poços baseado em confiabilidade.

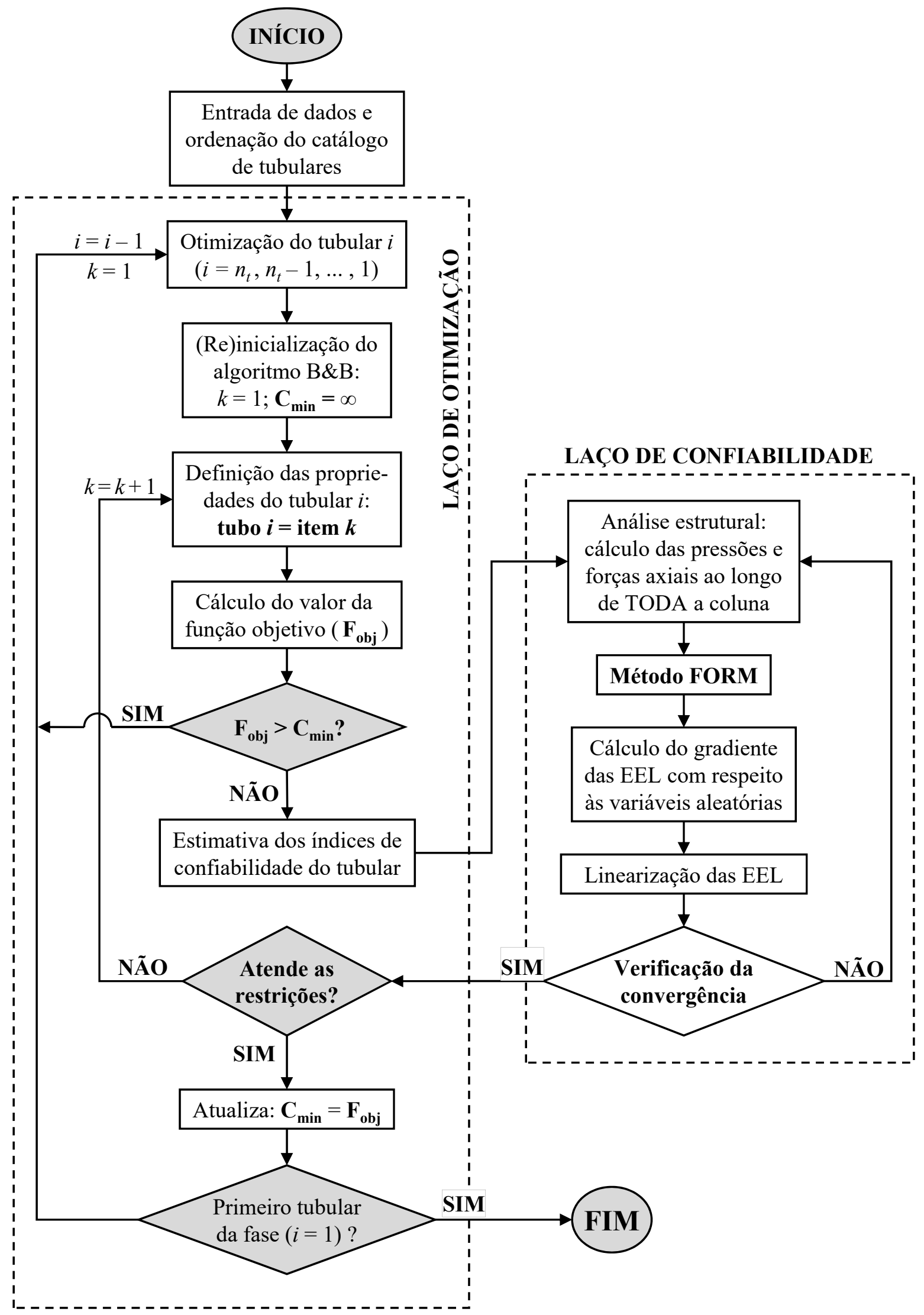





\section{Estudos de Caso}

Este capítulo tem por objetivo a reprodução dos estudos de caso conduzidos a fim de ilustrar a aplicabilidade da metodologia proposta e a verificação da correta programação da ferramenta computacional desenvolvida para o projeto ótimo de revestimentos. O capítulo é dividido em três partes:

- Primeiramente, apresenta-se a validação do módulo determinístico, que inclui as rotinas de cálculo das pressões externas e internas, das forças axiais e dos coeficientes de segurança ao longo da profundidade de cada fase;

- Em seguida, o módulo estocástico é averiguado com base nos resultados de análises simples de confiabilidade;

- Na parte final, realiza-se a otimização determinística e probabilística de revestimentos, de forma a comparar as soluções obtidas à configuração do poço de referência.

Para verificação da implementação realizada utilizou-se o software comercial Landmark Wellcat (2003), com a comparação dos resultados em termos de perfis de pressão, forças axiais e coeficientes de segurança. O referido software é uma ferramenta amplamente utilizada por companhias do setor de exploração de óleo e gás para o projeto de revestimentos de poços HTHP localizados em águas profundas. Permite analisar as tensões e deslocamentos sofridos pelo revestimento sob condições mecânicas complexas, que incluem desde pressões hidrostáticas, cargas de natureza térmica, até o comportamento de flambagem da tubulação.

Os casos analisados são de complexidade crescente a fim de permitir uma melhor apresentação das diferenças identificadas entre o código desenvolvido e aquele tomado como referência. A parte probabilística é apenas verificada qualitativamente em comparação com os resultados determinísticos obtidos, visto que não se tem acesso a nenhum software comercial que realize análises de confiabilidade em revestimentos de poços. Os resultados da otimização determinística e da otimização probabilística, por sua vez, são discutidos com base em análises paramétricas dos fatores de segurança admissíveis e índices de confiabilidade alvo considerados no projeto.

\subsection{Validação do Módulo Determinístico}

Para a validação do código computacional desenvolvido, considerou-se como referência a configuração do poço utilizada como exemplo no livro de Byrom (2015). Trata-se de um poço vertical profundo, com $14 \mathrm{mil} \mathrm{ft}$ de profundidade (aproximadamente $4300 \mathrm{~m}$ ), composto por quatro fases, cujas cotas de assentamento das sapatas estão indicadas na Figura 10.1. Os revestimentos condutor e de superfície estão cimentados ao longo de todo o seu comprimento, enquanto os revestimentos intermediário e de produção estão cimentados apenas parcialmente, até as cotas de topo da cimentação (TOC) representadas. 
Figura 10.1 - Configuração do poço de referência.

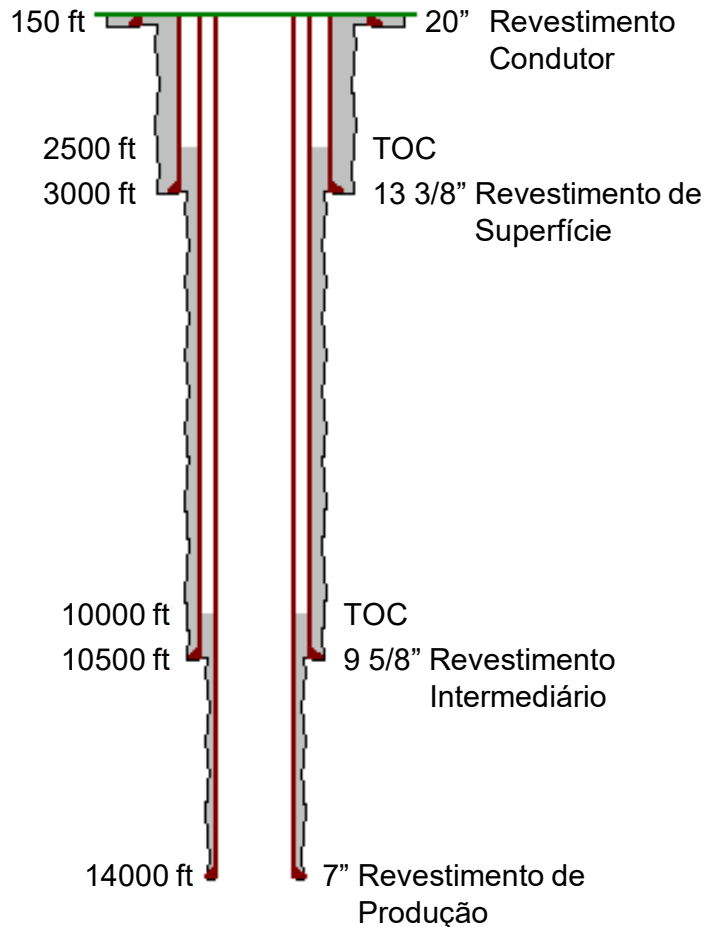

A descrição completa da janela operacional, das densidades dos fluidos de perfuração e cimentação, dos cenários de carregamento e das propriedades dos revestimentos que compõem a configuração inicial do poço de referência pode ser encontrada em Byrom (2015), nos capítulos 2 a 4. No entanto, os dados mais importantes serão replicados a seguir, a fim de facilitar a compreensão das etapas percorridas ao longo da verificação do código computacional desenvolvido.

Ressalta-se que o procedimento de análise a seguir descrito não incluiu o pré-dimensionamento dos revestimentos. Com base nos dados dos tubulares do poço de referência, comparouse a solicitação à resistência dos tubulares ponto a ponto e, a partir disso, efetuou-se o cálculo dos coeficientes de segurança e a estimativa das probabilidades de falha dos revestimentos ao longo da profundidade do poço.

As análises conduzidas apresentam crescente complexidade, visto que as colunas de revestimento mais profundas são compostas por um maior número de tubulares com propriedades mecânicas distintas, a fim de suportar maiores pressões. Além disso, o número de casos de carregamento é inicialmente baixo para o caso do revestimento condutor (dada sua pequena extensão), porém este número praticamente dobra para as demais fases do poço.

Ao todo foram analisados 17 cenários de carregamento. Para cada revestimento, os carregamentos aplicáveis foram organizados conforme a sequência natural de execução do poço. Iniciam-se as análises pelo revestimento condutor até a conclusão das verificações envolvendo o revestimento de produção. Perfis de pressão, forças axiais e coeficientes de segurança calculados pelo módulo determinístico foram comparados aos resultados do software comercial Wellcat. 


\subsubsection{Revestimento Condutor}

Para o revestimento condutor admitiu-se três cenários de carregamento:

1. O primeiro corresponde à situação em que é realizada a instalação e cimentação do tubo. A pasta de cimento encontra-se na região anular do poço, enquanto o interior dos tubulares é preenchido por fluido de perfuração ou de deslocamento;

2. Uma vez cimentado, realiza-se um teste de pressão, que provoca uma pressão diferencial de ruptura constante ao longo de toda a fase. Este é o único cenário de ruptura aplicável ao revestimento, visto que em pequenas profundidades não costuma haver presença de gás (eliminando assim a ocorrência de kicks);

3. O terceiro e último cenário corresponde ao caso em que o revestimento condutor está vazio internamente e submetido à pressão hidrostática em seu exterior.

Os perfis de pressões diferenciais correspondentes a cada um dos casos analisados são mostrados na Figura 10.2. Os perfis de pressão calculados (identificados pela letra C) pelo código desenvolvido e pelo software Wellcat (W) foram idênticos em todos os casos, concordando com os resultados apresentados em Byrom (2015).

Figura 10.2 - Revestimento Condutor: perfis de pressões diferenciais calculados (C) e do Wellcat (W).
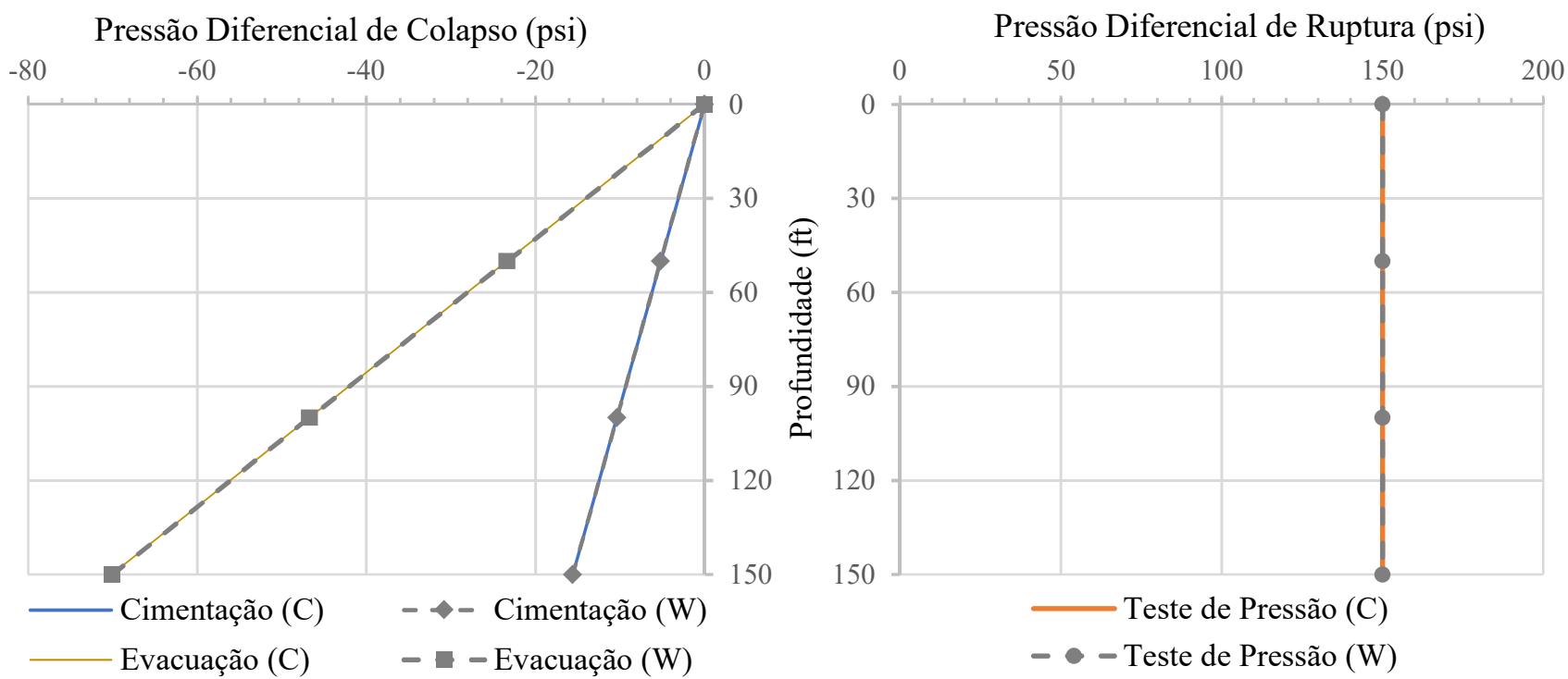

Para o cálculo dos esforços axiais, é necessário definir um cenário de carregamento a partir do qual serão levantadas as condições iniciais do revestimento em termos de pressão, força axial e temperatura. Este levantamento é importante, pois conforme explica Souza (2015), o estado final de forças a que um revestimento está submetido resulta da sobreposição da condição inicial com a variação das forças axiais provocadas pelo efeito pistão, pelo efeito Poisson (ballooning) e por efeitos de natureza térmica.

Basicamente, a condição inicial depende do estado da pasta de cimento no anular. Enquanto a pasta ainda está fluida, o revestimento é capaz de acomodar forças e deformações 
axiais impostas, em virtude de sua deslocabilidade. Contudo, após a cura da pasta e sua acoplagem ao revestimento, considera-se que o revestimento fica completamente impedido de se mover. Nesta situação, as forças de empuxo no tubo deixam de ser consideradas e surgem esforços axiais decorrentes da expansão/retração térmica do revestimento e do efeito Poisson, ocasionado pelo diferencial de pressão no trecho.

Sendo assim, as condições iniciais devem ser estabelecidas com base no estado de pressão referente ao último estágio da cimentação. Em geral, este estado corresponde à aplicação da pressão de vedação, após o cimento ter sido posicionado (pressão de plug-bump - item 4.2), pois resulta no pior cenário em termos de tensões axiais.

Em termos de projeto, a condição inicial de temperatura deve ser tomada como sendo o próprio perfil de temperatura decorrente do gradiente geotérmico, também conhecido como condição "não perturbada” (SOUZA, 2015). Esta é uma premissa robusta e visa maximizar os esforços causados por variações de temperatura.

Com base no conceito de condição inicial, admitiu-se o perfil de pressões correspondente à situação de cimentação para o cálculo do estado inicial de forças axiais no revestimento condutor. Os valores calculados estão exibidos na Figura 10.3, à esquerda, em conjunto com os resultados fornecidos pelo Wellcat. A estas forças foram sobrepostas as variações de esforços axiais decorrentes da mudança nos perfis de pressão dos demais casos de carregamento, compondo os estados finais de forças axiais, representados à direita da Figura 10.3.

Figura 10.3 - Revestimento Condutor: forças axiais calculadas (C) e do Wellcat (W).

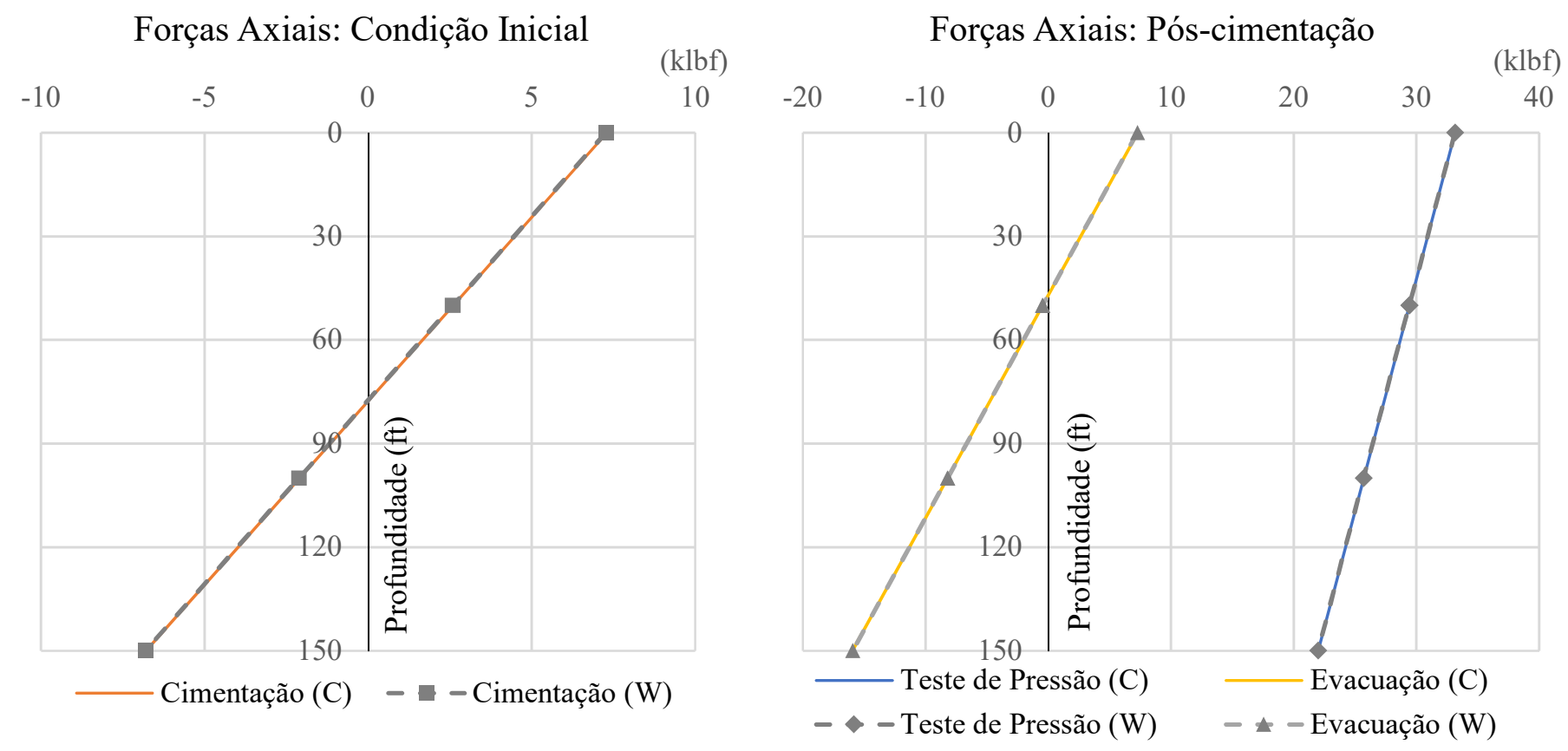

Os coeficientes de segurança ao colapso, à ruptura e ao modo de falha por tensões triaxiais foram calculados para a fase condutora admitindo um revestimento padrão API, com diâmetro externo de 20 in., densidade linear de 94 lb/ft e classe de aço H-40. Entretanto, devido à magnitude dos valores encontrados (todos acima ou próximos de 100), não foi possível efetuar 
uma comparação direta com os resultados do Wellcat - por padrão, o software limita a exibição dos fatores de segurança ao valor máximo de 100. Sob o ponto de vista estrutural, valores dessa ordem de grandeza representam que a possibilidade de falha do revestimento é remota.

Cabe ressaltar que o revestimento condutor é responsável por suportar os esforços compressivos causados pelo peso das demais fases e do equipamento de cabeça de poço. Logo, os esforços compressivos são preponderantes para seu dimensionamento e equações de resistência específicas associadas a falha por instabilidade devem ser utilizadas. Sendo assim, no presente trabalho não será avaliada a segurança do revestimento condutor, à semelhança do que foi feito na referência original. $\mathrm{O}$ estudo será limitado ao desempenho das equações de ruptura e colapso das normas API-5C3 (1994) e ISO/TR 10400 (2011), relevantes às demais fases.

\subsubsection{Revestimento de Superfície}

A segunda rodada de verificações envolveu a análise das pressões internas e externas, forças axiais e coeficientes de segurança do revestimento de superfície. Diferentemente do revestimento condutor, esta fase é composta por dois trechos de tubulares com diâmetros internos distintos, o que possibilitou aferir a precisão do código desenvolvido com relação ao cômputo das forças axiais devidas ao efeito pistão. A especificação completa do revestimento de superfície é exibida na Tabela 10.1 .

Tabela 10.1 - Revestimento de Superfície: propriedades mecânicas dos tubulares.

\begin{tabular}{|c|c|c|c|c|c|}
\hline Seção & $\begin{array}{c}\text { Profundidade } \\
\text { (ft) }\end{array}$ & $\begin{array}{c}\text { OD } \\
\text { (in.) }\end{array}$ & $\begin{array}{c}\text { ID } \\
\text { (in.) }\end{array}$ & $\begin{array}{c}\text { Peso Linear } \\
\text { (lb/ft) }\end{array}$ & $\begin{array}{c}\text { Classe de } \\
\text { aço }\end{array}$ \\
\hline 1 & 2000 & $133 / 8$ & 12.615 & 54.5 & $\mathrm{~K}-55$ \\
2 & 3000 & $133 / 8$ & 12.415 & 68 & $\mathrm{~K}-55$ \\
\hline
\end{tabular}

Fonte: Byrom (2015).

Para o revestimento de superfície foram admitidos seis cenários de carregamento, dentre os quais três correspondem a condições de cimentação. O primeiro dos três casos representados na Figura 10.4 é relativo ao bombeamento do cimento para dentro do poço. Nesta condição, o cimento de base (com maior densidade) encontra-se na porção superior da coluna, seguido pelo cimento de topo. $\mathrm{O}$ volume de cimento utilizado é tal que preenche parte do espaço anular. Do lado externo há também presença de fluido de perfuração, resultando em pressões diferenciais de ruptura. Nos dois outros casos, o cimento já está completamente posicionado no espaço anular do poço, sendo que no terceiro caso é aplicada uma pressão adicional para vedação interna do poço (plug-bump pressure). 
Figura 10.4 - Revestimento de Superfície: cenários de carregamento durante a etapa de cimentação.

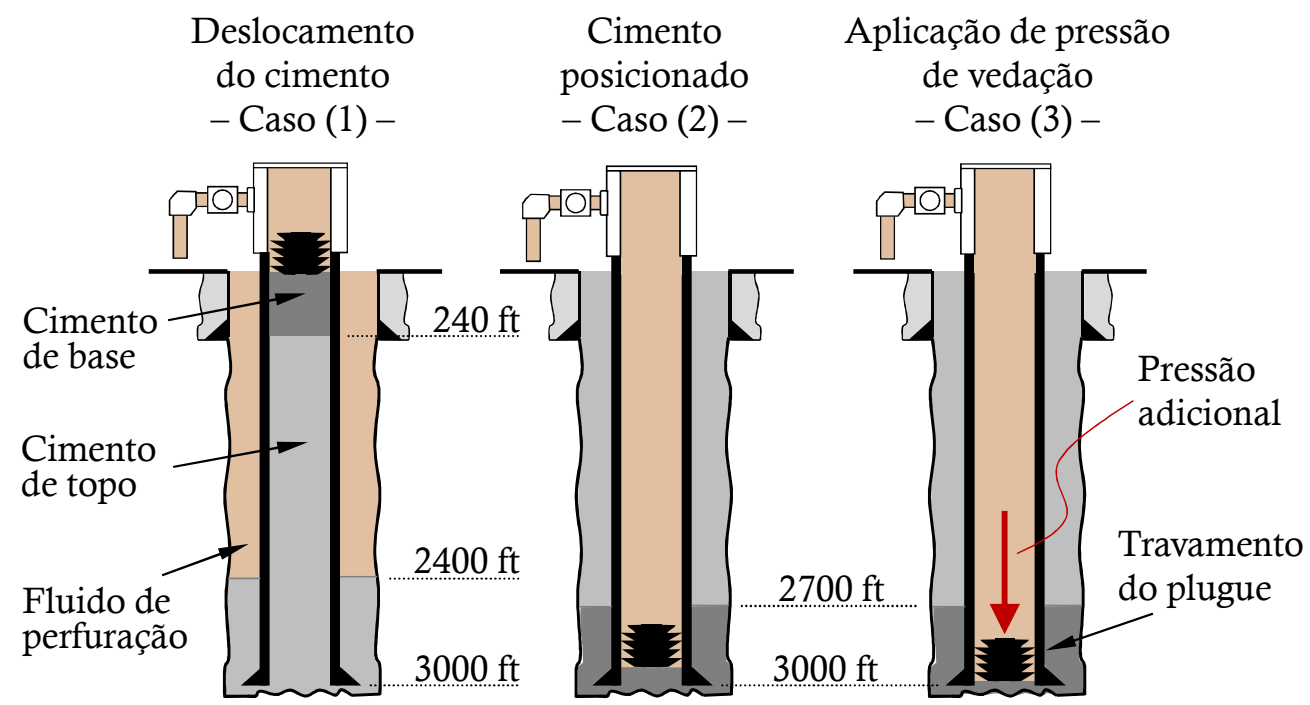

Os três casos de carregamento descritos foram especificamente analisados para estudar a evolução das forças axiais em decorrência da variação dos perfis de pressão. Além disso, procurou-se definir quais destes casos iria compor a chamada "condição inicial"em termos de pressões e esforços axiais ao longo do revestimento. A Figura 10.5 apresenta os resultados obtidos pelo código desenvolvido para cada um dos cenários descritos e, sobrepostos a eles, os valores extraídos do software de referência, cujas curvas estão indicadas por (W).

Figura 10.5 - Revest. de Superfície: condições iniciais de forças axiais calculadas (C) e do Wellcat (W).

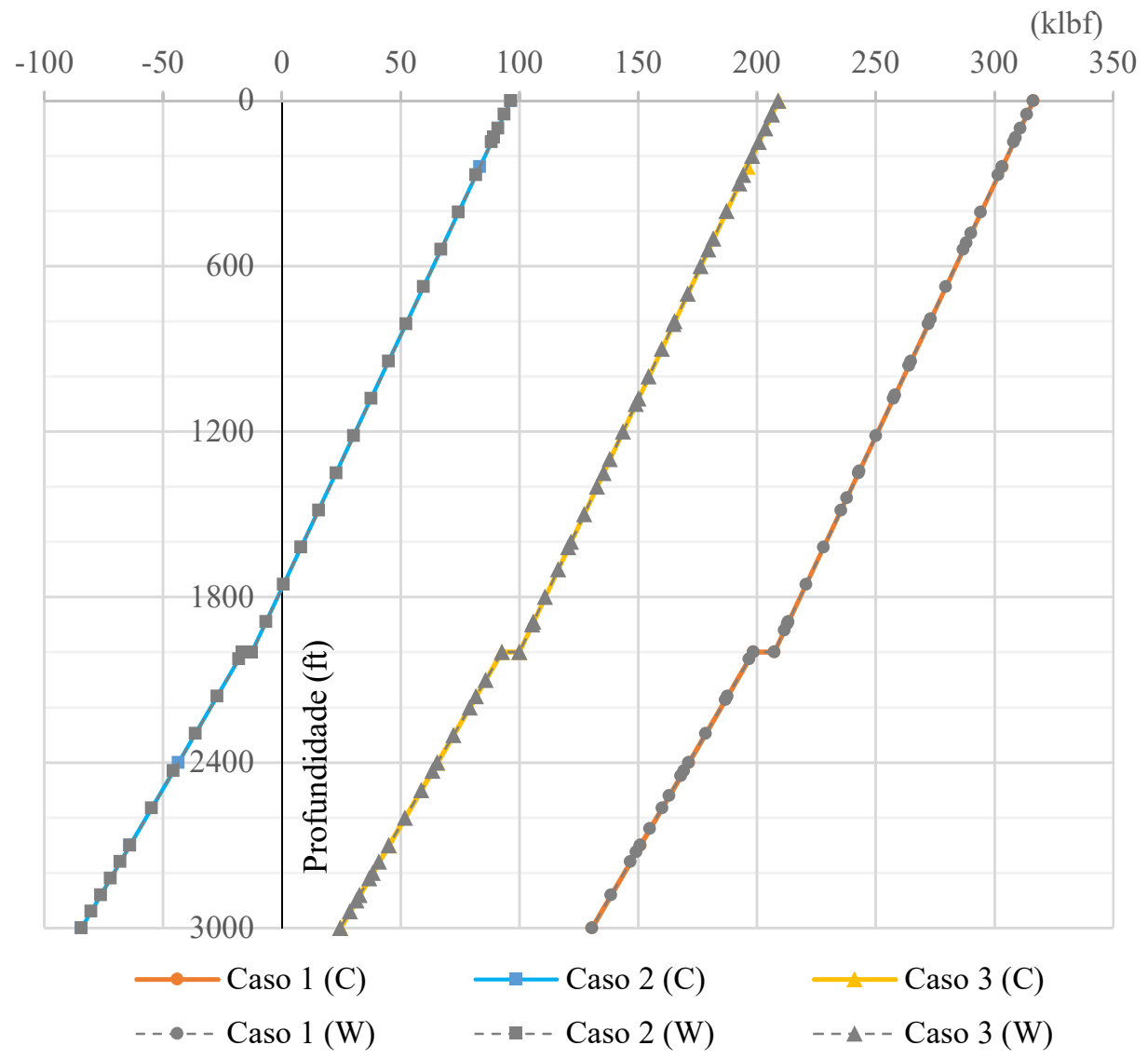


Com relação às forças axiais, percebe-se que o primeiro caso de carregamento (deslocamento do cimento) é o que gera os maiores esforços normais no revestimento. Contudo, ao final desta etapa o cimento ainda encontra-se em estado fresco, permitindo que os tubos se desloquem livremente em virtude da deformação a eles imposta. Não seria plausível, portanto, admiti-lo como condição inicial para a estimativa das forças axiais causadas pelos demais carregamentos.

O cimento só sofre endurecimento após o caso 3, motivo pelo qual este foi escolhido para compor o estado de forças inicial do revestimento. Após este estágio, qualquer elongação causada por variações de pressão ou temperatura será convertida em tensões internas equivalentes.

Ainda na Figura 10.5, observa-se a perfeita concordância entre os resultados calculados e os valores tomados como referência. Destaca-se a precisa captura do efeito pistão, decorrente da variação do diâmetro interno dos tubulares a $2000 \mathrm{ft}$ de profundidade.

Nenhum dos cenários de carregamento descritos anteriormente corresponde a casos críticos em termos de dimensionamento. Assim, outros três cenários foram considerados, organizados conforme a sequência natural de ocorrência:

- Realização de teste de pressão, com aplicação de uma pressão diferencial de 1500 psi;

- Perda severa de circulação, deixando o revestimento completamente vazio em seu interior. Do lado externo, admite-se que o trabalho de cimentação foi parcialmente falho e houve a formação de um canal de fluido de perfuração no espaço anular;

- Ocorrência de um kick de gás durante a perfuração da próxima fase. A coluna de gás preenche por completo o revestimento.

Os perfis de pressão calculados foram exatamente os mesmos do livro de referência, coincidindo também com os valores fornecidos pelo Wellcat. Dada a dependência intrínseca das forças axiais e dos coeficientes de segurança em relação aos perfis de pressão, os resultados deste último grupo serão omitidos na sequência do texto. A seguir, a Figura 10.6 reúne os casos de validação das forças axiais para os cenários de carregamento pós-cimentação do poço, admitindo a indeslocabilidade do revestimento. Considera-se, portanto, a influência do efeito pistão e do efeito Poisson.

À semelhança do que foi observado para o revestimento condutor, as respostas calculadas foram praticamente idênticas às fornecidas pelo Wellcat. Novamente foi possível registrar a influência do efeito pistão na cota de transição do diâmetro interno dos tubulares, a uma profundidade de $2000 \mathrm{ft}$. Além disso, a influência do efeito Poisson tornou-se evidente no cenário de carregamento de perda de circulação, onde observa-se um grande trecho do revestimento em compressão (de $1700 \mathrm{ft}$ até a base), em decorrência do engastamento promovido pelo cimento. 
Figura 10.6 - Revestimento de Superfície: forças axiais finais calculadas (C) e do Wellcat (W).

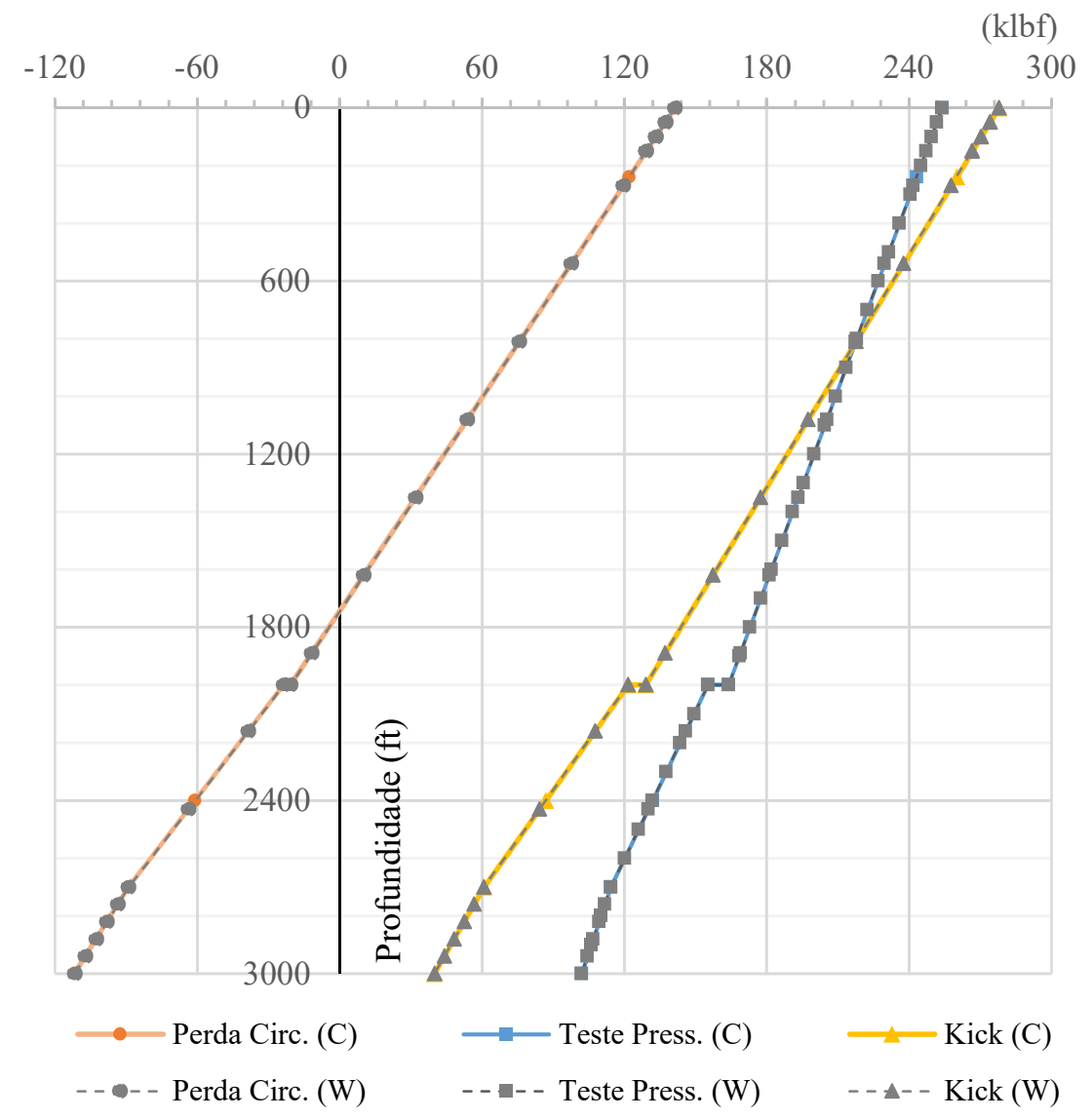

Uma vez verificada a precisão do código com relação aos cálculos envolvendo pressões e forças axiais, a etapa seguinte consistiu na análise dos fatores de segurança relativos aos diferentes modos de falha do tubular. Para o modo de falha por colapso, utilizou-se o critério indicado no Boletim 5C3 do API (1994). Para o modo de falha por ruptura, utilizou-se a fórmula de Barlow e, para o modo de falha triaxial, utilizou-se o critério de von Mises (ISO/TR 10400, 2007). Os dois primeiros critérios foram utilizados em lugar dos modelos de Klever-Tamano e Klever-Stewart, respectivamente, para possibilitar a comparação direta com os resultados do Wellcat, cuja versão não inclui as diretrizes modernas da norma ISO/TR 10400.

Na Figura 10.7 são mostrados os fatores de segurança ao colapso e à ruptura para todos os cenários de carregamento e, na Figura 10.8, os fatores de segurança calculados com base no critério de von Mises.

Os fatores de segurança de todos os cenários de carregamento de ruptura (representados pelas curvas em vermelho com marcador quadrado na Figura 10.7) e no cenário de perda de circulação foram idênticos aos valores obtidos pelo Wellcat. No "Caso 2", entretanto, houve uma grande diferença entre as respostas, cuja origem não foi identificada. Supõe-se que seja uma diferença apenas de ordem numérica em razão da conversão de unidades (o software Wellcat utiliza unidades USC enquanto o código desenvolvido realiza todos os cálculos no sistema SI). Isto afeta particularmente a equação de colapso do API, pois ela depende de constantes com dimensões escritas em unidades não consistentes. 
Figura 10.7 - Revestimento de Superfície: fatores de segurança ao colapso (API), em azul, e ruptura (Barlow), em vermelho.
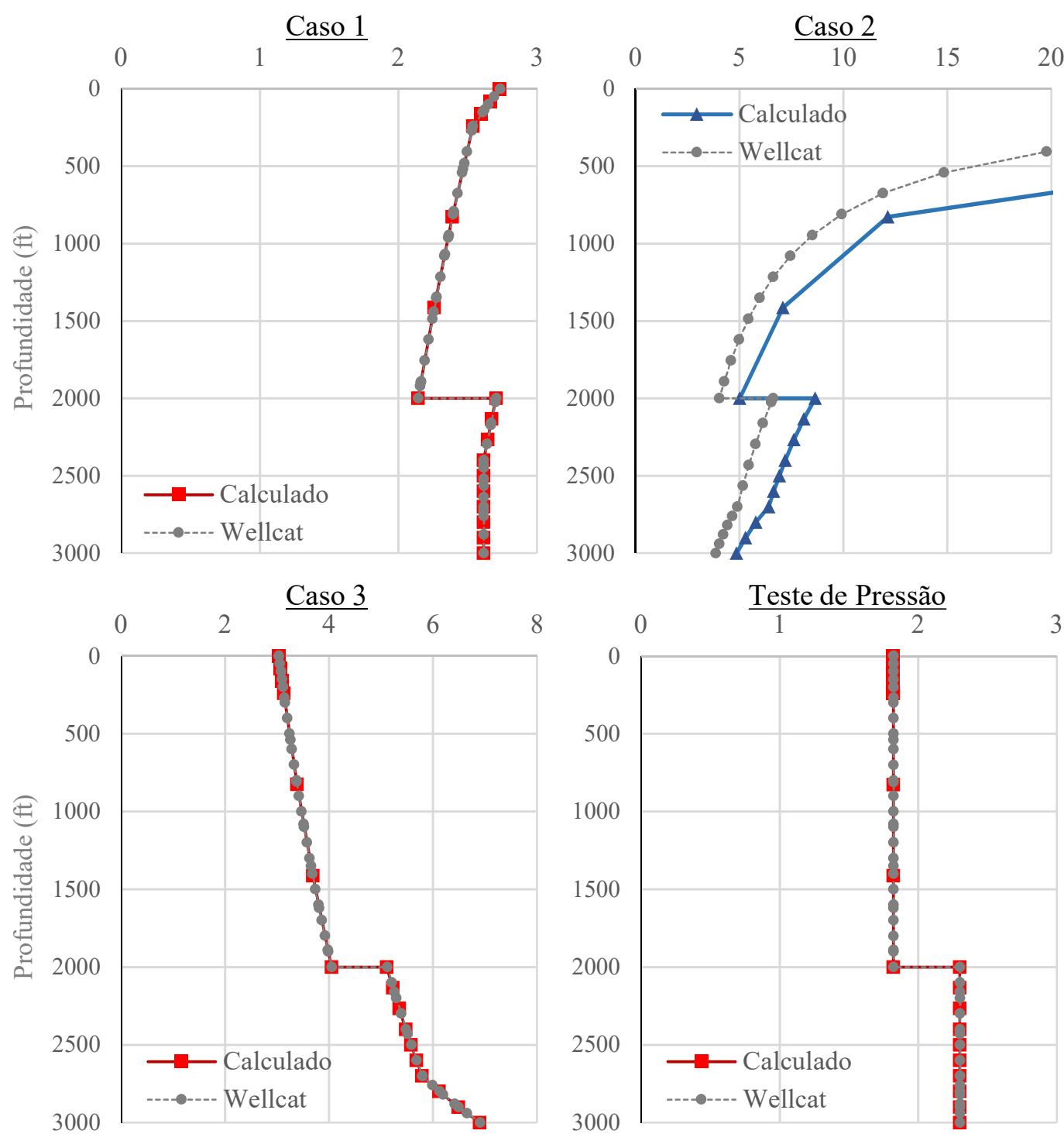

8
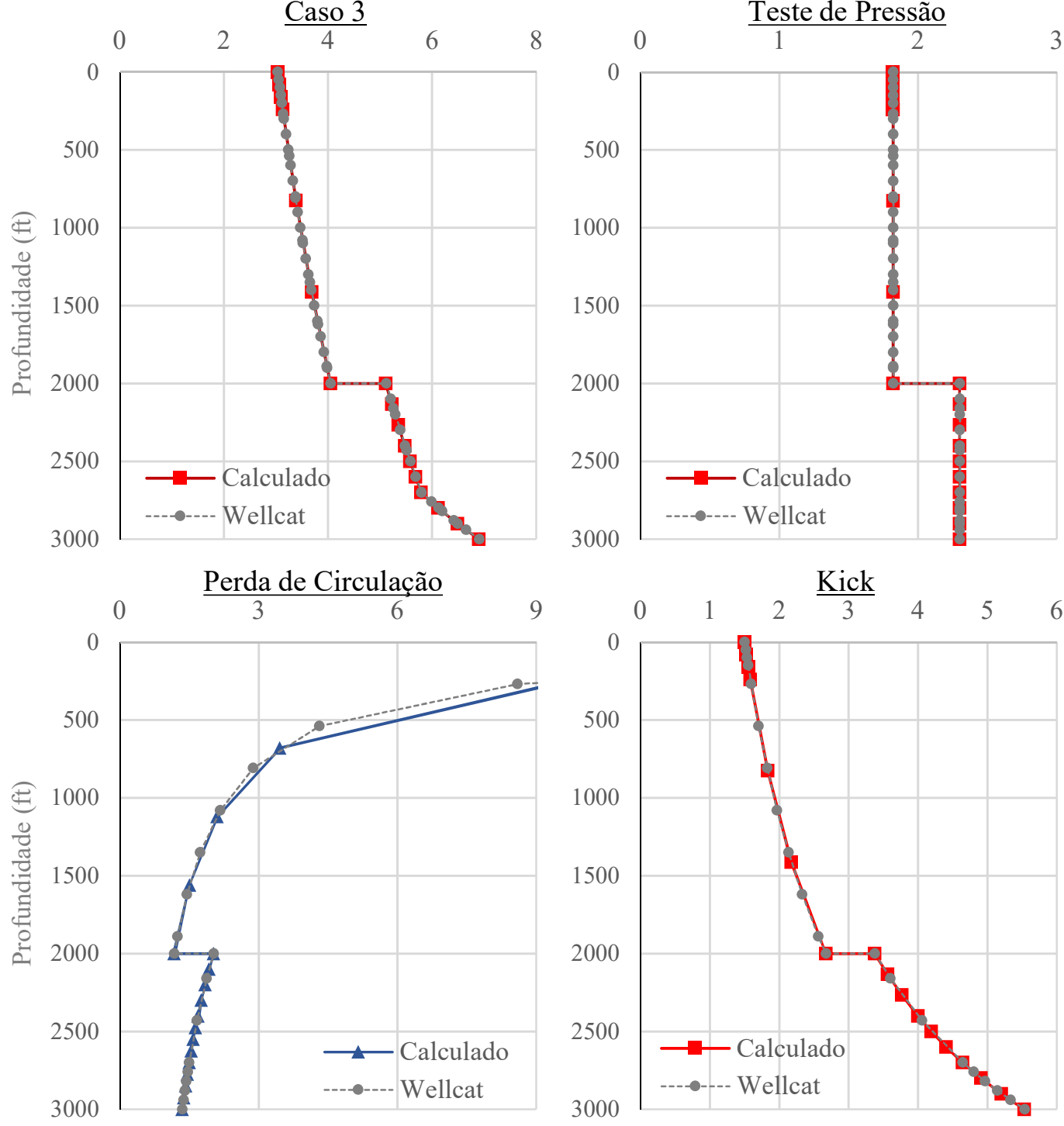
Figura 10.8 - Revestimento de Superfície: fatores de segurança à falha triaxial (von Mises).
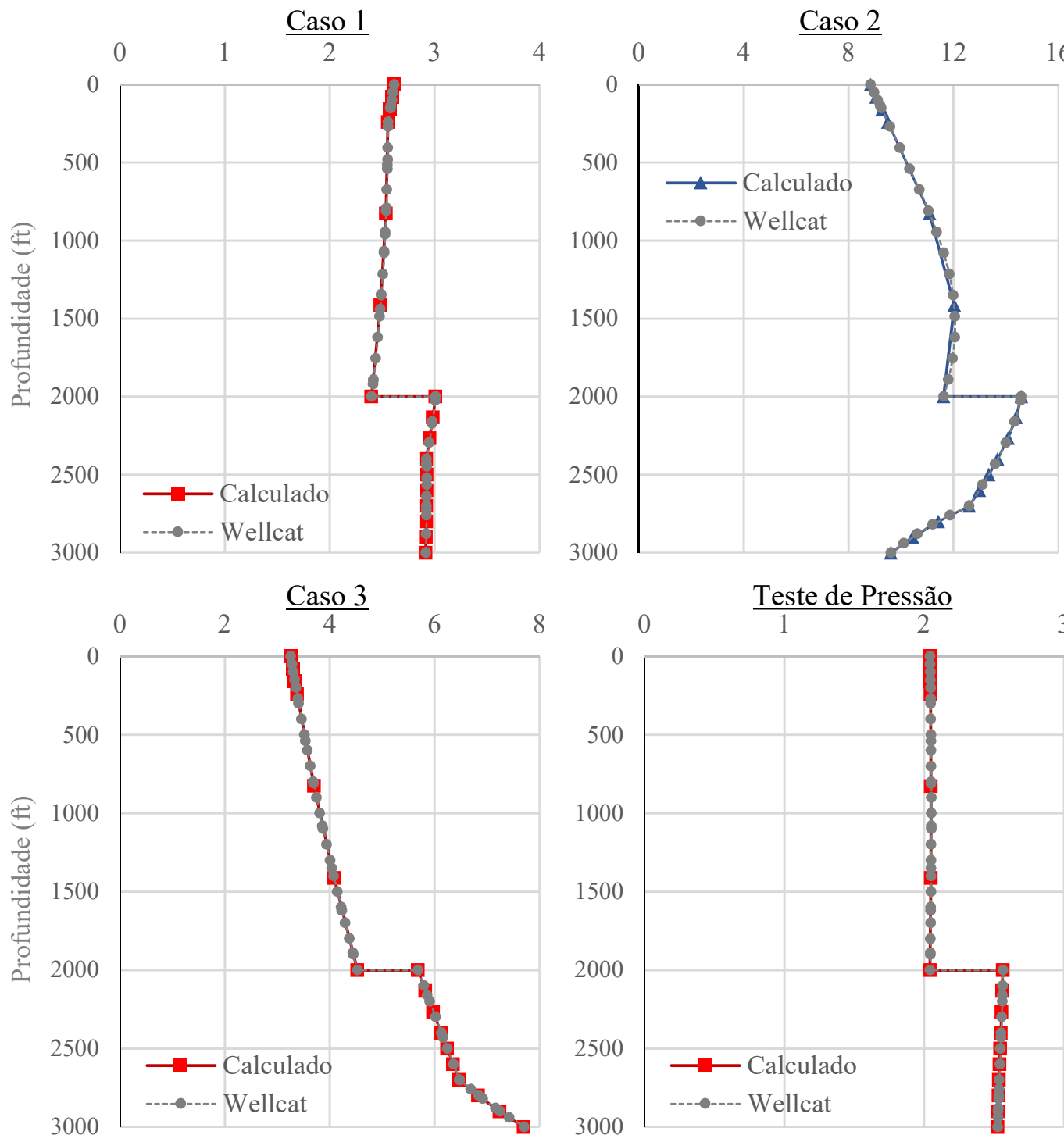

8

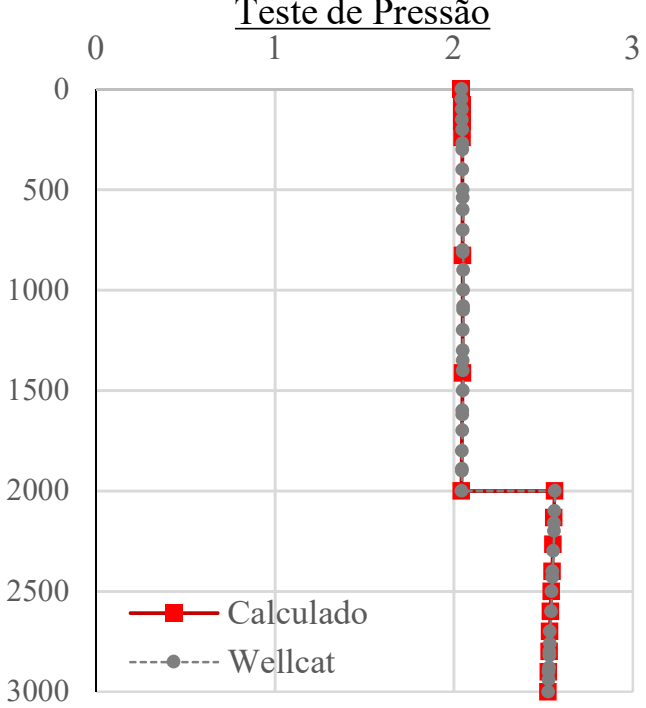

Perda de Circulação

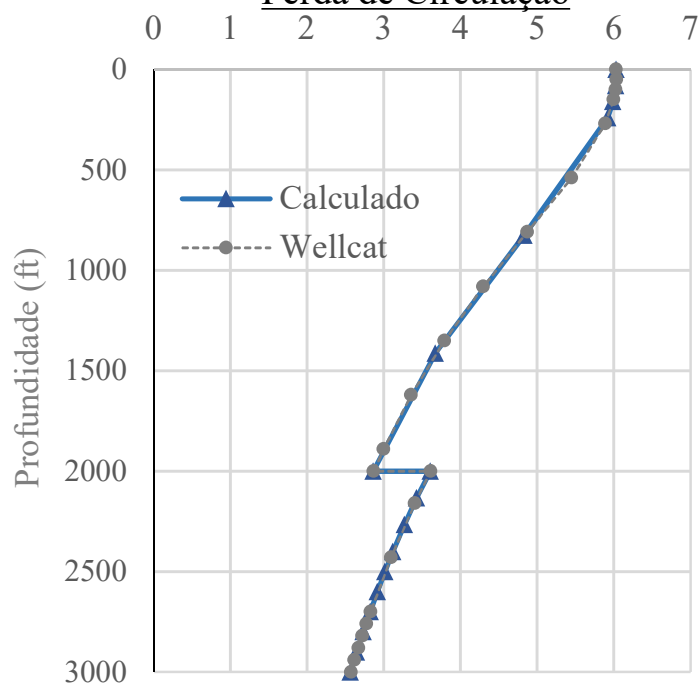

$\underline{\text { Kick }}$

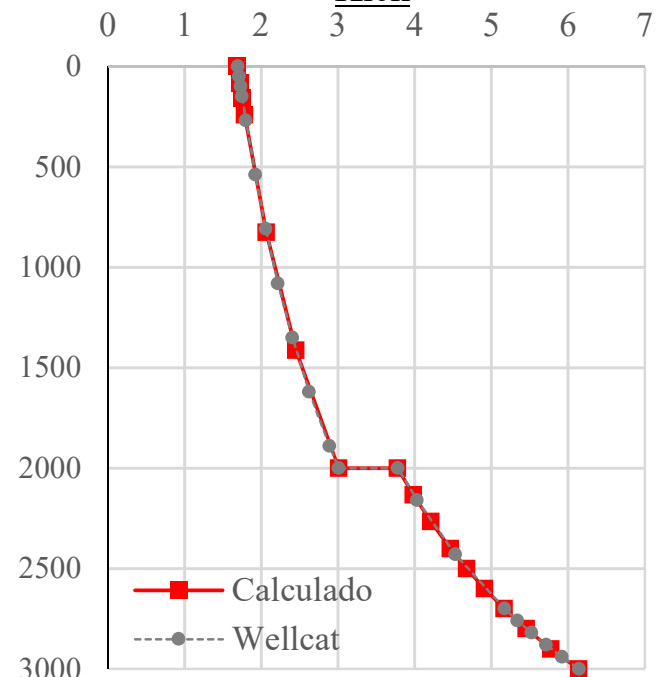


Os resultados exibidos na Figura 10.8, por outro lado, apresentaram perfeita concordância com os dados de referência para a condição de falha triaxial do revestimento em todos os cenários de carregamento. Como era esperado, o cenário crítico de colapso corresponde à perda de circulação. No entanto, devido à pequena profundidade da fase, os menores fatores de segurança para carregamentos de ruptura foram observados quando aplicados os testes de pressão, de modo que a eventual ocorrência de kicks de gás é preponderante apenas para o dimensionamento do trecho superior do revestimento (tubulares acima de $700 \mathrm{ft}$ ).

\subsubsection{Revestimento Intermediário}

A terceira etapa de verificação envolveu o estudo das curvas de pressão, forças axiais e fatores de segurança do revestimento intermediário. Ao contrário das fases anteriores, a atual fase não é cimentada ao longo de todo o seu comprimento, apresentando um comportamento ligeiramente diferente devido ao efeito de Poisson. Graças ao diâmetro interno constante ao longo de todo o comprimento do revestimento, foi possível estudar este fenômeno sem a interferência das forças axiais causadas pelo efeito pistão. A especificação completa dos tubulares utilizados na fase é exibida na Tabela 10.2.

Tabela 10.2 - Revestimento Intermediário: propriedades mecânicas dos tubulares.

\begin{tabular}{|c|c|c|c|c|c|}
\hline Seção & $\begin{array}{c}\text { Profundidade } \\
\text { (ft) }\end{array}$ & $\begin{array}{c}\text { OD } \\
\text { (in.) }\end{array}$ & $\begin{array}{c}\text { ID } \\
\text { (in.) }\end{array}$ & $\begin{array}{c}\text { Peso Linear } \\
\text { (lb/ft) }\end{array}$ & $\begin{array}{c}\text { Classe de } \\
\text { aço }\end{array}$ \\
\hline 1 & 6360 & $95 / 8$ & 8.755 & 43.5 & $\mathrm{P}-110$ \\
2 & 10500 & $95 / 8$ & 8.755 & 43.5 & $\mathrm{~N}-80$ \\
\hline
\end{tabular}

Fonte: Byrom (2015).

Os cenários de carregamento analisados foram praticamente os mesmos do revestimento de superfície, exceto pelos casos de carregamento 1 e 2 (ver Figura 10.4). Estes casos foram suprimidos em virtude da análise conduzida anteriormente acerca da deslocabilidade do revestimento durante sua cimentação. Naquela altura verificou-se que o cenário mais razoável para constituir a condição inicial corresponde ao de aplicação da pressão de vedação (plug-bump pressure), após o cimento estar corretamente posicionado no anular. Em resumo, os cenários de carregamento analisados foram:

1. Aplicação de pressão de vedação (condição inicial);

2. Realização de teste de pressão, com aplicação de uma pressão diferencial de 2500 psi;

3. Perda severa de circulação, com bombeamento de água para dentro do poço a fim de prevenir influxo de gases contidos na formação. No espaço anular, considera-se a existência de um canal de fluido de perfuração;

4. Ocorrência de um kick de gás durante a perfuração da fase de produção, com fratura da formação logo abaixo da base do revestimento, causando alívio de pressões. 
Os perfis de pressão calculados para cada um dos casos são iguais aos apresentados por Byrom (2015, p. 62 a 67), tal que os maiores diferenciais de pressão de colapso e ruptura correspondem aos dois últimos cenários de carregamento, respectivamente. Como decorrência disto, as forças axiais de compressão são máximas na base do revestimento quando há perda de circulação, e as forças de tração são máximas na superfície devido ao kick de gás. Na Figura 10.9 são apresentadas as curvas de força axial para a condição inicial e de pós-cimentação, para cada um dos casos de carregamento admitidos.

Figura 10.9 - Revestimento Intermediário: forças axiais na condição inicial e pós-cimentação.
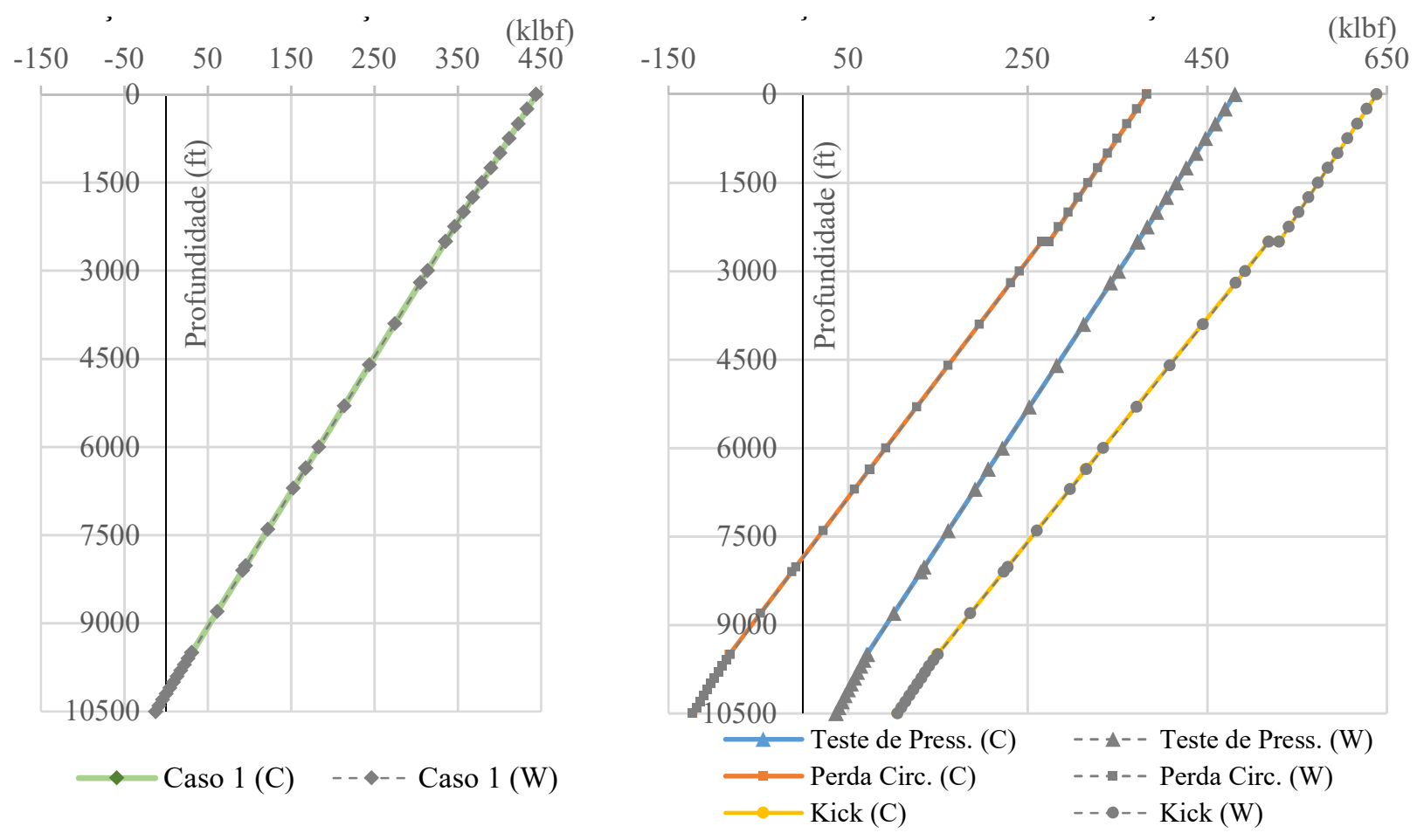

Os resultados apresentados na Figura 10.9 novamente evidenciam a correta implementação do cálculo das forças axiais que solicitam o revestimento, mostrando-se idênticas às calculadas pelo software comercial. Permite notar também a influência do efeito Poisson: visto que a coluna de revestimento possui diâmetro interno constante ao longo de toda sua extensão, os saltos observados nos diagramas de forças axiais na condição de pós-cimentação a uma cota de $2500 \mathrm{ft}$ (cota de topo do cimento - TOC) devem-se exclusivamente ao confinamento proporcionado pela cimentação. Outra manifestação física deste efeito pode ser observada no cenário de perda de circulação, quando um grande trecho passa a trabalhar em compressão devido à variação dos perfis de pressão interna e externa, à semelhança do que ocorre no revestimento de superfície.

Em virtude da maior profundidade da fase, os dois primeiros casos de carregamento não apresentam-se críticos sob o ponto de vista do dimensionamento e da segurança estrutural. Independentemente disto, foram calculados os fatores de segurança do revestimento para todos os cenários, para fins de verificação do código desenvolvido. Os fatores relativos aos modos de falha por ruptura e colapso são mostrados na Figura 10.10 . 
Figura 10.10 - Revestimento Intermediário: fatores de segurança ao colapso (API) e ruptura (Barlow).
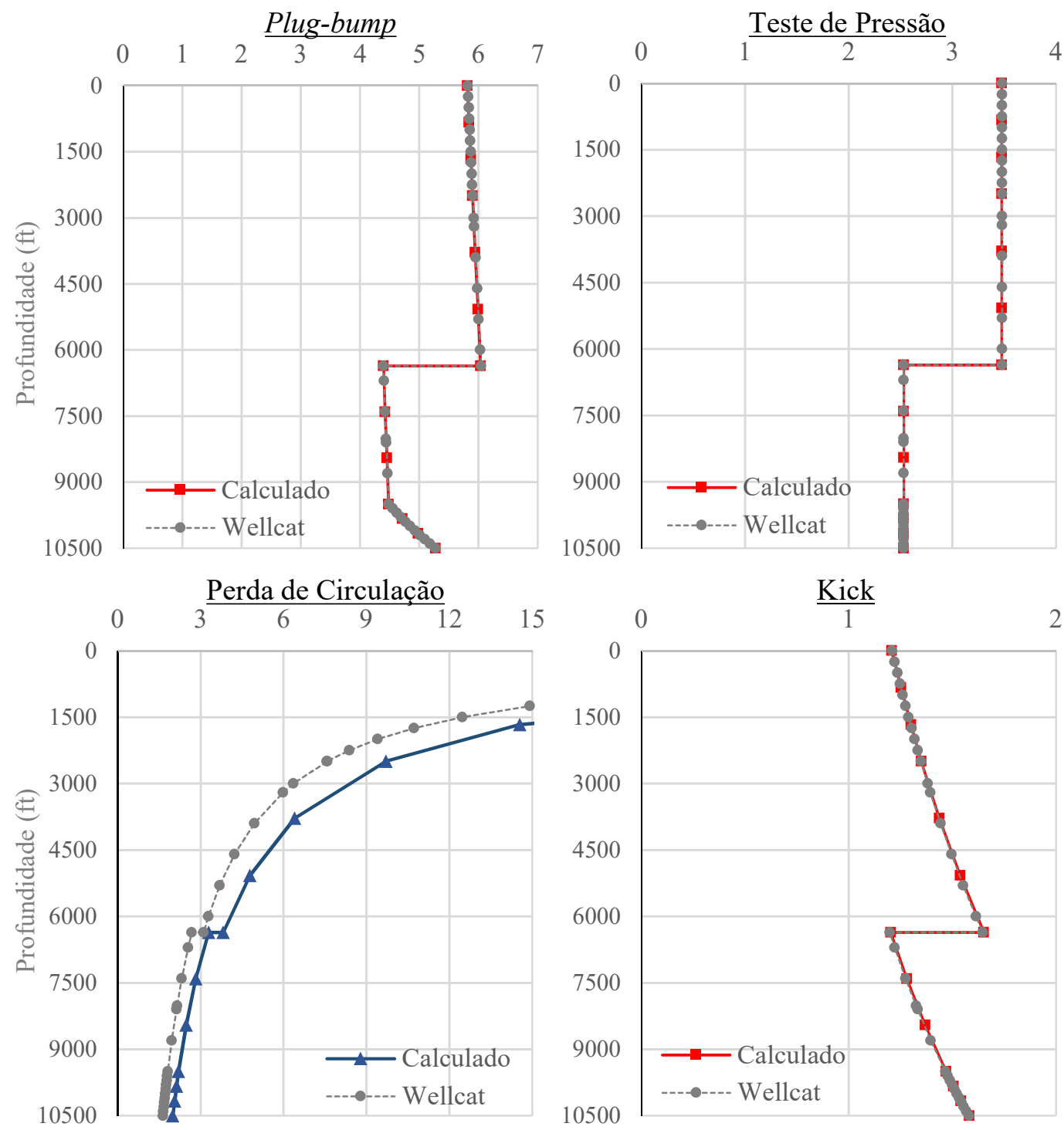

As mesmas tendências observadas nos resultados do revestimento de superfície se repetiram na fase intermediária. Novamente os fatores de segurança à ruptura calculados pela fórmula de Barlow foram idênticos aos valores de referência (curvas em vermelho), enquanto as diferenças foram mais expressivas para o caso de perda de circulação. Ainda que não tenha sido verificada a perfeita correspondência entre as curvas para este cenário de colapso, o comportamento de ambas seguiu a mesma tendência e o diagrama calculado capturou o salto na cota de $6360 \mathrm{ft}$, quando há mudança nas propriedades físicas dos tubulares. Com base nisso, os resultados obtidos foram considerados satisfatórios.

Quanto aos resultados referentes ao modo de falha triaxial (Figura 10.11), obteve-se a perfeita identidade com os valores de referência para todos os casos analisados. Para a fase intermediária, a ocorrência de um kick de gás provou ser o caso de carregamento mais crítico ao dimensionamento da fase, exibindo os menores fatores de segurança em relação aos demais (na faixa entre 1 e 2). 
Figura 10.11 - Revestimento Intermediário: fatores de segurança à falha triaxial (von Mises).
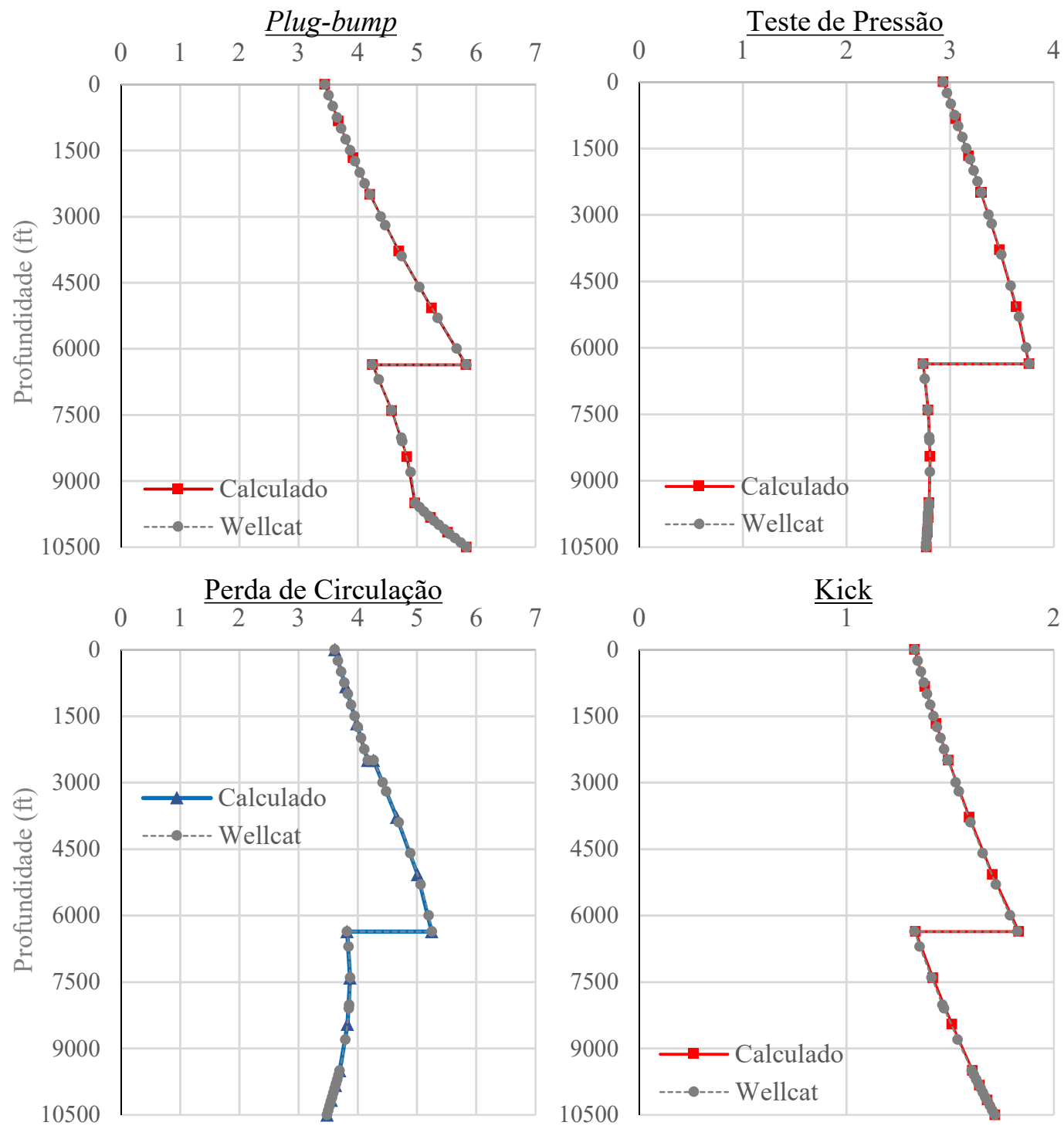

\subsubsection{Revestimento de Produção}

A última etapa de verificação consistiu no estudo das pressões, forças axiais e fatores de segurança do revestimento de produção. Trata-se da fase com maior nível de complexidade, pois é composta por tubulares com diferentes diâmetros internos, além de ser apenas parcialmente cimentada, à semelhança do revestimento intermediário. Por estar em contato quase direto com os fluidos de produção, apresenta também esforços axiais adicionais em virtude de efeitos térmicos. A especificação completa dos tubulares que compõem a coluna é exibida na Tabela 10.3. 
Tabela 10.3 - Revestimento de Produção: propriedades mecânicas dos tubulares.

\begin{tabular}{|c|c|c|c|c|c|}
\hline Seção & $\begin{array}{c}\text { Profundidade } \\
\text { (ft) }\end{array}$ & $\begin{array}{c}\text { OD } \\
\text { (in.) }\end{array}$ & $\begin{array}{c}\text { ID } \\
\text { (in.) }\end{array}$ & $\begin{array}{c}\text { Peso Linear } \\
\text { (lb/ft) }\end{array}$ & $\begin{array}{c}\text { Classe de } \\
\text { aço }\end{array}$ \\
\hline 1 & 3954 & 7 & 6.184 & 29 & P-110 \\
2 & 9220 & 7 & 6.094 & 32 & N-80 \\
3 & 12021 & 7 & 6.094 & 32 & P-110 \\
4 & 14000 & 7 & 6.004 & 35 & P-110 \\
\hline
\end{tabular}

Fonte: Byrom (2015).

Ao todo, quatro cenários de carregamento foram analisados. Para a condição inicial, novamente admitiu-se o perfil de pressões e forças axiais decorrentes da aplicação de uma pressão de vedação logo após o deslocamento do cimento. Com relação ao colapso do revestimento, considerou-se que o poço está em sua fase final de produção e que o reservatório foi esvaziado até uma pressão de abandono. Nesta condição, o diferencial de pressões de colapso é nulo na superfície e máximo na base do revestimento. O cenário crítico de ruptura, por sua vez, admite a ocorrência de um vazamento no topo do tubo de produção, levando à perda total do fluido de empacotamento (ver Seção 4.2). Finalmente, o revestimento deve ser capaz de resistir às pressões internas causadas pelo influxo de gases, na eventualidade do tubo de produção ter de ser substituído.

Em resumo, os casos de carregamento analisados foram:

1. Aplicação de pressão de vedação de 1200 psi (plug-bump);

2. Evacuação total do revestimento;

3. Ocorrência de um kick de gás (tubing backup);

4. Vazamento no tubo de produção (tubing leak).

Para o cálculo das forças axiais na condição inicial admitiu-se o perfil de temperatura correspondente ao próprio gradiente geotérmico do poço (BYROM, 2015, p. 52). Nos demais cenários de carregamento analisados, foram consideradas temperaturas mais elevadas, com base nas informações expostas por Rahman e Chilingarian (1995). Segundo os autores, à medida que o gás ou óleo explorado ascende no interior do poço, ocorrem mudanças na temperatura do revestimento. A troca de calor entre o fluido de produção e os tubulares faz com que a parte superior do revestimento seja submetida a um maior gradiente térmico, que induz tensões axiais adicionais devido à indeslocabilidade da fase após sua cimentação. A Tabela 10.4 apresenta as temperaturas adotadas no topo e na base do revestimento de produção, na ocasião de seu assentamento e durante a exploração do reservatório. Admite-se variação linear ao longo da profundidade em ambos os casos e coeficiente de dilatação térmica $\alpha=6,9 \cdot 10^{-6} /{ }^{\circ} \mathrm{F}$ (ou $\left.\alpha=12,42 \cdot 10^{-6} /{ }^{\circ} \mathrm{C}\right)$. 
Tabela 10.4 - Temperaturas no topo e na base do poço.

\begin{tabular}{|c|c|c|}
\hline Profundidade & Condição Inicial & Etapa de Produção \\
\hline $0 \mathrm{ft}$ & $74{ }^{\circ} \mathrm{F}$ & $140{ }^{\circ} \mathrm{F}$ \\
$14000 \mathrm{ft}$ & $326^{\circ} \mathrm{F}$ & $326^{\circ} \mathrm{F}$ \\
\hline
\end{tabular}

Fonte: Byrom (2015).

A seguir, a Figura 10.12 apresenta os resultados referentes à verificação do cálculo das forças axiais. Ressalta-se que, além do efeito térmico, continuaram sendo computados os esforços normais provocados pelo peso próprio do revestimento, pelo efeito pistão e pelo efeito Poisson.

Figura 10.12 - Revestimento de Produção: forças axiais iniciais e durante a exploração do poço.
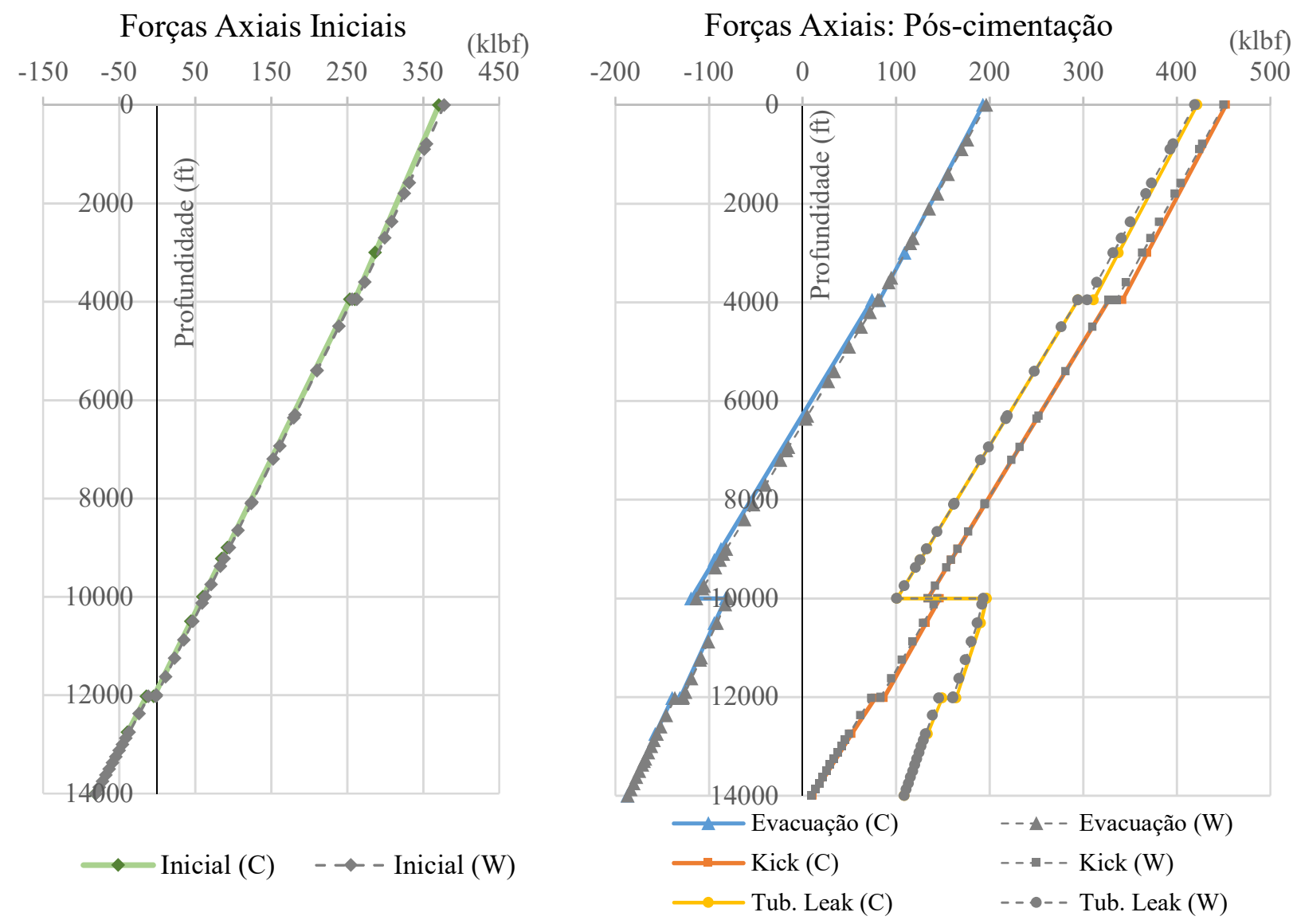

Tal como nos demais revestimentos analisados, houve um ajuste quase perfeito das forças axiais calculadas em relação aos valores de referência. Em média, o erro relativo foi inferior a $1,0 \%$ para os casos de carregamento 1, 3 e 4 . O cenário de evacuação total, entretanto, apresentou uma diferença ligeiramente maior, apresentando pontos com erro relativo de até $2,9 \%$. Apesar da diferença observada, os valores com maior erro associado ficaram restritos a uma faixa de forças axiais com baixa intensidade, no trecho não cimentado entre 4 mil e $10 \mathrm{mil} f \mathrm{ft}$. Isto fez com que não impactassem na segurança do revestimento, como pode ser visto nas Figuras 10.13 e 10.14, que exibem os coeficientes de segurança do poço para os diferentes modos de falha. 
Figura 10.13 - Revestimento de Produção: fatores de segurança ao colapso (API) e ruptura (Barlow).
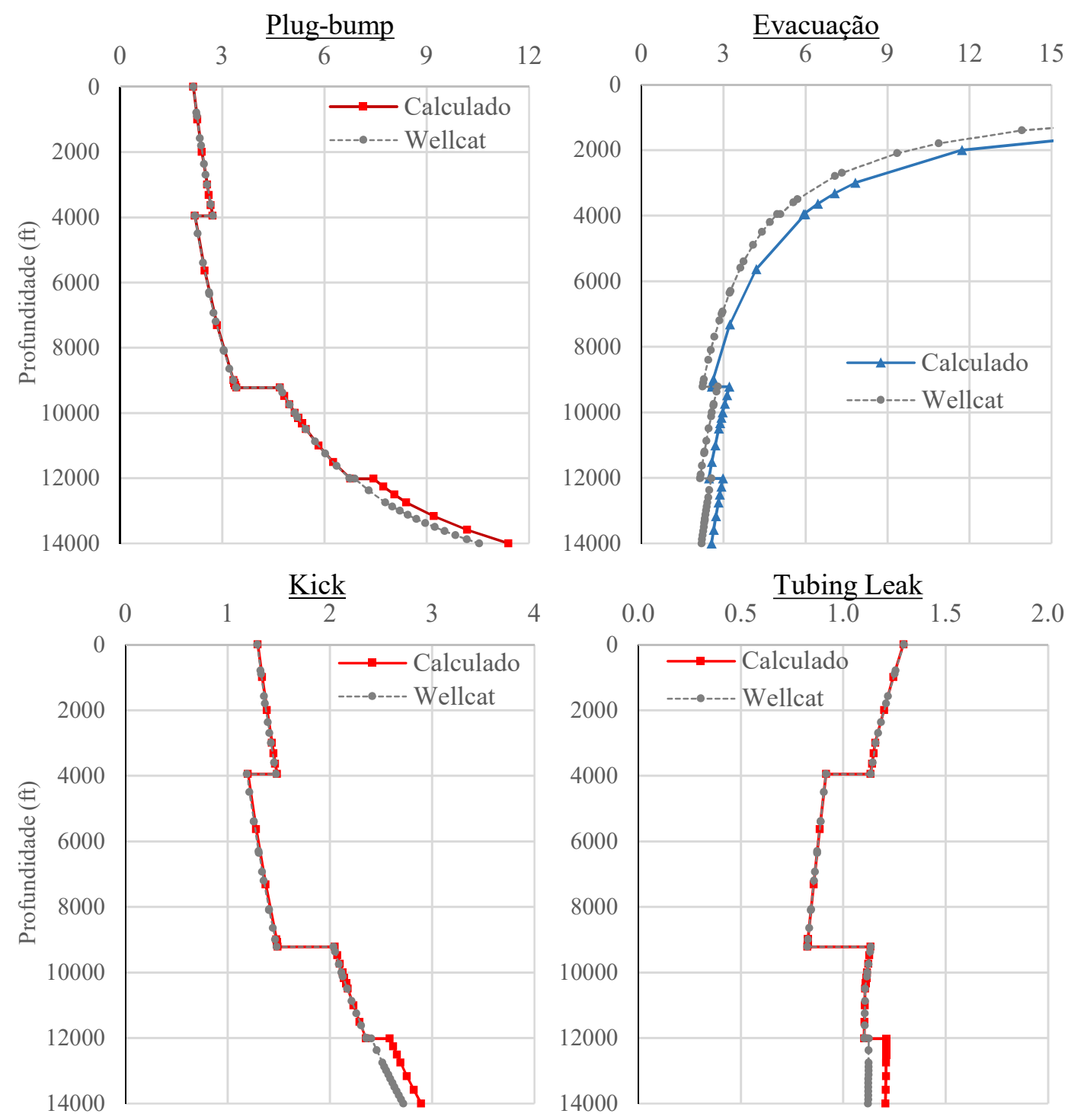

A Figura 10.13 reproduz os coeficientes de segurança ao longo da profundidade do poço para os modos de falha por ruptura e colapso. Observa-se uma ótima correspondência entre os resultados, ainda que as diferenças para o cenário de colapso tenham sido mais expressivas. O comportamento das curvas calculadas foi praticamente o mesmo daquelas tomadas como referência, porém nota-se um salto no último trecho do revestimento (a partir de $12.021 \mathrm{ft}$ ) nos cenários de ruptura. A origem deste fenômeno não foi identificada, porém especula-se que o erro não seja do código desenvolvido, em virtude da perfeita correspondência observada na Figura 10.14 para a totalidade dos casos analisados. Além disso, o salto apresentado por todas as curvas a aproximadamente 12 mil pés era esperado, uma vez que há mudança no diâmetro interno dos tubulares. 
Figura 10.14 - Revestimento de Produção: fatores de segurança à falha triaxial (von Mises).
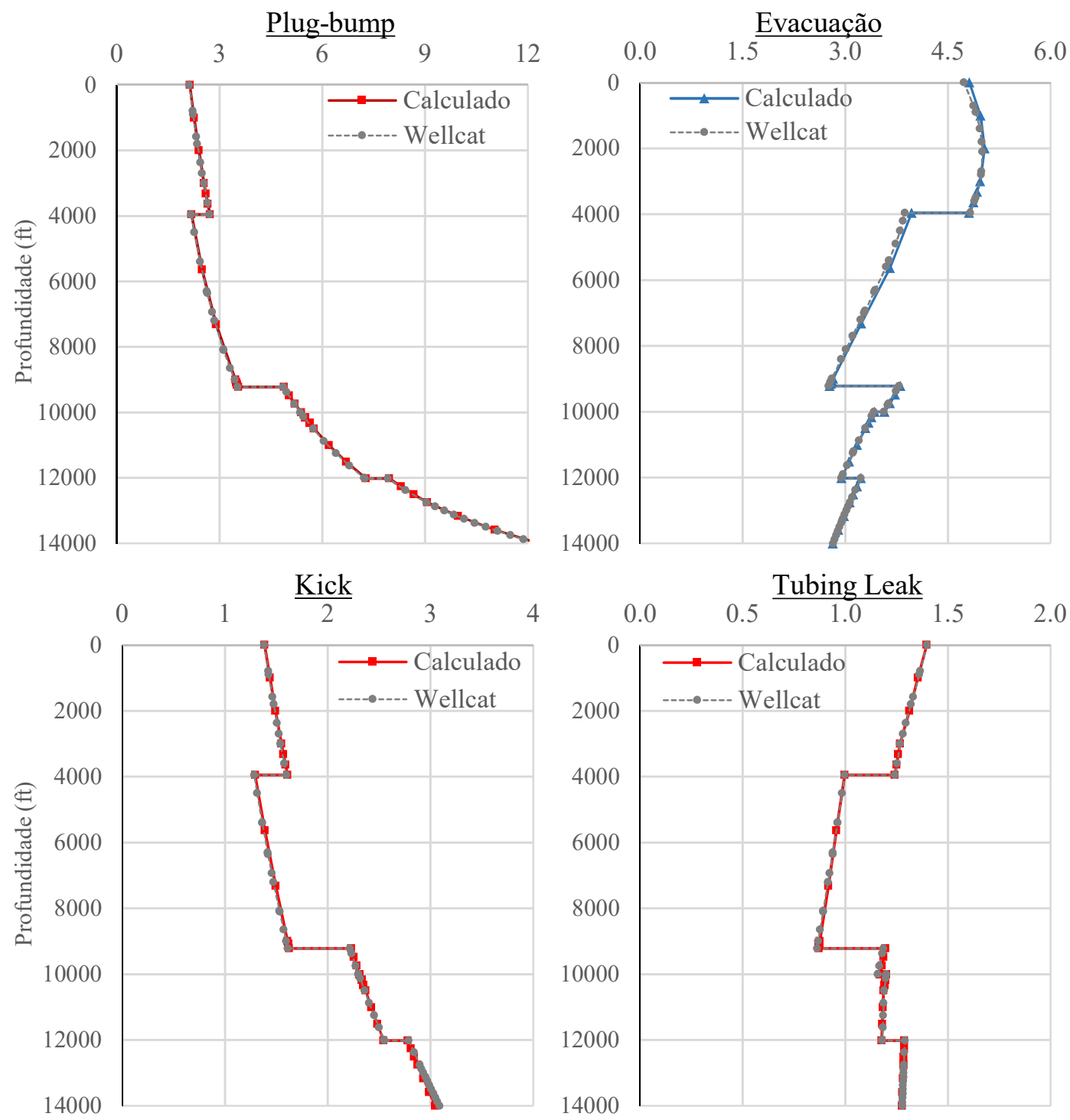

Analisando as Figuras 10.13 e 10.14, conclui-se que um vazamento no tubo de produção (tubing leak) é crítico em relação à segurança do revestimento. Valores inferiores à unidade são observados no segundo trecho de tubulares que compõem a coluna, indicando a total ausência de margens de segurança de projeto e uma maior probabilidade de falha do revestimento. Nesta situação, é usual refazer a seleção dos tubulares da fase, utilizando tubos de maior espessura ou aços de melhor qualidade.

O estudo do revestimento de produção conclui a avaliação do módulo determinístico, obtendo-se um parecer positivo com relação à implementação realizada. As etapas descritas a seguir têm o objetivo de analisar a consistência dos resultados obtidos pelo módulo estocástico em termos das probabilidades de falha dos revestimentos. 


\subsection{Verificação do Módulo Estocástico}

A presente seção tem por objetivo avaliar a correta implementação das rotinas do módulo estocástico. Conforme dito, não se tem acesso a nenhum software comercial que realize análises probabilísticas de revestimentos, motivo pelo qual os resultados são avaliados segundo duas estratégias. Em um primeiro momento, os índices de confiabilidade obtidos são comparados qualitativamente aos fatores de segurança calculados pelo módulo determinístico para averiguar se as mesmas descontinuidades e tendências são capturadas pelo programa. Em seguida, os resultados de diferentes métodos de análise de confiabilidade são comparados entre si para verificar a convergência das soluções numéricas. Para isso, são realizadas simulações de Monte Carlo simples (MCS) e simulações de Monte Carlo por Importância usando pontos de projeto (MCI), além da aplicação do método de confiabilidade de primeira ordem (FORM).

\subsubsection{Análise Qualitativa: verificação de tendências}

Nos estudos de caso para validação do módulo determinístico, os fatores de segurança foram calculados com base no critério de von Mises, na equação de Barlow e no modelo do API-5C3. Isto foi feito a fim de possibilitar a comparação direta com os resultados do Wellcat. Contudo, em virtude dos motivos expostos no Capítulo 6, nos estudos ora conduzidos os critérios de resistência à ruptura e ao colapso são substituídos pelos modelos de Klever-Stewart (KS) e de Klever-Tamano (KT), respectivamente.

Nas análises de confiabilidade, as equações de estado limite destes modelos são utilizadas - Eqs. (6.6), (6.41) e (6.48). Nas análises determinísticas, efetuam-se alguns ajustes a estas equações de modo a incorporar uma certa margem de segurança aos cálculos. No caso do critério de Klever-Stewart, substituem-se os dados amostrais de espessura mínima $t_{\text {min }}$ e resistência última $f_{u}$ por valores mínimos admissíveis de ambas as variáveis. De maneira semelhante, a espessura nominal $t$ do revestimento é substituída por uma espessura reduzida (igual a $0,875 t$ ) no critério de von Mises. O critério de Klever-Tamano, em contrapartida, sofre modificações substanciais, de modo que a equação de projeto determinística passa a ser dada pela Eq. (6.33).

Neste primeiro conjunto de análises de caráter qualitativo, a estimativa dos índices de confiabilidade dos revestimentos é realizada exclusivamente pelo método FORM. As variáveis aleatórias utilizadas e seus respectivos dados estatísticos estão descritos no Capítulo 8.

Probabilidades de falha e índices de confiabilidade foram obtidos para a totalidade das fases e dos cenários de carregamento, porém são apresentados apenas os resultados referentes aos casos críticos de colapso e ruptura dos revestimentos de superfície, intermediário e de produção. A seguir, os fatores de segurança (FS) e índices de confiabilidade $(\beta)$ da fase de superfície são apresentados na Figura 10.15 para os modos de falha de colapso e ruptura. 
Figura 10.15 - Revestimento de Superfície: FS e $\beta$ dos critérios de resistência à ruptura e ao colapso.
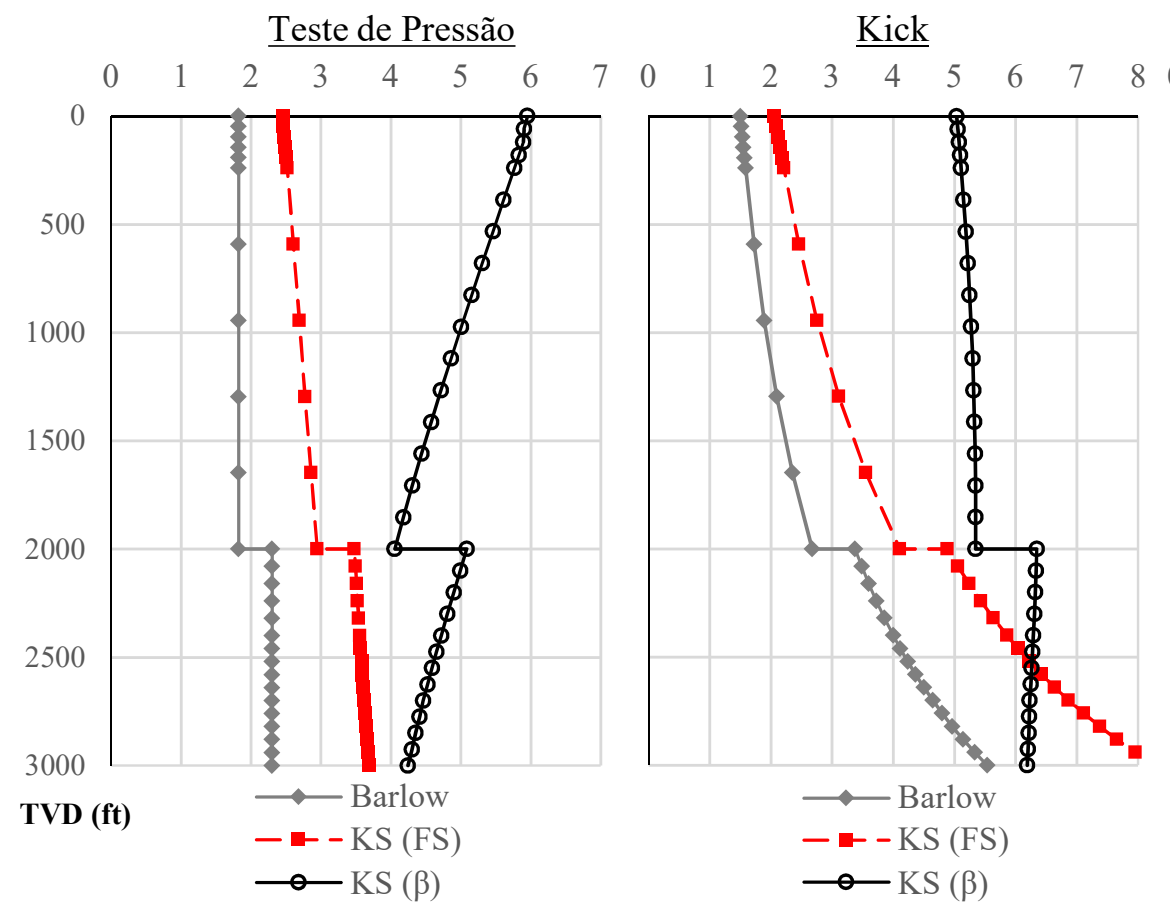

Perda de Circulação

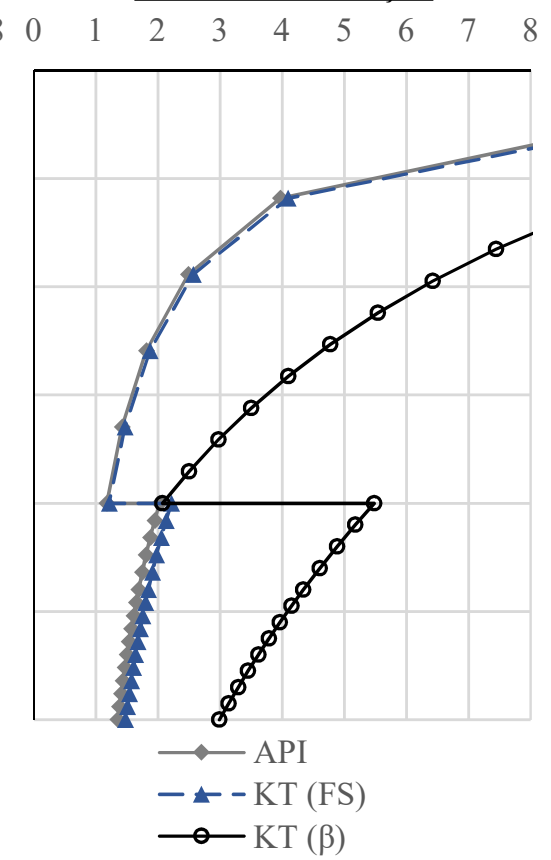

Da Figura 10.15, observa-se que em todos os cenários de carregamento o programa foi capaz de capturar a descontinuidade decorrente da mudança da geometria no revestimento. Além disso, as curvas referentes ao critério de Klever-Tamano exibiram a mesma tendência comportamental, apresentando valores decrescentes à medida que aumenta a profundidade do poço. Nas situações de ruptura o mesmo já não é constatado. Ao passo que os fatores de segurança crescem em direção ao fundo do poço nos casos de teste de pressão e kick, os índices de confiabilidade aumentam em direção à superfície no primeiro caso e permanecem aproximadamente constantes no segundo. Não há, portanto, uma relação direta de proporcionalidade entre estas grandezas, evidenciando a falsa sensação de segurança algumas vezes proporcionada pelo projeto determinístico: embora o fator de segurança mínimo do revestimento indique que o ponto mais suscetível a falha está situado no topo da coluna $\left(\mathrm{FS}_{K S}=2,064\right.$, em caso de kick), a análise de confiabilidade revela que o tubular com mais alta probabilidade de falha está situados a $2000 \mathrm{ft}$ de profundidade $\left(\beta_{K S}=4,055\right.$, em caso de teste de pressão).

Na Figura 10.15 são também representados os fatores de segurança dos critérios de Barlow e do API-5C3 para fins de comparação com os critérios mais modernos da norma ISO/TR 10400:2011. Verifica-se que o modelo de Klever-Stewart permite o melhor aproveitamento do material, proporcionando um grande ganho de resistência em comparação à equação de Barlow. Em caso de colapso há também um acréscimo de resistência, embora quase imperceptível. Salienta-se que não se deve esperar, obrigatoriamente, um comportamento mais arrojado de KT em relação ao critério da API, já que o primeiro considera as imperfeições do tubo e a tensão residual do aço, de modo que, para diferentes esbeltezes, essa tendência se altera.

A seguir, são apresentados na Figura 10.16 os índices de confiabilidade e os fatores de segurança calculados segundo o critério de von Mises para os mesmos cenários de carregamento do revestimento de superfície. 
Figura 10.16 - Revestimento de Superfície: FS e $\beta$ do modo de falha triaxial.
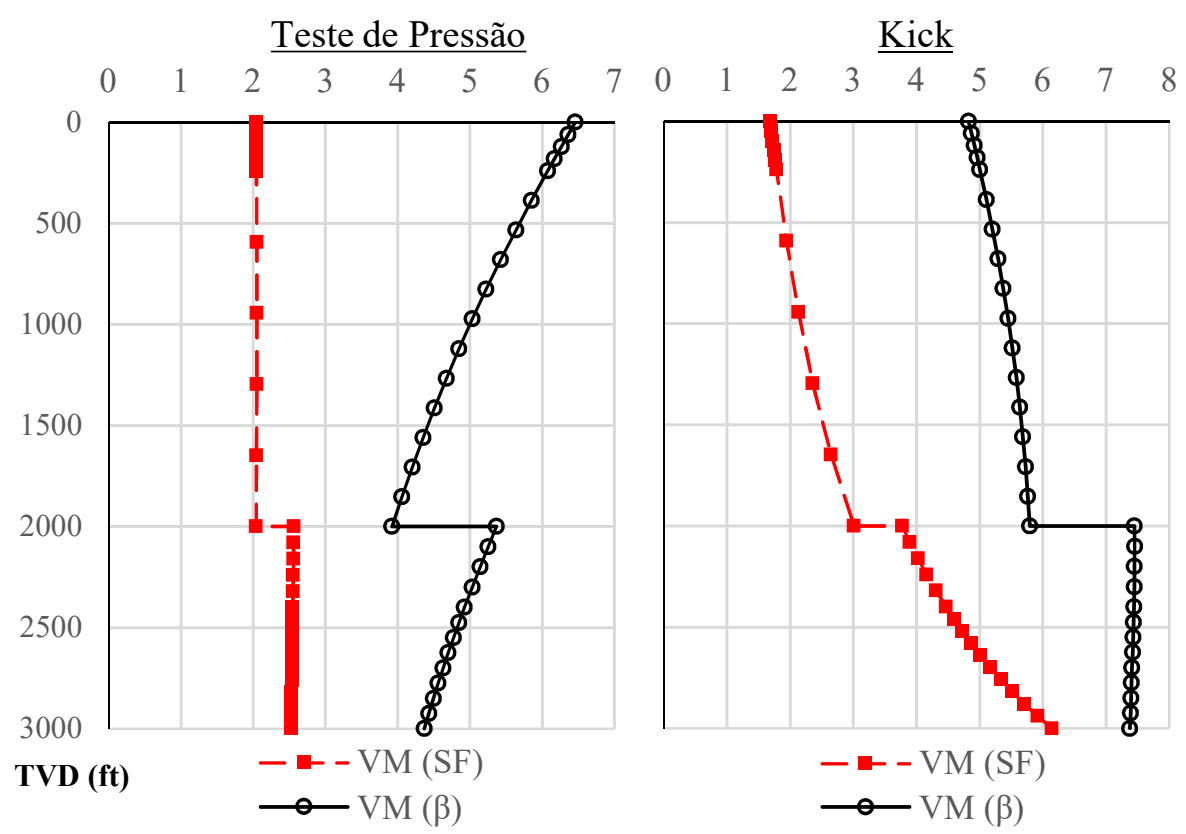

Perda de Circulação

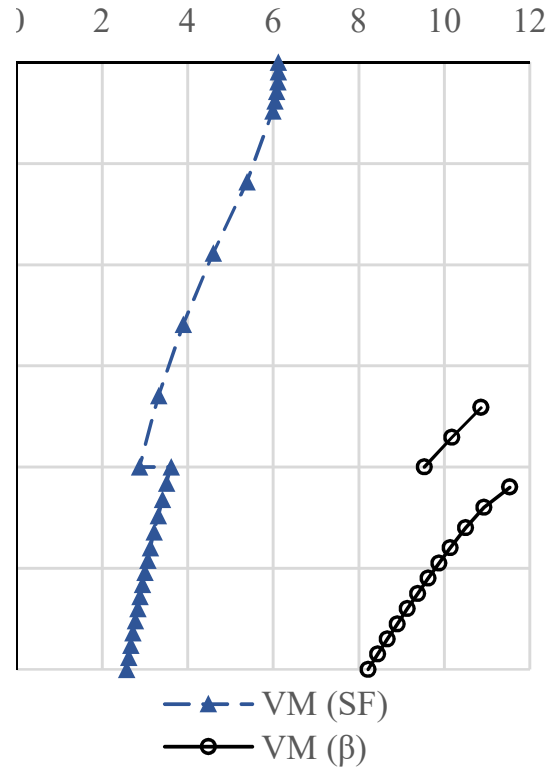

Em geral, as mesmas tendências são observadas. No cenário específico de perda de circulação o algoritmo do método FORM não apresentou convergência em alguns pontos, sendo representados no gráfico apenas os valores retornados pelo programa. Ainda que indesejável, a não convergência do algoritmo não representa um problema, pois só ocorre em trechos com índices de confiabilidade extremamente altos (acima de 12).

Repetindo o procedimento para o revestimento intermediário, percebe-se agora que as curvas dos índices de confiabilidade exibem um comportamento mais próximo ao das curvas dos fatores de segurança para o cenário de kick (Figuras 10.17 e 10.18). Desta vez, tanto o fator de segurança quanto a probabilidade de falha tornam-se maiores conforme a profundidade aumenta, exceto no trecho inferior do gráfico de $\operatorname{KS}(\beta)$.

Figura 10.17 - Revestimento Intermediário: FS e $\beta$ dos critérios de resistência à ruptura e ao colapso.

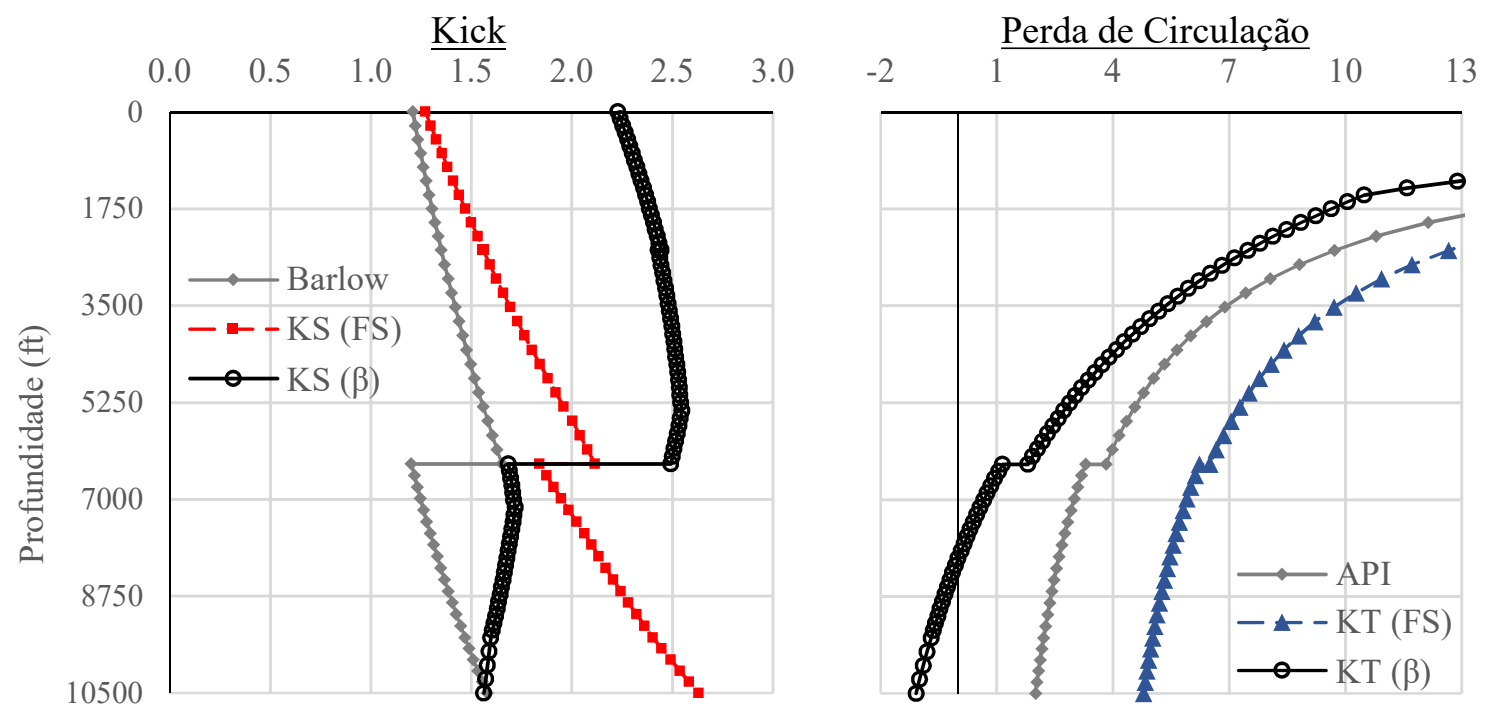


Figura 10.18 - Revestimento Intermediário: FS e $\beta$ do modo de falha triaxial.
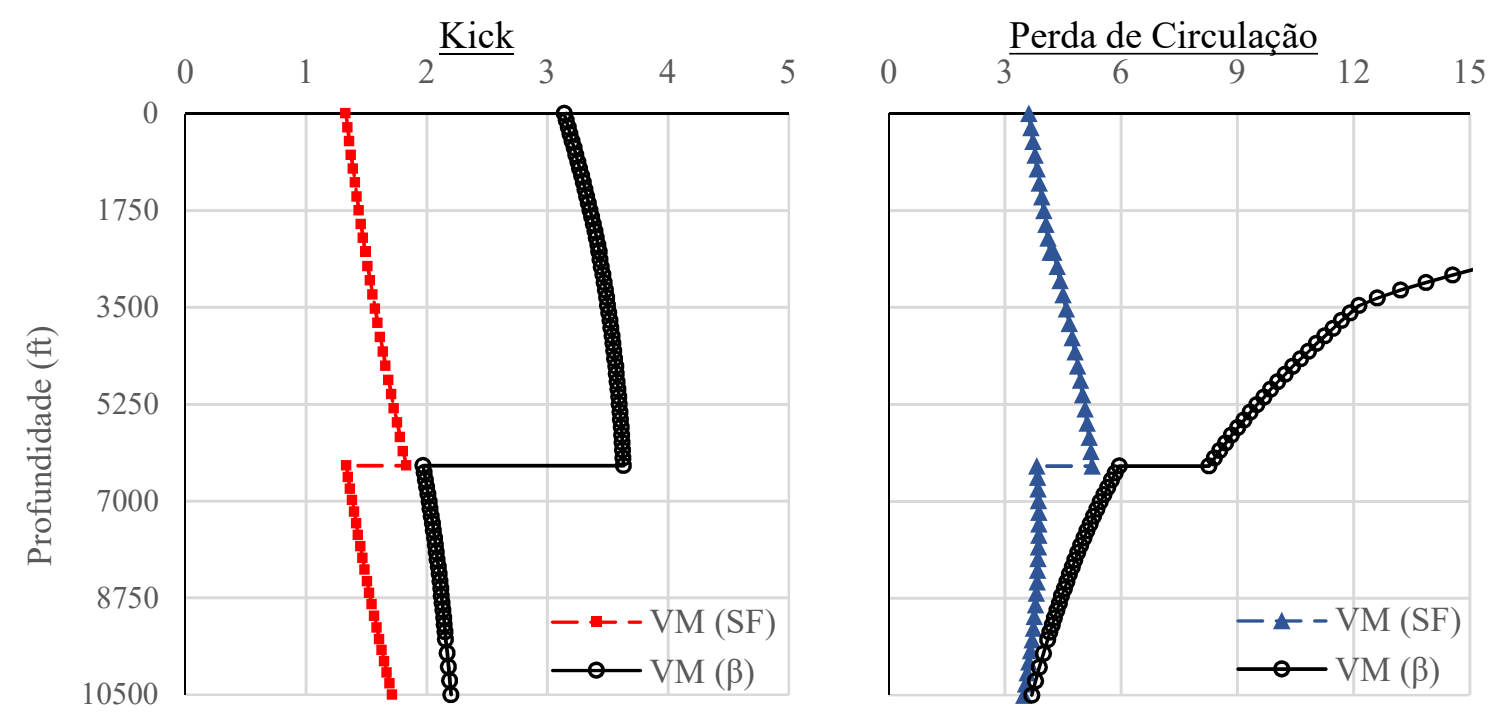

De modo geral, curvas de fatores de segurança e índices de confiabilidade exibiram uma relativa concordância entre si. O modo de falha triaxial para o cenário de perda de circulação foi o único caso excepcional, apresentando aspecto semelhante às curvas de colapso da Figura 10.17. Todavia, a descontinuidade provocada pela mudança nas propriedades físicas dos tubulares na cota de $6360 \mathrm{ft}$ (Tabela 10.2) foi capturada na totalidade dos casos.

Com relação aos critérios do API-5C3 e da ISO/TR 10400, nota-se uma maior diferença entre os perfis API e KT(FS) em comparação ao revestimento de superfície (Figura 10.17). A maior diferença entre os critérios pode ser explicada pela esbeltez dos tubos da fase intermediária, que é diferente dos tubos do revestimento de superfície. A diferença entre KT e API varia, para um mesmo grau de aço, ao longo da razão $O D / t$, conforme foi comprovado por Gouveia (2014). Torna-se evidente, portanto, o caráter mais conservador da normativa antiga em relação ao atual critério de Klever-Tamano.

Conclusões semelhantes podem ser traçadas para o revestimento de produção com base nos resultados mostrados nas Figuras 10.19 e 10.20. Nestes gráficos, porém, índices de confiabilidade foram calculados para uma situação adicional na qual as estatísticas originais do problema foram modificadas para estudar o efeito da variabilidade das ações sobre a probabilidade de falha do revestimento. Nesta situação, os coeficientes de variação da pressão interna e da pressão externa foram reduzidos de $20 \%$ para metade deste valor.

Como esperado, os índices estimados para a condição de variabilidade reduzida (curvas indicadas por "10\%") foram todos superiores àqueles na condição original (curvas representadas por " $\beta$ "). Observa-se ainda o reflexo que a mudança nas estatísticas das pressões tem sobre os modelos de resistência: ao plotar todos os gráficos numa mesma escala, percebe-se que o critério de von Mises foi o mais afetado pela mudança, exibindo as maiores diferenças entre as curvas de $10 \%$ e $20 \%$. 
Figura 10.19 - Revestimento de Produção: FS e $\beta$ dos critérios de resistência à ruptura e ao colapso.

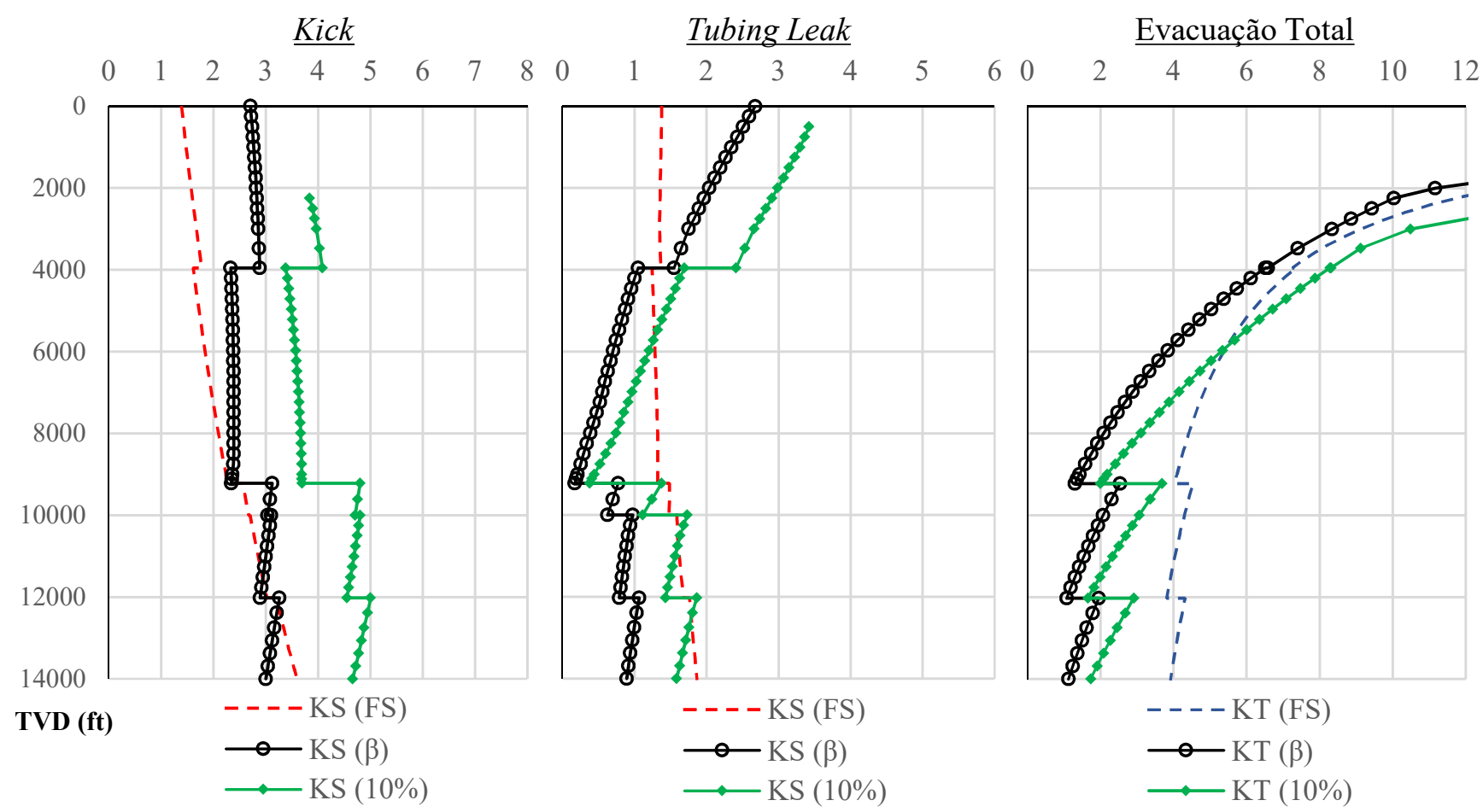

Figura 10.20 - Revestimento de Produção: FS e $\beta$ do modo de falha triaxial.

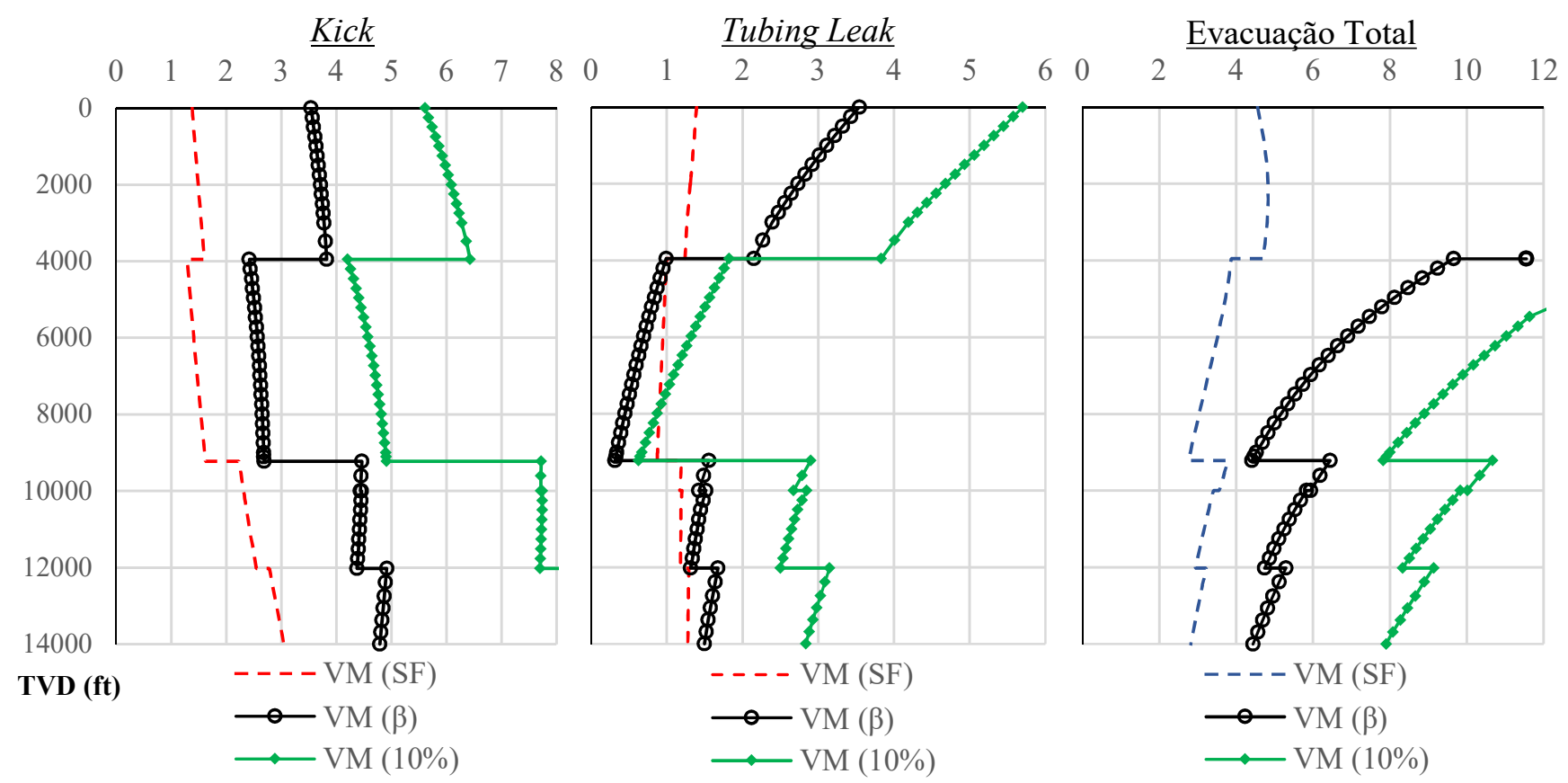


A influência de cada variável aleatória sobre as equações de estado limite pode ser melhor avaliada por meio dos fatores de sensibilidade $\alpha_{i}$. Tais fatores resultam da aplicação do método FORM e permitem quantificar a importância relativa de cada variável aleatória do problema. A seguir, as Figuras 10.21 e 10.22 mostram os fatores de sensibilidade das variáveis aleatórias pertinentes a cada um dos critérios de resistência, para os casos de evacuação total e ocorrência de um kick no revestimento de produção. Os fatores de sensibilidade são exibidos ao longo de toda a profundidade do revestimento a fim de capturar a evolução da sensibilidade de cada variável a medida que as pressões e as forças axiais se alteram. Basicamente, quanto maior o valor de $\alpha_{i}$, maior a contribuição da variável $i$ para a probabilidade de falha do revestimento.

Figura 10.21 - Fatores de sensibilidade relativos à evacuação total do revestimento de produção.

Modelo de Klever-Tamano

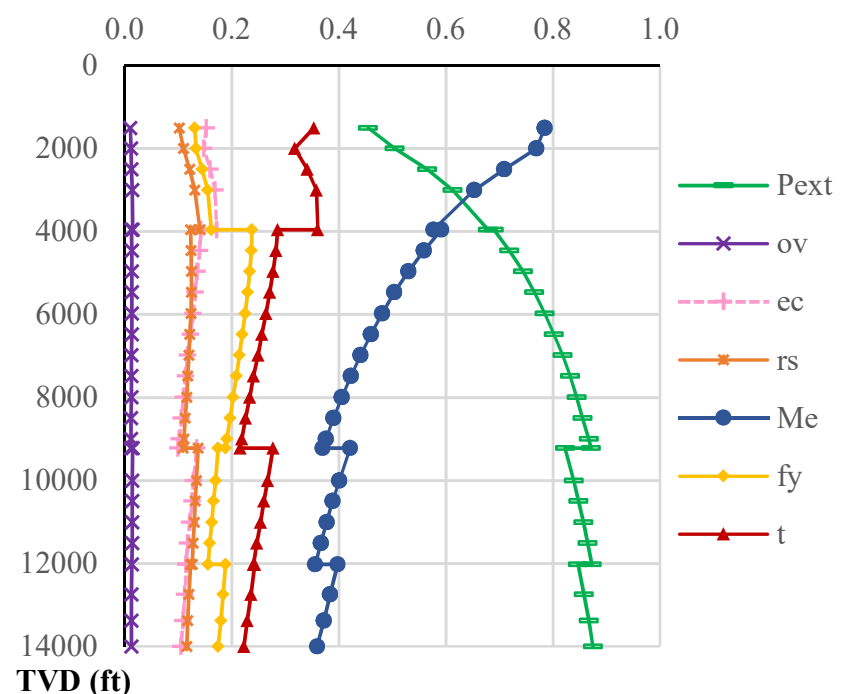

Critério de von Mises

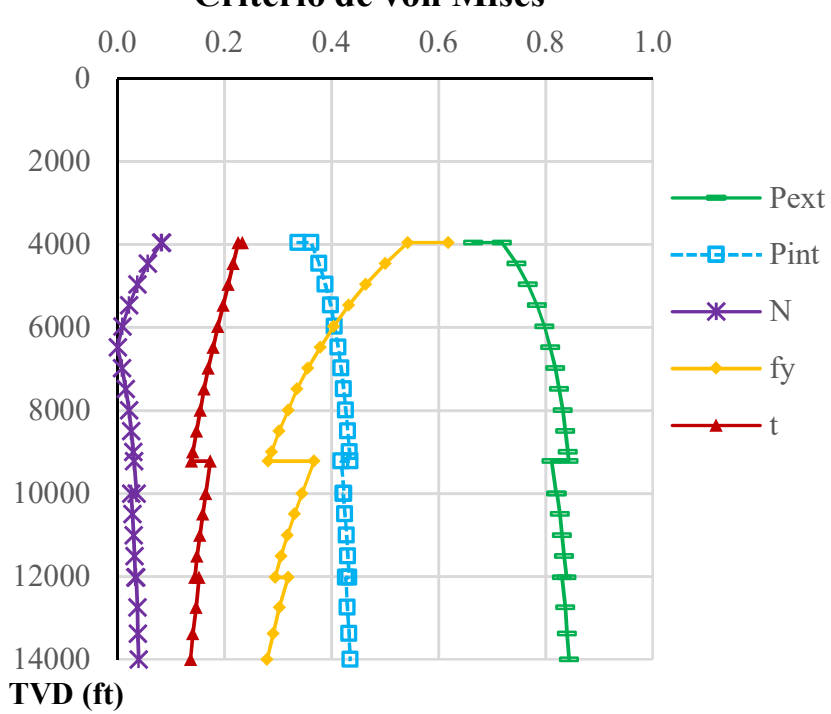

Figura 10.22 - Fatores de sensibilidade relativos à ocorrência de um kick no revestimento de produção.

Modelo de Klever-Stewart

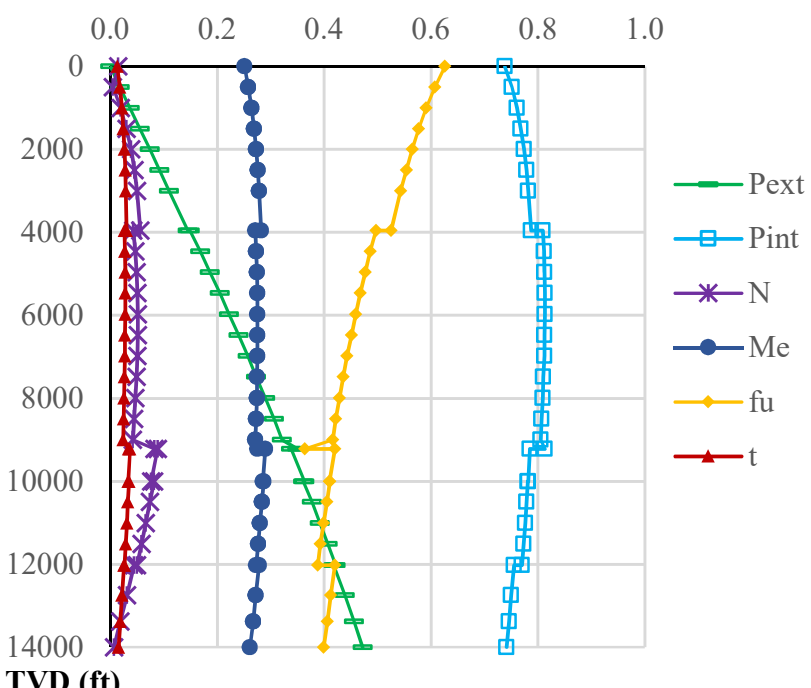

Critério de von Mises

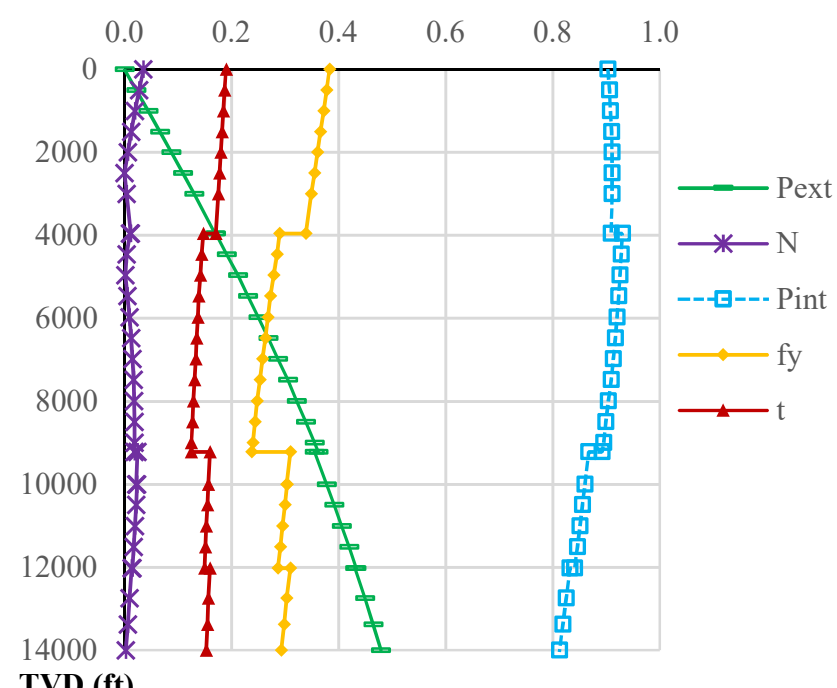

Com base nos gráficos, observa-se que a probabilidade de falha do revestimento em caso de evacuação total é governada pela incerteza inerente à pressão externa $\left(P_{\text {ext }}\right)$ em ambos 
os modelos de resistência, apresentando índices de sensibilidade superiores a 0,8 em grandes profundidades. Este resultado atende às expectativas, pois em cenários de colapso a pressão diferencial que causa a falha do revestimento é negativa $\left(P_{\text {ext }}>P_{\text {int }}\right)$ e cresce em direção ao fundo do poço. À medida que o diferencial de pressões se intensifica, portanto, a variabilidade da pressão torna-se crítica à segurança do poço. No cenário de kick, por outro lado, ocorre a inversão da pressão diferencial do poço, fazendo com que a pressão interna $\left(P_{\text {int }}\right)$ torne-se a fonte mais relevante de incerteza.

Em profundidades menores, o erro de modelo $\left(M_{\mathrm{e}}\right)$ corresponde à variável aleatória de resistência mais relevante para o modelo de Klever-Tamano, sendo seguida pela espessura do revestimento $(t)$ e pela tensão de escoamento $\left(f_{y}\right)$. No modelo de Klever-Stewart, em contrapartida, a variabilidade da tensão última do material $\left(f_{u}\right)$ é preponderante sobre as incertezas do modelo, conforme mostra a Figura 10.22.

Dentre as variáveis aleatórias com menor impacto sobre a segurança do revestimento estão a ovalidade do tubo (ov), para o caso do modelo de Klever-Tamano, a espessura do revestimento, $(t)$, para o modelo de Klever-Stewart, e o esforço normal $(N)$, no caso do critério de von Mises. Estas variáveis poderiam, em teoria, ser representadas por seu valor nominal (determinístico) sem prejuízo às análises de confiabilidade. No entanto, embora a incerteza sobre a espessura do revestimento não afete o modelo de Klever-Stewart, observa-se que ela é relevante para os outros modelos de resistência. Sendo assim, a redução da dimensão do vetor de variáveis aleatórias do problema deve ser avaliada com cautela.

Ressalta-se ainda que há uma lacuna de dados em ambos os gráficos da Figura 10.21 nos pontos próximos à superfície do revestimento. Nestes pontos o algoritmo FORM não apresentou convergência devido aos altos índices de confiabilidade no trecho.

De maneira geral, nota-se que a incerteza associada aos parâmetros de resistência é de menor importância em relação aos parâmetros de solicitação para os dados admitidos. Logo, a precisa caracterização estatística das pressões e forças axiais é imprescindível para a avaliação da segurança de revestimentos de poços reais.

\subsubsection{Análise da Precisão do FORM}

Uma vez concluídas as análises iniciais do módulo estocástico e constatada a correta integração do algoritmo FORM às rotinas de cálculo determinísticas, verifica-se agora a precisão numérica do método. Para esse fim, índices de confiabilidade foram estimados por meio de simulações de Monte Carlo simples (MCS) e simulações de Monte Carlo por Importância usando pontos de projeto (MCI), sendo então comparados aos valores obtidos pelo emprego do FORM.

O estudo se limitou ao revestimento de produção, em virtude dos mais baixos índices de confiabilidade observados. Isto permitiu reduzir o número de simulações de Monte Carlo necessárias para se obter resultados com reduzida variância.

Foram analisados os cenários de tubing leak e de evacuação completa. No primeiro caso, a coluna de revestimento foi dividida em 15 segmentos e computou-se a probabilidade de falha 
no topo e na base de cada um deles. Para cada um dos 30 pontos, foram realizadas 100 mil simulações de MCS e 10 mil simulações de MCI, totalizando 3,3 milhões de simulações. No segundo caso, a coluna foi dividida em 32 segmentos, ultrapassando 7 milhões de simulações.

Na Figura 10.23 são representados os índices de confiabilidade obtidos pelos métodos FORM e MCI para ambos os critérios de resistência, admitindo o cenário de tubing leak. A região hachurada dos gráficos representa a envoltória dos possíveis valores de $\beta$, considerando o número de simulações realizadas e um intervalo de confiança de $95 \%$.

Figura 10.23 - Índices de confiabilidade calculados para o cenário de tubing leak: FORM e MCI.

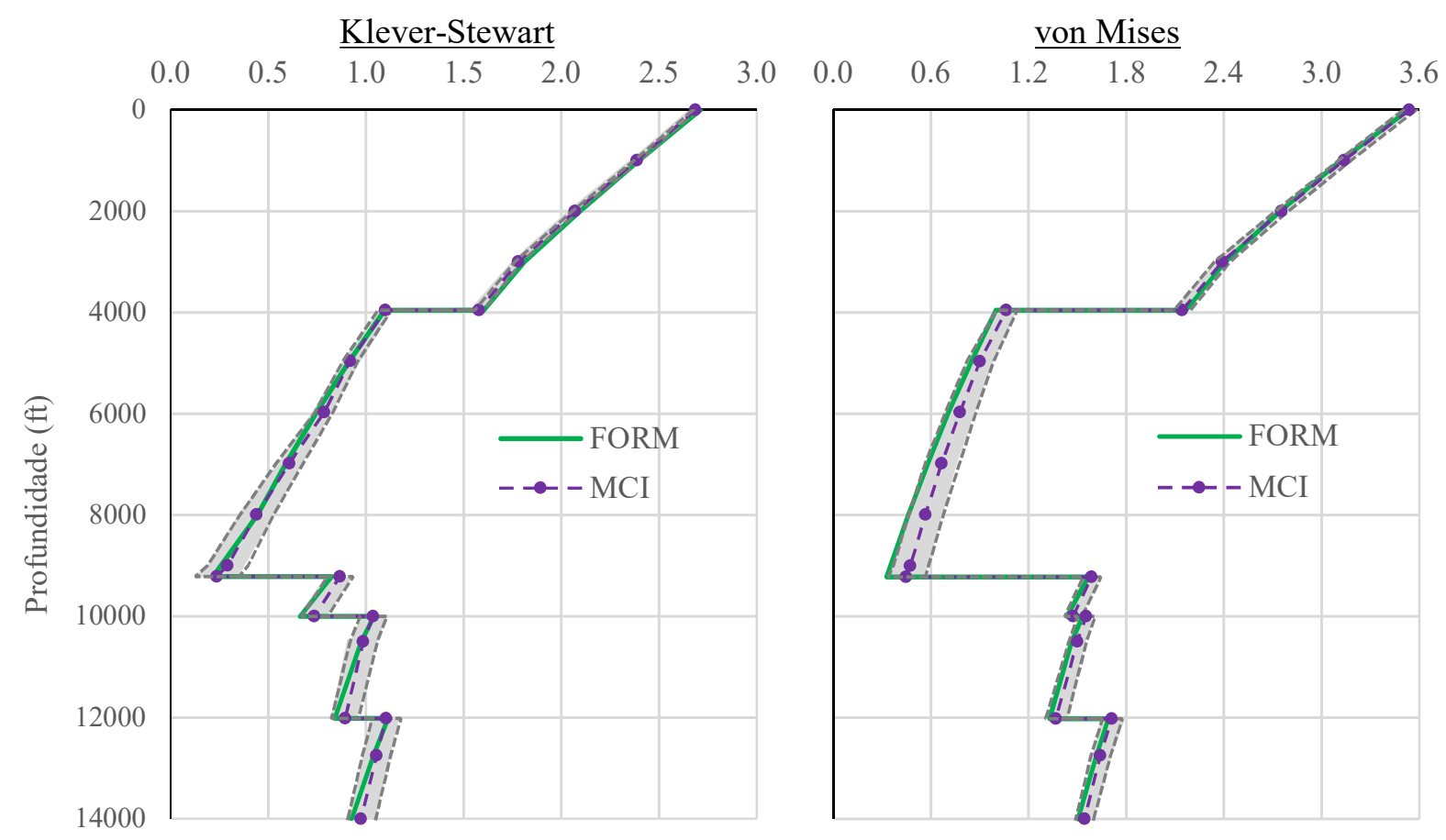

Observa-se que os resultados do FORM estão contidos no interior desta região na totalidade dos pontos, demonstrando a excelente convergência numérica dos métodos. Atenta-se ainda para o fato de que ora as estimativas do FORM coincidem com o valor médio do MCI (caso do modelo de Klever-Stewart), ora se sobrepõem ao seu limite inferior (critério de von Mises). Esta tendência é positiva do ponto de vista da segurança estrutural, pois demonstra que o FORM fornece valores iguais ou ligeiramente inferiores aos índices de confiabilidade "exatos"da estrutura, calculados por meio do MCI.

O resultado das simulações de Monte Carlo simples, por sua vez, são representados na Figura 10.24 em conjunto com os resultados do método FORM. Devido ao alto número de simulações realizadas em cada ponto, a variabilidade da resposta se reduz a aproximadamente zero (C.V. médio de $0,13 \%$ ). Como consequência, observa-se que a região hachurada praticamente desaparece, exceto nos pontos próximos à superfície, onde há menor probabilidade de falha (gráfico à direita). Novamente o método FORM apresenta excelente concordância com as simulações de Monte Carlo, demonstrando que seu caráter aproximativo não é empecilho à estimativa da confiabilidade de poços. 
Figura 10.24 - Índices de confiabilidade calculados para o cenário de tubing leak: FORM e MCS.
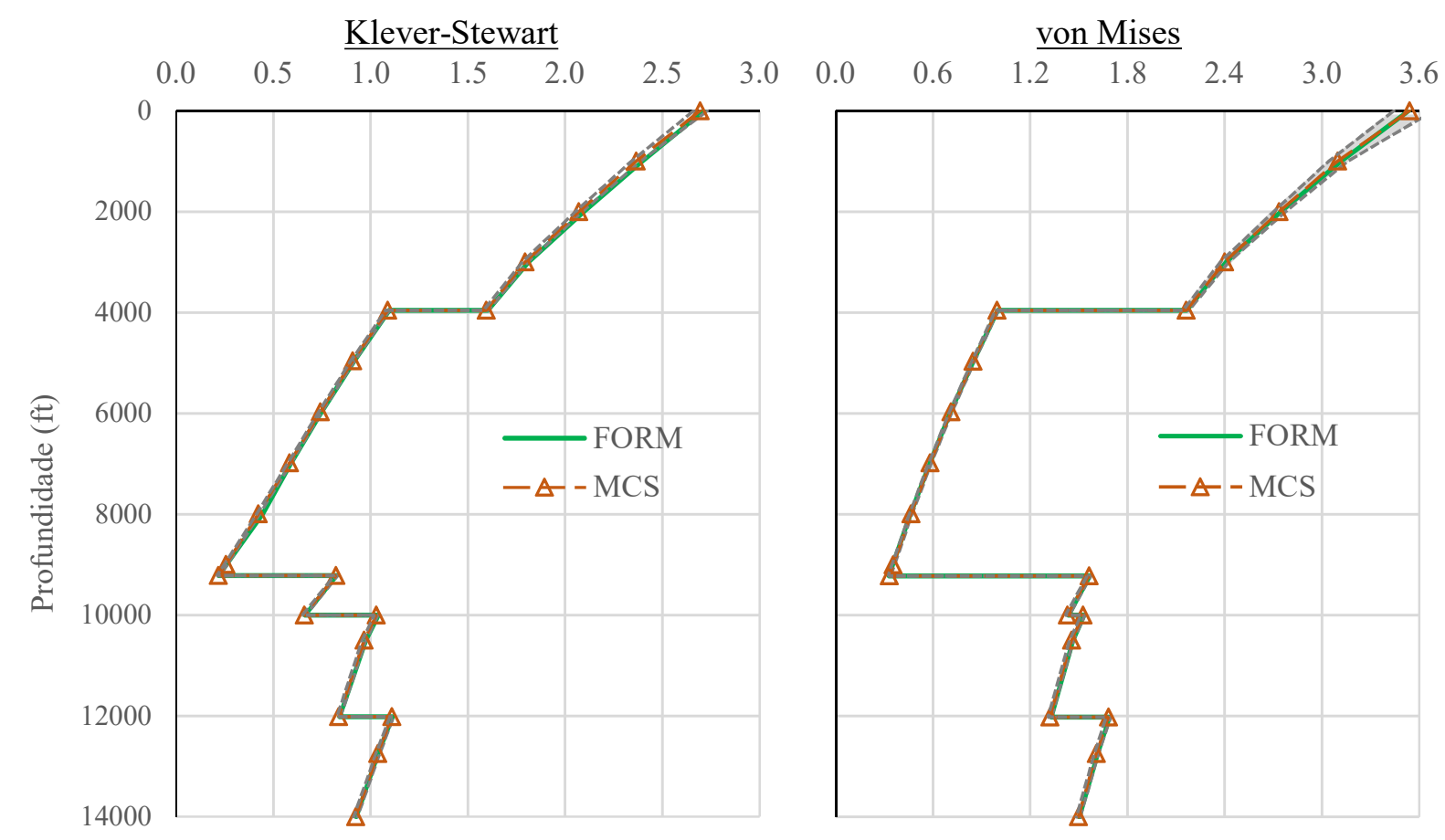

No cenário de evacuação total, apenas o modelo de resistência de Klever-Tamano foi analisado (Figura 10.25). Devido aos elevados índices de confiabilidade no trecho superior da coluna de produção, o MCS foi incapaz de estimar a probabilidade de falha em profundidades menores do que $7000 \mathrm{ft}$. Abaixo desta cota, os índices estimados se aproximaram bastante da curva de valores do FORM, apresentando elevada variabilidade para $\beta \approx 4$. As respostas do Monte Carlo por importância, em contrapartida, foram praticamente idênticas às do FORM na totalidade dos pontos analisados.

Figura 10.25 - Índices de confiabilidade do modelo de Klever-Tamano para caso de evacuação total.

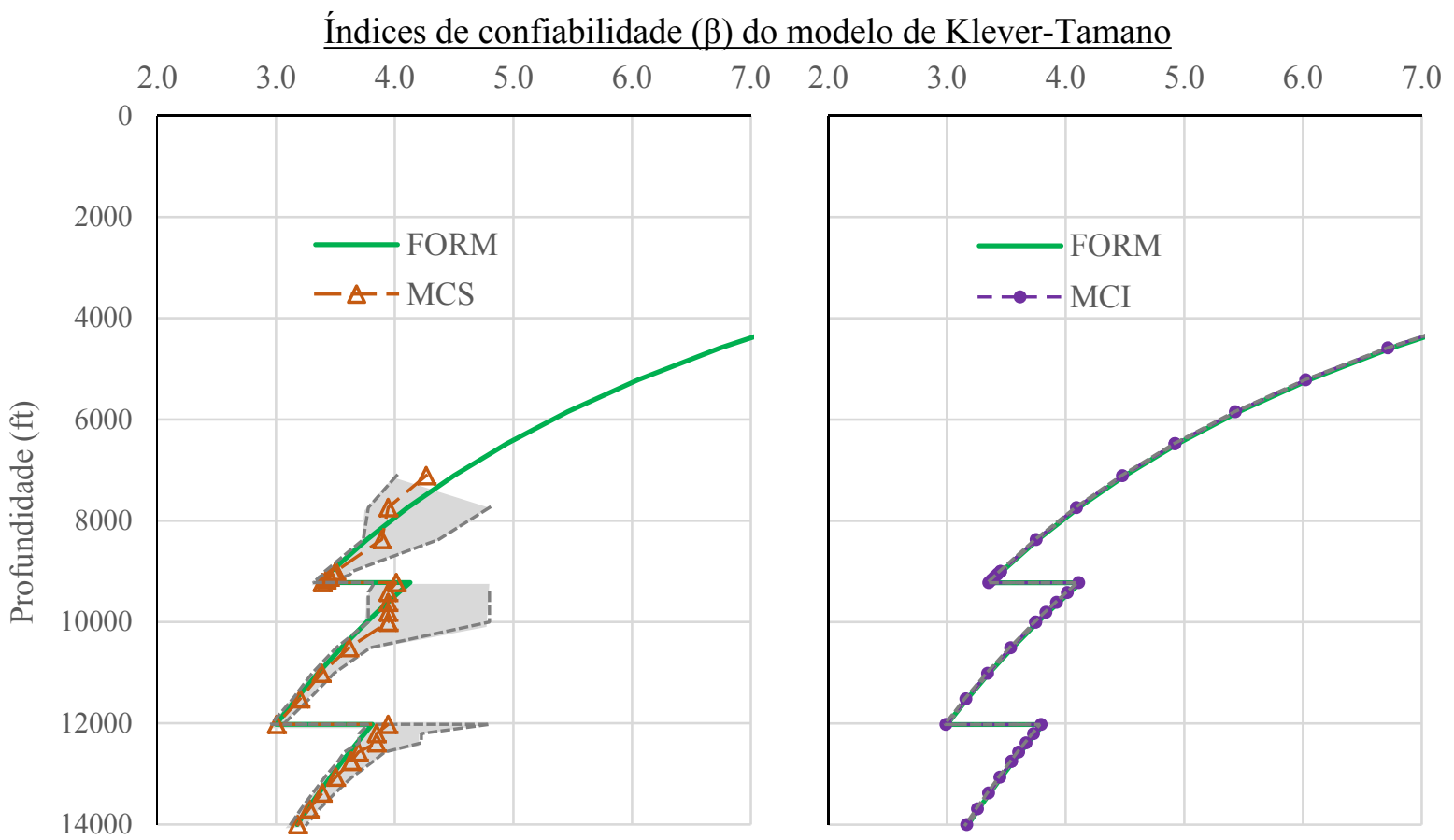


Nota-se um fato interessante ao analisar as Figuras 10.23, 10.24 e 10.25 em conjunto: para índices de confiabilidade pequenos $(\beta<2.0)$, o MCI apresenta maior variabilidade em comparação ao MCS (representada pelas regiões hachuradas na Figura 10.23); no entanto, isto se inverte à medida que a probabilidade de falha do revestimento diminui $(\beta>2.0)$. Isto indica que a função de amostragem do Monte Carlo por importância se comporta tão melhor quanto mais afastada estiver a equação de estado limite do centro do espaço normal padrão, não sendo indicada para valores pequenos de $\beta$.

Com base nos resultados apresentados, conclui-se que a linearização das equações de estado limite dos modelos de Klever-Stewart, Klever-Tamano e von Mises não gera erros significativos às estimativas do método FORM, tornando-o adequado ao cômputo da probabilidade de falha do revestimento. Salienta-se ainda que as simulações de MCS demoraram cerca de duas horas para o cenário de tubing leak e ultrapassaram cinco horas em caso de evacuação total, enquanto o FORM demorou menos de 15 segundos em ambos os casos. O uso do FORM é, portanto, imprescindível para viabilizar a otimização probabilística de revestimentos.

Conclui-se, assim, a verificação da implementação computacional do módulo estocástico. Na seção seguinte apresentam-se os estudos de caso envolvendo a otimização determinística e probabilística de revestimentos.

\subsection{Projeto Ótimo de Revestimentos}

A presente seção tem início com a apresentação de estudos de caso envolvendo a otimização determinística dos revestimentos de superfície, intermediário e de produção do poço de referência. Tais estudos permitem demonstrar o correto funcionamento das rotinas de otimização, bem como servem de base para a futura comparação com os resultados da otimização baseada em confiabilidade documentados no final deste capítulo.

A otimização dos revestimentos é realizada com base nas listas de preços apresentadas no Apêndice B, as quais foram adaptadas do livro de Rahman e Chilingarian (1995). Em virtude da falta de especificidade dos dados na referência original e do desuso das equações do API-5C3, apenas uma parcela dos revestimentos totais foi utilizada. Das listas originais foram eliminados os valores duplicados de tubos com iguais propriedades geométricas e mesma classe de aço. Ao todo, foram consideradas 13 opções de revestimento de superfície (diâmetro externo de 13 3/8"), 47 opções de revestimento intermediário (9 5/8") e 42 opções de revestimento de produção (7"). Ainda que os valores reproduzidos nas Tabelas B.1 a B.3 estejam desatualizados, os preços variam conforme a tendência esperada, sendo crescentes conforme aumenta a resistência do aço e o peso do revestimento (BYROM, 2015).

É importante ressaltar que o algoritmo B\&B se diferencia dos métodos tradicionais de programação matemática (método de Newton, programação quadrática sequencial, etc.) por dispensar a definição de um critério de convergência ou critério de parada. Basicamente, o algoritmo procura de maneira ordenada e sequencial os valores discretos possíveis de cada 
uma das variáveis de projeto em uma ou mais listas de tamanho finito, armazena a solução que simultaneamente minimize a função objetivo e satisfaça as restrições do problema e encerra sua execução após enumerar explicita- ou implicitamente os demais pontos do domínio do problema. Caso não encontre nenhum ponto candidato a ótimo em virtude da violação de uma ou mais restrições do problema, simplesmente encerra sua execução (fica a critério do programador exibir uma mensagem de alerta avisando que nenhum valor listado foi capaz de atender os requisitos de projeto).

\subsubsection{Otimização determinística (DDO)}

\section{Análise paramétrica de SF para um único modo de falha}

Inicia-se a otimização determinística pelo revestimento de superfície. Num primeiro momento, a robustez do código desenvolvido é avaliada por meio de uma análise paramétrica do fator de segurança admissível para o modo de falha triaxial, admitindo um kick de gás.

A Figura 10.26 exibe os resultados encontrados pelo software à medida que o mínimo valor admissível de FS aumenta. Nela estão representados os fatores de segurança do revestimento ao longo de sua profundidade. As curvas com linha tracejada representam os fatores de segurança da configuração original do poço de referência (vide Tabela 10.1), enquanto aquelas com linha cheia representam as configurações finais encontradas para cada um dos valores limite de FS admitidos. As descontinuidades observadas nos gráficos indicam mudanças nas propriedades mecânicas do revestimento devido à alteração do diâmetro interno e/ou da classe de aço dos tubos que compõem a fase.

Figura 10.26 - Configurações ótimas do revestimento de superfície para valores distintos de FS.
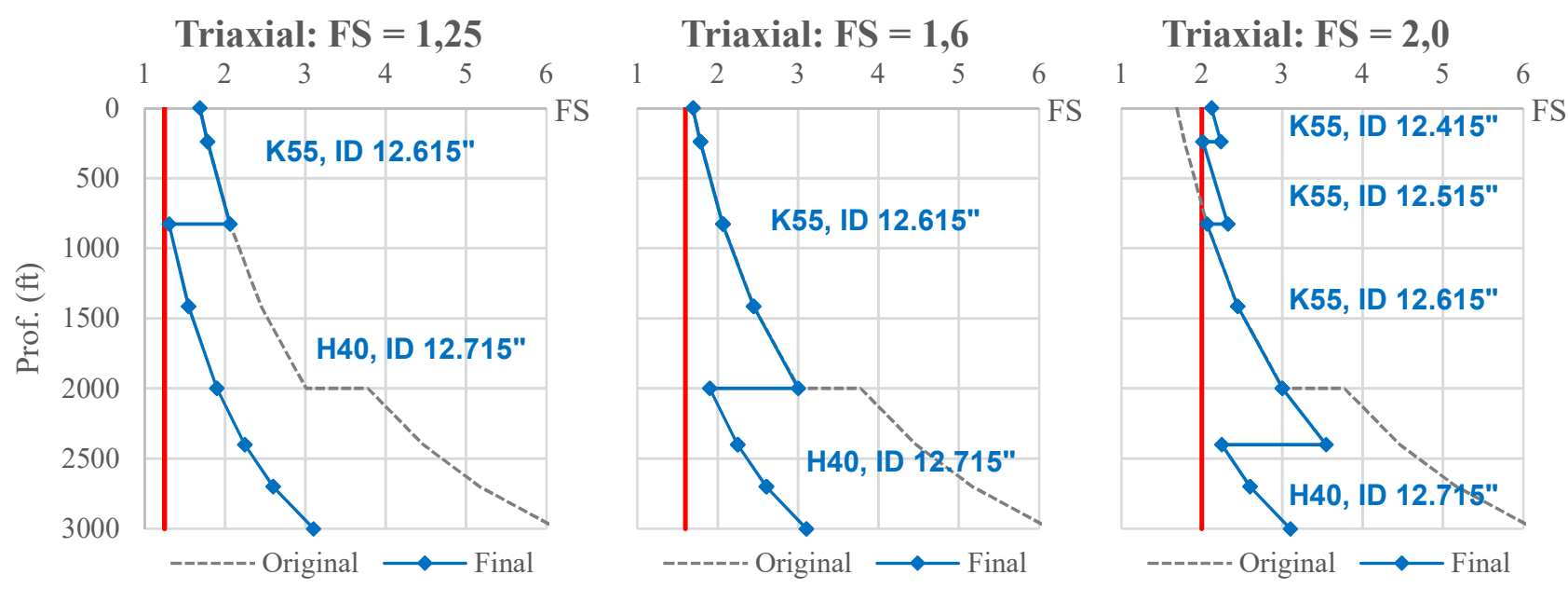

Da Figura 10.26 observa-se que todas as configurações encontradas atendem satisfatoriamente aos valores mínimos de SF especificados (representados pelas retas verticais em destaque). Basicamente, o programa procura utilizar o tubo mais barato dentre aqueles listados na Tabela B.1, partindo do fundo do poço em direção à superfície. O tubo mais barato (classe de aço H40 e diâmetro interno igual a 12,715 in.) é utilizado em todos os casos na porção inferior do 
revestimento, sendo substituído por tubos mais resistentes (e, consequentemente, mais caros) à medida que o fator de segurança do revestimento viola a restrição de segurança imposta. Nota-se ainda que conforme o número de segmentos aumenta (gráfico à direita), a margem de segurança do revestimento ao longo da profundidade diminui, indicando o melhor aproveitamento das propriedades mecânicas do tubo.

Ressalta-se que para a solução destes problemas não foi imposta qualquer restrição ao comprimento de cada segmento, de modo que na última solução a porção superior do revestimento apresenta apenas $240 \mathrm{ft}$ de comprimento. Operacionalmente pode não ser viável ter segmentos com comprimento inferior a 500 ou $1000 \mathrm{ft}$ (BYROM, 2015), porém demonstra-se através desse simples exemplo o potencial da ferramenta desenvolvida.

\section{Análise paramétrica de SF para múltiplos modos de falha}

Dando sequência às análises, estudou-se a interferência entre modos de falha concorrentes entre si. Dois cenários críticos de carregamento foram examinados: a ocorrência de um kick de gás e a perda total de circulação no revestimento de superfície.

Inicialmente realiza-se a otimização do revestimento considerando um único modo de falha por vez. Para isso, admite-se que o fator de segurança mínimo do modo analisado tem um valor fixo e o restante é nulo, ou seja:

- Para o cenário de kick, quando apenas a falha triaxial é considerada, faz-se $\mathrm{FS}_{\mathrm{axl}}=1,6$ e $\mathrm{FS}_{\text {rup }}=0$. Quando apenas o modo de falha por ruptura é considerado, admite-se $\mathrm{FS}_{\text {rup }}=1,2$ e $\mathrm{FS}_{\mathrm{axl}}=0$;

- Para o cenário de perda de circulação, admite-se ora que $\mathrm{FS}_{\mathrm{axl}}=1,6$ e $\mathrm{FS}_{\mathrm{col}}=0$, ora que $\mathrm{FS}_{\mathrm{col}}=1,125$ e $\mathrm{FS}_{\mathrm{axl}}=0$.

Quando múltiplos modos de falha são analisados, admite-se cada qual com seu respectivo fator de segurança admissível $\left(\mathrm{FS}_{\mathrm{axl}}=1,6, \mathrm{FS}_{\mathrm{rup}}=1,2\right.$ e $\left.\mathrm{FS}_{\mathrm{col}}=1,125\right)$. Os valores mínimos de FS foram estabelecidos de maneira a coincidir com os fatores utilizados por Byrom (2015) e permitir uma comparação direta com a solução de referência.

A seguir, as Figuras 10.27 e 10.28 reproduzem os resultados obtidos para ambos os cenários investigados. Observa-se que para a ocorrência de um kick, a falha triaxial é preponderante sobre a falha por ruptura, uma vez que a configuração do poço não se altera quando o primeiro modo é considerado isoladamente ou em conjunto com o segundo. No cenário de perda de circulação, em contrapartida, o modo de falha por colapso mostra-se dominante sobre o modo triaxial.

Analisando a Figura 10.27, nota-se que as pressões diferenciais de ruptura causadas pelo kick de gás são satisfatoriamente suportadas por uma coluna simples formada pelo tubo mais leve e menos resistente disponível (H40, ID 12,715"). No entanto, são necessários tubos com maior resistência em profundidades acima de $2000 \mathrm{ft}$ para garantia da segurança estrutural diante das tensões triaxiais solicitantes (K55, ID 12,615"). No cenário de colapso, por outro lado, tubulares mais resistentes devem ser utilizados na porção inferior da coluna, de modo que a configuração 
ótima do revestimento considerando múltiplos modos de falha corresponde à associação de 4 tipos distintos de tubos (Figura 10.28, à direita).

Figura 10.27 - Configurações ótimas do revestimento de superfície para cenário de kick considerando um único modo de falha / múltiplos modos de falha.
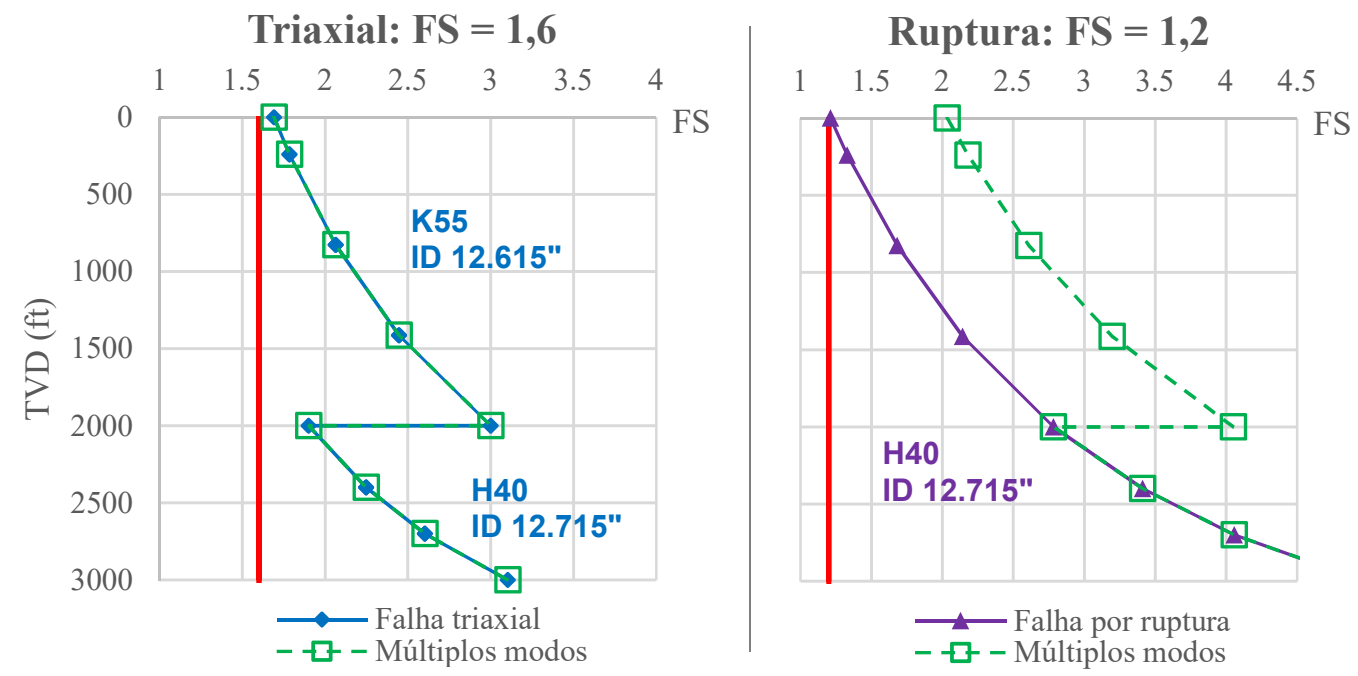

Figura 10.28 - Configurações ótimas do revestimento de superfície para cenário de perda de circulação considerando um único modo de falha / múltiplos modos de falha.
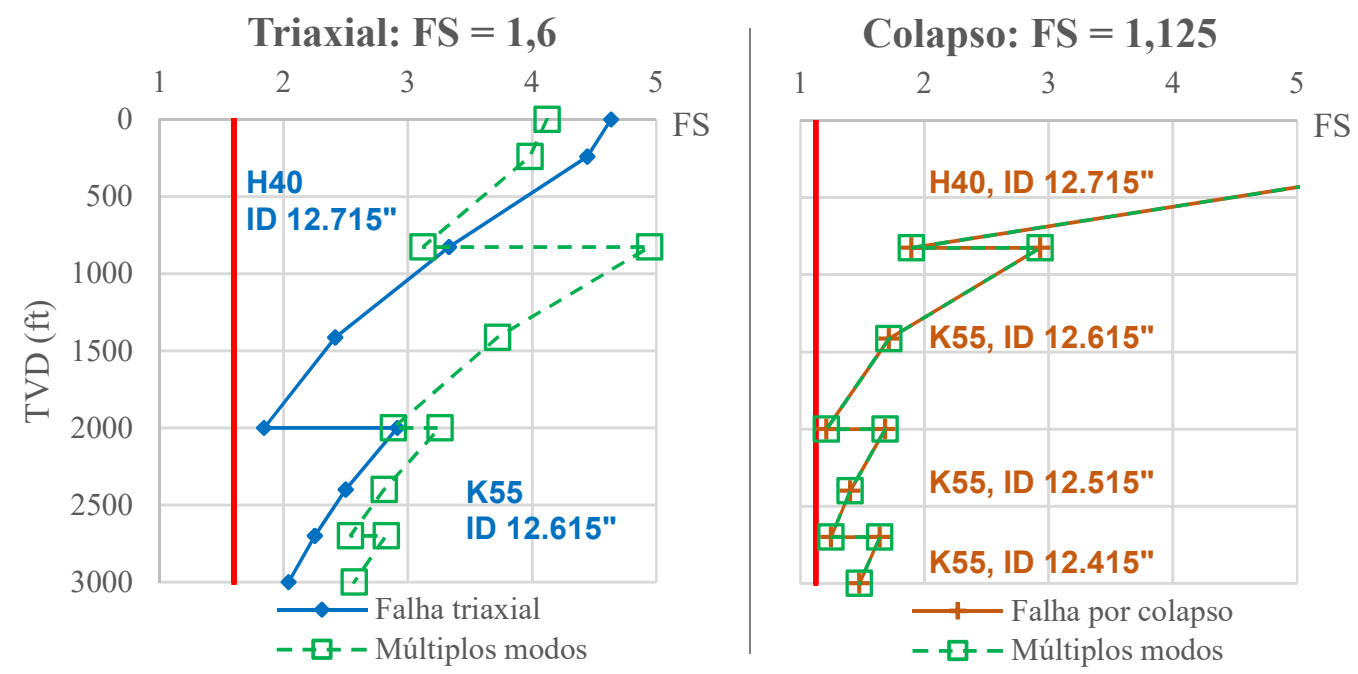

\section{Análise combinada de múltiplos carregamentos}

Até o presente momento, o revestimento de superfície foi otimizado separadamente para cada caso de carregamento. No entanto, o projeto deve ser capaz de garantir a segurança da estrutura ante todos os cenários de carga que possam vir a ocorrer ao longo de sua vida útil. Sendo assim, a última etapa da análise determinística conduzida corresponde à otimização da coluna de superfície considerando múltiplos modos de falha e múltiplos carregamentos.

Os mesmos cenários admitidos na validação do módulo determinístico foram considerados (Seção 10.1). Demonstraram ser críticos ao dimensionamento os cenários de teste de pressão, 
kick de gás e perda de circulação. A seguir, a Figura 10.29 apresenta a curva dos fatores de segurança do modo de falha triaxial para todos os referidos cenários e do modo de falha por colapso exclusivamente para o cenário de perda de circulação. Ao lado dos gráficos representa-se a configuração ótima determinística do revestimento de superfície.

Figura 10.29 - Configuração ótima do revestimento de superfície e respectivos cenários de carga críticos ao seu dimensionamento.
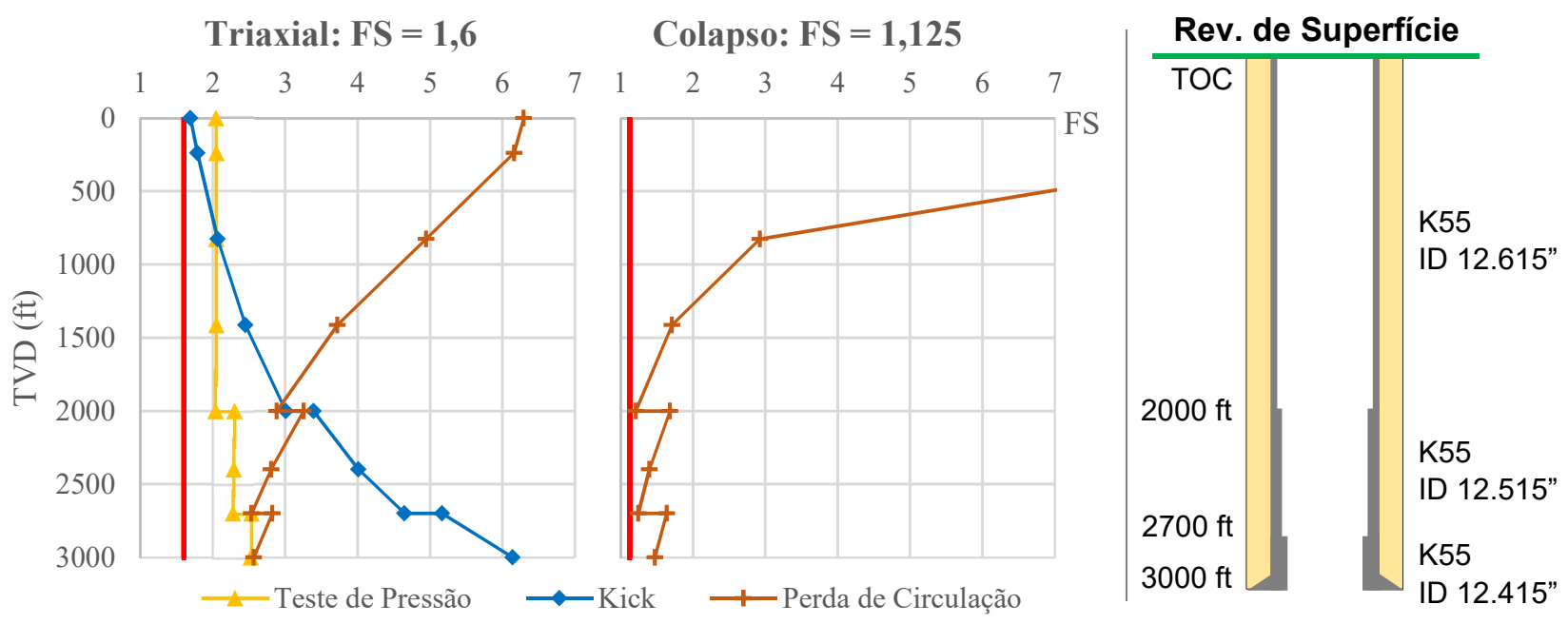

Analisando as Figuras 10.27, 10.28 e 10.29 em conjunto, percebe-se que a configuração ótima do revestimento é uma combinação dos resultados obtidos individualmente para cada um dos cenários de carregamento. Para o trecho de 0-800 ft, por exemplo, o projeto é governado pelo cenário de kick, que demanda uma maior resistência do revestimento. Assim, o tubo de propriedades ID = 12,615" e classe de aço K55 é selecionado. De 800 até $2000 \mathrm{ft}$, os três cenários de carregamento convergem para a mesma solução: K55, ID 12,615". A partir deste ponto, a perda de circulação no interior do revestimento passa a reger o dimensionamento, de modo que tubos ainda mais espessos devem ser empregados.

Comparativamente ao poço de referência, houve mudança apenas no segmento intermediário do revestimento. Na solução original de Byrom (2015), o tubo com diâmetro interno de 12,415" estende-se de $2000 \mathrm{ft}$ até a sapata da coluna. Em termos de custos, a redução da espessura do revestimento entre 2000 e $2700 \mathrm{ft}$ representa uma economia de 2,66\% em relação ao custo total do revestimento de referência, ou um montante de aproximadamente 223 mil dólares.

\section{Análise da solução ótima: custo vs. peso}

Nada se falou a respeito do conflito custo vs. preço anteriormente, pois ambas as formulações do problema de otimização conduziram à mesma solução ótima no caso do revestimento de superfície. Em parte isto se deve ao baixo número de tubos listados na Tabela B.1 (há no total apenas 13 itens), sendo somente um deles produzido em aço H40. Em razão disso, o preço dos quatro primeiros itens da tabela crescem conforme aumenta o peso do revestimento e, portanto, a solução mais barata é também a mais leve. 
Os revestimentos intermediário e de produção, por outro lado, apresentam soluções distintas conforme a formulação adotada. A Figura 10.30 a seguir mostra a diferença entre as configurações ótimas da fase intermediária obtidas mediante a minimização do custo e do peso do revestimento. É notável a diferença entre as soluções: a espessura do revestimento varia quatro vezes no primeiro caso, ao passo que há apenas duas transições de diâmetro interno na coluna de menor peso. A configuração (b) mostrou ser $0,37 \%$ mais barata em relação à configuração (c), porém a economia pode não ser justificada devido ao maior custo das conexões no primeiro caso.

Figura 10.30 - Comparativo das soluções ótimas determinísticas do revestimento intermediário.

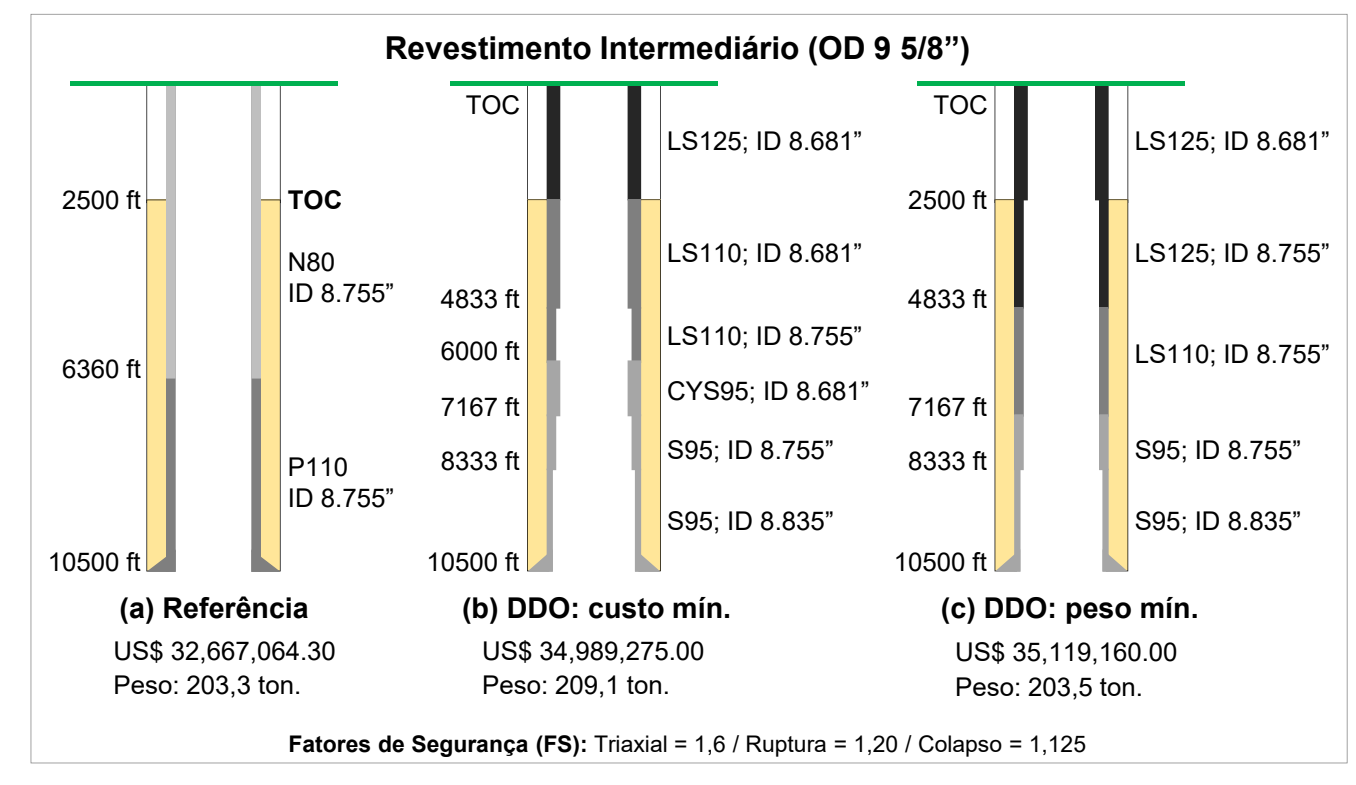

Em termos de custos, ambas as soluções encontradas pelo programa foram mais caras que a configuração de referência. O custo do revestimento original foi estimado em aproximadamente US\$ 32,67 mi, enquanto as configurações (b) e (c) da Figura 10.30 foram avaliadas em US\$ $34,99 \mathrm{mi}$ e US\$ $35,12 \mathrm{mi}$, respectivamente. Isto representa um gasto adicional de 7,1\% e 7,5\% sobre o valor total do revestimento.

Para investigar o motivo por trás disso, foram calculados os fatores de segurança do revestimento de referência e das soluções ótimas encontradas. Constatou-se que o cenário crítico ao dimensionamento corresponde à ocorrência de um kick de gás. A Figura 10.31 exibe os fatores de segurança dos modos de falha triaxial e de ruptura para os três arranjos do poço. Nota-se que a coluna de referência não atende ao fator de segurança admissível de 1,6 para o modo de falha triaxial, sendo por este motivo mais barata. 
Figura 10.31 - Fatores de segurança dos modos de falha triaxial e de ruptura para cenário de kick de gás no revestimento intermediário.

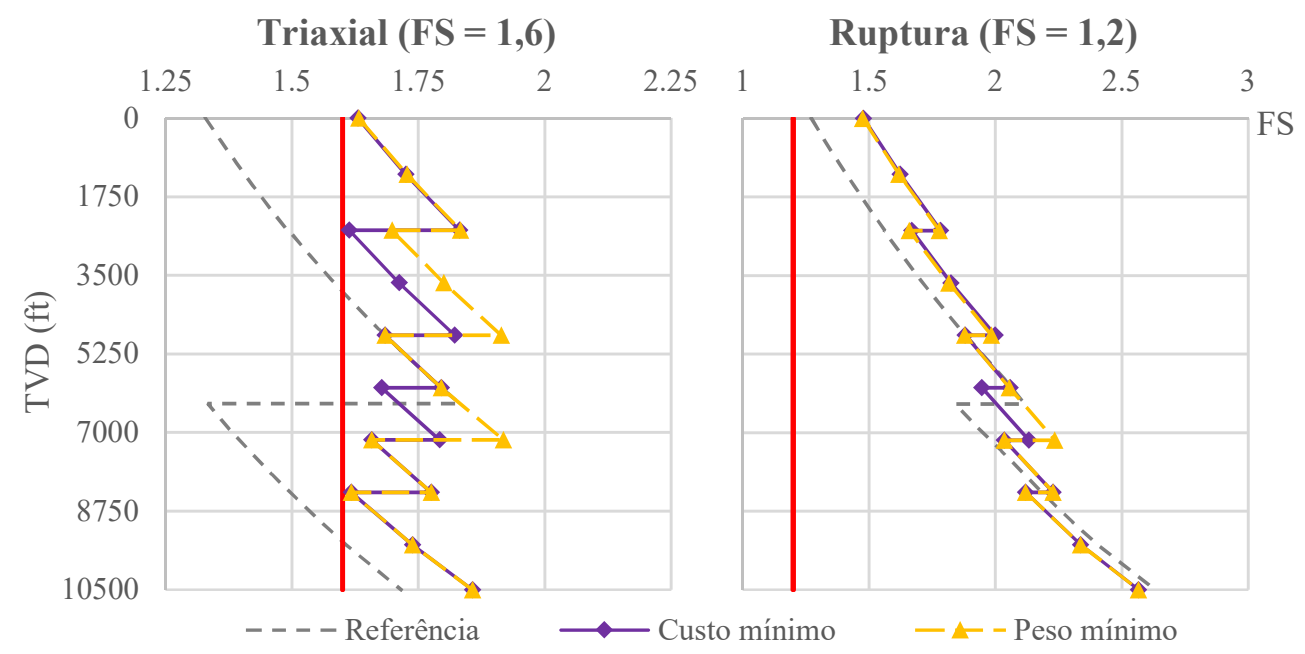

Reavaliando as soluções ótimas do revestimento para um fator de segurança $\mathrm{FS}_{\mathrm{axl}}=1,3$ (valor mínimo atendido pelo revestimento de referência), obtém-se soluções em média 8,5\% mais econômicas que a original. A Tabela 10.5 reúne as configurações ótimas em termos de custo e de peso do revestimento e a redução de gastos proporcionada por cada uma delas.

Tabela 10.5 - Revestimento Intermediário (OD 9 5/8”): propriedades mecânicas e preço dos tubos das soluções ótimas obtidas.

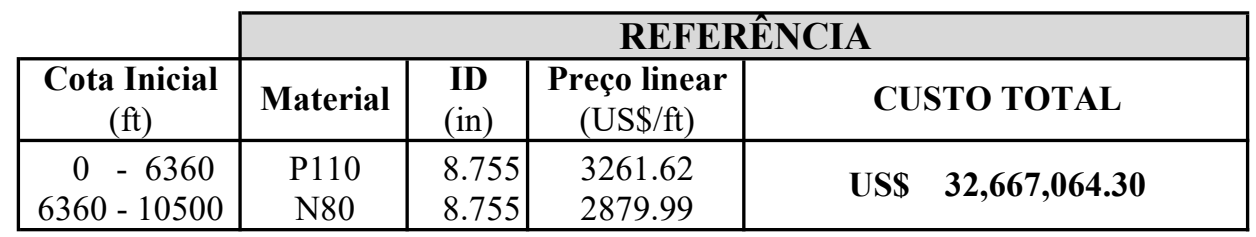

\begin{tabular}{|c|c|c|c|c|c|c|}
\cline { 2 - 7 } \multicolumn{1}{c|}{} & \multicolumn{3}{c|}{ CUSTO MÍNIMO } & \multicolumn{3}{c|}{ PESO MÍNIMO } \\
\hline $\begin{array}{c}\text { Extensão } \\
(\mathrm{ft})\end{array}$ & Material & $\begin{array}{c}\text { ID } \\
\text { (in) }\end{array}$ & $\begin{array}{c}\text { Preço linear } \\
(\text { US\$/ft) }\end{array}$ & Material & $\begin{array}{c}\text { ID } \\
\text { (in) }\end{array}$ & $\begin{array}{c}\text { Preço linear } \\
\text { (US\$/ft) }\end{array}$ \\
\hline $0-1250$ & LS110 & 8.755 & 3261.62 & LS110 & 8.755 & 3261.62 \\
$1250-2500$ & CYS95 & 8.681 & 3240.61 & LS110 & 8.755 & 3261.62 \\
$2500-3667$ & CYS95 & 8.681 & 3240.61 & LS110 & 8.755 & 3261.62 \\
$3667-4833$ & S95 & 8.755 & 3007.88 & S95 & 8.755 & 3007.88 \\
$4833-6000$ & S95 & 8.835 & 2783.29 & S95 & 8.835 & 2783.29 \\
$6000-7167$ & S95 & 8.835 & 2783.29 & S95 & 8.835 & 2783.29 \\
$7167-8333$ & S95 & 8.835 & 2783.29 & S95 & 8.835 & 2783.29 \\
$8333-9500$ & S80 & 8.835 & 2324.96 & S80 & 8.835 & 2324.96 \\
$9500-10500$ & S80 & 8.921 & 1992.44 & S80 & 8.921 & 1992.44 \\
\hline
\end{tabular}

As mesmas análises foram repetidas para o revestimento de produção. Para o caso específico dessa coluna, admitiu-se um comprimento mínimo de $2000 \mathrm{ft}$ para cada segmento de revestimento e os seguintes fatores de segurança admissíveis: $\mathrm{FS}_{\mathrm{axl}}=1,3, \mathrm{FS}_{\mathrm{rup}}=1,2 \mathrm{e}$ $\mathrm{FS}_{\mathrm{col}}=1,125$. Na Figura 10.32 são apresentadas as configurações de mínimo custo e mínimo 
peso lado a lado com o projeto de referência.

Figura 10.32 - Comparativo das soluções ótimas determinísticas do revestimento de produção.

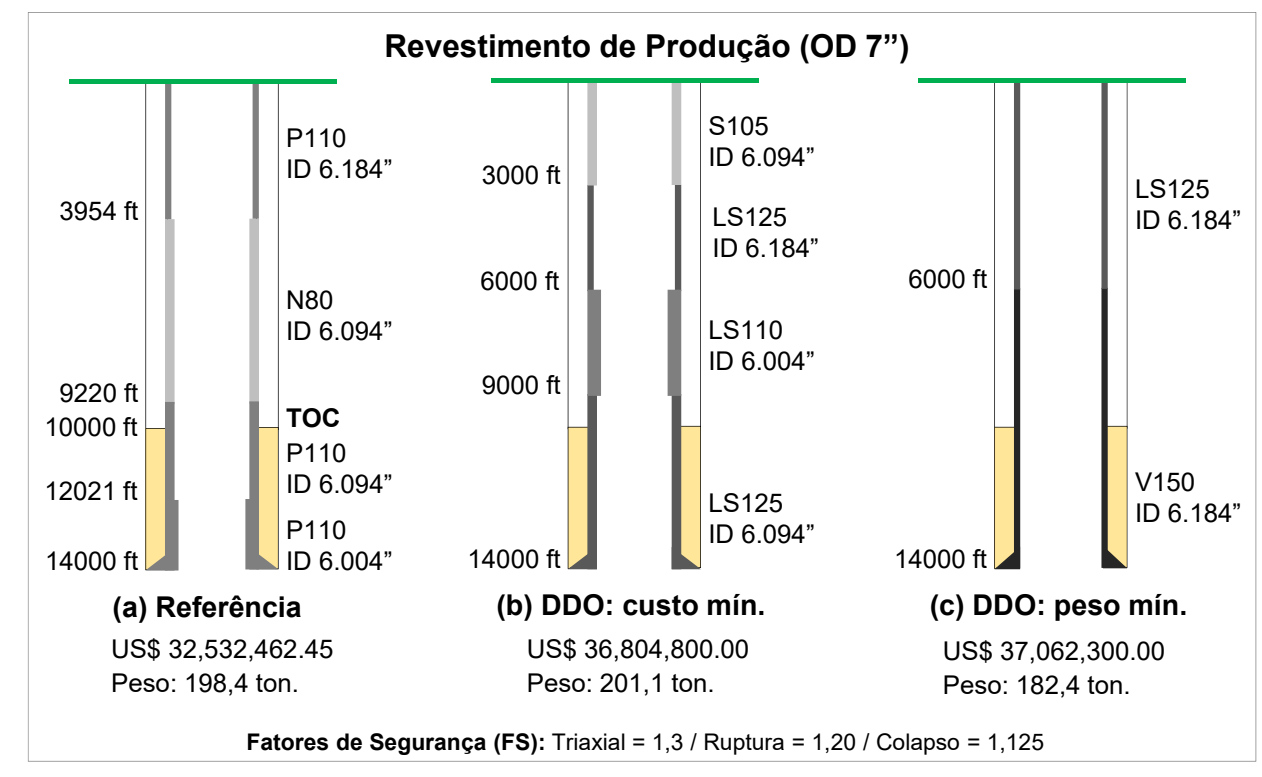

Dentre os quatro casos de carregamento analisados, o cenário de tubing leak mostrou-se crítico ao dimensionamento da coluna, conforme visto durante a validação do módulo determinístico (Figura 10.14). Novamente os custos obtidos foram superiores ao de referência devido à violação da restrição de segurança do modo de falha triaxial. A solução ótima em termos de peso da coluna apresentou maior simplicidade de execução dentre todas as configurações, sendo apenas $0,70 \%$ mais cara que a solução de mínimo custo.

Uma vez concluídos os estudos de caso determinísticos, procede-se com a otimização baseada em confiabilidade de todas as fases do poço.

\subsubsection{Otimização Baseada em Confiabilidade (RBDO)}

Para a otimização baseada em confiabilidade são aplicadas restrições em termos de probabilidades de falha alvo a cada um dos segmentos de revestimento, segundo um modelo de componente. Para os cenários de ruptura, a probabilidade de falha alvo é admitida com valor igual a $10^{-5}\left(\beta^{T}=4.26\right)$, devido ao alto risco imposto à vida dos operadores e ao meio ambiente. Para falha por colapso ou por escoamento do tubo causado por estados triaxiais de tensão, admite-se $P_{f}^{T}=10^{-3}\left(\beta^{T}=3.09\right)$ devido às menores consequências de falha associadas a ambos os modos. Maiores detalhes a respeito do modelo de componente e dos valores de $P_{f}^{T}$ considerados são apresentados no Capítulo 7.

A seguir, a Figura 10.33 apresenta um comparativo entre o arranjo estrutural de referência e as soluções ótimas do revestimento de superfície considerando ou não as incertezas sobre as variáveis do problema. Notam-se mudanças substanciais entre a solução das abordagens determinística e probabilística: na última, tubos mais espessos foram necessários ao longo de quase toda a extensão da coluna, bem como classes de aço de maior resistência foram empregadas 
(N80) para atender as restrições de segurança. Em termos de custos, a solução probabilística representou um acréscimo de $20 \%$ sobre o valor total do revestimento de referência.

Figura 10.33 - Comparativo das soluções ótimas do revestimento de superfície.

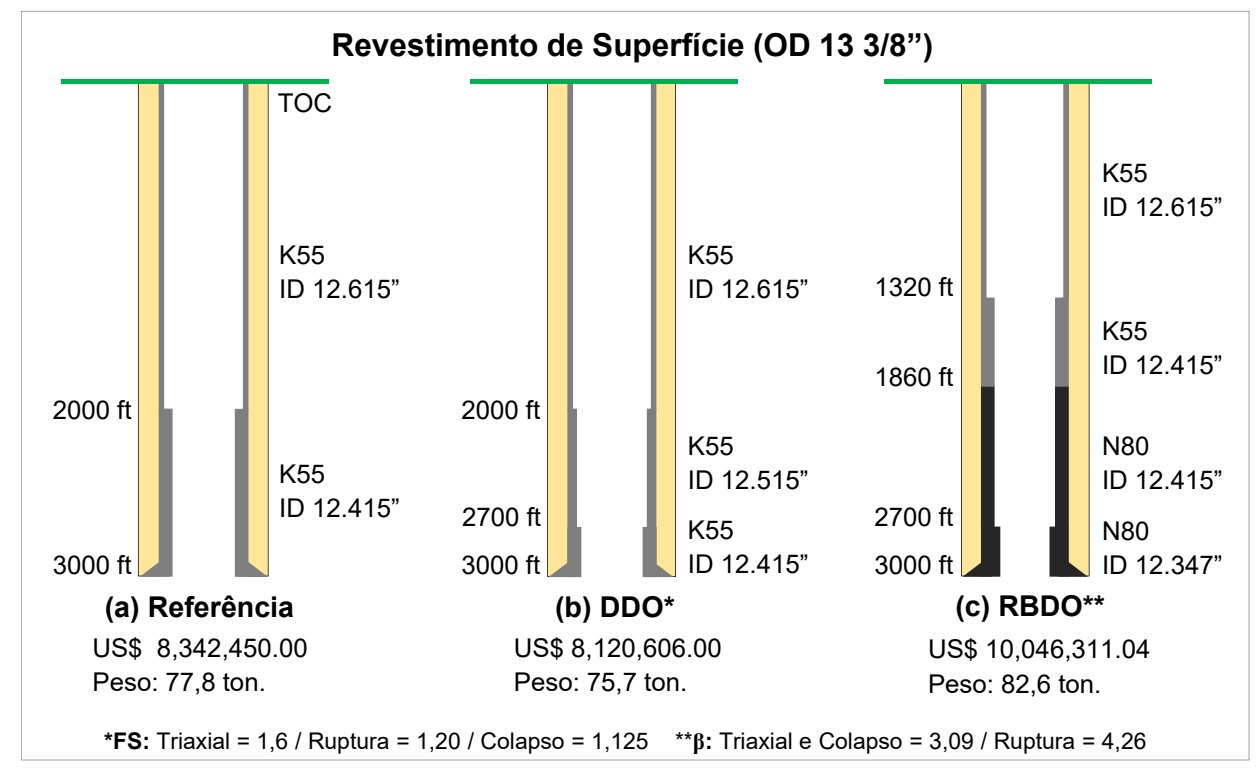

Ao contrário do que ocorreu na otimização determinística, o cenário de evacuação total não demonstrou ser crítico ao dimensionamento do revestimento de superfície. Ao invés disso, as pressões de colapso decorrentes da cimentação do poço (com fluido de deslocamento no interior da coluna e cimento do lado de fora) mostrou-se mais importante, regendo a seleção dos tubos posicionados abaixo de $1320 \mathrm{ft}$ de profundidade. Os tubos que compõem o trecho superior da fase foram determinados com base nos cenários de teste de pressão e de kick de gás, à semelhança do que foi observado para a formulação DDO.

Ao todo, o algoritmo B\&B realizou 113 e 117 ciclos de busca até encontrar as configurações de mínimo custo e mínimo peso do revestimento, respectivamente. As equações de estado limite do problema foram avaliadas em média apenas $90 \%$ dos ciclos, proporcionando uma grande economia computacional (sobretudo se fossem empregadas simulações de Monte Carlo para avaliação da probabilidade de falha do revestimento). Caso a enumeração completa fosse realizada, o número total de ciclos para cada caso de carregamento corresponderia ao produto do número de segmentos da fase pelo número de itens catalogados. Assim, ter-se-ia um total de 546 laços de busca ( 7 segmentos $\times 13$ tubos de $133 / 8 \times 6$ cenários de carregamento). Portanto, a redução proporcionada pela técnica de enumeração parcial foi de aproximadamente $80 \%$.

Assim como para o revestimento de superfície, a minimização do custo e do peso da coluna intermediária convergiram para o mesmo resultado. A Figura 10.34 exibe o arranjo ótimo encontrado, juntamente com a configuração de referência e a solução ótima da análise DDO de mínimo peso. Houve um aumento superior a 50\% no custo total do revestimento em relação ao de referência e a enumeração parcial avaliou 53\% do número total de combinações possíveis. Para o caso de carregamento crítico (kick de gás), os tubos mais pesados da classe de aço mais 
resistente foram os únicos capazes de suportar as pressões de ruptura solicitantes e, por este motivo, o algoritmo realizou praticamente a enumeração completa para este cenário (ao todo, foram analisadas 413 opções de um total de 423).

Figura 10.34 - Comparativo das configurações do revestimento intermediário.

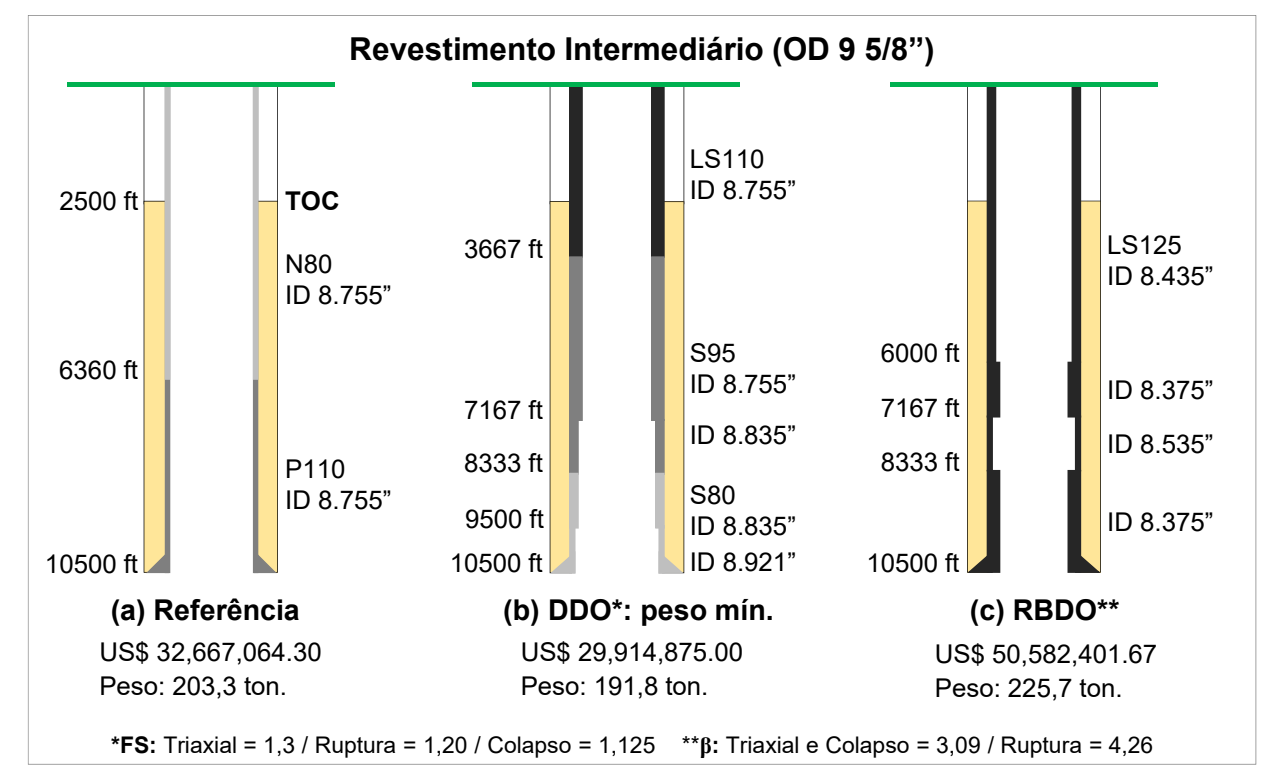

Por fim, ao realizar a otimização probabilística do revestimento de produção, o programa não conseguiu encontrar nenhum tubo com resistência mecânica suficiente capaz de atender os requisitos de segurança impostos em caso de tubing leak. Mesmo adotando o tubo com maior espessura (ID = 5.920") e classe de aço V150 ao longo de todo o comprimento da coluna, as probabilidades de falha se aproximaram de 0,02 na região vizinha à base da coluna. Tentou-se reduzir a variabilidade arbitrada para as pressões internas e externas pela metade, porém também não houve convergência do código (ainda que as probabilidades de falha tenham diminuído para valores na ordem de $1 \cdot 10^{-3}$ ). Neste caso, recomenda-se ao projetista reavaliar os índices de confiabilidade alvo admitidos ou os carregamentos previstos, sob a pena de inviabilizar a execução do poço.

Os carregamentos de kick de gás e de evacuação total, em compensação, foram satisfatoriamente suportados. A Figura 10.35 a seguir apresenta os resultados encontrados pelo software desconsiderando o cenário de tubing leak. Salienta-se que ao longo das análises foi considerado um comprimento mínimo de $2000 \mathrm{ft}$ para cada segmento da fase de produção, a fim de evitar a discretização exagerada do revestimento.

As soluções RBDO de custo e peso mínimo apresentaram custos muito parecidos entre si (diferença de $0,04 \%$ ), sendo 38,6\% mais caras que o projeto de referência. Isto representa um montante adicional de aproximadamente US\$12,5 mi para garantia da confiabilidade mínima desejada. 
Figura 10.35 - Configurações ótimas probabilísticas do revestimento de produção.

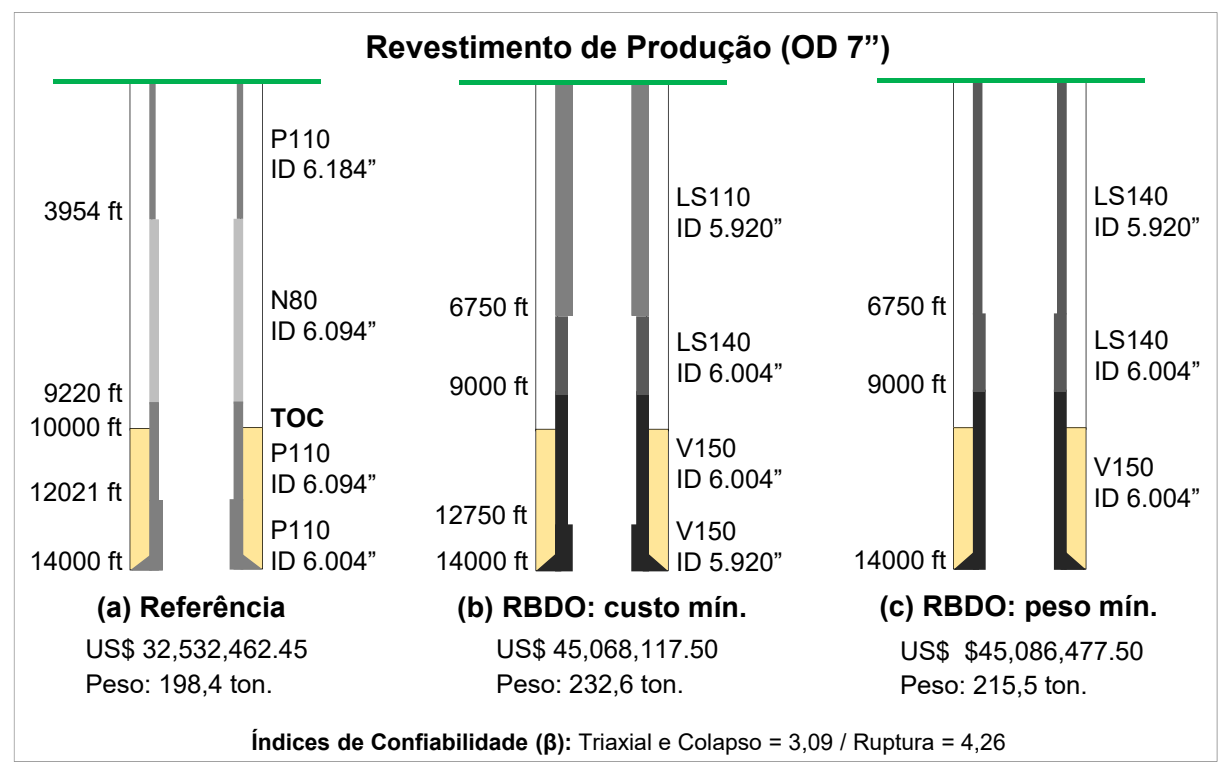

Em média, o algoritmo B\&B realizou a enumeração parcial de $71 \%$ do número total de combinações em busca do menor custo e apenas $63 \%$ ao procurar pelo mínimo peso. Dada a pequena diferença de custo entre ambas as soluções e a identidade no caso das fases precedentes, nota-se que a abordagem de mínimo peso apresenta vantagens não apenas em termos de custo computacional, mas também em simplicidade de execução. Nesse sentido, deve-se ter em mente que muitas mudanças no diâmetro do revestimento podem implicar em maiores conexões de transição, mudança de elevadores para sustentação, dificuldades logísticas e de padronização, o que pode configurar algo crítico para montagem das colunas.

$\mathrm{Na}$ totalidade dos casos estudados, a otimização probabilística do poço resultou em revestimentos com custos mais elevados do que aqueles obtidos segundo uma abordagem determinística. O maior conservadorismo das soluções RBDO tem relação direta com os valores selecionados para os índices de confiabilidade alvo, os quais demonstraram ser excessivamente altos e inadequados quando carregamentos com pequena probabilidade de ocorrência (caso de kick com poço $100 \%$ cheio de gás e tubing leak com vazamento do tubo de produção próximo à superfície do poço) são tratados como eventos certos. Sendo assim, a investigação de níveis de confiabilidade alvo mais adequados ao projeto de revestimentos de poços pode ser objeto de estudo de trabalhos futuros.

Para finalizar o capítulo e os estudos de caso conduzidos, apresenta-se na Figura 10.36 um resumo das soluções encontradas para todo o poço com base na abordagem de mínimo peso. 
Figura 10.36 - Configurações ótimas probabilísticas e determinísticas do poço de referência.

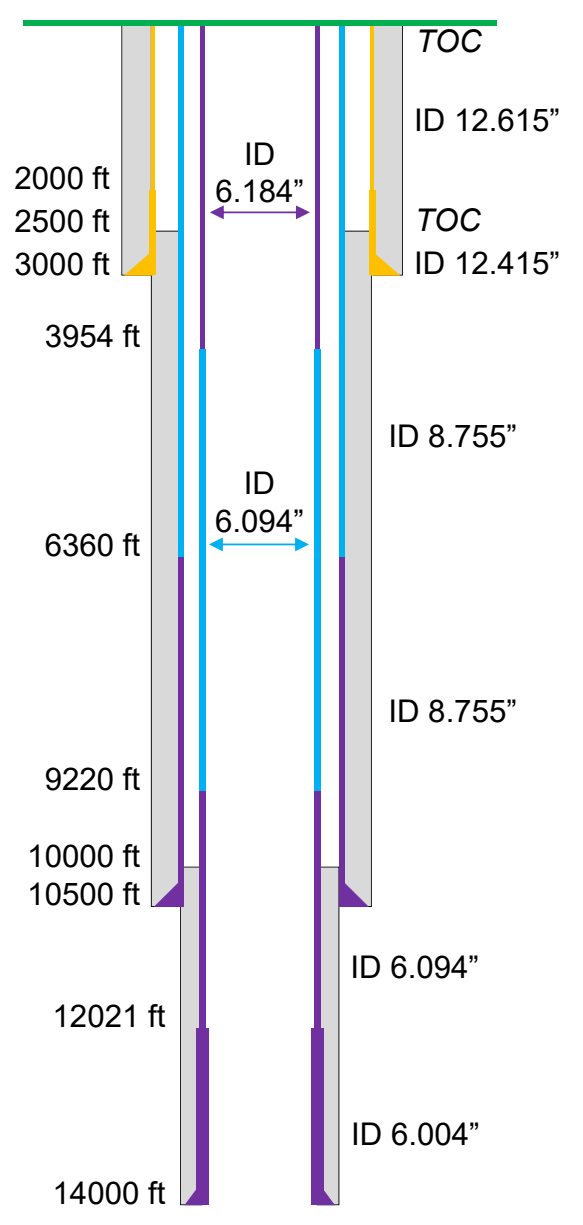

(a) Referência US $\$ 73,541,976.75$ Peso: 479,5 ton.

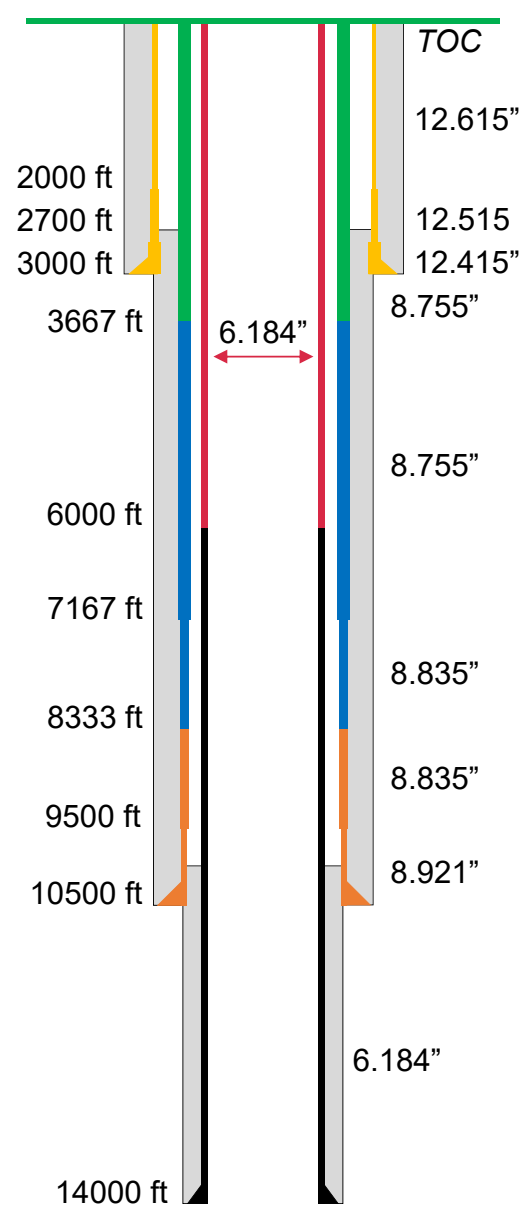

(b) DDO*: peso mín. US $\$ 75,097,781.00$ Peso: 449,9 ton.

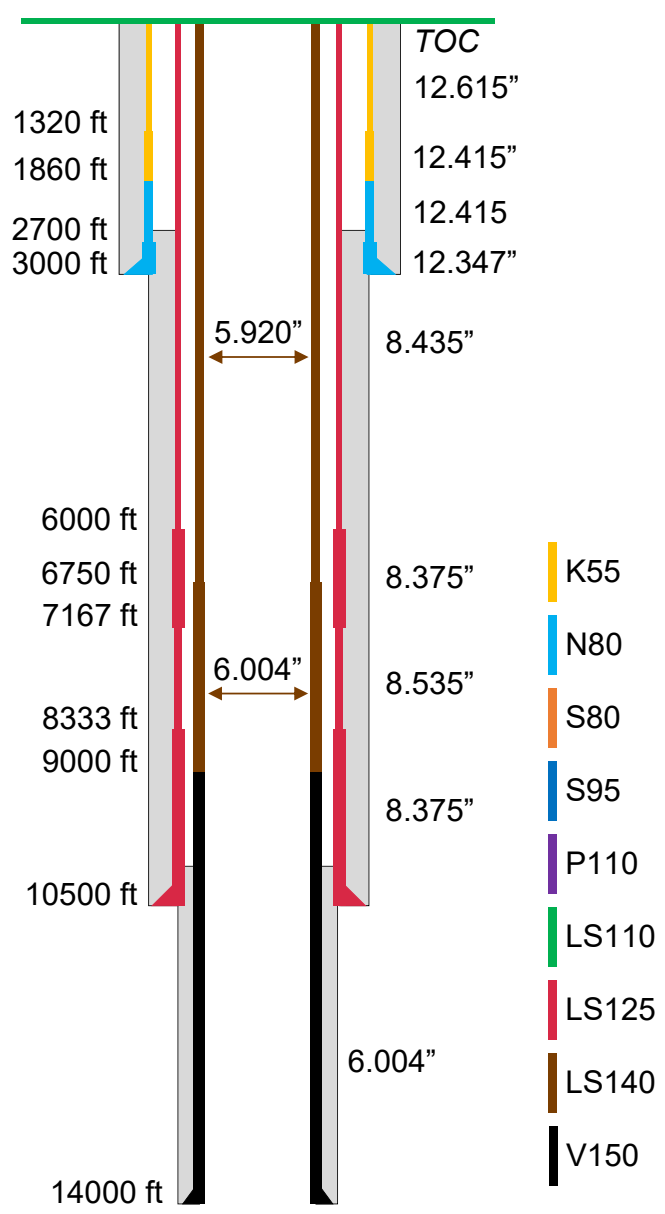

(c) RDDO**: peso mín. US\$ $105,715,190.21$ Peso: 523,8 ton.

${ }^{*}$ FS: Triaxial $=1,3 /$ Ruptura $=1,20 /$ Colapso $=1,125 \quad{ }^{* *} \beta$ : Triaxial e Colapso $=3,09 /$ Ruptura $=4,26$ 



\section{Conclusões}

No presente trabalho, propôs-se uma metodologia para a otimização de revestimentos de poços com base em requisitos expressos em termos de probabilidades de falha. Para isso, investigou-se uma série de princípios e conceitos de natureza prática e teórica fundamentais ao seu desenvolvimento.

Num primeiro momento, foi feito o estudo do procedimento de cálculo realizado na indústria para o projeto determinístico de revestimentos e identificou-se as principais variáveis sobre as quais o projetista do poço exerce efetivo controle. Com base nisso foi possível delimitar o escopo do trabalho, de forma que ficou estabelecido que a otimização envolveria basicamente a manipulação de propriedades físicas e geométricas do revestimento, com destaque à classe de aço e à espessura dos tubulares que o compõem.

A simplificação das variáveis de projeto para apenas dois parâmetros de resistência foi possível graças à natureza discreta do problema de otimização de poços, uma vez que as escolhas do projetista estão limitadas às opções de revestimento comercializadas. Também por este motivo decidiu-se pela utilização de um algoritmo de enumeração parcial do tipo branch and bound (B\&B) para a solução do problema de otimização.

O desenvolvimento da metodologia envolveu também o equacionamento dos modos de falha a que revestimentos estão suscetíveis. Três modelos de resistência foram selecionados com base nas atuais recomendações da norma ISO/TR 10400:2011: o modelo de Klever-Stewart, para pressões diferenciais de ruptura; o modelo de Klever-Tamano, para pressões de colapso; e o modelo de von Mises, para estados triaxiais de tensão.

Para a estimativa da confiabilidade do revestimento, fez-se necessário quantificar a incerteza dos parâmetros aleatórios mais importantes a cada um dos modelos de resistência. Um resumo com os dados estatísticos das variáveis de resistência foi elaborado, buscando subsidiar a aplicação da metodologia. As variáveis de solicitação, em contrapartida, não puderam ser precisamente caracterizadas, em virtude da carência ou do antagonismo dos dados disponíveis na literatura.

Ainda com respeito às análises de confiabilidade, foi imperativo investigar as probabilidades de falha admissíveis em diferentes campos da engenharia estrutural para a completa definição do problema RBDO. Tal etapa foi necessária para a definição das restrições e imposição de um nível mínimo de segurança ao projeto.

Paralelamente à concepção da metodologia, foi desenvolvido um código computacional capaz de realizar o cálculo das pressões hidrostáticas, da força axial e da tensão interna em cada ponto do revestimento ao longo de sua profundidade. Sua implementação passou por um processo minucioso de validação, exibindo resultados satisfatórios. Este código (determinístico) foi posteriormente integrado a rotinas específicas para estimativa da confiabilidade estrutural e rotinas de otimização. Estudos de caso foram então conduzidos a fim de ilustrar a aplicabilidade 
da metodologia e quantificar seu desempenho.

Com respeito às análises de confiabilidade, a linearização das equações de estado limite efetuada pelo FORM não demonstrou ser empecilho à aplicação do método, o qual apresentou excelente concordância com os resultados das simulações de Monte Carlo simples e por importância. Além disso, a existência de gradientes analíticos das equações de estado limite garante elevada eficiência ao método e reduz significativamente seu custo computacional, tornando-o a escolha mais adequada à solução do problema RBDO.

Os resultados das análises de otimização, por sua vez, mostraram que a metodologia é capaz de garantir o atendimento do nível de confiabilidade alvo frente a todos os modos de falha e cenários de carregamento considerados, permitindo a seleção autônoma dos revestimentos que proporcionam a minimização da função objetivo. Com respeito à função objetivo, duas formulações distintas foram investigadas: ora buscou-se a minimização do custo do revestimento, ora a minimização de seu peso. Com base nas listas de preço consideradas, verificou-se que ambas as abordagens conduzem a custos muito próximos entre si, porém a formulação de mínimo peso conduziu a resultados mais adequados sob o ponto de vista da execução.

A otimização é realizada de modo a proporcionar uma margem de segurança mais homogênea ao longo da profundidade de cada fase, procurando estreitar a distância entre o índice de confiabilidade do modo de falha dominante e o índice alvo, considerado aceitável, cuja escolha cabe ao analista do projeto. Acredita-se, portanto, que a metodologia contribui para o avanço do setor de exploração de gás e óleo ao proporcionar economia na etapa de planejamento, sem comprometer a segurança do poço durante sua perfuração e completação.

\subsection{Sugestões para trabalhos futuros}

Visando a continuidade e o aperfeiçoamento deste trabalho, deixam-se algumas ideias para estudos posteriores:

- Reunir dados de campo ou da literatura a fim de obter distribuições de probabilidade adequadas à representação das variáveis de solicitação, tais como pressão de poros, permeabilidade, gradiente de fratura, pressão do reservatório e temperatura;

- Construir modelos probabilísticos para os cenário de carregamento de kick e de tubing leak que admitam os parâmetros volume de kick e intensidade de kick como variáveis aleatórias e cujos valores estejam associados a uma determinada probabilidade de ocorrência;

- Investigar quais os níveis de confiabilidade alvo mais adequados ao projeto de revestimentos de poços considerando solicitações com ou sem comportamento aleatório;

- Adicionar restrições de natureza executiva ao software, de modo a obter soluções mais condizentes com a prática (como, por exemplo, definir um número máximo de seções por fase, evitar transições que demandem conexões de alto custo, dentre outras);

- Incorporar um modelo de resistência para a análise da instabilidade de tubos;

- Incorporar um modelo de resistência para a análise da falha de conexões. 


\section{Referências}

ADAMS, A. QRA for casing/tubing design. In: SOCIETY OF PETROLEUM ENGINEERS. 1995 Seminar of Norwegian HPHT Program. Norway, 1995.

ADAMS, A.; GLOVER, S. An investigation into the application of qra in casing design. In: SOCIETY OF PETROLEUM ENGINEERS. SPE Applied Technology Workshop on Risk Based Design of Well Casing and Tubing. Houston, USA, 1998.

ADAMS, A.; HODGSON, T. Calibration of casing/tubing design criteria by use of structural reliability techniques. SPE drilling \& completion, Society of Petroleum Engineers, v. 14, n. 01, p. 21-27, 1999.

ADAMS, A.; MOORE, P.; PAYNE, M. On the calibration of design collapse strengths for quenched and tempered pip. SPE drilling \& completion, Society of Petroleum Engineers, v. 18, n. 03, p. 214-227, 2003.

ADAMS, A. et al. Casing system risk analysis using structural reliability. In: Proceedings of the SPE/IADC Drilling Conference. Amsterdam, Netherlands: Society of Petroleum Engineers, 1993.

ADAMS, A. et al. On the development of reliability-based design rules for casing collapse. In: SOCIETY OF PETROLEUM ENGINEERS. SPE Applied Technology Workshop on Risk Based Design of Well Casing and Tubing. Texas, USA, 1998.

AMERICAN PETROLEUM INSTITUTE. Bulletin 5C3 - Bulletin on Formulas and Calculations for Casing, Tubing, Drill Pipe, and Line Pipe Properties. Washington, DC, 1994.

AMERICAN PETROLEUM INSTITUTE. Bulletin 5C2 - Bulletin of Performance Properties of Casing, Tubing, and Drill Pipe. Washington, DC, 1999.

AMERICAN PETROLEUM INSTITUTE. Recommended Practice 5C5 - Recommended Practice on Procedures for Testing Casing and Tubing Connections. 3rd. ed. Washington, DC, 2003.

AMERICAN PETROLEUM INSTITUTE. Recommended Practice 59 - Recommended Practice for Well Control Operations. 2nd. ed. Washington, DC, 2006.

AMERICAN PETROLEUM INSTITUTE. Specification 5CT - Specifications for Casing and Tubing. 8th. ed. Washington, DC, 2006.

AMERICAN PETROLEUM INSTITUTE. Technical Report on Equations and Calculations for Casing, Tubing, and Line Pipe Used as Casing or Tubing; and Performance Properties Tables for Casing and Tubing, First Edition (Identical to ISO 10400:2007). Washington, DC, 2008.

AMERICAN PETROLEUM INSTITUTE. Recommended Practice 65 - Part 2 - Isolating Potential Flow Zones During Well Construction. 1st. ed. Washington, DC, 2010.

AMERICAN PETROLEUM INSTITUTE. Recommended Practice 96 - Deepwater Well Design and Construction. 1. ed. Washington, DC, 2013. 
ANG, A. H.-S.; TANG, W. H. Probability Concepts in Engineering Planning and Design: Basic principles. 1. ed. New York, NY: John Wiley \& Sons, 1975. v. 1. ISBN 9780471032007.

AOUES, Y.; CHATEAUNEUF, A. Benchmark study of numerical methods for reliability-based design optimization. Structural and multidisciplinary optimization, Springer, v. 41, n. 2, p. 277-294, 2010.

ARORA, J. S. Introduction to optimum design. 3. ed. [S.1.]: Elsevier, 2012.

ARORA, J. S.; HUANG, M.-W. Discrete structural optimization with commercially available sections: a review. Journal of Structural and Earthquake Engineering, JSCE, v. 13, n. 2, p. 93-110, 1996.

BEA, R. G. Reliability based design criteria for coastal and ocean structures. In: NATIONAL COMMITTEE ON COASTAL AND OCEAN ENGINEERING. Ninth Australasian Conference on Coastal and Ocean Engineering. Australia, 1989. p. 1.

BEA, R. G. Offshore platform reliability acceptance criteria. SPE Drilling Engineering, Society of Petroleum Engineers, v. 6, n. 02, p. 131-137, 1991.

BECK, A. Desenvolvimento de programa computacional para análise de confiabilidade de estruturas. Projeto de pesquisa FAPESP 2007/00154-4, 2007.

BECK, A. Otimização estrutural sob incerteza e risco. Projeto de Pesquisa Individual FAPESP 2009/12099-6, 2009.

BECK, A. Curso de Confiabilidade Estrutural: Notas de aula. São Carlos: Universidade de São Paulo, 2014.

BECK, A. Confiabilidade e segurança das estruturas. Elsevier Editora Ltda., 2019. ISBN 9788535288957. Disponível em: <https://books.google.com.br/books?id=-BSGDwAAQBAJ>.

BECK, A.; GOMES, W. A comparison of deterministic, reliability-based and risk-based structural optimization under uncertainty. Probabilistic Engineering Mechanics, v. 28, p. 18-29, 2012.

BECK, A. et al. Projeto probabilístico de revestimentos de poços: Relatorio final consolidado. Contrato CENPES n. 0050.0089855.14.2, 2017.

BECK, A. et al. Projeto probabilístico de revestimentos de poços: Relatório 1 - Revisão bibliográfica do estado da arte. Contrato CENPES n. 0050.0089855.14.2, 2015.

BHATTACHARYA, B.; BASU, R.; MA, K.-t. Developing target reliability for novel structures: the case of the mobile offshore base. Marine structures, Elsevier, v. 14, n. 1-2, p. 37-58, 2001.

BLADE ENERGY PARTNERS. Principles and Practice Of Casing Design. Texas, USA, 2007.

BOOTH, J. Measurement and data management key to quality well control. Petroleum Engineer International, v. 66, n. 2, 1994. ISSN 0164-8322.

BRAND, P.; WHITNEY, W.; LEWIS, D. Load and resistance factor design case histories. In: OFFSHORE TECHNOLOGY CONFERENCE. OTC 7937. Houston, Texas, 1995.

BYROM, T. G. Casing and liners for drilling and completion: design and application: design and application. 2. ed. [S.1.]: Elsevier, 2015. ISBN 978-0-12-800570-5. 
CANADIAN STANDARDS ASSOCIATION. S471 - General requirements, design criteria, the environment, and loads. 1. ed. Ontario, Canada, 2008.

CHEN, T.; GUAN, Z. Generic. Theory and technology of drilling engineering. 2. ed. [S.1.]: Petroleum University Press, 2000. 238 p.

CLINEDINST, W. A rational expression for the critical collapsing pressure of pipe under external pressure. In: AMERICAN PETROLEUM INSTITUTE. API Drilling and Production Practice. Dallas, TX, 1939. Disponível em: <https://www.onepetro.org/conference-paper/API-39-383>.

COMMITTEE EUROPEAN DE NORMALISATION. EN 1990: Eurocode - basis of structural design. Bruxelas, 2002. 90 p.

DEDENUOLA, A. D. et al. Stochastic approach to kick tolerance determination in risk based designs. In: SOCIETY OF PETROLEUM ENGINEERS. SPE Annual Technical Conference and Exhibition. Denver, USA, 2003.

DOMINGUES, F. C. P. Aplicação de um projeto de perfuração para um poço marítimo. 76 p. Dissertação (Trabalho de Conclusão de Curso) - Universidade Federal Fluminense, Niterói, 2013.

DORIGO, M.; BIRATTARI, M. Ant Colony Optimization. Boston, MA: Springer US, 2010. 36-39 p. ISBN 978-0-387-30164-8.

DU, X.; CHEN, W. Sequential optimization and reliability assessment method for efficient probabilistic design. In: AMERICAN SOCIETY OF MECHANICAL ENGINEERS. ASME 2002 International Design Engineering Technical Conferences and Computers and Information in Engineering Conference. Montreal, Canada, 2002. p. 871-880.

DU, X.; CHEN, W. Sequential optimization and reliability assessment method for efficient probabilistic design. Journal of Mechanical Design, American Society of Mechanical Engineers, v. 126, p. 225-233, 2004.

ERIVWO, O. E.; ADELEYE, O. A. Narrow margin drilling in deepwater: Solution concepts. In: SOCIETY OF PETROLEUM ENGINEERS. SPE Deepwater Drilling and Completions Conference. Galveston, USA, 2012.

FABER, M. Risk and Safety in Civil, Surveying and Environmental Engineering: Notas de aula. Switzerland: Swiss Federal Institute of Technology (ETHZ), 2006.

FABER, M. H. et al. Risk assessment for structural design criteria of fpso systems. part i: Generic models and acceptance criteria. Marine Structures, Elsevier, v. 28, n. 1, p. 120-133, 2012.

GEN, M.; LIN, L. Genetic algorithms. Wiley Encyclopedia of Computer Science and Engineering, Wiley Online Library, p. 1-15, 2007.

GONG, J.-X.; YI, P. A robust iterative algorithm for structural reliability analysis. Structural and Multidisciplinary Optimization, Springer, v. 43, n. 4, p. 519-527, 2011.

GOUVEIA, L. P. d. Avaliação da confiabilidade em tubos de revestimento de poços de petróleo. Dissertação (Mestrado em Estruturas) — Universidade Federal de Alagoas, Maceió, 2014. 
GRANDHI, R. V.; WANG, L. book. Structural Reliability Analysis and Optimization: Use of Approximations: Nasa/cr 1999-209154. Dayton, Ohio: National Aeronautics and Space Administration,, 1999.

GUAN, Z. et al. Oil \& gas drilling risk analysis utilizing quantitative risk assessment. Journal of Applied Science and Engineering, v. 21, n. 4, p. 541-546, 2018.

HALAL, A.; MITCHELL, R. Casing design for trapped annular pressure buildup. SPE Drilling \& Completion, Society of Petroleum Engineers, v. 9, n. 02, p. 107-114, 1994.

HINTON, A. Will risk based casing design mean safer wells? In: SOCIETY OF PETROLEUM ENGINEERS. SPE 48326. [S.1.], 1998.

HUANG, M.-W.; ARORA, J. S. Optimal design with discrete variables: some numerical experiments. International Journal for Numerical Methods in Engineering, Wiley Online Library, v. 40, p. 165-188, 1997a.

HUANG, M.-W.; ARORA, J. S. Optimal design of steel structures using standard sections. Structural optimization, Springer, v. 14, p. 24-35, 1997b.

HUDSON, P. et al. Tripod delta: Proactive approach to enhanced safety. Journal of petroleum technology, Society of Petroleum Engineers, v. 46, n. 01, p. 58-62, 1994.

INTERNATIONAL ORGANIZATION FOR STANDARDIZATION. ISO 13679. General principles on reliability for structures. Brussels, 1998.

INTERNATIONAL ORGANIZATION FOR STANDARDIZATION. ISO 13679. Petroleum and natural gas industries - Procedures for testing casing and tubing connections. Brussels, 2002.

INTERNATIONAL ORGANIZATION FOR STANDARDIZATION. ISO/TR 10400. Petroleum and natural gas industries - Equations and calculations for the properties of casing, tubing, drill pipe and line pipe used as casing or tubing. Brussels, 2007.

JIN, Y.; LI, C.; WU, Q. Methodology for kick tolerance calculation and well killing in deepwater drilling. Natural Gas Industry B, Elsevier, v. 3, n. 5, p. 472-478, 2016.

JOINT COMMITTEE ON STRUCTURAL SAFETY. JCSS Probabilistic model code. Denmark, 2001. 179 p. Disponível em: <http://www.jcss.ethz.ch/>.

KENNEDY, J. Particle swarm optimization. Encyclopedia of machine learning, Springer, p. 760-766, 2010.

KING, G. E. An Introduction to the Basics of Well Completions, Stimulations and Workovers. 2. ed. Tulsa, Oklahoma: George E. King, 1998.

KLEVER, F.; STEWART, G. Analytical burst strength prediction of OCTG with and without defects. In: SOCIETY OF PETROLEUM ENGINEERS. SPE Applied technology workshop on risk based design of well casing and tubing. The Woodlands, USA, 1998.

KLEVER, F. J.; TAMANO, T. A new OCTG strength equation for collapse under combined loads. Society of Petroleum Engineers, v. 21, n. 03, 2004.

KROETZ, H. M. Meta-modelagem em confiabilidade estrutural. Dissertação (Mestrado em Estruturas) - Escola de Engenharia de São Carlos, Universidade de São Paulo, São Carlos, 2015. 
LAARHOVEN, P. J. V.; AARTS, E. H. Simulated annealing. In: Simulated annealing: Theory and applications. [S.1.]: Springer, 1987. p. 7-15.

LEWIS, D. et al. Load and resistance factor design for oil country tubular good. In: OFFSHORE TECHNOLOGY CONFERENCE. OTC 7936. Houston, Texas, 1995.

LEWIS, D. et al. Load and resistance factor design for oil country tubular good. In: Proceedings of the Offshore Technology Conference. Houston, Texas: OTC, 1995.

LIANG, J.; MOURELATOS, Z. P.; TU, J. A single-loop method for reliability-based design optimization. In: AMERICAN SOCIETY OF MECHANICAL ENGINEERS. ASME 2004 Int. Des. Eng. Tech. Conf. Comput. Inf. Eng. Conf. [S.1.], 2004. p. 419-430.

LIANG, Q. Application of quantitative risk analysis to pore pressure and fracture gradient prediction. In: SPE Annual Technical Conference and Exhibition. San Antonio, Texas: Society of Petroleum Engineers, 2002.

LIAO, H.; GUAN, Z.; LONG, G. Quantitative risk assessment on safety and reliability of casing strength for oil and gas wells. Energy Procedia, Elsevier, v. 17, p. 429-435, 2012.

LIU, S. et al. Equations to calculate collapse strength of defective casing for steam injection wells. Engineering failure analysis, Elsevier, v. 42, p. 240-251, 2014.

LOPEZ, R. et al. An approach for the global reliability based optimization of the size and shape of truss structures. Mechanics \& Industry, EDP Sciences, v. 16, n. 6, p. 603, 2015.

MASON, S.; CHANDRASEKHAR, S. Stochastic kick load modeling. In: SPE High Pressure/High Temperature Sour Well Design Applied Technology Workshop. The Woodlands, Texas: Society of Petroleum Engineers, 2005.

MELCHERS, R.; BECK, A. Structural reliability analysis and prediction. [S.1.]: John Wiley \& Sons, 2018.

MELCHERS, R. E. Generic. Structural Reliability Analysis and Prediction. 2. ed. [S.1.]: John Wiley \& Sons, 1999.

MILLER, R. A. Real world implementation of qra methods in casing design. In: SOCIETY OF PETROLEUM ENGINEERS. SPE Applied Technology Workshop on Risk Based Design of Well Casing and Tubing. [S.1.], 1998.

MITCHELL, R. F. Casing design. In: LAKE, L. W.; MITCHELL, R. F. (Ed.). Petroleum Engineering Handbook. [S.1.]: Society of Petroleum Engineers, 2006. cap. 7, p. 287-342.

MIURA, K. et al. Characterization of operational safety in offshore oil wells. Journal of Petroleum Science and Engineering, Elsevier, v. 51, n. 1-2, p. 111-126, 2006.

MOOS, D. et al. Comprehensive wellbore stability analysis utilizing quantitative risk assessment. Journal of Petroleum Science and Engineering, v. 38, n. 3, p. 97 - 109, 2003. ISSN 0920-4105.

NARENDRA, P. M.; FUKUNAGA, K. A branch and bound algorithm for feature subset selection. IEEE Transactions on computers, IEEE, n. 9, p. 917-922, 1977.

NORSOK. Standard D-010 - Well integrity in drilling and well operations. 3rd. ed. Norwegian Technology Centre, 2004. 
NUNES, F.; LUNA, D. Pré-sal já compete com oriente médio. Estadão, out. 2017. Acesso em: 16 out. 2018. Disponível em: <http://economia.estadao.com.br/-noticias/geral/ pre-sal-ja-compete-com-oriente-medio/>.

OKASHA, N. M. An improved weighted average simulation approach for solving reliability-based analysis and design optimization problems. Structural Safety, Elsevier, v. 60, p. 47-55, 2016.

PAYNE, M.; SATHUVALLI, U.; CRABTREE, S. Select topics and applications of probabilistic octg design. In: SOCIETY OF PETROLEUM ENGINEERS. SPE Applied Technology Workshop on Risk Based Design of Well Casing and Tubing. The Woodlands, USA, 1998.

PAYNE, M.; SIMPSON, B.; LIVESAY, R. Advanced octg topics for critical service, deepwater welldesign. World Oil, v. 225, n. 7, p. 41 - 46, 2004. ISSN 00438790.

PETROBRAS, 2014. Pré-Sal: Reduzimos em 55\% o tempo de perfuração de poços no pré-sal. 01 jul. 2014. Disponível em: http://www.petrobras.com.br/fatos-e-dados/reduzimos-em-55-otempo-de-perfuracao-de-pocos-no-pre-sal.htm. Acesso em: 20 fev. 2018.

PETROBRAS, 2016. Um ano de recordes para o pré-sal. 26 dez. 2016. Disponível em: http://www.petrobras.com.br/fatos-e-dados/um-ano-de-recordes-para-o-pre-sal.htm. Acesso em: 20 fev. 2018.

PETROBRAS, 2018a. Pré-Sal. 2018. Disponível em: http://www.petrobras.com.br/pt/nossasatividades/areas-de-atuacao/exploracao-e-producao-de-petroleo-e-gas/pre-sal/. Acesso em: 20 fev. 2018.

PETROBRAS, 2018b. Planejamento e capacidade técnica de nossas equipes levam a recorde de produção. 16 jan. 2018. Disponível em: http://www.petrobras.com.br/fatose-dados/planejamento-e-capacidade-tecnica-de-nossas-equipes-levam-a-recorde-deproducao.htm. Acesso em: 20 fev. 2018.

PETRÓLEO BRASILEIRO S/A. N-2752: Segurança de Poço para Projetos de Perfuração de Poços Marítimos. 2. ed. Rio de Janeiro, 2017.

PETROSKI, H. To Engineer is Human: the role of failure in engineering design. [S.1.]: Vintage Books, 1992.

RAHMAN, S. S.; CHILINGARIAN, G. V. Casing Design: theory and practice. [S.1.]: Elsevier, 1995. v. 42. ISBN 0-444-54062-8.

RASHKI, M.; MIRI, M.; MOGHADDAM, M. A. A simulation-based method for reliability based design optimization problems with highly nonlinear constraints. Automation in Construction, Elsevier, v. 47, p. 24-36, 2014.

REMMEN, T. Evaluation of Industry Practice for Buckling Analysis in Well Design. Dissertação (Master Thesis on Petroleum Geoscience Engineering) - Norwegian University of Science and Technology, Trondheim, 2018.

ROYSET, J. O.; KIUREGHIAN, A. D.; POLAK, E. Reliability-based optimal structural design by the decoupling approach. Reliability Engineering \& System Safety, Elsevier, v. 73, n. 3, p. 213-221, 2001. 
SANTOS, K. R. M. Técnicas de amostragem inteligente em simulação de Monte Carlo. Dissertação (Mestrado em Estruturas) — Escola de Engenharia de São Carlos, Universidade de São Paulo, São Carlos, 2014.

SANTOS, K. R. M. d. Técnicas de amostragem inteligente em simulação de Monte Carlo. Tese (Mestrado) - Universidade de São Paulo, São Carlos, SP, 2014.

SCHLUMBERGER. The Schlumberger Oilfield Glossary: dogleg. 2019. Disponível em: https://www.glossary.oilfield.slb.com/en/Terms/d/dogleg.aspx. Acesso em: fev. 2019.

SCHWIND, B. et al. Implementing and benchmarking of reliability methods in well design 11-7/8 71.80 q125 t1 s btc-1 tin drilling casing. In: OFFSHORE TECHNOLOGY CONFERENCE. OTC 13052. Houston, Texas, 2001.

SHAUGHNESSY, J. M. et al. Problems of ultra-deep high-temperature, high-pressure drilling. In: SOCIETY OF PETROLEUM ENGINEERS. SPE Annual Technical Conference and Exhibition. Denver, USA, 2003.

SIQUEIRA, L.; BATISTA, R.; OLIVEIRA, T. A descoberta do pré-sal e suas vantagens e desvantagens. Revista de divulgação do Projeto Universidade Petrobras e IF Fluminense, v. 2, n. $1,2012$.

SKLET, S. Safety barriers: Definition, classification, and performance. Journal of loss prevention in the process industries, Elsevier, v. 19, n. 5, p. 494-506, 2006.

SKOGDALEN, J. E.; UTNE, I. B.; VINNEM, J. E. Developing safety indicators for preventing offshore oil and gas deepwater drilling blowouts. Safety science, Elsevier, v. 49, n. 8-9, p. 1187-1199, 2011.

SKOGDALEN, J. E.; VINNEM, J. E. Quantitative risk analysis of oil and gas drilling, using deepwater horizon as case study. Reliability Engineering \& System Safety, Elsevier, v. 100, p. 58-66, 2012.

SORENSEN, J. D. Generic, Notes in Structural Reliability Theory And Risk Analysis. 2004.

SOUZA, C. O. Capítulo sobre levantamento de cargas em revestimentos. In: PETRÓLEO BRASILEIRO S/A. Dimensionamento de Revestimento. Rio de Janeiro, 2015.

STEWART, G.; KLEVER, F. Accounting for flaws in the burst strength of OCTG. In: SOCIETY OF PETROLEUM ENGINEERS. SPE Applied Technology Workshop on Risk Based Design of Well Casing and Tubing. The Woodlands, USA, 1998.

SUN, Y. X. et al. Burst strength prediction of octg. In: TRANS TECH PUBL. Advanced Materials Research. [S.1.], 2012. v. 503, p. 1173-1176.

TALLIN, A. et al. Risk assessment of exploration well designs in the oman ara salt. In: Proceedings of the SPE Annual Technical Conference and Exhibition. Dallas, Texas: Society of Petroleum Engineers, 2000.

TAMANO, T.; MIMAKI, T.; YANAGIMOTO, S. A new empirical formula for collapse resistance of commercial casing. Nippon Steel Tech. Rep., n. 26, p. 19-26, 1985.

TESSARI, R.; KROETZ, H.; BECK, A. Hybrid method for accurate and efficient solution of rbdo problems. In: Proceedings of the ICOSSAR 2017. Vienna, Austria: 12th International Conference on Structural Safety \& Reliability, 2017. 
TESSARI, R. K. Projeto baseado em desempenho de torres metálicas sujeitas à ação do vento. Dissertação (Mestrado em Estruturas) — Escola de Engenharia de São Carlos, Universidade de São Paulo, São Carlos, 2016.

URIBE, J. C. M. Modelagem numérica e análise de modos de falha de conexões entre tubulares de revestimento de poços. Dissertação (Mestrado em Estruturas) — Escola de Engenharia de São Carlos, Universidade de São Paulo, São Carlos, 2017.

VALIGURA, G. A.; TALLIN, A. Connections for hpht well applications and connection leak probability. In: SOCIETY OF PETROLEUM ENGINEERS. SPE High Pressure/High Temperature Sour Well Design Applied Technology Workshop. The Woodlands, USA, 2005.

WANG, Z.; WANG, R. Pore pressure prediction using geophysical methods in carbonate reservoirs: Current status, challenges and way ahead. Journal of Natural Gas Science and Engineering, Elsevier, v. 27, p. 986-993, 2015.

WELLCAT 2003.0.2 for Windows 10. Build 420. [S.1.]: Landmark Graphics Corporation, 2003.

WYLIE, W.; VISRAM, A. Drilling kick statistics. In: Proceedings of the SPE/IADC Drilling Conference. Houston, Texas: Society of Petroleum Engineers, 1990.

XUE, L. et al. A safety barrier-based accident model for offshore drilling blowouts. Journal of loss prevention in the process industries, Elsevier, v. 26, n. 1, p. 164-171, 2013. 
Apêndices 



\section{APÊNDICE A - Gradientes das EEL}

\section{A.1 Gradientes do critério de Klever-Stewart}

A equação de estado limite para ruptura é expressa genericamente da seguinte forma:

$$
g(\mathbf{X})=M_{E} \cdot P_{R}-P_{S}
$$

onde a pressão resistente, $P_{R}$, é calculada por meio do modelo de Klever-Stewart (Eq. 6.6) e a pressão solicitante corresponde à pressão interna atuante, ou seja, $P_{S}=P_{i}$.

Do ponto de vista da resistência, as variáveis aleatórias que influenciam a capacidade resistente de um tubular são: o erro de modelo $\left(M_{E}\right)$, o diâmetro externo do tubo $\left(D_{o}\right)$, a espessura da parede $(t)$, a tensão última de tração do material $\left(f_{u}\right)$, a força axial $\left(F_{a}\right)$ e a pressão externa $\left(P_{o}\right)$.

Logo, o vetor $\mathbf{X}$ das variáveis aleatórias corresponde a:

$$
\mathbf{X}=\left\{M_{E}, D_{o}, t, f_{u}, F_{A}, P_{o}\right\}
$$

e o vetor gradiente é dado por:

$$
\vec{\nabla} g=\left\{\frac{\partial g}{\partial \mathbf{X}}\right\}=\left\{P_{R}, M_{E} \frac{\partial P_{R}}{\partial D_{o}}, M_{E} \frac{\partial P_{R}}{\partial t}, M_{E} \frac{\partial P_{R}}{\partial f_{u}}, M_{E} \frac{\partial P_{R}}{\partial F_{a}}, M_{E} \frac{\partial P_{R}}{\partial P_{o}},-\frac{\partial P_{S}}{\partial P_{i}}\right\}
$$

O primeiro termo do vetor gradiente é a derivada em relação ao erro de modelo, que é a própria pressão de ruptura avaliada em $\mathbf{x}$. O último termo do vetor gradiente é simplesmente $-\partial P_{S} / \partial P_{i}=-1$. Os demais termos são calculados a seguir.

$$
k_{a}=2,0 \quad a_{N}=0,05 t ; \quad t_{r}=t_{\min }-k_{a} a_{N} \quad \rightarrow \frac{\partial t_{r}}{\partial t}=-0.05 k_{a}
$$

$\begin{array}{ll}A=\pi\left(D t-t^{2}\right) & \frac{\partial A}{\partial t}=\pi(D-2 t)\end{array} \quad \frac{\partial A}{\partial D}=\pi t$

$$
\begin{aligned}
& p_{u}=\frac{2 t_{r} f_{u}}{\left(D-t_{r}\right)} \\
& \frac{\partial p_{u}}{\partial D}=-\frac{2 t f_{u}}{\left(D-t_{r}\right)^{2}} \quad \frac{\partial p_{u}}{\partial t}=-0.05 k_{a} \frac{2 D f_{u}}{\left(D-t_{r}\right)^{2}} \quad \frac{\partial p_{u}}{\partial f_{u}}=\frac{2 t_{r}}{\left(D-t_{r}\right)} \\
& p_{\mathrm{rT}}=\left(\frac{1}{2}\right)^{n} \cdot p_{u} \\
& \frac{\partial p_{\mathrm{rT}}}{\partial D}=\left(\frac{1}{2}\right)^{n} \cdot \frac{\partial p_{u}}{\partial D} \quad \frac{\partial p_{\mathrm{rT}}}{\partial t}=\left(\frac{1}{2}\right)^{n} \cdot \frac{\partial p_{u}}{\partial t} \quad \frac{\partial p_{\mathrm{rT}}}{\partial f_{u}}=\left(\frac{1}{2}\right)^{n} \cdot \frac{\partial p_{u}}{\partial f_{u}} \\
& p_{\mathrm{rM}}=\left(\frac{2}{\sqrt{3}}\right)^{1+n} \cdot\left(\frac{1}{2}\right)^{n} \cdot p_{u} \quad \rightarrow \frac{\partial p_{\mathrm{rM}}}{\partial p_{u}}=\left(\frac{2}{\sqrt{3}}\right)^{1+n} \cdot\left(\frac{1}{2}\right)^{n} \\
& \frac{\partial p_{\mathrm{rM}}}{\partial D}=\frac{\partial p_{\mathrm{rM}}}{\partial p_{u}} \cdot \frac{\partial p_{u}}{\partial D} \quad \frac{\partial p_{\mathrm{rM}}}{\partial t}=\frac{\partial p_{\mathrm{rM}}}{\partial p_{u}} \cdot \frac{\partial p_{u}}{\partial t} \quad \frac{\partial p_{\mathrm{rM}}}{\partial f_{u}}=\frac{\partial p_{\mathrm{rM}}}{\partial p_{u}} \cdot \frac{\partial p_{u}}{\partial f_{u}}
\end{aligned}
$$




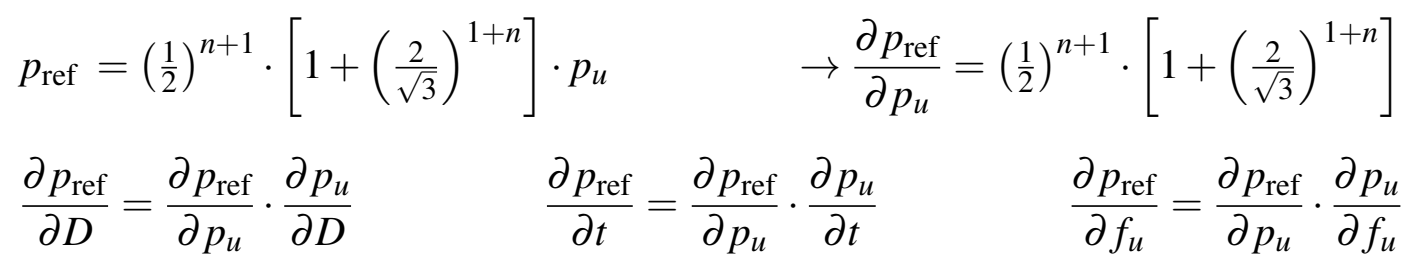

$$
\begin{array}{rlrl}
F_{u} & =A f_{u} & \\
\frac{\partial F_{u}}{\partial D} & =f_{u} \cdot \frac{\partial A}{\partial D} & \frac{\partial F_{u}}{\partial t}=f_{u} \cdot \frac{\partial A}{\partial t} & \frac{\partial F_{u}}{\partial f_{u}}=A
\end{array}
$$

$$
\begin{aligned}
K_{\text {aux }} & =\frac{\left(D-2 t_{r}\right)^{2}}{4 t_{r}\left(D-t_{r}\right)} & \\
\frac{\partial K_{\text {aux }}}{\partial D} & =\frac{D\left(D-2 t_{r}\right)}{4 t_{r}\left(D-t_{r}\right)^{2}} & \frac{\partial K_{a u x}}{\partial t}=-\frac{D^{2}\left(D-2 t_{r}\right)}{4 t_{r}^{2}\left(D-t_{r}\right)^{2}} \cdot \frac{\partial t_{r}}{\partial t}
\end{aligned}
$$$$
\begin{array}{rlrl}
a_{1} & =A^{2} K_{\text {aux }}^{2}+\frac{F_{u}^{2}}{k_{r} p_{\mathrm{rM}}^{2}} \\
\frac{\partial a_{1}}{\partial A} & =2 A K_{\text {aux }}^{2} \quad \frac{\partial a_{1}}{\partial K_{\text {aux }}}=2 A^{2} K_{\text {aux }} & \frac{\partial a_{1}}{\partial F_{u}}=\frac{2 F_{u}}{k_{r} p_{\mathrm{rM}}^{2}} & \frac{\partial a_{1}}{\partial p_{\mathrm{rM}}}=-\frac{2 F_{u}^{2}}{k_{r} p_{\mathrm{rM}}^{3}}
\end{array}
$$$$
\frac{\partial a_{1}}{\partial t}=\frac{\partial a_{1}}{\partial A} \cdot \frac{\partial A}{\partial t}+\frac{\partial a_{1}}{\partial K_{a u x}} \cdot \frac{\partial K_{a u x}}{\partial t}+\frac{\partial a_{1}}{\partial F_{u}} \cdot \frac{\partial F_{u}}{\partial t}+\frac{\partial a_{1}}{\partial p_{\mathrm{rM}}} \cdot \frac{\partial p_{\mathrm{rM}}}{\partial t}
$$$$
\frac{\partial a_{1}}{\partial D}=\frac{\partial a_{1}}{\partial A} \cdot \frac{\partial A}{\partial D}+\frac{\partial a_{1}}{\partial K_{a u x}} \cdot \frac{\partial K_{\text {aux }}}{\partial D}+\frac{\partial a_{1}}{\partial F_{u}} \cdot \frac{\partial F_{u}}{\partial D}+\frac{\partial a_{1}}{\partial p_{\mathrm{rM}}} \cdot \frac{\partial p_{\mathrm{rM}}}{\partial D}
$$$$
\frac{\partial a_{1}}{\partial f_{u}}=\frac{\partial a_{1}}{\partial F_{u}} \cdot \frac{\partial F_{u}}{\partial f_{u}}+\frac{\partial a_{1}}{\partial p_{\mathrm{rM}}} \cdot \frac{\partial p_{\mathrm{rM}}}{\partial f_{u}}
$$

$$
\begin{array}{rlrl}
b_{1} & =-2 F_{a} A K_{\text {aux }}-2 P_{o} A^{2} K_{\text {aux }} & \\
\frac{\partial b_{1}}{\partial K_{\text {aux }}} & =-2 F_{a} A-2 P_{o} A^{2} & \frac{\partial b_{1}}{\partial A}=-2 F_{a} K_{\text {aux }}-4 P_{o} A K_{\text {aux }} \\
\frac{\partial b_{1}}{\partial D}=\frac{\partial b_{1}}{\partial K_{\text {aux }}} \cdot \frac{\partial K_{\text {aux }}}{\partial D}+\frac{\partial b_{1}}{\partial A} \cdot \frac{\partial A}{\partial D} & \frac{\partial b_{1}}{\partial F_{a}}=-2 A K_{\text {aux }} \\
\frac{\partial b_{1}}{\partial t}=\frac{\partial b_{1}}{\partial K_{\text {aux }}} \cdot \frac{\partial K_{\text {aux }}}{\partial t}+\frac{\partial b_{1}}{\partial A} \cdot \frac{\partial A}{\partial t} & \frac{\partial b_{1}}{\partial P_{o}}=-2 A^{2} K_{\text {aux }}
\end{array}
$$

$c_{1}=F_{a}^{2}+P_{o}^{2} A^{2}+2 F_{a} P_{o} A-F_{u}^{2} / k_{r}$

$\frac{\partial c_{1}}{\partial A}=2 A P_{o}^{2}+2 F_{a} P_{o} \quad \frac{\partial c_{1}}{\partial F_{u}}=-2 F_{u} / k_{r} \quad \frac{\partial c_{1}}{\partial f_{u}}=-2 F_{u} A / k_{r}$

$$
\begin{array}{ll}
\frac{\partial c_{1}}{\partial D}=\frac{\partial c_{1}}{\partial A} \cdot \frac{\partial A}{\partial D}+\frac{\partial c_{1}}{\partial F_{u}} \cdot \frac{\partial F_{u}}{\partial D} & \frac{\partial c_{1}}{\partial F_{a}}=-2 F_{a}+2 P_{o} A \\
\frac{\partial c_{1}}{\partial t}=\frac{\partial c_{1}}{\partial A} \cdot \frac{\partial A}{\partial t}+\frac{\partial c_{1}}{\partial F_{u}} \cdot \frac{\partial F_{u}}{\partial t} & \frac{\partial c_{1}}{\partial P_{o}}=-2 P_{o} A^{2}+2 F_{a} A
\end{array}
$$




$$
\begin{aligned}
& \Delta_{\mathrm{bkr}}=\sqrt{b_{1}^{2}-4 a_{1} c_{1}} \quad p_{M}=\frac{-b+\Delta_{\mathrm{bkr}}}{2 a_{1}} \\
& \frac{\partial p_{M}}{\partial a_{1}}=\frac{b_{1}-\Delta_{\mathrm{bkr}}}{2 a_{1}^{2}}-\frac{c_{1}}{a_{1} \cdot \Delta_{\mathrm{bkr}}} \quad \frac{\partial p_{M}}{\partial b_{1}}=\left[\frac{b_{1}}{\Delta_{\mathrm{bkr}}}-1\right] \cdot \frac{1}{2 a_{1}} \quad \frac{\partial p_{M}}{\partial c_{1}}=\frac{-1}{\Delta_{\mathrm{bkr}}} \\
& \frac{\partial p_{M}}{\partial D}=\frac{\partial p_{M}}{\partial a_{1}} \cdot \frac{\partial a_{1}}{\partial D}+\frac{\partial p_{M}}{\partial b_{1}} \cdot \frac{\partial b_{1}}{\partial D}+\frac{\partial p_{M}}{\partial c_{1}} \cdot \frac{\partial c_{1}}{\partial D} \\
& \frac{\partial p_{M}}{\partial t}=\frac{\partial p_{M}}{\partial a_{1}} \cdot \frac{\partial a_{1}}{\partial t}+\frac{\partial p_{M}}{\partial b_{1}} \cdot \frac{\partial b_{1}}{\partial t}+\frac{\partial p_{M}}{\partial c_{1}} \cdot \frac{\partial c_{1}}{\partial t} \\
& \frac{\partial p_{M}}{\partial f_{u}}=\frac{\partial p_{M}}{\partial a_{1}} \cdot \frac{\partial a_{1}}{\partial f_{u}}+\quad 0 \quad+\frac{\partial p_{M}}{\partial c_{1}} \cdot \frac{\partial c_{1}}{\partial f_{u}} \\
& \frac{\partial p_{M}}{\partial F_{a}}=\quad 0 \quad+\frac{\partial p_{M}}{\partial b_{1}} \cdot \frac{\partial b_{1}}{\partial F_{a}}+\frac{\partial p_{M}}{\partial c_{1}} \cdot \frac{\partial c_{1}}{\partial F_{a}} \\
& \frac{\partial p_{M}}{\partial P_{o}}=\quad 0 \quad+\frac{\partial p_{M}}{\partial b_{1}} \cdot \frac{\partial b_{1}}{\partial P_{o}}+\frac{\partial p_{M}}{\partial c_{1}} \cdot \frac{\partial c_{1}}{\partial P_{o}}
\end{aligned}
$$

\section{A.2 Gradientes do critério de Klever-Tamano}

A equação de estado limite de colapso é expressa genericamente da seguinte forma:

$$
g(\mathbf{X})=M_{E} \cdot P_{R}-P_{S}
$$

onde a pressão resistente, $P_{R}$, é calculada por meio do modelo de Klever-Tamano (Eq. 6.41) e a pressão solicitante corresponde à pressão externa atuante, ou seja, $P_{S}=P_{o}$.

As variáveis aleatórias que exercem influência sobre a resistência ao colapso de um tubular são: erro de modelo (ME), diâmetro externo $\left(D_{o}\right)$, espessura do tubo $(t)$, ovalidade do tubo $(o v)$, excentricidade $(e c)$, tensão residual $(r s)$ e tensão de escoamento $\left(f_{y}\right)$. Além destas, exercem influência ainda alguns parâmetros determinísticos do material, nomeadamente o módulo de Young $(E)$ e o coeficiente de Poisson $(v)$.

Desta forma, para o modo de falha de colapso, o vetor $\mathbf{X}$ é dado por:

$$
\mathbf{X}=\left\{M_{E}, D_{o}, t, o v, e c, r s, f_{y}\right\}
$$

e o vetor gradiente é tal que:

$$
\vec{\nabla} g=\left\{\frac{\partial g}{\partial \mathbf{X}}\right\}=\left\{P_{R}, M_{E} \frac{\partial P_{R}}{\partial D_{o}}, M_{E} \frac{\partial P_{R}}{\partial t}, M_{E} \frac{\partial P_{R}}{\partial o v}, M_{E} \frac{\partial P_{R}}{\partial e c}, M_{E} \frac{\partial P_{R}}{\partial r s}, M_{E} \frac{\partial P_{R}}{\partial f_{y}},-\frac{\partial P_{S}}{\partial P_{o}}\right\}
$$

O primeiro termo do vetor gradiente é igual à pressão de colapso avaliada em $\mathbf{x}$ e o último termo corresponde a $-\partial P_{S} / \partial P_{o}=-1$. As demais derivadas parciais do modelo de Klever-Tamano são apresentadas a seguir. 
$H=\max \left[0 ; 0.127 o v+0.0039 e c-0.440 r s+h_{n}\right]$

$$
\begin{array}{rlrl}
P_{e c} & =\frac{2 k_{e} E}{\left(1-v^{2}\right)} \cdot \frac{1}{\left(D_{o} / t\right) \cdot\left(D_{o} / t-1\right)^{2}} & P_{y c} & =2 k_{y} f_{y} \cdot\left(t / D_{o}\right) \cdot\left[1+t /\left(2 D_{o}\right)\right] \\
\frac{\partial P_{e c}}{\partial t}=\frac{2 k_{e} E}{\left(1-v^{2}\right)} \cdot \frac{t^{2}\left(t-3 D_{o}\right)}{D_{o}\left(t-D_{o}\right)^{3}} & \frac{\partial P_{y c}}{\partial t}=2 k_{y} f_{y} \cdot \frac{\left(D_{o}+t\right)}{D_{o}^{2}} \\
\frac{\partial P_{e c}}{\partial D_{o}}=-\frac{\partial P_{e c}}{\partial t} \cdot \frac{t}{D_{o}} & \frac{\partial P_{y c}}{\partial D_{o}}=-\frac{\partial P_{y c}}{\partial t} \cdot \frac{t}{D_{o}} \\
& \frac{\partial P_{y c}}{\partial f_{y}}=P_{y c} / f_{y}
\end{array}
$$

$P_{R}=\frac{P_{e c}+P_{y c}-\sqrt{\left(P_{e c}-P_{y c}\right)^{2}+4 P_{e c} P_{y c} H}}{(2-2 H)} \quad \rightarrow$ Root $=\sqrt{\left(P_{e c}-P_{y c}\right)^{2}+4 P_{e c} P_{y c} H}$

$\frac{\partial P_{R}}{\partial H}=\frac{2 P_{R}}{(2-2 H)}-\frac{2 P_{e c} P_{y c}}{(2-2 H) \cdot \text { Root }}$

$\frac{\partial P_{R}}{\partial D}=\frac{\partial P_{R}}{\partial P_{y c}} \cdot \frac{\partial P_{y c}}{\partial D_{o}}+\frac{\partial P_{R}}{\partial P_{e c}} \cdot \frac{\partial P_{e c}}{\partial D_{o}}$

$\frac{\partial P_{R}}{\partial t}=\frac{\partial P_{R}}{\partial P_{y c}} \cdot \frac{\partial P_{y c}}{\partial t}+\frac{\partial P_{R}}{\partial P_{e c}} \cdot \frac{\partial P_{e c}}{\partial t}$

$\frac{\partial P_{R}}{\partial f_{y}}=\frac{\partial P_{R}}{\partial P_{y c}} \cdot \frac{\partial P_{y c}}{\partial f y}$

$\frac{\partial P_{R}}{\partial o v}=\frac{\partial P_{R}}{\partial H} \cdot+0.127$

$\frac{\partial P_{R}}{\partial e c}=\frac{\partial P_{R}}{\partial H} \cdot+0.0039$

$\frac{\partial P_{R}}{\partial r s}=\frac{\partial P_{R}}{\partial H} \cdot-0.440$ 


\section{A.3 Gradientes do critério de von Mises}

A equação que representa o estado limite último de escoamento de um revestimento submetido a um estado triaxial de tensão é dada por:

$$
g(\mathbf{X})=\sigma_{R}-M_{E} \cdot \sigma_{V M}
$$

onde a tensão resistente, $\sigma_{R}$, é expressa por meio da tensão que causa o escoamento do material quando submetido a um ensaio uniaxial de tração $\left(\sigma_{R}=f_{y}\right)$; a tensão solicitante, $\sigma_{V M}$, é calculada por meio do critério de von Mises (Eq. 6.48); e a variável erro de modelo, $M_{E}$, é considerada determinística e com valor unitário, uma vez que a norma ISO TR 10400:2011 não apresenta dados estatísticos para este critério.

Por tratar de um estado geral de tensão, o critério de von Mises é função das seguintes variáveis aleatórias: diâmetro externo $(D)$, espessura do tubo $(t)$, força axial solicitante $\left(F_{a}\right)$, pressão externa $\left(P_{o}\right)$ e pressão interna $\left(P_{i}\right)$. Sendo assim, o vetor $\mathbf{X}$ é dado por:

$$
\mathbf{X}=\left\{D, t, F_{a}, P_{o}, P_{i}\right\}
$$

e o vetor gradiente é tal que:

$$
\vec{\nabla} g=\left\{\frac{\partial g}{\partial \mathbf{X}}\right\}=\left\{\frac{\partial \sigma_{R}}{\partial f_{y}},-\frac{\partial \sigma_{V M}}{\partial D},-\frac{\partial \sigma_{V M}}{\partial t},-\frac{\partial \sigma_{V M}}{\partial F_{a}},-\frac{\partial \sigma_{V M}}{\partial P_{o}},-\frac{\partial \sigma_{V M}}{\partial P_{i}}\right\}
$$

O primeiro termo do vetor gradiente corresponde a $\partial \sigma_{R} / \partial f_{y}=1$, sendo os demais apresentados a seguir.

$r_{o}=D / 2 \rightarrow k_{o}=r_{o}^{2} \quad r_{i}=r_{o}-t \rightarrow k_{i}=r_{i}^{2} \quad A=\pi \cdot\left(D t-t^{2}\right)$

Axial stress: $\quad \sigma_{a}=F_{a} / A$

Radial stress: $\quad \sigma_{r}=-P_{i}$

Tangential stress: $\sigma_{t}=\frac{P_{i} k_{i}\left(k_{i}+k_{o}\right)-2 P_{o} k_{i} k_{o}}{G}$

$$
\begin{array}{ll}
\frac{\partial \sigma_{a}}{\partial F_{a}}=1 / A & G=k_{i}\left(k_{o}-k_{i}\right) \\
\frac{\partial \sigma_{a}}{\partial D}=-\pi t \cdot \frac{F_{a}}{A^{2}} & \frac{\partial G}{\partial D}=k_{i} \cdot r_{o}+\left(k_{o}-2 k_{i}\right) \cdot r_{i} \\
\frac{\partial \sigma_{a}}{\partial t}=-\pi(D-2 t) \cdot \frac{F_{a}}{A^{2}} & \frac{\partial G}{\partial t}=-2 r_{i}\left(k_{o}-2 k_{i}\right)
\end{array}
$$




$$
\begin{aligned}
\frac{\partial \sigma_{t}}{\partial P_{i}} & =\frac{k_{i}\left(k_{i}+k_{o}\right)}{G} \\
\frac{\partial \sigma_{t}}{\partial P_{o}} & =\frac{-2 k_{i} k_{o}}{G} \\
\frac{\partial \sigma_{t}}{\partial G} & =\frac{-\left[P_{i} k_{i}\left(k_{i}+k_{o}\right)-2 P_{o} k_{i} k_{o}\right]}{G^{2}} \\
\frac{\partial \sigma_{t}}{\partial D} & =\frac{\left(P_{i} k_{i}-2 P_{o} k_{i}\right) \cdot r_{o}}{G}+\frac{\left[P_{i}\left(2 k_{i}+k_{o}\right)-2 P_{o} k_{o}\right] \cdot r_{i}}{G}+\frac{\partial \sigma_{t}}{\partial G} \cdot \frac{\partial G}{\partial D} \\
\frac{\partial \sigma_{t}}{\partial t} & =\left[\frac{\left(P_{i}\left(2 k_{i}+k_{o}\right)-2 P_{o} k_{o}\right)}{G}\right] \cdot\left(-2 r_{i}\right)+\frac{\partial \sigma_{t}}{\partial G} \cdot \frac{\partial G}{\partial t}
\end{aligned}
$$

$\begin{array}{llrl}\sigma_{12}=\sigma_{r}-\sigma_{t} & \sigma_{23}=\sigma_{t}-\sigma_{a} & \sigma_{31}=\sigma_{a}-\sigma_{r} \\ \frac{\partial \sigma_{12}}{\partial P_{i}}=-1-\frac{\partial \sigma_{t}}{\partial P_{i}} & \frac{\partial \sigma_{23}}{\partial P_{i}}=\frac{\partial \sigma_{t}}{\partial P_{i}} & \frac{\partial \sigma_{31}}{\partial P_{i}}=1 \\ \frac{\partial \sigma_{12}}{\partial P_{o}}=-\frac{\partial \sigma_{t}}{\partial P_{o}} & \frac{\partial \sigma_{23}}{\partial P_{o}}=\frac{\partial \sigma_{t}}{\partial P_{o}} & \frac{\partial \sigma_{31}}{\partial P_{o}}=0 \\ \frac{\partial \sigma_{12}}{\partial D}=-\frac{\partial \sigma_{t}}{\partial D} & \frac{\partial \sigma_{23}}{\partial D}=\frac{\partial \sigma_{t}}{\partial D}-\frac{\partial \sigma_{a}}{\partial D} & \frac{\partial \sigma_{31}}{\partial D}=\frac{\partial \sigma_{a}}{\partial D} \\ \frac{\partial \sigma_{12}}{\partial t}=-\frac{\partial \sigma_{t}}{\partial t} & \frac{\partial \sigma_{23}}{\partial t}=\frac{\partial \sigma_{t}}{\partial t}-\frac{\partial \sigma_{a}}{\partial t} & \frac{\partial \sigma_{31}}{\partial t}=\frac{\partial \sigma_{a}}{\partial t} \\ \frac{\partial \sigma_{23}}{\partial F_{a}}=0 & \frac{\partial \sigma_{23}}{\partial F_{a}}=-1 / A & \frac{\partial \sigma_{31}}{\partial F_{a}}=1 / A\end{array}$

$\sigma_{V M}=\frac{1}{\sqrt{2}} \cdot\left[\sigma_{12}^{2}+\sigma_{23}^{2}+\sigma_{31}^{2}\right]$

$\frac{\partial \sigma_{V M}}{\partial \sigma_{12}}=\frac{\sigma_{12}}{2 \cdot \sigma_{V M}} \quad \frac{\partial \sigma_{V M}}{\partial \sigma_{23}}=\frac{\sigma_{23}}{2 \cdot \sigma_{V M}} \quad \frac{\partial \sigma_{V M}}{\partial \sigma_{31}}=\frac{\sigma_{31}}{2 \cdot \sigma_{V M}}$

$\frac{\partial \sigma_{V M}}{\partial D}=\frac{\partial \sigma_{V M}}{\partial \sigma_{12}} \cdot \frac{\partial \sigma_{12}}{\partial D}+\frac{\partial \sigma_{V M}}{\partial \sigma_{23}} \cdot \frac{\partial \sigma_{23}}{\partial D}+\frac{\partial \sigma_{V M}}{\partial \sigma_{31}} \cdot \frac{\partial \sigma_{31}}{\partial D}$

$\frac{\partial \sigma_{V M}}{\partial t}=\frac{\partial \sigma_{V M}}{\partial \sigma_{12}} \cdot \frac{\partial \sigma_{12}}{\partial t}+\frac{\partial \sigma_{V M}}{\partial \sigma_{23}} \cdot \frac{\partial \sigma_{23}}{\partial t}+\frac{\partial \sigma_{V M}}{\partial \sigma_{31}} \cdot \frac{\partial \sigma_{31}}{\partial t}$

$\frac{\partial \sigma_{V M}}{\partial F_{a}}=\quad 0 \quad+\frac{\partial \sigma_{V M}}{\partial \sigma_{23}} \cdot \frac{\partial \sigma_{23}}{\partial F_{a}}+\frac{\partial \sigma_{V M}}{\partial \sigma_{31}} \cdot \frac{\partial \sigma_{31}}{\partial F_{a}}$

$\frac{\partial \sigma_{V M}}{\partial P_{o}}=\frac{\partial \sigma_{V M}}{\partial \sigma_{12}} \cdot \frac{\partial \sigma_{12}}{\partial P_{o}}+\frac{\partial \sigma_{V M}}{\partial \sigma_{23}} \cdot \frac{\partial \sigma_{23}}{\partial P_{o}}+\frac{\partial \sigma_{V M}}{\partial \sigma_{31}} \cdot \frac{\partial \sigma_{31}}{\partial P_{o}}$

$\frac{\partial \sigma_{V M}}{\partial P_{i}}=\frac{\partial \sigma_{V M}}{\partial \sigma_{12}} \cdot \frac{\partial \sigma_{12}}{\partial P_{i}}+\frac{\partial \sigma_{V M}}{\partial \sigma_{23}} \cdot \frac{\partial \sigma_{23}}{\partial P_{i}}+\frac{\partial \sigma_{V M}}{\partial \sigma_{31}} \cdot \frac{\partial \sigma_{31}}{\partial P_{i}}$ 


\section{APÊNDICE B - Lista de Tubulares}

As listas de preços de revestimentos apresentadas nas Tabelas B.1, B.2 e B.3 foram adaptadas do livro de Rahman e Chilingarian (1995) e serviram de base para a realização dos estudos de caso apresentados no Capítulo 10. Em virtude da carência de dados na referência original e do desuso das equações do API-5C3, uma série de revestimentos teve de ser descartada. Ao todo, as listas originais continham 144 revestimentos de 7", 98 tubos de 9 5/8"e 25 de 13 3/8". Destes, foram selecionados apenas 42, 47 e 13 tubulares, respectivamente.

É importante salientar que os preços reproduzidos a seguir estão desatualizados e não correspondem a valores reais de mercado. A estrutura de preços, no entanto, exibe o comportamento relatado por Byrom (2015), sendo crescente conforme aumentam o peso do tubular e a classe de aço.

Tabela B.1 - Lista de preços de revestimentos de 13 3/8"(340 mm).

\begin{tabular}{ccccc}
\hline $\begin{array}{c}\text { Preço linear } \\
(\mathrm{US} \$ \mathrm{ft})\end{array}$ & $\begin{array}{c}\text { Peso linear } \\
(\mathrm{lbf} / \mathrm{ft})\end{array}$ & $\begin{array}{c}\text { ID } \\
(\mathrm{in} .)\end{array}$ & $\begin{array}{c}\text { Classe } \\
\text { de aço }\end{array}$ & $\begin{array}{c}f_{y} \\
(\mathrm{ksi})\end{array}$ \\
\hline 2342,94 & 48 & 12,715 & $\mathrm{H} 40$ & 40 \\
2593,04 & 54,5 & 12,615 & $\mathrm{~K} 55$ & 55 \\
2839,45 & 61 & 12,515 & $\mathrm{~K} 55$ & 55 \\
3156,37 & 68 & 12,415 & $\mathrm{~K} 55$ & 55 \\
4249,20 & 68 & 12,415 & $\mathrm{~N} 80$ & 80 \\
4655,11 & 68 & 12,415 & $\mathrm{C} 75$ & 75 \\
4780,00 & 68 & 12,415 & $\mathrm{~L} 80$ & 80 \\
4967,34 & 68 & 12,415 & $\mathrm{P} 110$ & 110 \\
5185,91 & 68 & 12,415 & $\mathrm{C} 95$ & 95 \\
4499,15 & 72 & 12,347 & $\mathrm{~N} 80$ & 80 \\
5061,18 & 72 & 12,347 & $\mathrm{~L} 80$ & 80 \\
5259,54 & 72 & 12,347 & $\mathrm{P} 110$ & 110 \\
5490,97 & 72 & 12,347 & $\mathrm{C} 95$ & 95 \\
\hline
\end{tabular}


Tabela B.2 - Lista de preços de revestimentos de $95 / 8 "(245 \mathrm{~mm})$.

\begin{tabular}{ccccc}
\hline $\begin{array}{c}\text { Preço linear } \\
\text { (US\$fft) }\end{array}$ & $\begin{array}{c}\text { Peso linear } \\
\text { (lbf/ft) }\end{array}$ & $\begin{array}{c}\text { ID } \\
\text { (in.) }\end{array}$ & $\begin{array}{c}\text { Classe } \\
\text { de aço }\end{array}$ & $\begin{array}{c}f_{y} \\
(\mathrm{ksi})\end{array}$ \\
\hline 1826,23 & 36 & 8,921 & K55 & 55 \\
1992,44 & 36 & 8,921 & S80 & 80 \\
1999,88 & 40 & 8,835 & K55 & 55 \\
2324,96 & 40 & 8,835 & S 80 & 80 \\
2565,56 & 40 & 8,835 & N80 & 80 \\
2783,29 & 40 & 8,835 & S95 & 95 \\
2886,11 & 40 & 8,835 & L80 & 80 \\
2961,52 & 40 & 8,835 & CYS95 & 95 \\
3121,70 & 40 & 8,835 & SS95 & 95 \\
3131,24 & 40 & 8,835 & C95 & 95 \\
2879,99 & 43,5 & 8,755 & N80 & 80 \\
3007,88 & 43,5 & 8,755 & S95 & 95 \\
3138,59 & 43,5 & 8,755 & L80 & 80 \\
3200,49 & 43,5 & 8,755 & CYS95 & 95 \\
3261,62 & 43,5 & 8,755 & LS110 & 110 \\
3374,26 & 43,5 & 8,755 & SS95 & 95 \\
3405,16 & 43,5 & 8,755 & C95 & 95 \\
3569,20 & 43,5 & 8,755 & LS125 & 125 \\
3014,47 & 47 & 8,681 & N80 & 80 \\
3240,61 & 47 & 8,681 & CYS95 & 95 \\
3391,11 & 47 & 8,681 & L80 & 80 \\
3421,44 & 47 & 8,681 & S95 & 95 \\
3524,04 & 47 & 8,681 & LS110 & 110 \\
3679,12 & 47 & 8,681 & C95 & 95 \\
3680,10 & 47 & 8,681 & SS95 & 95 \\
3856,37 & 47 & 8,681 & LS125 & 125 \\
3431,34 & 53,5 & 8,535 & N80 & 80 \\
3732,44 & 53,5 & 8,535 & C75 & 75 \\
3860,07 & 53,5 & 8,535 & L80 & 80 \\
3970,98 & 53,5 & 8,535 & S95 & 95 \\
3982,28 & 53,5 & 8,535 & S105 & 105 \\
3984,63 & 53,5 & 8,535 & P110 & 110 \\
4011,38 & 53,5 & 8,535 & LS110 & 110 \\
4187,86 & 53,5 & 8,535 & CYS95 & 95 \\
4187,92 & 53,5 & 8,535 & C95 & 95 \\
4198,64 & 53,5 & 8,535 & SS95 & 95 \\
4389,67 & 53,5 & 8,535 & LS125 & 125 \\
4334,68 & 58,4 & 8,435 & S95 & 95 \\
4364,52 & 58,4 & 8,435 & S105 & 105 \\
4550,04 & 58,4 & 8,435 & SS95 & 95 \\
4571,42 & 58,4 & 8,435 & CYS95 & 95 \\
4791,72 & 58,4 & 8,435 & LS125 & 125 \\
4535,08 & 61,1 & 8,375 & S95 & 95 \\
4566,30 & 61,1 & 8,375 & S105 & 105 \\
4782,75 & 61,1 & 8,375 & CYS95 & 95 \\
5013,24 & 61,1 & 8,375 & SS95 & 95 \\
\hline & 61,1 & 8,375 & LS125 & 125 \\
\hline & & & & \\
\hline
\end{tabular}


Tabela B.3 - Lista de preços de revestimentos de 7"(178 mm).

\begin{tabular}{|c|c|c|c|c|}
\hline $\begin{array}{c}\text { Preço linear } \\
\text { (US\$/ft) }\end{array}$ & $\begin{array}{c}\text { Peso linear } \\
(\mathrm{lbf} / \mathrm{ft})\end{array}$ & $\begin{array}{l}\text { ID } \\
\text { (in.) }\end{array}$ & $\begin{array}{l}\text { Classe } \\
\text { de aço }\end{array}$ & $\begin{array}{c}f_{y} \\
\text { (ksi) }\end{array}$ \\
\hline 1028,79 & 20,3 & 6,456 & $\mathrm{H} 40$ & 40 \\
\hline 1054,91 & 20,3 & 6,456 & K55 & 55 \\
\hline 1194,09 & 23,0 & 6,366 & K55 & 55 \\
\hline 1750,23 & 23,0 & 6,366 & $\mathrm{C} 75$ & 75 \\
\hline 1809,04 & 23,0 & 6,366 & L80 & 80 \\
\hline 1896,81 & 23,0 & 6,366 & CYS95 & 95 \\
\hline 1397,08 & 26,0 & 6,276 & K55 & 55 \\
\hline 1950,89 & 26,0 & 6,276 & $\mathrm{C} 75$ & 75 \\
\hline 2016,62 & 26,0 & 6,276 & L80 & 80 \\
\hline 2061,17 & 26,0 & 6,276 & CYS95 & 95 \\
\hline 2095,71 & 26,0 & 6,276 & LS110 & 110 \\
\hline 2119,42 & 29,0 & 6,184 & C75 & 75 \\
\hline 2191,20 & 29,0 & 6,184 & L80 & 80 \\
\hline 2266,91 & 29,0 & 6,184 & CYS95 & 95 \\
\hline 2270,31 & 29,0 & 6,184 & S105 & 105 \\
\hline 2277,12 & 29,0 & 6,184 & LS110 & 110 \\
\hline 2491,93 & 29,0 & 6,184 & LS125 & 125 \\
\hline 2763,84 & 29,0 & 6,184 & V150 & 150 \\
\hline 2325,85 & 32,0 & 6,094 & $\mathrm{C} 75$ & 75 \\
\hline 2404,71 & 32,0 & 6,094 & L80 & 80 \\
\hline 2480,92 & 32,0 & 6,094 & CYS95 & 95 \\
\hline 2484,98 & 32,0 & 6,094 & S105 & 105 \\
\hline 2499,00 & 32,0 & 6,094 & LS110 & 110 \\
\hline 2734,75 & 32,0 & 6,094 & LS125 & 125 \\
\hline 2970,46 & 32,0 & 6,094 & LS140 & 140 \\
\hline 3033,03 & 32,0 & 6,094 & V150 & 150 \\
\hline 2544,05 & 35,0 & 6,004 & $\mathrm{C} 75$ & 75 \\
\hline 2630,30 & 35,0 & 6,004 & L80 & 80 \\
\hline 2696,48 & 35,0 & 6,004 & CYS95 & 95 \\
\hline 2699,46 & 35,0 & 6,004 & S105 & 105 \\
\hline 2733,44 & 35,0 & 6,004 & LS110 & 110 \\
\hline 2991,28 & 35,0 & 6,004 & LS125 & 125 \\
\hline 3249,13 & 35,0 & 6,004 & LS140 & 140 \\
\hline 3317,57 & 35,0 & 6,004 & V150 & 150 \\
\hline 2762,11 & 38,0 & 5,920 & $\mathrm{C} 75$ & 75 \\
\hline 2855,76 & 38,0 & 5,920 & L80 & 80 \\
\hline 2909,99 & 38,0 & 5,920 & CYS95 & 95 \\
\hline 2939,24 & 38,0 & 5,920 & S105 & 105 \\
\hline 2967,74 & 38,0 & 5,920 & LS110 & 110 \\
\hline 3247,68 & 38,0 & 5,920 & LS125 & 125 \\
\hline 3527,63 & 38,0 & 5,920 & LS140 & 140 \\
\hline 3601,94 & 38,0 & 5,920 & V150 & 150 \\
\hline
\end{tabular}





\section{APÊNDICE C - Código Computacional para o Projeto Ótimo de Revestimentos}

O presente anexo visa descrever sumariamente a ferramenta computacional que inspirou o desenvolvimento do presente trabalho. Tal ferramenta foi concebida para atender a um projeto de Pesquisa e Desenvolvimento em parceria com a Petrobras (BECK et al., 2017), cujo objetivo central era estimar a confiabilidade de revestimentos de poços.

Originalmente o software apresentava duas partes razoavelmente independentes: a primeira correspondia ao módulo determinístico e à interface gráfica, ambas desenvolvidas em conjunto com a empresa SimWorx; enquanto a segunda parte correspondia ao módulo estocástico para cálculo das probabilidades de falha do poço.A seguir, detalhes pertinentes ao módulo determinístico e à interface gráfica são apresentados.

\section{C.1 Módulo Determinístico e Interface Gráfica}

O código computacional desenvolvido conta com uma interface gráfica para facilidade de utilização. A partir desta interface, o projetista do poço (usuário) constrói o problema, entrando com os dados da geometria do poço, janela operacional, perfil de temperatura, profundidades das sapatas, classes e diâmetros dos revestimentos, casos de carregamento, dentre outras opções. O usuário formula também o problema de confiabilidade, quando opta por personalizar as estatísticas das variáveis aleatórias envolvidas (parâmetros geométricos e físicos dos tubulares com distribuições estatísticas adequadas ao problema) e escolhe um método de análise préprogramado (FORM ou simulação de Monte Carlo). A interface permite ainda a visualização gráfica dos resultados, especificamente dos fatores de segurança e das forças axiais ao longo da profundidade do poço.

Para tornar o uso do programa mais intuitivo, valores usuais são sugeridos ao usuário. Incluem desde dimensões e classes de revestimento padronizados até distribuições estatísticas e momentos das variáveis de resistência. Naturalmente, é responsabilidade do usuário decidir se os valores fornecidos condizem com a realidade do problema particular a ser resolvido, podendo substituí-los em caso contrário.

A interface foi implementada em linguagem C\#, porém foi integrada aos módulos de cálculo, todos programados em linguagem FORTRAN. As janelas com apresentação de resultados foram elaboradas para apresentação das forças axiais, dos fatores de segurança e dos índices de confiabilidade calculados.

As opções principais da interface gráfica são: Poço, Revestimento, Janela Operacional, Carregamento, Solvers e Resultados. O usuário pode navegar entre estas opções clicando no menu mostrado à esquerda da Figura C.1. 
Figura C.1 - Menu "Revestimentos"para definição dos tubulares de cada fase.

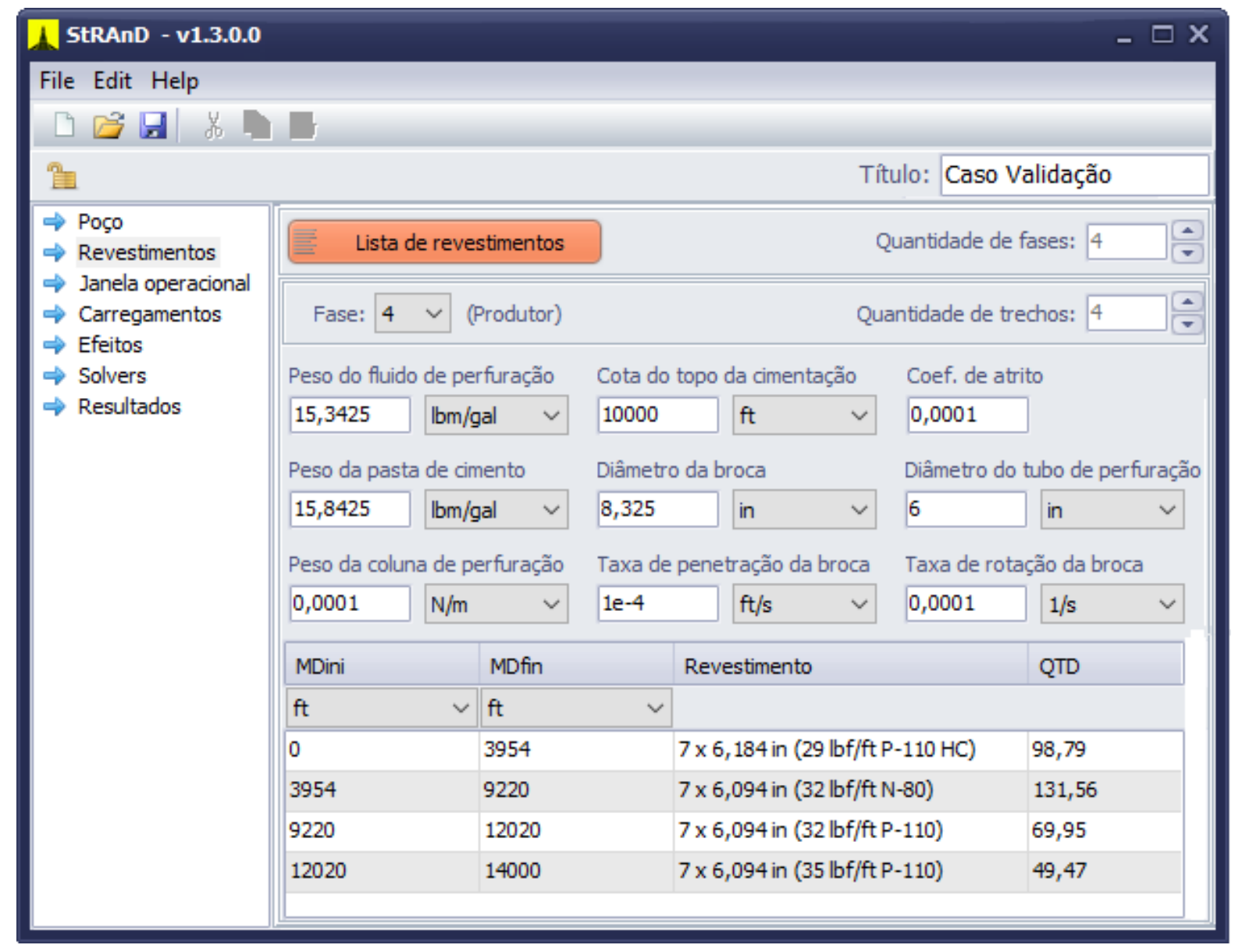

\section{C.1.1 Interface para entrada dos dados}

Na seção "Poço", o usuário especifica o número de fases e suas respectivas extensões (ponto de início e cota de assentamento das sapatas). Após o lançamento da geometria, o usuário avança para a personalização de cada fase na seção "Revestimentos", onde deve informar dados relativos ao diâmetro de broca, aos fluidos de perfuração e cimentação utilizados na fase, além do número de trechos com propriedades mecânicas e/ou geométricas distintas.

A Figura C.1 ilustra a seleção dos tubulares que compõem o revestimento de produção que serviu de referência ao estudo de caso realizado no presente trabalho. Em destaque encontrase o botão "Lista de revestimentos", que fornece ao usuário uma lista pré-definida de tubulares padronizados utilizados na indústria. Ao acessá-lo, o usuário tem a opção de adicionar novos tubulares ou editar qualquer uma de suas propriedades mecânicas, geométricas ou estatísticas (distribuição de probabilidades, momentos de primeira e segunda ordem, valores máximos e mínimos).

Em seguida, na seção "Janela operacional” o usuário insere os dados de pressão de poros e pressão de fratura da formação, além do perfil geotérmico do poço. O menu de "Carregamentos", por sua vez, é a parte mais importante da interface gráfica (Figura C.2). Nele, o usuário define todos os casos de carregamento a serem considerados no projeto dos revestimentos, agrupados de acordo com o mecanismo de falha: colapso ou ruptura. 
Figura C.2 - Opções de customização para carregamento de kick durante a perfuração do poço.

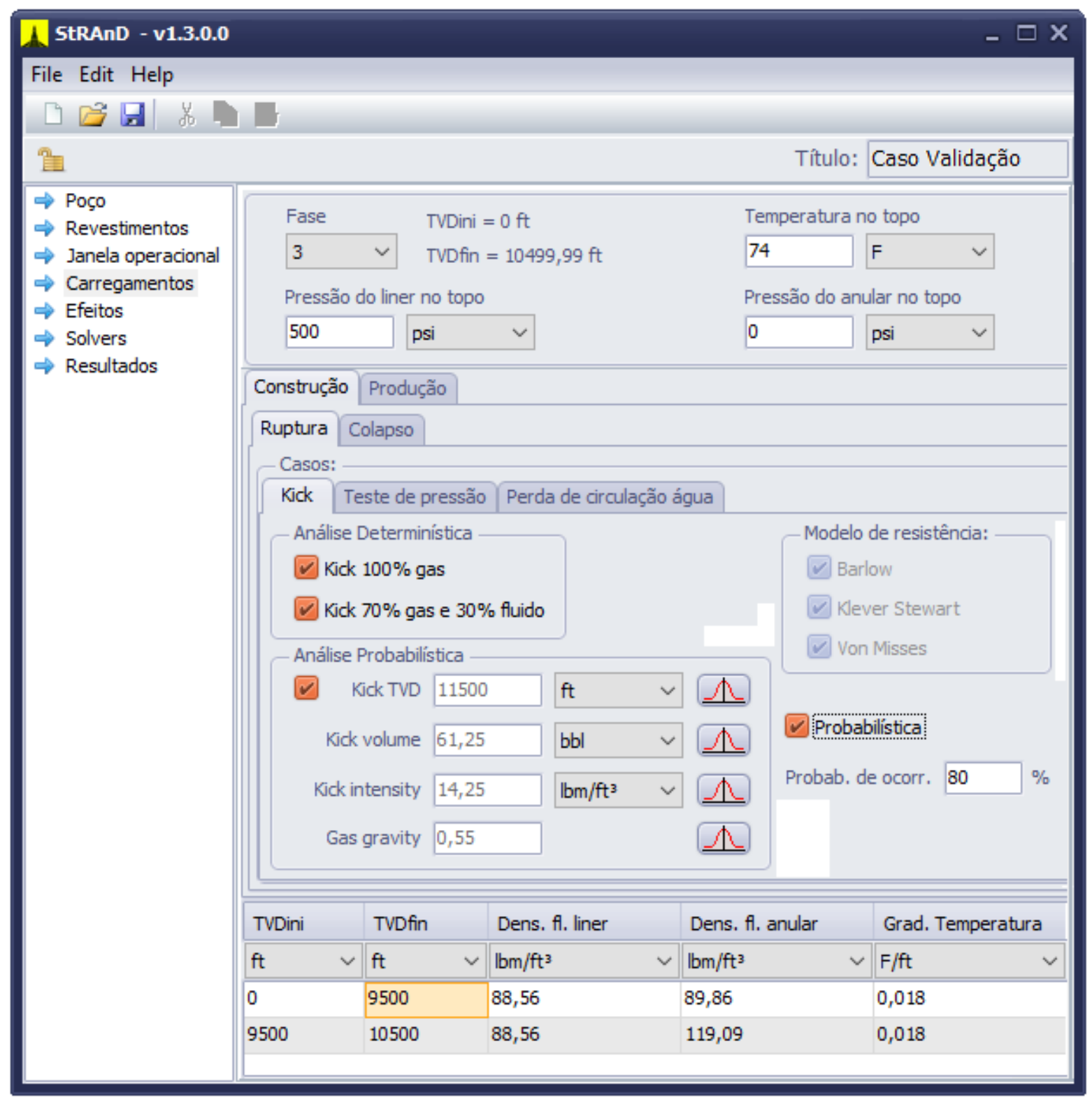

Conforme visto no Capítulo 4, tanto o colapso quanto a ruptura do revestimento pode ocorrer ao longo da perfuração, lançamento e exploração do poço. Por este motivo, os casos de carregamento foram adicionalmente subdivididos entre as etapas de construção (que engloba perfuração e lançamento da coluna) e produção.

$\mathrm{Na}$ etapa de construção, os principais carregamentos de ruptura disponíveis estão relacionados à ocorrência de um kick e a execução de testes de pressão. Neste último, o usuário necessita especificar a sobrepressão que será aplicada ao revestimento. Para o caso de kick, o usuário pode optar por maiores opções de customização (Figura C.2):

1. Análise determinística: os cenários de carregamento admitem o poço cheio de gás ou parcialmente ocupado por lama;

2. Análise probabilística: nesta situação, o usuário pode especificar o volume de kick a ser considerado, sua intensidade, a densidade do gás, além das estatísticas de cada uma destas 
variáveis.

Ainda na aba de construção o usuário tem a opção de avaliar a perda de circulação da lama, que, em geral, corresponde ao pior cenário de carregamento de colapso. Para isto, necessita informar a densidade da lama e a profundidade em que o nível do fluido se estabilizou.

Todos estes casos de carregamentos são aplicáveis a todas as fases de revestimento. Os demais casos reunidos na aba "Produção"aplicam-se quase exclusivamente ao revestimento de produção. Nesta etapa, os carregamentos de ruptura são: tubing leak (vazamento no tubo de produção), teste de pressão, injeção e anular pressure build-up (APB). Já os carregamentos de colapso são: colapso do cimento, evacuação total, evacuação parcial e APB. A Figura C.3 ilustra os diferentes cenários aplicáveis à etapa de produção, para os modos de falha por ruptura e colapso do revestimento, respectivamente.

Figura C.3 - Cenários de carregamento de ruptura e colapso na etapa de produção.

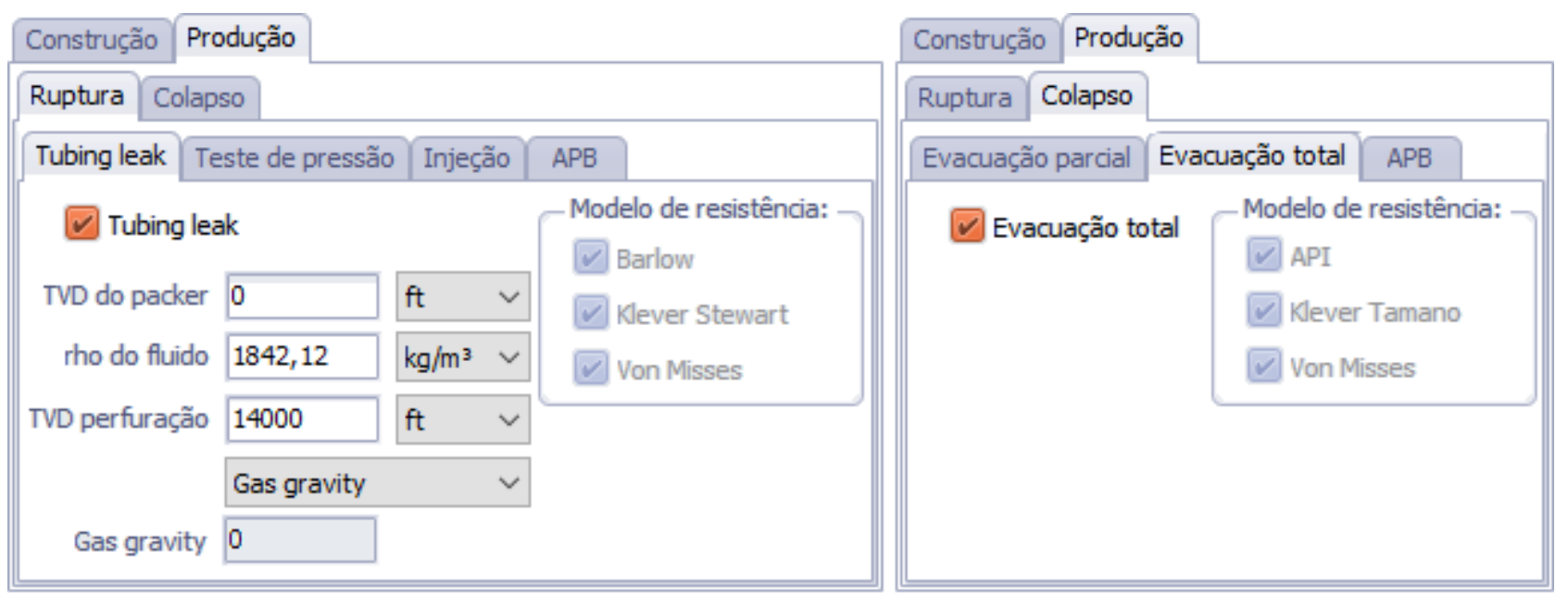

\section{C.1.2 Descrição do solver determinístico}

Informados a geometria do poço, seus revestimentos, a janela operacional e os casos de carregamento a analisar, o usuário tem acesso ao módulo de cálculo determinístico. O solver programado realiza o cálculo de pressões externas e internas solicitantes com base na densidade dos fluidos e das sobrepressões aplicadas; calcula as tensões axiais em cada tubular causadas pelo peso dos revestimentos, pelas forças de empuxo (efeito pistão), pelo efeito ballooning e pela variação térmica do revestimento ao longo da profundidade do poço; e, por fim, computa os coeficientes de segurança para todas as fases do poço e todos os casos de carregamento, ao longo da profundidade dos revestimentos. Para maiores detalhes sobre o cálculo das pressões e forças axiais recomenda-se a leitura dos Capítulos 4 e 5.

Os critérios de resistência utilizados por padrão são: modelo de Klever-Stewart para ruptura; modelo de Klever-Tamano para colapso; e critério de von Mises para verificar o escoamento do aço sob estados triaxiais de tensão (vide Capítulo 6). A verificação do escoamento é feita tanto em carregamentos de colapso, quanto de ruptura. Adicionalmente, o programa permite calcular 
os coeficientes de segurança à ruptura pelo modelo de Barlow e ao colapso pelo antigo modelo de cálculo do Boletim 5C3 do API (1994). O emprego destes últimos critérios, no entanto, é limitado a análises determinísticas.

\section{C.1.3 Interface para visualização de resultados}

A interface gráfica para saída de resultados gera gráficos dos coeficientes de segurança e dos índices de confiabilidade em função da profundidade do poço, para os casos de carregamento aplicáveis a cada fase. O usuário navega entre as diferentes colunas de revestimento e entre os diversos modos de falha por meio de abas, posicionadas na parte superior do gráfico. A título de ilustração, a Figura C.4 mostra os gráficos com os resultados dos fatores de segurança em função da profundidade, para o caso de colapso do revestimento de superfície.

Figura C.4 - Fatores de segurança ao colapso calculados pelo solver determinístico.

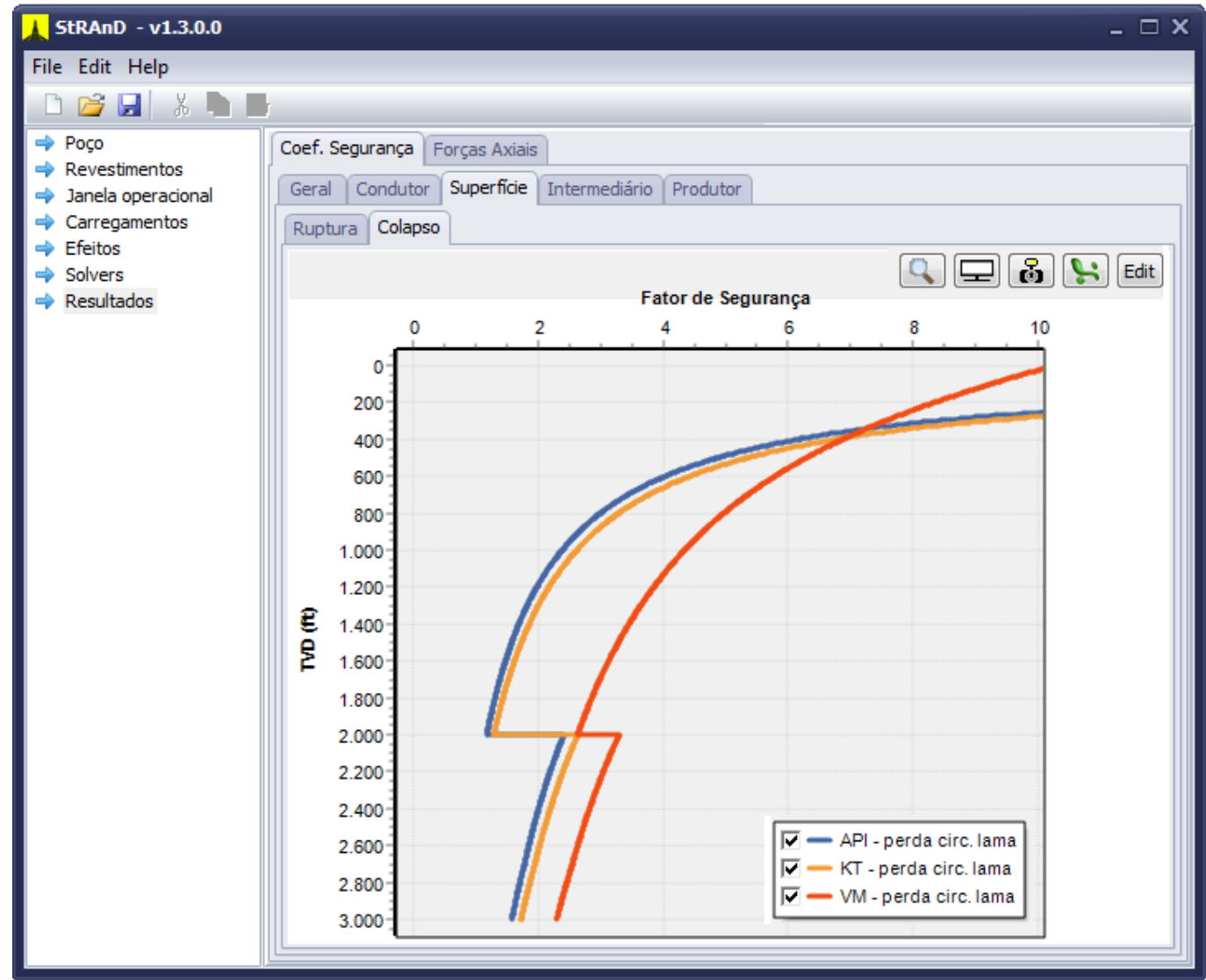

\section{C.2 Módulo Estocástico}

O núcleo (kernel) do módulo estocástico foi desenvolvido com base no programa acadêmico StRAnD (Structural Reliability Analysis and Design), desenvolvido junto ao Departamento de Engenharia de Estruturas da USP ao longo da última década (BECK, 2007; BECK, 2009; SANTOS, 2014a; KROETZ, 2015). Em termos de recursos, o StRAnD é comparável aos melhores softwares de confiabilidade estrutural disponíveis no mercado atualmente. 
O módulo permite o cálculo da confiabilidade do revestimento dos poços através dos métodos aproximativos de primeira ordem (FORM) e de segunda ordem (SORM), além de técnicas de simulação de Monte Carlo utilizando estratégias modernas de amostragem inteligente. O software permite também a solução de problemas de confiabilidade dependente do tempo, envolvendo processos estocásticos de carregamento ou de redução da resistência ao longo do tempo, através de simulação de Monte Carlo e de outras técnicas analíticas.

Todas as rotinas de cálculo foram programadas utilizando conceitos de orientação a objetos, tornando o código-fonte extremamente legível e de fácil manutenção e atualização. Estratégias de programação em paralelo também foram introduzidas nas rotinas responsáveis pelas simulações de Monte Carlo devido ao enorme custo computacional envolvido. O módulo estocástico foi implementado em linguagem FORTRAN 2003.

\section{C.2.1 Métodos de confiabilidade aproximativos (FORM e SORM)}

Foram programadas rotinas para a transformação das variáveis aleatórias do espaço de projeto para o espaço normal padrão. As transformações são realizadas pelos métodos Normal Tail Approximation, decomposição ortogonal e de Cholesky, utilizando coeficientes de correlação equivalentes.

Em cada cenário de carregamento, para cada equação de estado limite, o software procura o ponto de projeto através do algoritmo HLRF modificado (GONG; YI, 2011). Para cada ponto encontrado é feita uma estimativa de primeira ordem da probabilidade de falha usando o método FORM. Alternativamente, é possível proceder com a construção da matriz Hessiana para avaliação da curvatura de cada equação de estado limite, a partir da qual é realizada a estimativa de segunda ordem da probabilidade de falha (método SORM).

A busca pelo ponto de projeto tem como base gradientes estimados via diferenças finitas. Para as equações de estado limite pré-programadas na biblioteca foram também pré-programados os vetores gradiente correspondentes. Assim, evita-se o uso de diferenças finitas, tornando as computações mais rápidas e estáveis.

\section{C.2.2 Método de simulação de Monte Carlo}

No código desenvolvido, a simulação de Monte Carlo pode ser realizada de diferentes maneiras, sempre conjugada ao método de amostragem por Hipercubo Latino (SANTOS, 2014a). Foram implementadas técnicas de simulação simples ou bruta e de amostragem por importância utilizando pontos de projeto. Dentre as programadas, a técnica de simulação bruta é considerada a mais robusta, porém exige um número muito grande de simulações para problemas envolvendo pequenas probabilidades de falha $(\beta>4)$. 